Florida International University

FIU Digital Commons

\title{
Determination of Signature Volatile Odor Chemicals Emanating from Novel Biological Specimens by Non-invasive Analytical Techniques for the Potential use in Forensic Identifications
}

Jessica S. Brown

Florida International University, JWirk001@fiu.edu

DOI: $10.25148 /$ etd.FI12111909

Follow this and additional works at: https://digitalcommons.fiu.edu/etd

\section{Recommended Citation}

Brown, Jessica S., "Determination of Signature Volatile Odor Chemicals Emanating from Novel Biological Specimens by Non-invasive Analytical Techniques for the Potential use in Forensic Identifications" (2012). FIU Electronic Theses and Dissertations. 737.

https://digitalcommons.fiu.edu/etd/737 


\section{FLORIDA INTERNATIONAL UNIVERSITY \\ Miami, Florida}

\section{DETERMINATION OF SIGNATURE VOLATILE ODOR CHEMICALS \\ EMANATING FROM NOVEL BIOLOGICAL SPECIMENS BY NON-INVASIVE \\ ANALYTICAL TECHNIQUES FOR THE POTENTIAL USE IN FORENSIC \\ IDENTIFICATIONS}

A dissertation submitted in partial fulfillment of

the requirements for the degree of

DOCTOR OF PHILOSOPHY

in

CHEMISTRY

by

Jessica Sara Brown

2012 
To: Dean Kenneth G. Furton

College of Arts and Sciences

This dissertation, written by Jessica Sara Brown, and entitled Determination of Signature Volatile Odor Chemicals Emanating from Novel Biological Specimens by Non-invasive Analytical Techniques for the Potential Use in Forensic Identifications, having been approved in respect to style and intellectual content, is referred to you for judgment.

We have read this dissertation and recommend that it be approved.

Jose Almirall

Yong Cai

Stewart D'Alessio

Watson Lees

Kenneth G. Furton, Major Professor

Date of Defense: July 16, 2012

The dissertation of Jessica Sara Brown is approved.

Dean Kenneth G. Furton

College of Arts and Sciences

Dean Lakshmi N. Reddi

University Graduate School

Florida International University, 2012 
(C) Copyright 2012 by Jessica Sara Brown

All rights reserved. 


\section{DEDICATION}

I would like to dedicate this dissertation to my mother, Barbara Wirks, and my husband, Michael Brown. Your love, support, encouragement and counsel have helped make my dream a reality. 


\section{ACKNOWLEDGMENTS}

First, I would like to acknowledge Dr. Kenneth G. Furton. When I first introduced myself to you, in Survey of Forensic Science, I had no idea how many doors you would open for me. You granted me the ability to conduct exciting research, travel to new places (both domestic and international), introduced me to amazing people and work with "puppies". My graduate experience would not have been the same if I weren't a part of your research group. Thank you!

Additionally, I would like to thank Dr. Jose Almirall, Dr. Yong Cai, Dr. Stewart D’Alessio and Dr. Watson Lees for serving on my committee. I have felt blessed to be able to tell my colleagues how much I enjoyed working with my dissertation committee. You all continuously encouraged me to do my best and explore new avenues, and for that I feel proud of the research that I have produced.

To my lab partner in crime, Norma Iris Caraballo, thank you for being my sounding board, editor, cheerleader and one of my best friends. I would like to give an immense thank you to Howard Holness, for your guidance in the lab has made me the scientist I am today. I would also like to thank Lorraine Sweeney for assisting me and for always going above and beyond the call of duty even when it was not solicited. To my lab mates past and present, Jenny Gallo, Paola Prada, Maiko Kusano, Lauryn DeGreeff, Davia Hudson-Holness, Adrian Torres and Alan McKenzie, thank you for the good times.

Last, but not least, I would like to thank my family and friends. I know I would not have been able to make it through the last five years without your love and support. 


\author{
ABSTRACT OF THE DISSERTATION \\ DETERMINATION OF SIGNATURE VOLATILE ODOR CHEMICALS \\ EMANATING FROM NOVEL BIOLOGICAL SPECIMENS BY NON-INVASIVE \\ ANALYTICAL TECHNIQUES FOR THE POTENTIAL USE IN FORENSIC \\ IDENTIFICATIONS
}

by

Jessica Sara Brown

Florida International University, 2012

Miami, Florida

Professor Kenneth G. Furton, Major Professor

Human scent, or the volatile organic compounds (VOCs) produced by an individual, has been recognized as a biometric measurement because of the distinct variations in both the presence and abundance of these VOCs between individuals. In forensic science, human scent has been used as a form of associative evidence by linking a suspect to a scene/object through the use of human scent discriminating canines. The scent most often collected and used with these specially trained canines is from the hands because a majority of the evidence collected is likely to have been handled by the suspect. However, the scents from other biological specimens, especially those that are likely to be present at scenes of violent crimes, have yet to be explored. Hair, fingernails and saliva are examples of these types of specimens.

In this work, a headspace solid phase microextraction gas chromatography-mass spectrometry (HS-SPME-GC-MS) technique was used for the identification of VOCs from hand odor, hair, fingernails and saliva. Sixty individuals were sampled and the 
profiles of the extracted VOCs were evaluated to assess whether they could be used for distinguishing individuals. Preliminary analysis of the biological specimens collected from an individual (intra-subject) showed that, though these materials have some VOCs in common, their overall chemical profile is different for each specimen type. Pair-wise comparisons, using Spearman Rank correlations, were made between the chemical profiles obtained from each subject, per a specimen type. Greater than $98.8 \%$ of the collected samples were distinguished from the subjects for all of the specimen types, demonstrating that these specimens can be used for distinguishing individuals.

Additionally, field trials were performed to determine the utility of these specimens as scent sources for human scent discriminating canines. Three trials were conducted to evaluate hair, fingernails and saliva in comparison to hand odor, which was considered the standard source of human odor. It was revealed that canines perform similarly to these alternative human scent sources as they do to hand odor implying that, though there are differences in the chemical profiles released by these specimens, they can still be used for the discrimination of individuals by trained canines. 


\section{TABLE OF CONTENTS}

CHAPTER

PAGE

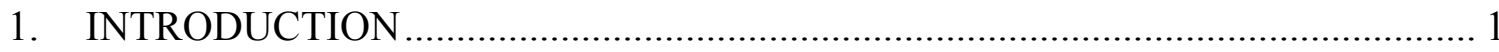

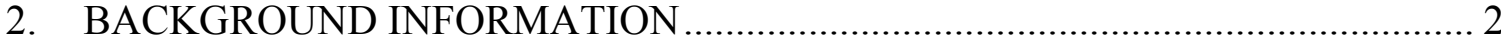

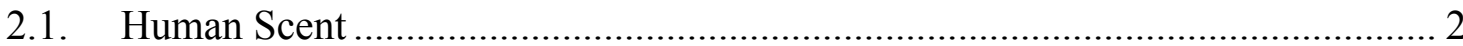

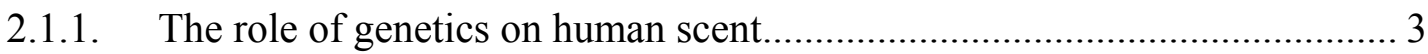

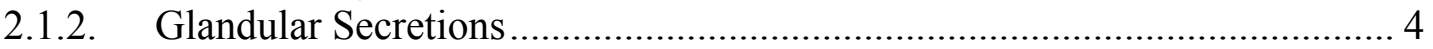

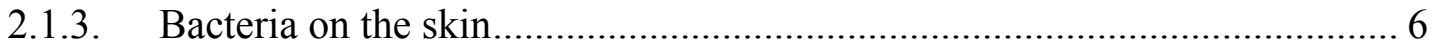

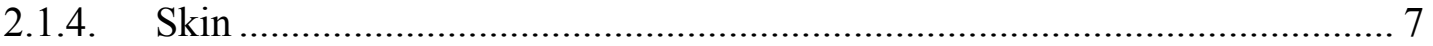

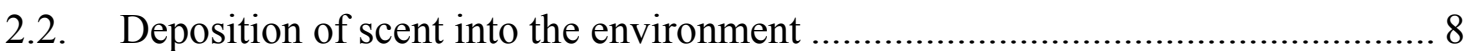

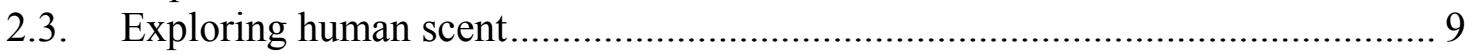

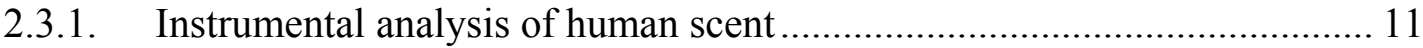

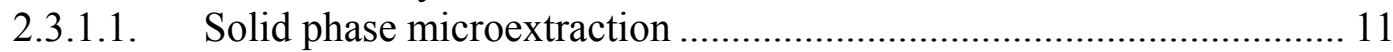

2.3.1.2. Gas Chromatography ............................................................... 14

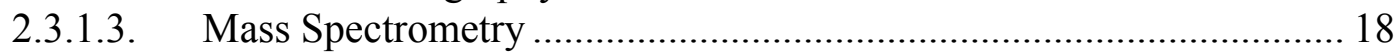

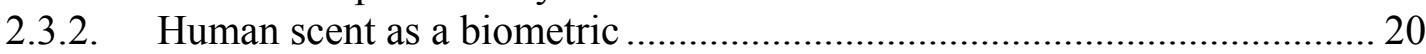

2.4. Application for human scent discrimination ..................................................... 21

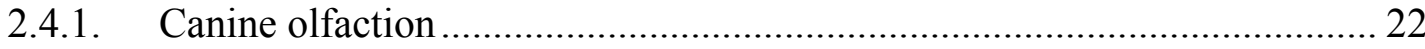

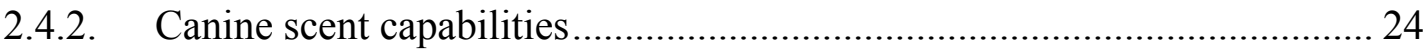

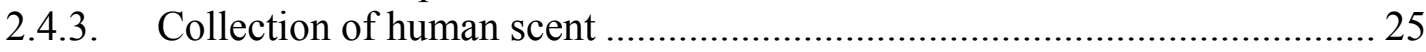

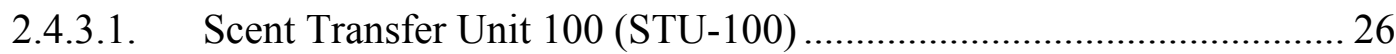

2.4.3.2. Human Scent Collection System .................................................... 27

2.5. Alternative trace biological specimens ......................................................... 29

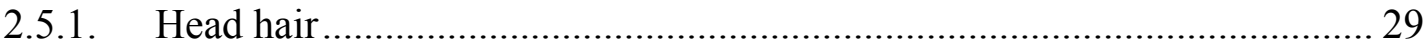

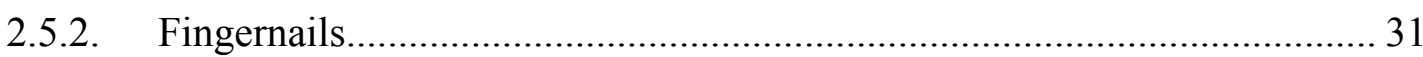

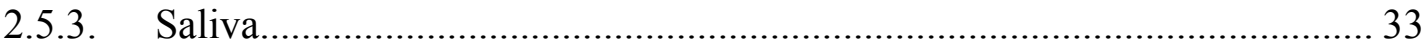

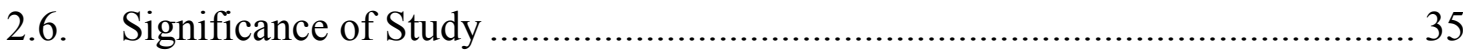

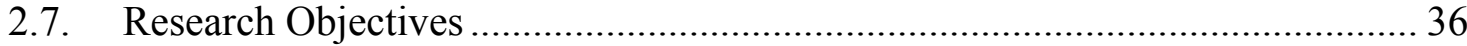

3. INSTRUMENTAL EVALUATIONS OF BIOLOGICAL SPECIMENS ……...........38

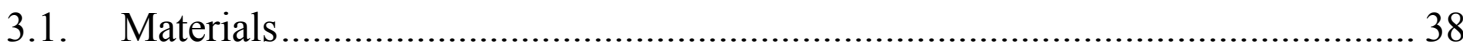

3.1.1. Biological specimen collection and storage............................................... 38

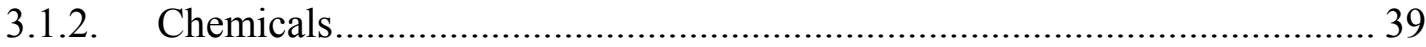

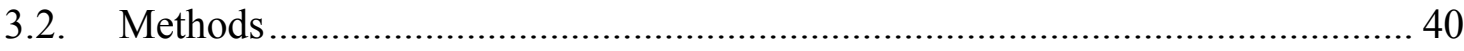

3.2.1. Collection of multiple biological specimens............................................. 40

3.2.1.1. Hand odor collection procedures ....................................................... 41

3.2.1.1.1. Pretreatment of cotton gauze .......................................................... 41

3.2.1.2. Head hair collection procedures ......................................................... 42

3.2.1.3. Fingernail collection procedures ....................................................... 42

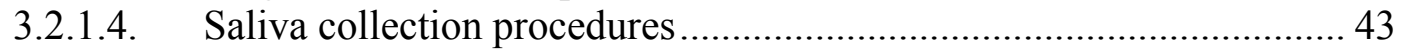

3.2.1.4.1. Pretreatment of cotton swabs ......................................................... 43

3.2.2. Extraction optimization of VOCs from biological specimens using SPME44 
3.2.2.1. Extraction optimization of VOCs from head hair samples using

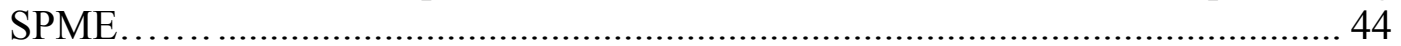

3.2.2.2. Extraction optimization of VOCs from fingernail samples using

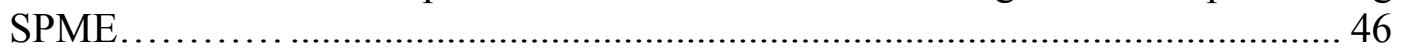

3.2.2.3. Extraction optimization of VOCs from saliva samples using SPME.. 48

3.2.3. Collection of multiple biological specimens over time .............................. 49

3.2.4. Comparison of different types of samples of the same biological specimen

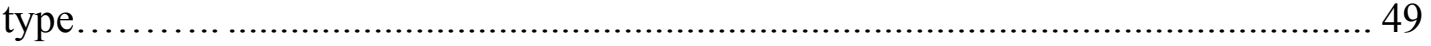

3.2.4.1. Comparison of head hair to arm hair ............................................... 49

3.2.4.2. Comparison of fingernails to toe nails................................................ 50

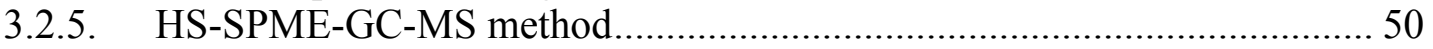

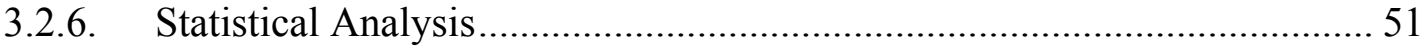

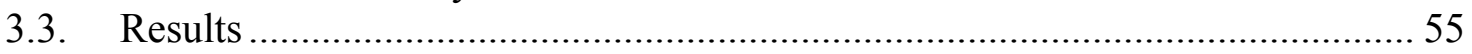

3.3.1. Extraction optimization of VOCs from biological samples using SPME... 55

3.3.1.1. Extraction optimization of VOCs from head hair samples using

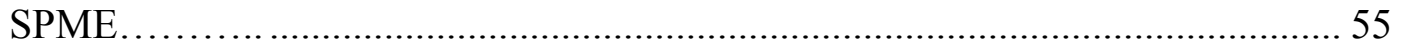

3.3.1.2. Extraction optimization of VOCs from fingernail samples using

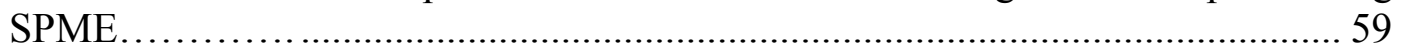

3.3.1.3. SPME extraction optimization for VOCs from saliva samples ........... 63

3.3.2. Collection of multiple biological specimens from a 60 person population 65

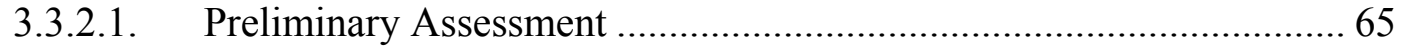

3.3.2.2. Human scent VOCs of different biological specimens collected from 60 individuals.................................................................................................. 75

3.3.2.3. Contributions from male and female subjects to the types of VOCs

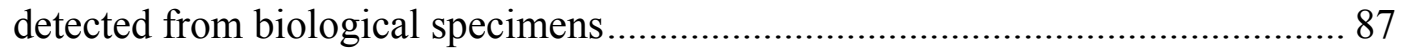

3.3.2.4. Statistical evaluation of VOCs detected from different biological specimens from 60 individuals ....................................................................... 95

3.3.3. Collection of multiple biological specimens over time …........................ 102

3.3.3.1. Discrimination of individuals using VOCs from biological specimens

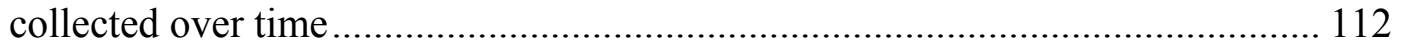

3.3.4. Comparison of different types of samples of the same biological specimen

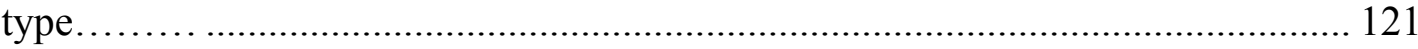

3.3.4.1. Comparison of head hair to arm hair .............................................. 121

3.3.4.2. Comparison of fingernails to toe nails.............................................. 129

4. CANINE EVALUATIONS OF BIOLOGICAL SPECIMENS ……………........... 139

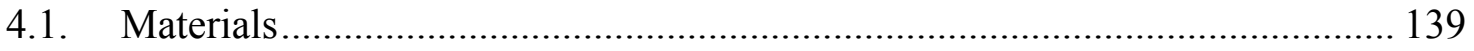

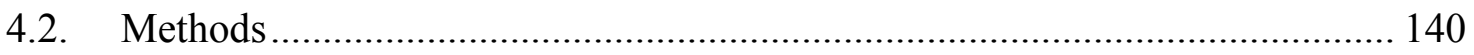

4.2.1. Canine evaluation of collected biological specimens ............................... 140

4.2.1.1. Evaluation of head hair ................................................................ 140

4.2.1.2. Evaluation of fingernail clippings .................................................... 144

4.2.1.3. Evaluation of saliva ........................................................................ 147

4.2.2. Canine evaluation of scent collection systems........................................ 152

4.2.2.1. Evaluation of the operational parameters of the Human Scent Collection System (HSCS) …………………………....................................... 153 
4.2.2.2. Evaluation of the HSCS and the Scent Transfer Unit 100 (STU-

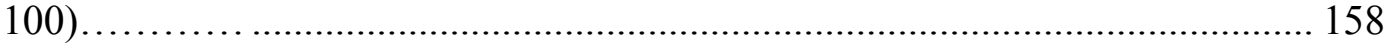

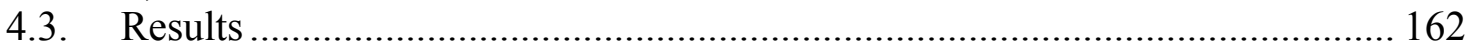

4.3.1. Canine evaluation of collected biological specimens ............................... 162

4.3.1.1. Evaluation of head hair................................................................. 162

4.3.1.2. Evaluation of fingernail clippings ................................................... 166

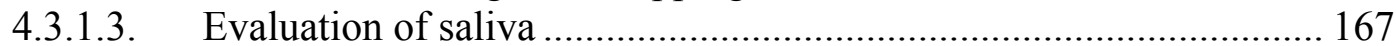

4.3.1.4. Canine response to blank samples ................................................. 169

4.3.2. Canine evaluation of scent collection systems........................................ 171

4.3.2.1. Evaluation of the operation parameters of the Human Scent Collection System (HSCS) ……................................................................................. 171

4.3.2.2. Evaluation of the HSCS and the Scent Transfer Unit 100 (STU-

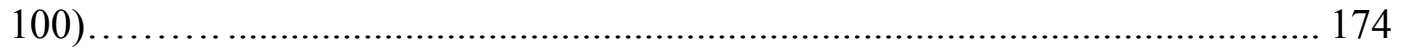

4.3.2.3. Canine response to blank samples .................................................. 180

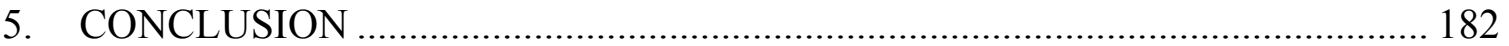

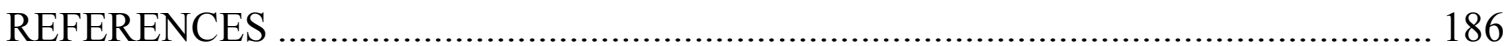

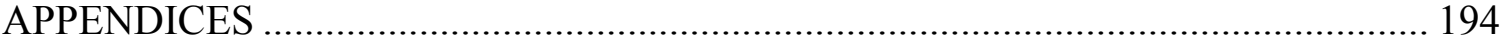

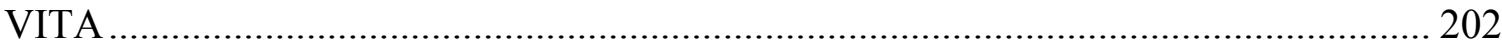




\section{LIST OF TABLES}

TABLE

PAGE

Table 1: Review of publications investigating non-axillary skin scent ......................... 10

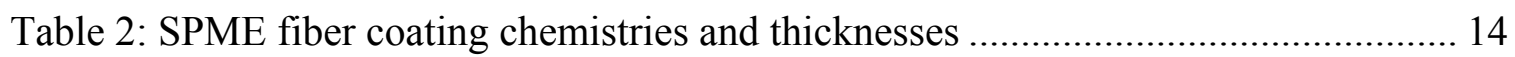

Table 3: Examples of stationary phases used in gas chromatography........................... 17

Table 4: Information pertaining to the samples used during the evaluation of sample mass

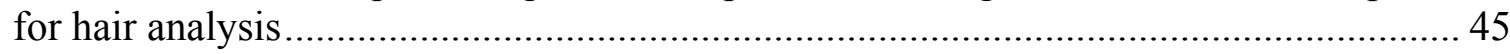

Table 5: Fingernail sample type corresponding to extraction time tested ...................... 47

Table 6: Length and mass of fingernails used for the evaluation of optimal sample type 48

Table 7: The combination of equilibration and extraction times tested for the headspace

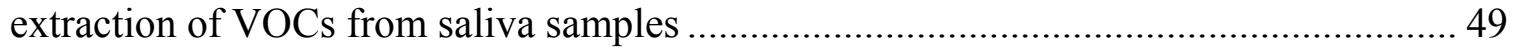

Table 8: Human scent compounds identified from each biological specimen and frequency of occurrence in collected samples ....................................................... 76

Table 9: Limit of detection (LOD) of human scent VOCs …................................... 78

Table 10: Human scent compounds detected from biological samples and the frequency of occurrence from male (M) and female $(\mathrm{F})$ subjects. ........................................... 88

Table 11: Indistinguishable pairs for each biological specimen at the 0.9 Spearman Rank correlation coefficient threshold 96

Table 12: Common human scent VOCs from Subject 1F following a six month sampling period ...... 103

Table 13: Common human scent VOCs from Subject 2F following a six month sampling period 103

Table 14: Common human scent VOCs from Subject 8F following a six month sampling period 104

Table 15: Common human scent VOCs from Subject 4M following a six month sampling period 104

Table 16: Common human scent VOCs from Subject $16 \mathrm{M}$ following a six month sampling period. 105 
Table 17: Common human scent VOCs from Subject 28M following a six month sampling period. 105

Table 18: Similarities among biological specimens collected over a six month period. 111

Table 19: Common human scent VOCs from hand odor samples of six individuals..... 113

Table 20: Common human scent VOCs from hair samples of six individuals............... 115

Table 21: Common human scent VOCs from fingernail samples of six individuals ..... 117

Table 22: Common human scent VOCs from saliva samples of six individuals............ 119

Table 23: VOCs detected from biological specimens from Subject 16M .................... 125

Table 24: VOCs detected from biological specimens from Subject 2F........................ 133

Table 25: Environmental conditions at each test location, for the evaluation of head hair, at the times the 1) trails were laid and 2) when canine testing was conducted............... 142

Table 26: Listing of which collection device, specimen type and collection time was used to create scent samples at each test location. 143

Table 27: Canine teams used for the evaluation of head hair and their corresponding information. 144

Table 28: Environmental conditions at each test location for the evaluation of fingernails 146

Table 29: Canine teams used for the evaluation of fingernails and their corresponding information.

Table 30: Environmental conditions at each test location for the evaluation of saliva . 150

Table 31: Canine teams used for the evaluation of saliva and their corresponding information. 152

Table 32: HSCS parameters: Environmental conditions at each test location. 156

Table 33: HSCS Parameters: Collection time, airflow speed and specimen type tested at each test location.

Table 34: HSCS parameters: Information pertaining to each participating canine team 158

Table 35: Device comparison: Environmental conditions at each test location 160 
Table 36: Device comparison: Information pertaining to each participating canine team 161 


\section{LIST OF FIGURES}

FIGURE

PAGE

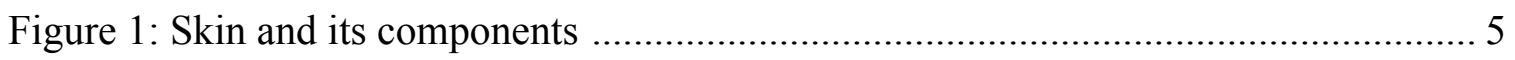

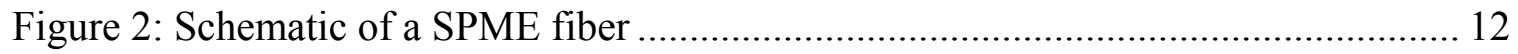

Figure 3: Components of a gas chromatograph .................................................... 15

Figure 4: Components of a mass spectrometer ...................................................... 18

Figure 5: Diagram depicting the passage of an ion corresponding to selected $\mathrm{m} / \mathrm{z}$, through the center of a linear quadrupole, while ions of a different $m / z$ collide with the rods ...... 20

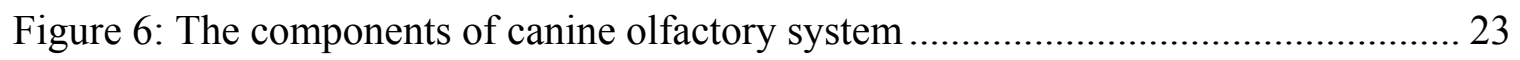

Figure 7: Scent Transfer Unit 100 (STU-100) collecting scent from head hair .............. 27

Figure 8: Human Scent Collection System (HSCS) ................................................. 28

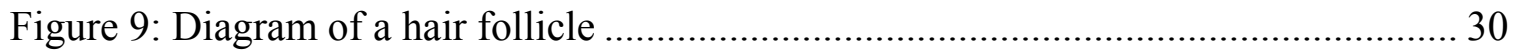

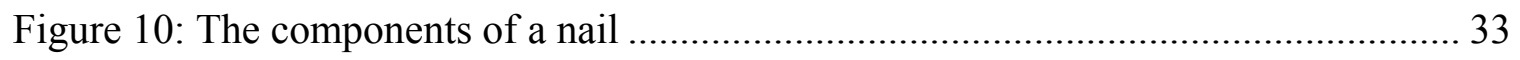

Figure 11: Location of major salivary glands in the mouth........................................ 34

Figure 12: Abundance of VOCs extracted from head hair samples at different extraction

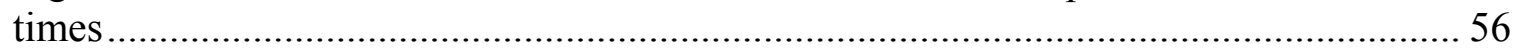

Figure 13: Number of extracted VOCs from head hair at different extraction times ...... 56

Figure 14: Abundance of VOCs extracted from head hair for various sample masses .... 57

Figure 15: Number of extracted VOCs from head hair for various sample masses ......... 58

Figure 16: Abundance of VOCs extracted from fingernails at different extraction times59

Figure 17: Number of extracted VOCs from fingernails at different extraction times.... 60

Figure 18: Profile of extracted VOCs from individual and collective fingernail samples 61

Figure 19: Abundance of VOCs extracted from fingernails for different sample types... 62 
Figure 20: Number of extracted VOCs from fingernails for different sample types 62

Figure 21: Abundance of VOCs extracted from saliva samples at varying equilibration/extraction times 64

Figure 22: Number of extracted VOCs from saliva samples at different extraction times65

Figure 23: Chromatograms of hand odor, saliva, fingernail and hair from a male subject 66

Figure 24: Profiles of the VOCs from triplicate biological specimens for subjects $13 \mathrm{~F}$ and $13 \mathrm{M}$ 68

Figure 25: Profiles of the VOCs from triplicate biological specimens for subjects $28 \mathrm{~F}$ and $16 \mathrm{M}$ 69

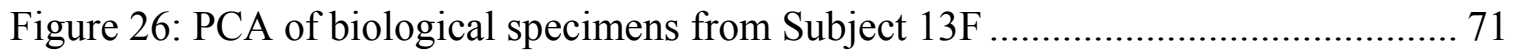

Figure 27: Cluster Analysis of biological specimens from Subject 13F ....................... 71

Figure 28: Mass of extracted VOCs from biological specimens collected from four individuals. 74

Figure 29: Profile of human scent VOCs from the hand odor samples of 60 individuals 83

Figure 30: Profile of human scent VOCs from the hair samples of 60 individuals 84

Figure 31: Profile of human scent VOCs from the fingernail samples of 60 individuals 85

Figure 32: Profile of human scent VOCs from the saliva samples of 60 individuals....... 86

Figure 33: Human scent compounds detected from hand odor samples from male and female subjects. 91

Figure 34: Human scent compounds detected from hair samples from male and female subjects. 92

Figure 35: Human scent compounds detected from fingernail samples from male and female subjects. 94

Figure 36: Human scent compounds detected from saliva samples from male and female subjects. 95 
Figure 37: Color map of Spearman Rank correlations for hand odor samples collected from 60 individuals.....

Figure 38: Color map of Spearman Rank correlations for hair samples collected from 60 individuals.

Figure 39: Color map of Spearman Rank correlations for fingernail samples collected from 60 individuals 100

Figure 40: Color map of Spearman Rank correlations for saliva samples collected from 60 individuals. 101

Figure 41: Chemical profiles of biological specimens from Subject 1F over a six month period 106

Figure 42: PCA of biological specimens six individuals 108

Figure 43: Dendogram of biological specimens from Subject 1F collected over a six month period 110

Figure 44: Hand odor samples collected over six months for six individuals..... 114

Figure 45: Hair samples collected over six months for six individuals. 116

Figure 46: Fingernail samples collected over six months for six individuals................. 118

Figure 47: Saliva samples collected over six months for six individuals 120

Figure 48: Profile of the VOCs generated from head hair and arm hair collected from a male subject. 122

Figure 49: PCA of head hair and arm hair collected from a male subject. 123

Figure 50: Profile of the VOCs generated from the biological specimens for Subject 16M 126

Figure 51: PCA of biological specimens from Subject 16M 127

Figure 52: Dendogram of biological specimens from Subject 16M 128

Figure 53: VOCs profile for fingernails and toe nails collected from a female subject. 130 Figure 54: PCA of fingernails and toe nails collected from a female subject 131 
Figure 55: Profile of the VOCs generated from the biological specimens for Subject $2 \mathrm{~F}$

Figure 56: PCA of biological specimens from Subject 2F ....................................... 136

Figure 57: Dendogram of biological specimens from Subject 2F ............................. 137

Figure 58: Maps of scent trails created by targets for the evaluation of head hair ........ 141

Figure 59: Maps of scent trail created by targets for the evaluation of fingernails ........ 145

Figure 60: Maps of scent trails created by targets for the evaluation of saliva ............. 148

Figure 61: Maps of scent trails created by targets at Long Beach test locations ............ 154

Figure 62: Maps of scent trails created by targets at Alameda test locations ................ 155

Figure 63: Maps of scent trails created by targets at Long Beach test locations ............ 159

Figure 64: Maps of scent trails created by targets at Alameda test locations ................. 159

Figure 65: Canine response to hand odor and hair samples.................................... 163

Figure 66: Canine response to two different scent collection systems ........................ 165

Figure 67: Canine response to aged scent trails................................................... 165

Figure 68: Canine response to hand odor and fingernail samples .............................. 167

Figure 69: Canine response to hand odor and saliva samples ................................. 168

Figure 70: Canine response to scent samples collected using the HSCS at two different collection times 172

Figure 71: Canine response to scent samples collected using the HSCS at three different airflow speeds 173

Figure 72: Canine response to scent samples collected using the HSCS and the STU-100 175

Figure 73: Airflow speeds of the STU-100 and the HSCS while running at the highest airflow setting for $60 \mathrm{~s}$ 176

Figure 74: Canine response to scent samples of hand odor and saliva 177 
Figure 75: Chemical profile of VOCs extracted from hand odor and saliva from Subject 23F . 178

Figure 76: Total abundance (peak area) of VOCs extraction from hand odor and saliva from Subject 23F. 179

Figure 77: Abundance of common compounds in hand odor and saliva samples from Subject $23 \mathrm{~F}$ 180

Figure 78: Chemical profiles of biological specimens from Subject 2F over a six month period. 194

Figure 79: Chemical profiles of biological specimens from Subject 8F over a six month period. 195

Figure 80: Chemical profiles of biological specimens from Subject 4M over a six month period. 195

Figure 81: Chemical profiles of biological specimens from Subject 16M over a six month period. 196

Figure 82: Chemical profiles of biological specimens from Subject 28M over a six month period 196

Figure 83: Dendogram of biological specimens from Subject 2F collected over a six month period 197

Figure 84: Dendogram of biological specimens from Subject $8 \mathrm{~F}$ collected over a six month period 198

Figure 85: Dendogram of biological specimens from Subject 4M collected over a six month period 199

Figure 86: Dendogram of biological specimens from Subject $16 \mathrm{M}$ collected over a six month period 200

Figure 87: Dendogram of biological specimens from Subject 28M collected over a six month period 201 


\section{INTRODUCTION}

When investigators process a crime scene it is imperative that they locate and collect all items of evidence that will link a suspect to the crime and inevitably bring them to justice. With the popularity of crime-solving television shows like CSI (Crime Scene Investigation), viewers have come to understand the value of trace evidence (such as broken glass, fingerprints and shoe marks) and criminals have come to learn that when committing a crime they must ensure that no trace evidence is left at the scene of the crime. Fortunately, for investigators there is one type of trace evidence that is always present at a crime scene and overlooked by criminals, human scent evidence.

At the simplest form, someone would understand human scent to be the odor of a person which canines use to identify and locate people. Scientifically, human scent is defined as the most abundant volatile organic compounds (VOCs) present in the headspace above a collected scent sample (1). It is theorized that the combination of both the presence and abundance of these VOCs provides every individual with a human scent profile that is different from anyone else's, thereby making it a potential biometric measurement.

The current tool used to identify and match human scent at a crime scene or on a piece of evidence is a human scent discriminating canine. These specialized biological detectors have been trained to use human scent, primarily taken from an object, and match it to either the individual or the path that the person took. As with any forensic tool, human scent discrimination by canines, as a form of evidence, is subject to scrutiny in a court of law prior to its admission into any criminal proceedings (2-5). As a result, it is important that scientists continue to conduct research to advance the use of human 
scent in forensic science and provide a scientific foundation for the individual characteristics of human scent.

In the field of forensic science, the scent from hands (or hand odor) is the most useful source of human scent because most evidential items were likely handled by the suspect (6); however, the scent of other biological specimens that are likely to be deposited at a crime scene, such as during a violent crimes, have yet to be evaluated. Hair, fingernails and saliva are examples of these types of specimens; to date very little is known about the differentiation capabilities of these specimens and their use for identifying individuals. Therefore, the goals of this research was to explore the VOCs produced by hand odor, hair, fingernails and saliva, both instrumentally and in the field using scent discriminating canines, to determine whether these profiles could be used to differentiate individuals.

\section{BACKGROUND INFORMATION}

\subsection{Human Scent}

Fingerprints and DNA possess individual characteristics that can be used to identify a person, to the exclusion of others. Another individual characteristic, which is widely overlooked, is human scent. Human scent has great usefulness in forensic science because it is constantly being deposited into the environment. Human scent has been used in conjunction with human scent discriminating canines during criminal and missing person cases. Human scent is defined as the most abundant volatile organic compounds (VOCs) identified in the headspace of a scent sample (1). The composition of human 
scent has been described as being the sum of the contributions from genetics, bacteria present on the body, diet, environment and exogenous materials (7).

\subsubsection{The role of genetics on human scent}

The genetic contribution to human scent is commonly associated to the major histocompatibility complex (MHC), which is a large chromosomal region that contains highly polymorphic genes present within the genome (8). In humans, the MHC is more specifically known as the human leukocyte antigen (HLA). The primary function of the MHC gene is immunological, which includes controlling self/non-self recognition, as well as activating immune defenses (8). Additionally, MHC genes have been linked to the production of body odors which are widely regarded as influencing mate selection and kin recognition, in both mice and humans (8). During the mate selection process, mice with dissimilar (heterozygous) $\mathrm{MHC}$ alleles are likely to procreate, thereby enhancing the heterozygosity of the genes of their offspring and prevent inbreeding. In humans, studies were performed evaluating people's preferences to the odortypes of others (9-11). The study by Wedekind et al. (10) showed that, just as with mice, the participants preferred the odors of individuals with dissimilar MHC.

It has been proposed that two types of compounds are produced from the MHC: small volatile molecules and non-volatile peptide ligands (12). Numerous volatile molecules have been identified and have been characterized as components of human odortypes; however, MHC-specific molecules have yet to be recognized. Recently, the VOCs produced by cell lines containing HLA alleles were extracted using Headspace Solid Phase Microextraction (HS-SPME) and analyzed using Gas Chromatography-Mass 
Spectrometry (GC-MS) (13). The results revealed that there were 14 VOCs that were identified as being significantly different between the different cell lines and the variation in both the presence and abundance of the VOCs produced was explained as being "attributed to the differences in specific HLA alleles (13)."

A recent study performed by Martin et al., revealed that the production of axillary odor is linked to the variants in the ABCC11 gene (14). Martin et al. showed that homozygous individuals for a single-nucleotide polymorphism (SNP) (538G>A), which is common in Asians, had significantly less axillary odorants. The outcomes of these two works $(9-11,13,14)$ have established a bridge between genetics and the production of body odors.

\subsubsection{Glandular Secretions}

Internally derived human scent is transported to the outside of the body by the secretions from three types of exocrine glands, which include eccrine (merocrine) sweat, apocrine sweat and sebaceous (Figure 1). Eccrine (or merocrine) glands are distributed all over the body with the greatest density being found on the palms of hands, soles of the feet and on the forehead (15). Eccrine sweat glands are absent on the surface of the lips and the external ear canal (16). With nearly 2-4 million eccrine sweat glands present in the body, an individual can secrete approximately 2-4 liters of sweat per hour (7). Eccrine secretions originate as a filtrate of blood plasma and are comprised of $99 \%$ water and $1 \%$ of other chemicals (e.g., electrolytes, metabolites and waste products) (15). Functions of eccrine sweat glands include temperature regulation (through the evaporation of fluids), secretions (eliminating excess water and electrolytes from the 
body) and protection (diluting harmful chemicals and inhibiting the growth of microorganisms) (15).

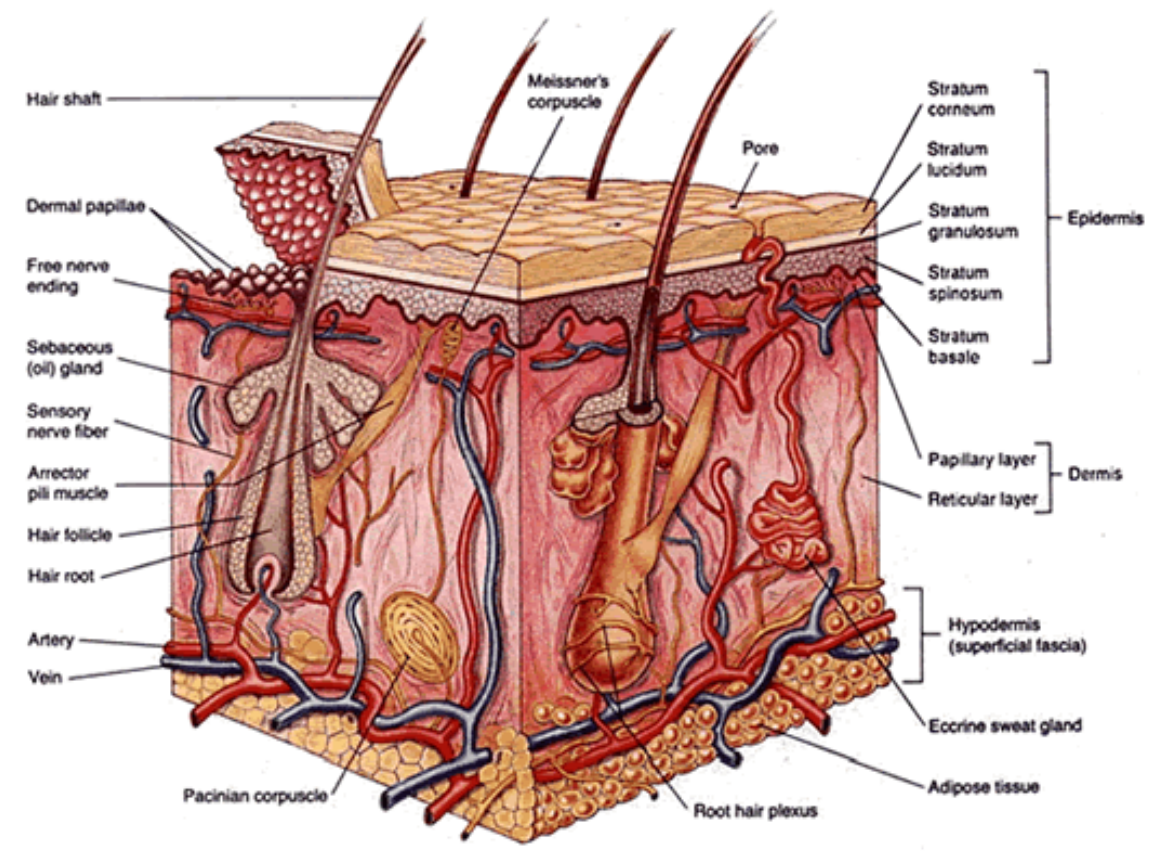

Figure 1-Skin and its components (Picture from reference 17)

Apocrine glands are found in the dermis and are associated with hair follicles. There are fewer apocrine glands present in the human skin than eccrine glands. Apocrine glands contribute to temperature regulation, as well as assist with chemical communication. These sweat glands are concentrated in the axillae, perineal and genital area and the secretions of these glands are regulated by hormones. Apocrine secretions are basic (18) and include lipids, steroids and proteins (19).

The compounds released in the axillary regions of the body are often associated with body odor, or malodor $(19,20)$. About thirty years ago, research had established that steroids (androstenol and androstenone) were the source of odor in the underarm regions 
(21). However, since then, new research has shown that acids (saturated, branched and unsaturated) are the source of axillary malodor, with (E)-3-methyl-2-hexenoic acid serving as the primary culprit (21), and are brought to the surface of the skin by watersoluble proteins.

The secretion from sebaceous glands is an oily, waxy substance, called sebum, which is excreted into a hair follicle. The compounds present in sebum have been previously analyzed using gas chromatography (22). As a result of the difficulty in isolating and analyzing the contents of sebaceous glands the present study used hair bulbs as an alternative source for sebum since hair bulbs lay beneath the surface of the skin. Free fatty acids (FFA), squalene, cholesterol, wax esters, cholesteryl esters and triglycerides, were among the types of compounds identified in the extract. Although cholesterol was detected from hair bulbs, its presence is associated with the epidermal lipids present in hair and not with the sebum. The material that is secreted from the sebaceous glands coats the surface of the hair and skin providing a protective layer that keeps them from becoming dry and brittle.

\subsubsection{Bacteria on the skin}

The human body is a home for bacteria, there are hundreds of millions of microorganisms present on the surface of the skin alone (23). Various genera of microbiota found on human skin have been classified and include staphylococci, aerobic corynebacteria, micrococci, propionibacteria, and Pityrosporum species (24). The bacterial contribution to human scent is the result of metabolism of dead epidermal cells and gland secretions. Odorless secretions of the eccrine, sebaceous and, more notably, apocrine glands are 
transformed, following bacterial metabolism, into odorous compounds frequently associated with body odor. Kuhn and Natsch detailed bacterial transformation with axilla secretions extracted into an aqueous phase (25). They noted that the initial extract possessed a faintly acidic odor; however, when the axilla extract was treated with a bacterial enzyme that had also been isolated from the axilla, the secretion produced an odiferous smell that is typical of malodor. More specifically, research has shown that there is "a strong correlation between high population of corynebateria and a strong axillary odor formation (26).”

\subsubsection{Skin}

Skin, the largest organ of the body, serves as the first line of defense against physical, chemical and biological agents. It covers the entire surface of the body and accounts for $15 \%$ of an adult's total body weight (27), approximately nine pounds (23). Skin is organized into three layers which include the epidermis, dermis and hypodermis (Figure 1). Epidermis, the topmost layer of skin, is comprised of a stratified squamous epithelium and is constantly being renewed. Newly created epithelial cells produced in the basal layer of the epidermis slowly migrate to the surface of the skin where they are shed, which can occur in about 30 days (27). The dermis, which can be found underneath the epidermis, contains a large vascular network that plays a role in regulating body temperature, healing wounds and immune responses. The great majority of dermal glands (e.g. sweat glands) are found within the dermis. The most internal layer of skin is the hypodermis, which is a fatty tissue made up of adipocytes, and functions by providing insulation, energy and protection to the body (27). 
The VOCs present on the surface of the skin do not originate from glandular secretions alone. Skin, itself, has also been shown to generate VOCs (28). Skin that is in different stages of growth produces significantly different profiles of volatile organic compounds. These varying chemical profiles have demonstrated a future application as biomarkers for age, given that as a person ages so does their skin.

\subsection{Deposition of scent into the environment}

Endogenous VOCs make their way through the body and eventually onto the surface of the skin. Recall that the epidermis is constantly releasing dead skins cells. Approximately 0.5-1 gram of dead skin is being deposited into the environment daily (7) along with human scent. These skin cells, also known as rafts, are about 14 microns in size and are soaked with scent secretions (29). In addition, bacteria are also present on the rafts. Just as it occurs on the body, bacteria metabolize the skin cell and secretions, even after the raft leaves the body and lands in the environment (29).

Another mode that introduces human odor into the environment is through the thermal plume $(29,30)$. The average human body is about nine degrees warmer than the environment. The difference in temperature produces a thermal convection process, which transfers body heat to the cooler environment (30) at a rate of 0.64 meters per second (29). It begins down at the feet and migrates up the body until it disperses approximately 0.46 meters above the head. The thermal plume that surrounds the body supports the movement of volatile compounds and skin rafts away from the body. Once it enters into the environment, human scent lingers where it was deposited leaving a record of someone's presence. 


\subsection{Exploring human scent}

Much research has been conducted with the intention of elucidating the identities of compounds being released from skin for cosmetic, medicinal and forensic applications (31-33). An array of techniques has been used for the identification of compounds from skin, with a primary emphasis on odors from axillae (1,25,34-36). The apocrine secretions and bacterial action on those secretions produces a distinct axillary scent.

Non-axillary scent has been explored using samples from various locations on the body, such as the forearm (31,37-40), back (37), abdomen (39), whole body (41) and hand $(32,38,41-43)$. The compounds identified from these skin sources include acids, alcohols, aldehydes, esters, halides, hydrocarbons, heterocyclics, ketones, nitrogen- and sulfur-containing compounds (Table 1). The compounds identified from each specimen were dictated by the extraction technique used by the researcher. For instance, the use of glass beads for the collection of hand secretions (42) produced the largest listing of nonaxillary secretions of the studies listed in Table 1. The direct transfer of the secretions to the collection material provided a wider range of extracted compounds as opposed to when solid phase microextraction was used, which did not extract halides, heterocyclics, nitrogen- and sulfur-containing compounds. Each method has provided a distinct selection of compounds through the preferential extraction of specific functional groups or volatilities. 
Table 1-Review of publications investigating non-axillary skin scent

\begin{tabular}{|c|c|c|c|c|c|c|c|c|c|c|c|c|c|}
\hline \multirow[t]{2}{*}{ Specimen } & \multirow{2}{*}{$\begin{array}{l}\text { Extraction } \\
\text { Technique }\end{array}$} & \multirow[t]{2}{*}{ Instrumental Analysis } & \multicolumn{10}{|c|}{ Compounds Detected* } & \multirow[t]{2}{*}{ Reference } \\
\hline & & & ACD & ALC & ALD & EST & HAL & $\mathrm{HC}$ & HET & KET & NIT & SUL & \\
\hline $\begin{array}{l}\text { Hands, } \\
\text { Whole } \\
\text { body }\end{array}$ & $\begin{array}{l}\text { Porapak tubes } \\
\text { (porous polymer) }\end{array}$ & $\begin{array}{c}\text { Gas chromatography- } \\
\text { electrophysiology (GC-EAG) } \\
\text { and gas chromatography-mass } \\
\text { spectrometry (GC-MS) }\end{array}$ & $\mathrm{X}$ & $\mathrm{X}$ & $\mathrm{X}$ & & $\mathrm{X}$ & $\mathrm{X}$ & $\mathrm{X}$ & $\mathrm{X}$ & & & $(41)$ \\
\hline $\begin{array}{l}\text { Left } \\
\text { forearm, } \\
\text { abdomen }\end{array}$ & $\begin{array}{l}\text { Polydimethylsiloxane } \\
\text { (PDMS) membrane }\end{array}$ & Thermal desorption GC-MS & & $\mathrm{X}$ & $X$ & $\mathrm{X}$ & & $\mathrm{X}$ & $\mathrm{X}$ & $\mathrm{X}$ & & & (39) \\
\hline Arm & PDMS stir bar & Thermal desorption GC-MS & $\mathrm{X}$ & $\mathrm{X}$ & $\mathrm{X}$ & & & & & $\mathrm{X}$ & & & $(40)$ \\
\hline $\begin{array}{l}\text { Upper } \\
\text { back, } \\
\text { forearm }\end{array}$ & $\begin{array}{c}\text { Solid phase } \\
\text { microextraction } \\
\text { (SPME), solvent } \\
\text { extraction } \\
\end{array}$ & $\begin{array}{c}\text { Gas chromatography-flame } \\
\text { photometric detection (GC- } \\
\text { FPD), GC-MS }\end{array}$ & $\mathrm{X}$ & $\mathrm{X}$ & $\mathrm{X}$ & & & & & $\mathrm{X}$ & & $\mathrm{X}$ & $(37)$ \\
\hline Forearm & SPME & GC-MS & & & $\mathrm{X}$ & & & $\mathrm{X}$ & & $\mathrm{X}$ & & & $(31)$ \\
\hline Hands & Glass beads & GC-MS & $\mathrm{X}$ & $\mathrm{X}$ & $\mathrm{X}$ & $\mathrm{X}$ & $\mathrm{X}$ & $\mathrm{X}$ & $\mathrm{X}$ & $\mathrm{X}$ & $\mathrm{X}$ & $\mathrm{X}$ & $(42)$ \\
\hline Hands & SPME & GC-MS & $\mathrm{X}$ & $\mathrm{X}$ & $\mathrm{X}$ & $\mathrm{X}$ & & $X$ & & $\mathrm{X}$ & & & $(32)$ \\
\hline Arm & SPME & GC-MS & & $\mathrm{X}$ & $\mathrm{X}$ & $\mathrm{X}$ & & $\mathrm{X}$ & & & & & $(38)$ \\
\hline Hand & Air sampling probe & $\begin{array}{c}\text { Secondary electrospray } \\
\text { ionization-mass spectrometry } \\
\text { (SESI-MS) }\end{array}$ & & & & & & & & & $\mathrm{X}$ & & $(43)$ \\
\hline
\end{tabular}

*-ACD-acid, ALC-alcohol, ALD-aldehyde, EST-ester, HAL-halide, HC-hydrocarbon, HET-heterocyclic, KET-ketone, NITnitrogen-containing compound, SUL-sulfur-containing compound 
Though the method of extraction varied between the different research groups, the one analytical approach that was agreed upon by nearly all of the researchers was the use of gas chromatography. Gas chromatography (GC) is an ideal choice for the analysis of skin volatile organic compounds. GC is best suited for the separation of volatile and thermally stable compound mixtures, similar to human scent. Additionally, GC is compatible with many extraction techniques, specifically solid phase microextraction (SPME), and detection systems, such as mass spectrometry (MS), making the exploration of human scent extremely feasible. The human scent research performed in this study utilized SPME for the extraction of VOCs and GC-MS for the separation and identification of the mixtures of volatile organic compounds. The theories behind each of these techniques will be detailed in the subsequent sections.

\subsubsection{Instrumental analysis of human scent}

\subsubsection{Solid phase microextraction}

Solid phase microextraction (SPME) is composed of a silica rod surrounded by a polymeric coating that is used for the selective extraction of volatile and semi-volatile compounds from an assortment of matrices. Solid phase microextraction offers the advantages of being solvent-free, rapid and portable. The design of a SPME fiber includes a silica rod, with a diameter ranging from $100-200 \mu \mathrm{m}$ that is coated with a liquid or solid phase which has a thickness ranging from 3-100 microns (44). The SPME fiber is attached to a microsyringe (Figure 2) making it amenable to many analytical techniques. The size of a SPME fiber is quite small preventing it from exhaustively 
extracting analytes from samples; therefore, SPME extractions are classified as an equilibration extraction technique.

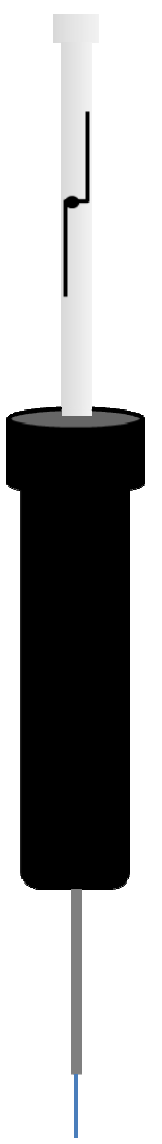

\section{Figure 2-Schematic of a SPME fiber}

There are two modes of SPME extractions: headspace and direct extraction (44). Headspace extractions are best suited for the extraction of volatile compounds. Headspace extractions require that the analyte achieve a three-way equilibration between the sample, the headspace above the sample and the fiber coating. Direct extraction is intended for the extraction of semi-volatiles from aqueous matrices. For direct extraction, the analyte must achieve a two-way equilibration between the sample and the fiber coating. To ensure a proper headspace extraction was conducted, researchers need 
to optimize the time required for the sample to equilibrate with the headspace (equilibration time) as well as the time required for the headspace to equilibrate with the fiber coating (extraction time).

At the point of equilibration, the amount of analyte absorbed onto the coating of the SPME fiber can be related to the concentration of the analyte in the sample, using Equation 1, where $\mathrm{n}$ is the mass of the analyte absorbed by the coating, $\mathrm{K}_{\mathrm{fs}}$ is the partition coefficient of the analyte between the fiber coating and the sample, $\mathrm{C}_{0}$ is the initial concentration of the analyte in the sample, $V_{f}$ is the volume of the coating and $V_{s}$ is the volume of the sample (44).

\section{Equation 1-Amount of analyte absorbed by the SPME fiber coating}

$$
n=\frac{K_{f s} V_{f} C_{0} V_{s}}{K_{f s} V_{f}+V_{s}}
$$

Because the nearly negligible volume of the fiber coating, in comparison to the sample volume, Equation 1 is often simplified to what is seen in Equation 2 (44).

\section{Equation 2-Reduced equation for the amount of analyte absorbed by the SPME fiber coating}

$$
n=K_{f s} V_{f} C_{0}
$$

There is an assortment of coating chemistries commercially available for SPME (Table 2) that range in polarity and thickness. The polarity of the coating influences the type of 
compounds that are extracted from samples, such as polar coatings preferentially extracting polar compounds and non-polar coatings preferentially extracting non-polar compounds. The thickness of the coating influences the amount of analyte extracted which also effects the time it takes for the sample to reach equilibrium with the coating.

Table 2-SPME fiber coating chemistries and thicknesses

\begin{tabular}{|lccc|}
\hline \multicolumn{1}{|c}{ Stationary Phase } & Acronym & Polarity & Thickness $(\boldsymbol{\mu m})$ \\
\hline Polydimethylsiloxane & PDMS & Non-polar & 100 \\
& & & 30 \\
& & & 7 \\
\hline Divinylbenzene/Carboxen/Polydimethylsiloxane & DVB/CAR/PDMS & Bi-polar & $50 / 30$ \\
\hline Carboxen/Polydimethylsiloxane & CAR/PDMS & Bi-polar & 75 \\
& & & 85 \\
\hline Polydimethylsiloxane/Divinylbenzene & PDMS/DVB & Bi-polar & 65 \\
\hline Polyacrylate & PA & Polar & 85 \\
\hline Carbowax-Polyethylene Glycol & PEG & Polar & 60 \\
\hline
\end{tabular}

Solid phase microextraction has demonstrated performances comparable to liquid-liquid extraction, headspace analysis and purge-and-trap (44). Additionally, it has the ability to be coupled to analytical instruments such as, gas chromatography, high performance liquid chromatography and capillary electrophoresis, making it a useful tool for environmental, pharmaceutical and forensic analyses.

\subsubsection{Gas Chromatography}

Gas chromatography (GC) is the ideal choice for the analysis of volatile compounds which are largely present in human scent. Fundamentally, GC is a separation technique for gas samples which uses a gas mobile phase and a liquid or solid stationary phase to facilitate the separation of mixtures. Though there are gas-liquid and gas-solid 
chromatography they are simply referred to as gas chromatography (45). The major components of a gas chromatograph are the carrier gas supply, sample introduction region (inlet), column within a thermostated oven, and the detector (Figure 3).

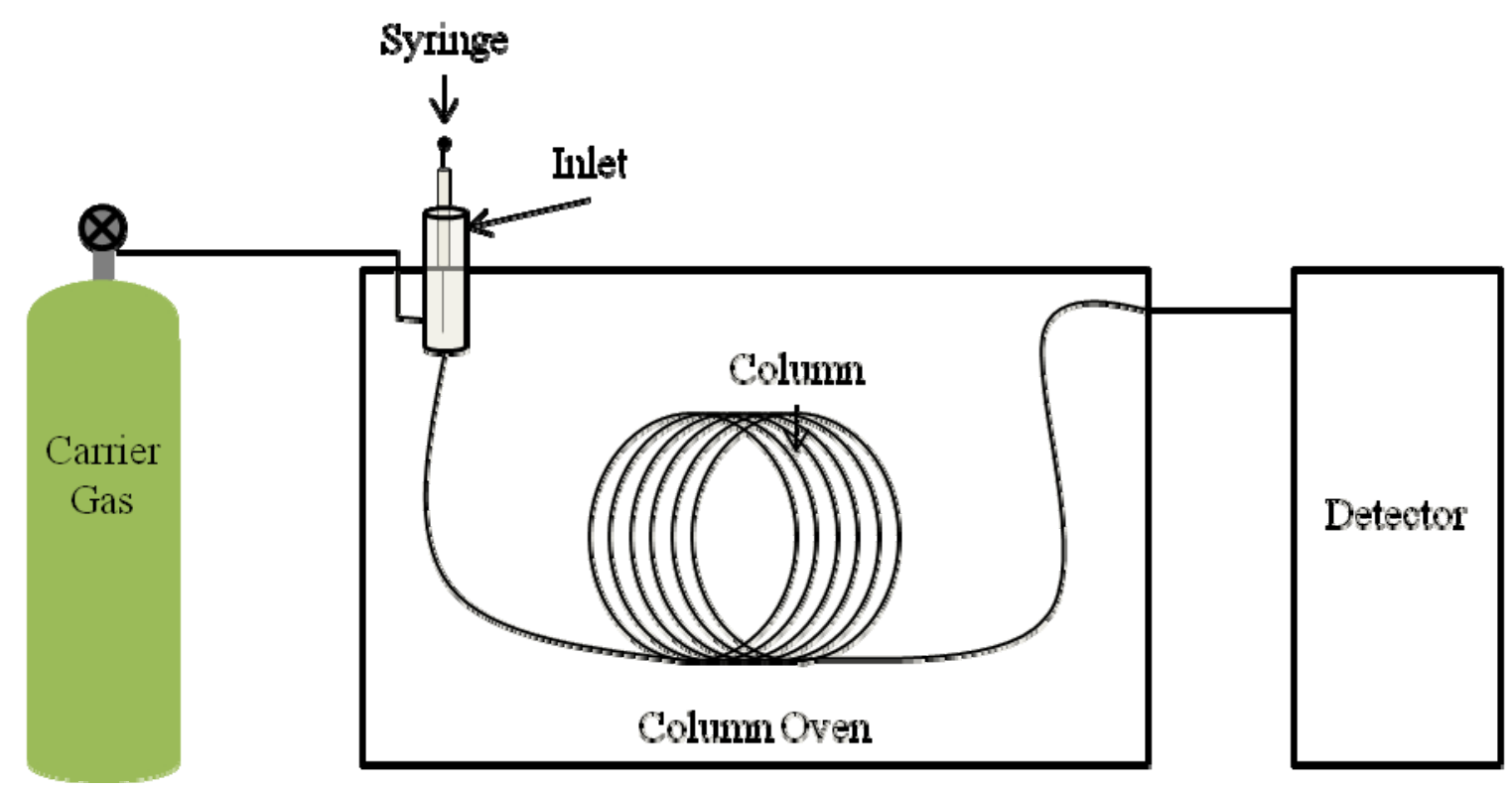

Figure 3-Components of a gas chromatograph

The carrier gas, also termed the mobile phase, is an inert gas, that does not interact with the compounds in the mixture, and includes helium, hydrogen and nitrogen. The flow rate of the carrier gas is regulated to achieve flow rates that range from 1-25 $\mathrm{mL} / \mathrm{min}$ in open tubular capillary columns (45). The carrier gas is introduced, along with the sample, into the chromatograph at the location of the inlet.

A liquid or gas sample typically enters the GC inlet by injection with a microsyringe. Inside the inlet, the sample is heated to a high temperature (usually greater than $200^{\circ} \mathrm{C}$ ) where it is flash vaporized. The conversion of liquids into gas, during flash vaporization, requires sample volumes $\leq 1 \mu \mathrm{L}$ be used for chromatographic analysis. 
Inlets can function in both split and splitless mode. When highly concentrated samples are introduced into the inlet, the split vent can be opened to allow a portion of the sample to exit into the atmosphere through the vent while the remainder of the sample is introduced into the column. In splitless mode, the split vent remains closed and the entire sample is introduced into the column. Splitless mode is used for the analysis of extremely volatile compounds and trace samples (46). Following vaporization the orthogonally placed carrier gas pushes the sample into the GC column.

Modern gas chromatographs are suited with open tubular capillary columns, which range from 1-100 $\mathrm{m}$ in length with internal diameters from $0.25-0.75$ millimeter (45). These capillary columns contain a stationary phase coating, which vary in chemistry and polarity (Table 3 ) and play a large role in the separation of mixtures (47). For instance, if a polar stationary phase is used, such as polyethylene glycol, then polar compounds, such as fatty acids, will have a greater interaction with the phase and will take a longer time to exit the column, or elute. On the contrary, if a non-polar stationary phase is used, such as polydimethylsiloxane, then polar compounds will have a weak interaction with the phase and will quickly elute from the column. Therefore, it is important that the chemistries of the compounds in the sample and stationary phase of the column are compatible for analysis. The different degrees of interaction between each component of the mixture and the stationary phase results in a different elution time, or retention factor, for each component. 
Table 3-Examples of stationary phases used in gas chromatography (47)

\begin{tabular}{|c|c|}
\hline Stationary Phase & Polarity \\
\hline Poly(dimethyl siloxane) & Non-polar \\
\hline $\begin{array}{c}\text { Poly(5\% diphenyl/95\% } \\
\text { dimethyl siloxane) }\end{array}$ & Non-polar \\
\hline $\begin{array}{c}\text { Poly(6\% } \\
\text { cyanopropylphenyl/94\% } \\
\text { dimethyl siloxane) }\end{array}$ & Intermediate Polar \\
\hline $\begin{array}{c}\text { Poly(35\% diphenyl/65\% } \\
\text { dimethyl siloxane) }\end{array}$ & Intermediate Polar \\
\hline $\begin{array}{c}\text { Poly(50\% } \\
\text { cyanopropylphenyl/50\% } \\
\text { dimethyl siloxane) }\end{array}$ & Polar \\
\hline \begin{tabular}{c} 
Poly(ethylene glycol) \\
\hline
\end{tabular} & Polar \\
\hline
\end{tabular}

Chromatographic columns are housed inside a programmable oven which can be adjusted to desired temperatures throughout analysis (45). Increasing the temperature of the oven encourages the elution of high-boiler compounds at faster times. On the other hand, if a compound elutes too quickly, then it might be necessary to reduce the temperature of the oven to reduce its elution time. When dealing with complex mixtures, the temperature of the oven can be programmed to remain constant or increase at desired intervals to allow for the resolved separation of compounds. 


\subsubsection{Mass Spectrometry}

As the separated components of the original sample exit the chromatographic column they are subsequently introduced into a detector. There are many types of detectors that are compatible with GC (e.g. flame ionization detector, electron capture detector, atomic emission detector), but mass spectrometry is most commonly used. Mass spectrometry determines the mass-to-charge $(\mathrm{m} / \mathrm{z})$ ratio of ionized gases through a process of ionization, separation and detection (Figure 4). Once eluted from the column, the gaseous compounds enter the mass spectrometer and are then ionized. Different from chromatographs, mass spectrometers are maintained under high vacuum pressure $\left(10^{-6}\right.$ Torr) in an effort to minimize the interactions between the generated ionized gases. Additionally, the low pressure atmosphere allows for the manipulation of ions by both magnetic and electrostatic fields (48).

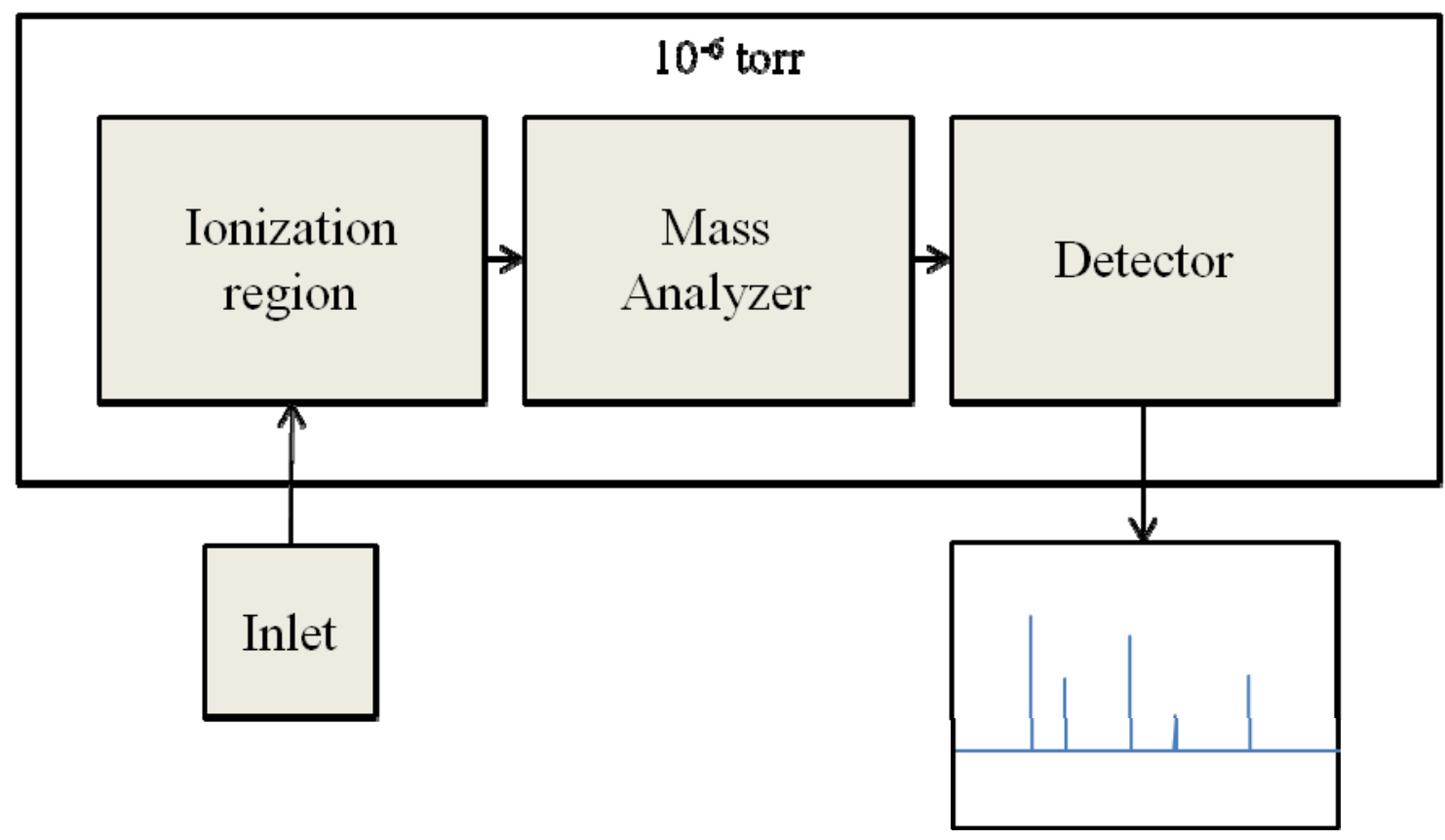

Figure 4-Components of a mass spectrometer 
There are two types of ionization sources that are widely incorporated into mass spectrometers coupled to gas chromatographs; they are electron-impact (EI) and chemical ionization (CI) (49). These ionization techniques can be classified as hard and soft ionization techniques, respectively. A hard ionization source transfers a sufficient amount of energy to the gaseous compound leaving that compound in an excited state. As the ionized gas relaxes, chemical bonds can break producing smaller fragments of the original ion. With soft ionization sources, very little energy is transferred to the compound which simply ionizes it with little to no fragmentation.

The mechanics by which electron impact ionization occurs involves bombarding the gaseous compound with a beam of electrons. The beam of electrons is accelerated by a potential of approximately $70 \mathrm{eV}$ in a direction orthogonal to the incoming gaseous compound. The electrons collide with the compounds and an electron is removed from the sample causing ionization to occur, as depicted by Equation 3 (49).

\section{Equation 3-Ionization reaction occurring during electron impact}

$$
M+e^{-} \rightarrow M^{++}+2 e^{-}
$$

During chemical ionization, instead of ionizing the sample directly through the bombardment of electrons, a reagent gas is ionized first via electron impact. Once the reagent gas (e.g., methane) is ionized, the gaseous compounds are introduced into the ionization region where ionization occurs through proton transfer producing a $\mathrm{M}+\mathrm{H}^{+}$ion. The sample ions enter into the mass analyzer where they are separated according to $\mathrm{m} / \mathrm{z}$ ratios. 
The quadrupole is one of the most commonly used mass analyzers (49). A linear quadrupole mass analyzer is comprised of four rods arranged in a parallel and opposite configuration. Electrostatic fields, a direct current and a varying radiofrequency, are applied to the four rods at right angles. The combination of the direct current and a specific radiofrequency will allow for the passage of a single $\mathrm{m} / \mathrm{z}$ through the rods, while other ions of higher or lower $\mathrm{m} / \mathrm{z}$ collide with the rods and return to their neutral state (Figure 5). Ions that steadily travel through the linear quadrupole collide with an electron multiplier, producing a signal. The ions that are detected are incorporated into a mass spectrum which plots the abundance of the detected ions, according to their $m / z$.

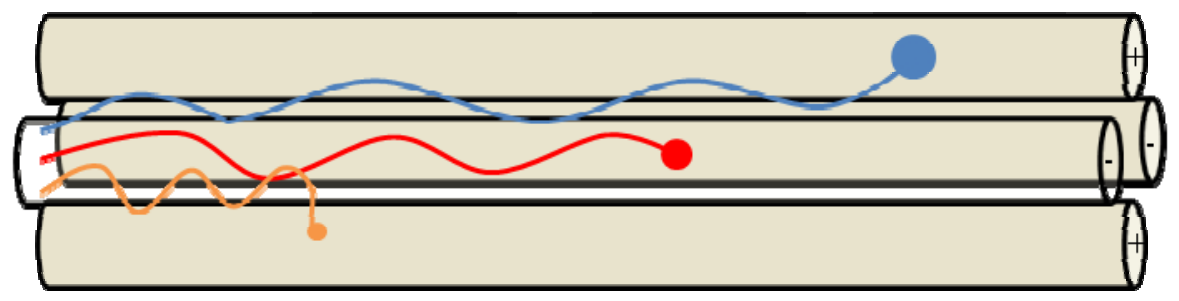

Figure 5-Diagram depicting the passage of an ion corresponding to selected $m / z$ (red), through the center of a linear quadrupole, while ions of a different $\mathrm{m} / z$ (blue and orange) collide with the rods

\subsubsection{Human scent as a biometric}

In addition to identifying the compounds that make up human scent, researchers are beginning to quantify the distinctiveness of these compounds. In a study by Curran et al. (50) the distinguishability of VOCs extracted from hand odor was evaluated for a population of 60 individuals. Volatile organic compounds were extracted from the headspace of hand odor samples using a bipolar SPME fiber revealing 63 compounds that 
included an assortment of functionalities, such as, alcohols, acids, aldehydes, alkanes, ketones, esters, and nitrogen-containing compounds. These detected compounds were present in the samples of the subjects with varying degrees of frequency (high, medium, and low). Through the use of non-parametric statistical analysis, such as Spearman Rank Correlations, $99.67 \%$ hand odor samples, obtained from among the 60 subjects, were discriminated. When only using a small selection $(n=63)$ of all of the compounds that make up human scent, a high level of discrimination was seen for these scent samples.

Another research group demonstrated that the VOCs emitted by an individual can be used to identify a person over time (51). In this study, sweat samples were collected from nearly 200 subjects, five times over a 10 week period, and analyzed using gas chromatography-mass spectrometry. A combination of qualitative distance (Jaccard distance), quantitative distance (Euclidean distance), principal coordinate analysis and a rank test was used to assess intra-subject and inter-subject differences over time. The results indicated that the inter-subject differences were always significantly different from the intra-subject differences. The application of statistics to acquired instrumental data has supported the claim that human scent is different for every individual and has thereby extended its usefulness outside of the laboratory and into important applications.

\subsection{Application for human scent discrimination}

Bodily materials, such as, fingernails, hair and saliva are often collected from crime scenes and are subsequently analyzed using comparison matches, microscopic evaluations, and/or DNA analyses. In turn, this trace evidence may objectively link a suspect to a crime and develop important investigative leads (52,53). Another form of 
trace evidence that is being collected, more regularly, by law enforcement agencies within the United States is human scent. The use of human scent in criminal investigation stems from the fact that every individual has a distinct scent. The use of these odors for their individualizing properties has provided forensic analysts with a useful tool for the identification and matching of human scent; however, these processes are not achieved through instrumental evaluation, they are performed using trained canines.

\subsubsection{Canine olfaction}

Canine olfaction acuity is nearly 10,000-100,000 times greater than that of humans allowing them to detect minute concentrations of compounds down to 1-2 parts per trillion (54). Their superior sense of smell has served well for the detection of scents that are not perceivable by humans, such as explosives, drugs and human scent. The process that occurs (7), which permits canines to detect an odor, begins with it entering the nose or mouth and makes its way to the odor receptors inside the nasal cavity. Deep inside the nose there is an olfactory epithelium that is covered with mucus and contains small hairs called cilia. Olfactory receptors are located on the cilia; however, to reach the receptor, the odor must dissolve into the watery mucus surrounding the cilia. Odors tend to be weakly polar, chemically, and must adhere to an olfactory binding protein, which will assist in the dissolution of the odor into the mucus and transport it to the receptor. The cilia are connected to sensory neurons which deliver impulses to the bulbus olfactorius within the brain once the receptor is activated. 


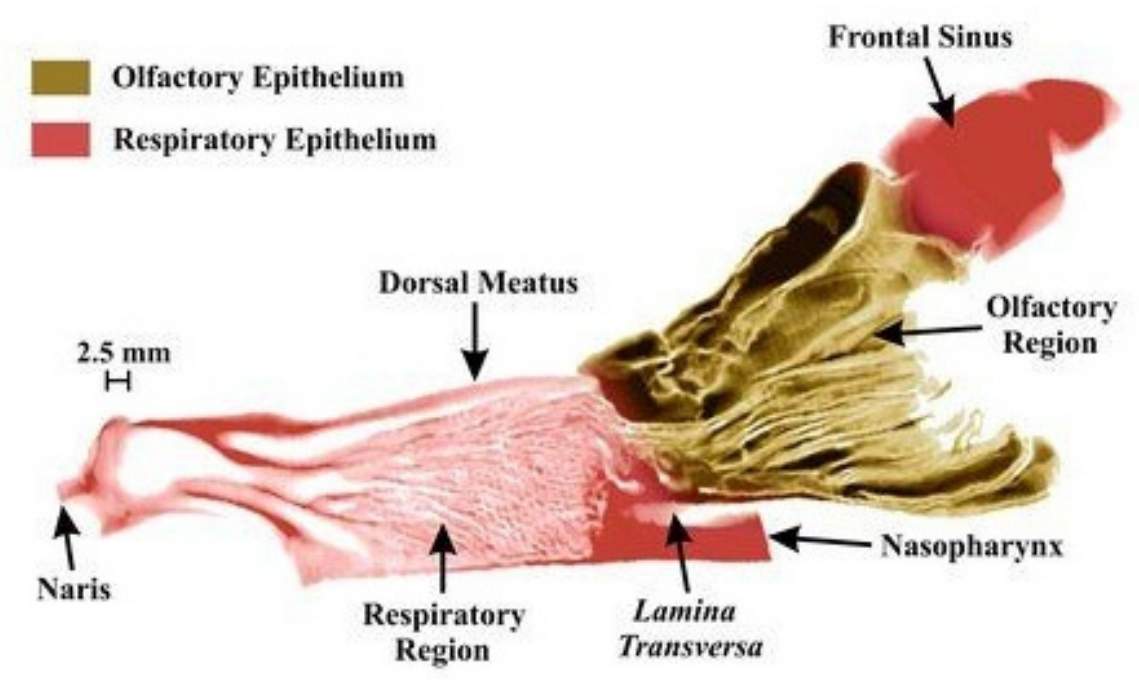

Figure 6-The components of canine olfactory system ( Picture from reference 54)

There are nearly a thousand different receptors that odors can bind to, which allows for the detection of a large variety of odors (7). Once an odor binds to a receptor an impulse is sent through the sensory neuron directly to the brain. The nerve endings are bound together with other olfactory receptors of the same type forming what could be described as a nerve-knot, called a glomerulus, in the bulbus olfactorius. The bundling of nerve endings from the same receptor provides an amplified response to an odorant.

Once the signal had reached the brain, there are two routes the brain will use to process the perceived odor (7). One, the signal will go to the cortex region which will elicit learned responses, or a cognitive response. When a signal is sent to this part of the brain, a canine can recognize the odor and be trained to react or ignore the odor. The other route taken by an odor signal is to travel to the limbic system eliciting noncognitive behaviors, such as, happiness, when a canine smells his owner approaching the home. 


\subsubsection{Canine scent capabilities}

As far back as 400 B.C., canines have been used in forensic investigations to track individuals (7). For ages, canines have accompanied law enforcement officials to assist with finding perpetrators and helping to solve crimes. Early accounts of canine work would detail bringing a canine to the scene of a crime; the canine would smell the area near where the crime occurred and would follow the trail of the fleeing suspect. In some of the successful accounts, the canine would walk directly to the individual with the matching scent and would alert his finding to an officer (sometimes by lunging on the suspect) (7). In the early 1900 s, this practice often led to a conviction with the only witness being the canine's nose. Since then, police canine work has become increasingly structured, but has endured much more scrutiny.

Canine olfaction has been assessed on numerous occasions with tests addressing many factors (e.g. role of genetics, role of environment) and they continue to demonstrate their superiority over humans in olfaction. One study evaluated whether trained bloodhounds were influenced by genetics or the environment when tracking humans (55). Monozygotic twins, related people and non-related people (genetic factor) participated in this study with members of each group either having lived together or apart (environmental factor). The results showed that trained bloodhounds had a difficult time

differentiating between monozygotic twins (which have the same DNA) than with related or non-related individuals revealing that bloodhounds rely more on genetics, when discriminating individuals, then on environmental cues.

Canines also have the ability of matching scents collected from different places of the body (56). In this study, six Dutch police dogs (German shepherd, Malinois or 
mixed) were evaluated as to whether they can match three different sets of scents: elbow $v s$. hand, hand $v s$. elbow, and pocket $v s$. hand. For all three trials, the canines performed significantly better than chance when matching the different sets of scents; however, canines performed best when matching the pocket scent to the hand scent. These studies validate that trained canines are able to detect human scent and use it to identify individuals, regardless of confounding factors, and have proved to possess a skill that would be useful for forensic investigators.

When called upon to work a case (either criminal or search and rescue), the trained canine and its assigned handler will be taken to either the last known location of the suspect/victim or will be presented with a scent article that belonged to the person of interest. The path that the canine follows can lead law enforcement officials to the present location of an individual or to a significant location prompting officials to take further action, such as arresting the suspect or filing a search warrant.

\subsubsection{Collection of human scent}

The collection of scent is an important aspect to consider when using canines in criminal investigations because the manner of collection could potentially damage or contaminate the evidence. The collection of human scent can be performed by several different methods: direct scenting, swiping, absorption, and non-contact collection (57). Direct sampling occurs when a scent article is presented directly to a canine. Swiping an object allows for the rapid collection of human scent onto a sorbent material; however, this method of collection introduces the potential of destroying important evidence, such as, fingerprints. Absorption of human scent is a lengthier process which involves placing a 
sorbent material on an object for a period of time resulting in the transfer of human scent from the object to the material. Absorption also has the same disadvantage as the previously mentioned techniques, as well as being a lengthier process. Lastly, noncontact collection utilizes a dynamic airflow system to draw human scent away from an object and onto a sorbent material. The non-contact collection of human scent is a quick process leaving any potential evidence intact for further forensic analysis. There are two devices that were created with the intention of being used for scent collection and they are the Scent Transfer Unit 100 (STU-100) and the Human Scent Collection System (HSCS).

\subsubsection{Scent Transfer Unit 100 (STU-100)}

The STU-100 is a portable vacuum that is designed to hold a 5" x 9" gauze pad (Figure 7). The device, used by many law enforcement agencies, as well as the Federal Bureau of Investigation (FBI), works by producing an airflow to draw in scent from the surface of an item and on to a sorbent material (57). Following scent collection, the scent pad is presented to a canine to initiate trailing to the matching scent. The STU-100 can be adjusted to operate at different rates of airflow speed and is equipped with a rechargeable battery. 


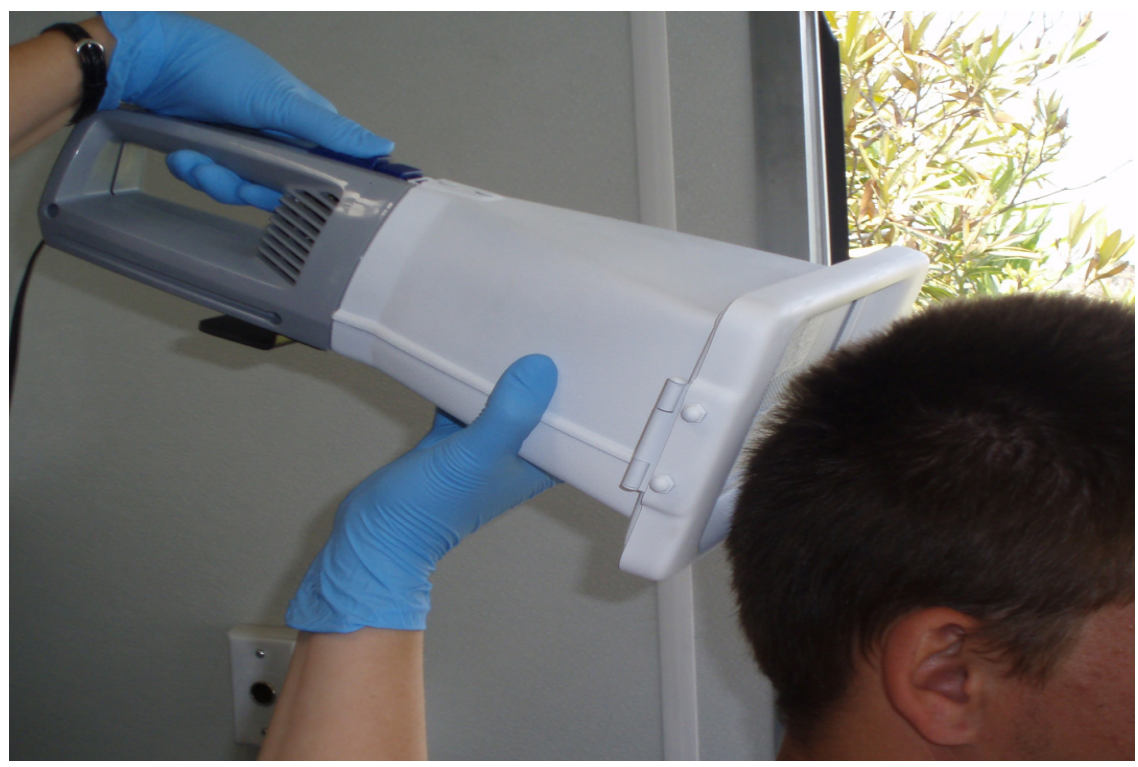

Figure 7-Scent Transfer Unit 100 (STU-100) collecting scent from head hair

\subsubsection{Human Scent Collection System}

The Human Scent Collection System (HSCS) is a device which was created for the noncontact collection of human scent from objects and/or locations (Figure 8). Once collected onto a sorbent material, human scent can be presented to a human scent discriminating canine for matching purposes (e.g., scent identification line-ups or tracking/trailing individuals). The HSCS is a lightweight, cylindrical device that provides a dynamic airflow, drawing human scent onto a 4" x 4" sorbent material. Features, such as, a digital screen, battery powered, pre-set collection times and airflow speeds, make the HSCS easy to use. The HSCS offers two collection time settings of 30 seconds (default) and 60 seconds, as well as three airflow settings of low, medium (default), and high. These programmed settings aid with standardizing scent collection between individuals or agencies and can be easily reproduced. 


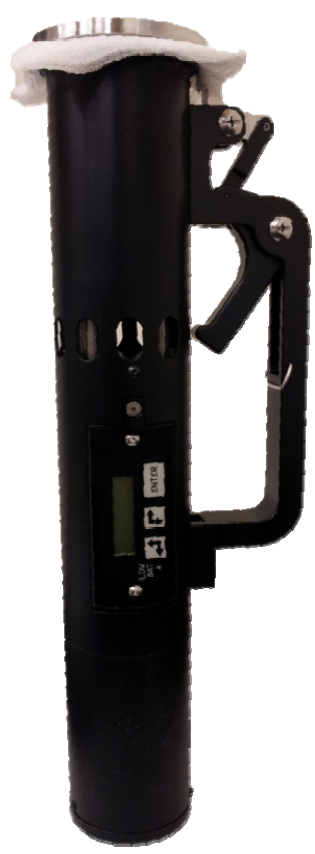

Figure 8-Human Scent Collection System (HSCS)

Quite commonly the perpetrator of a crime is not apprehended at a crime scene and very little physical evidence remains linking the suspect to the crime; however, their human scent is constantly being deposited wherever they go. Therefore, it is important to carefully select a collection time and airflow speed that will allow for the collection of a sufficient amount of human scent so that the scent sample can be presented to a trained canine. Failure to utilize the optimal collection time and airflow speed could lead to the capture of little to no human scent which will hinder the canine from working effectively. 


\subsection{Alternative trace biological specimens}

In forensic science, hand scent is of particular interest to investigators since $73 \%$ of collected scent evidence in the United States is comprised of items which have come into contact with hands (6). Attention is now being turned to alternative biological specimens, such as head hair, fingernail clippings and saliva. These specimens can be dislodged during a violent crime and could possess evidentiary value as scent evidence articles. The VOCs released by these materials has yet to be thoroughly investigated. Fortunately, they can be collected non-invasively making the evaluation of these materials, from a large population, relatively easy.

\subsubsection{Head hair}

Head hair is a human biological specimen that is frequently deposited into the environment. Historically, hair found at crime scenes have been analyzed microscopically to evaluate morphological characteristics that can be used to determine species type (human or non-human), ethnicity and/or used for comparison matches (58). Hair has also been used in forensic work for mitochondrial DNA typing (59), nuclear DNA typing (when a follicular tag is present) (60) and drug analysis $(61,62)$. 


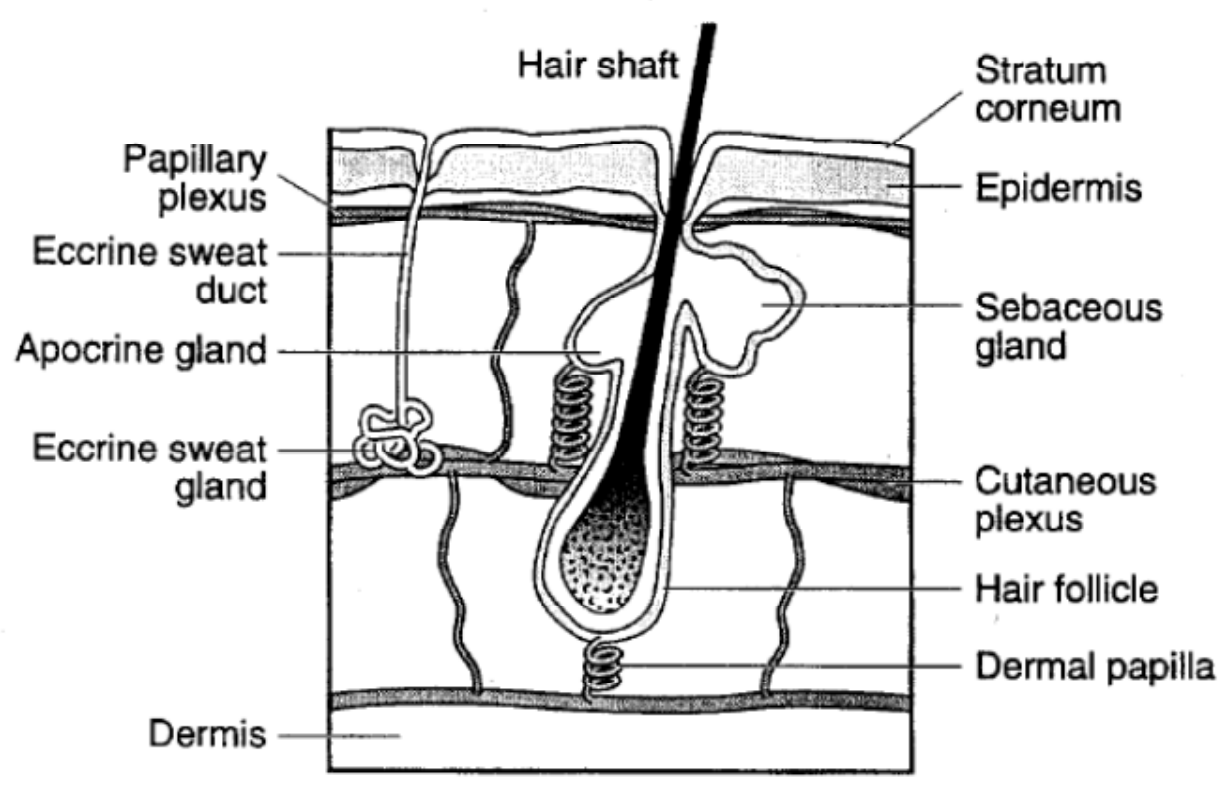

Figure 9-Diagram of a hair follicle ( Picture from reference 63)

Hair is composed of a durable protein called keratin. The crystalline keratin is extruded from the hair follicle and emerges as a hair shaft resulting in the appearance of hair. The chemical composition of hair includes $65-95 \%$ protein, $15-35 \%$ water and 1$9 \%$ lipids (63). The diameter of human hair ranges from 15-120 $\mu \mathrm{m}$, depending upon the region of the body the follicle is located (63). Three types of cells make up the hair shaft: the cuticle, the cortex and the medulla. The cuticle is found on the surface of the hair shaft. Species type (human or non-human) can be ascertained by the scale patterns of the cuticle cells which can be seen using a microscope. Underneath the cuticle is the cortex which makes up the largest portion of the hair shaft. The pigments that impart color to hair can also be found in the cortex. The medulla is found in the center of the shaft and in some cases could be absent from human hair. 
The average rate of growth, for hair is $1 \mathrm{~cm} /$ month but actual rates of growth have been noted to range from $0.6-3.36 \mathrm{~cm} /$ month (63). Hair grows in three cycles: anagen, catagen and telogen. The initial growth of hair begins in the anagen phase. It is at this stage that any drugs present in the body can be incorporated inside the hair shaft. The catagen phase is a period of active hair growth. Subsequently, hair transitions into the telogen, or resting, phase where the hair stops growing and can be easily pulled out of the follicle.

Sebaceous glands, which surround the hair follicle, and eccrine sweat glands, which cover the scalp, coat the hair and impart it with characteristic odors. A few studies have explored the types of compounds present on the surface of hair. In 1988, headspace extraction was used to identify the volatile compounds present on head hair and scalp of twenty individuals (64). Compounds, which include alkanes, alkenes, alcohols, aldehydes, ketones, acids and lactones, were detected. Using online supercritical fluid extraction followed by GC-MS it was discovered that acids, cholesterols, esters and squalene (65) were present in human hair extract.

\subsubsection{Fingernails}

Similar to hair, fingernails are also composed of keratin. The combination of a stable protein matrix and an enclosed structure makes fingernails a source of trace evidence (66). Fingernails provide an isolated area that allows for the accumulation of both biological and non-biological debris, such as, skin cells and fibers. Furthermore, normal and daily activities such as rubbing of the eyes, scalp and mouth, add to the quantity of cell transfer found underneath the fingernails (67). The transfer of DNA from 
the victim or the suspect, during a struggle, has given this matrix great evidentiary value (68-70). Various criminal investigations have exploited the use of fingernail debris as a DNA source even after a time lapse between incident and laboratory examination. Lederer et al. (71) discussed a report where fingernail debris was collected, in a hospital setting, after two days of an alleged sexual assault and later served as a form of associative evidence in the criminal proceeding.

Medical uses of fingernails have also been evaluated, such as the use of nails to indicate human health or for the identification of xenobiotics in the body. For instance, discoloration of the nail bed can be indicative of an ailment, such that a red nail bed can be the result of heart disease while a pale nail bed can be caused by anemia (72). Moreover, nails have been used to monitor human exposure to metals found in the environment, such as arsenic, which can be consumed in drinking water (73).

Fingernails, a skin structure, are an important tool for humans. They allow humans to grasp objects, provide a mechanism for defense, protect the fingertips from injury and allow for the cutting of items, such as, fruits. The nail plate originates from the nail matrix (root) and rests on a vascular nail bed which is seen through the nail plate. Fingernails are also comprised of the durable, fibrous protein, called keratin. A mixture of soft keratin (similar to that found in skin) and hard keratin (similar to that found in the hair follicle) have been identified within human nail plates (74). Though impeded as one ages or through malnutrition, the average growth rate of fingernails is $0.1 \mathrm{~mm}$ a day. Much of what is known of the composition of fingernails pertains to its elemental composition and very little, if any, research has been conducted to assess the VOCs being released by this specimen. 


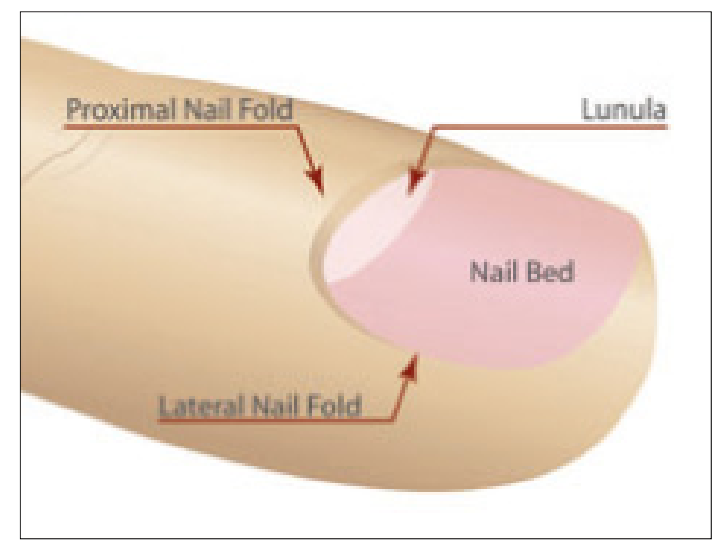

Figure 10-The components of a nail ( Picture from reference 75)

\subsubsection{Saliva}

Comparable to fingernails, saliva, which can be deposited during physical aggression activities, such as biting or sucking, can also provide DNA evidence. Salivary DNA evidence has gained usefulness for identity testing because of its ease of collection and availability, being that daily saliva production averages 1.5 liters in volume. Recently, saliva has been used for DNA analysis by extracting salivary epithelial cells left on a number of objects, such as cigarette butts or postage stamps, to link a suspect to a particular crime scene $(76,77)$.

Chemicals present in the headspace of saliva samples have previously been explored, both forensically and medicinally. Yonamine et al. (78) were able to detect the presence of illegal substances, such as methamphetamines, cocaine and tetrahydrocannabinol, by evaluating the headspace of saliva samples. Kostelc et al. (79) assessed the use of saliva for medicinal purposes, by determining if it could be used as tool for the diagnosis of a dental disease known as periodontitis. Volatile organic compounds from various biological specimens, such as saliva collected onto a buccal 
swab, were explored in a study by Kusano et al. (80) using headspace SPME-GC-MS for its use in the identification of individuals.

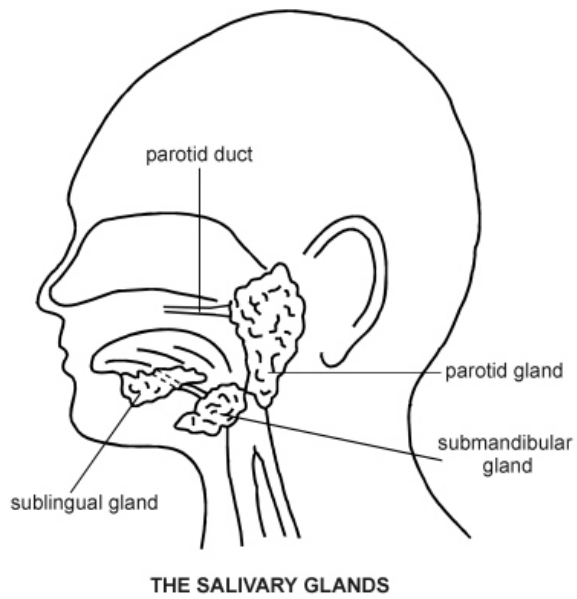

Figure 11-Location of major salivary glands in the mouth (Picture from reference 81)

Saliva is produced from the salivary glands, of which there are three major types (Figure 11): parotid, submandibular and sublingual glands. Salivary secretions are further classified as serous and mucous type. The secretions from serous glands are typically clear and of a watery nature, whereas mucous secretions are made of a more viscous solution of glycoproteins, which are typically used as a lining for internal and external organs (82). The glandular contributions to unstimulated saliva include, in descending order, the submandibular with $65-70 \%$, parotid with $20 \%$, sublingual with 7 $8 \%$ and the minor salivary glands with $<10 \%(83,84)$. During stimulated saliva production, the parotid gland increases its contribution to over $50 \%$ of the total secretion. The $\mathrm{pH}$ of saliva is nearly neutral (about 6 or 7 ); however, changes in the salivary flow 
can fluctuate the $\mathrm{pH}$, such that a decrease in flow, results in a lower $\mathrm{pH}$ (5.3) while an increased salivary flow raises the $\mathrm{pH}(7.8)(84)$.

The constituents secreted by salivary glands include: water, proteins, fatty acids, amino acids, lipids, glucose, hormones, electrolytes, etc. (83). Additional components have also been identified in whole saliva, such as, serum and blood derivatives, oral bacterial and viral products, bronchial and nasal secretions, epithelial lining cells and exogenous materials.

\subsection{Significance of Study}

Prior to the admission of scientific evidence into an American court of law, it must meet the requirements set forth by the Frye vs. United States or Daubert v. Merrell Dow Pharmeceuticals, Inc. case laws or the Federal Rules of Evidence (Rule 702). The jurisdiction in which the case is being handled, will dictate whether the Frye or the Daubert ruling will be utilized. The Frye ruling (85) allows for the admittance of scientific evidence that was generally accepted in the field. The Daubert ruling (86) made judges the "gatekeepers" of scientific evidence or testimony in which they must ensure that the evidence and/or testimony is relevant and reliable. To assess the reliability of the scientific evidence or testimony the following factors must be

considered: has it been subjected to peer-reviews, are there standards that control how the involved techniques are applied, are there known or potential error rates and has it gained a widespread acceptance within the relevant scientific community (87). This demand for reliable science and widespread acceptance in the scientific community has required that forensic scientists continue to conduct proper research validating all 
concepts that could potentially make its way into a court of law. Human scent, though widely explored by researchers, is still controversial and is often being challenged in court (50). It is important that strides continually be made to validate the distinctiveness of human scent and show that canines and the tools used to collect human scent are reliable.

\subsection{Research Objectives}

The main objective of this research was to use analytical instruments and trained canines to assess the distinctiveness of different biological specimens which included hand odor, hair, fingernails and saliva. The different tasks that were addressed are listed below.

a. Optimization of the extraction of VOCs from hair, fingernail and saliva samples using HS-SPME

b. Evaluation of the profiles of extracted VOCs from different specimens collected from 60 individuals

a. Conduct statistical evaluations to determine the distinctiveness of VOCs from individuals for each specimen type

c. Evaluation of the profiles of extracted VOCs from different specimens collected over time from 6 individuals

a. Conduct statistical evaluation to determine the persistence of VOCs from individuals for each specimen type

d. Evaluation of the profiles of extracted VOCs from different types of the same biological specimen

a. Head hair vs. arm hair 
b. Fingernails vs. toe nails

e. Conduct field trials with human scent discriminating canines to assess the usefulness of different biological specimens as scent sources
a. Head hair
b. Fingernails
c. Saliva

f. Conduct field trials with human scent discriminating canines to assess the performance of two scent collection devices
a. Human scent collection system (HSCS)
b. Scent Transfer Unit 100 (STU-100) 


\section{INSTRUMENTAL EVALUATIONS OF BIOLOGICAL SPECIMENS}

\subsection{Materials}

\subsubsection{Biological specimen collection and storage}

\section{Hand Odor}

Prior to collecting each hand odor sample, subjects washed their hands and forearms with Natural, Clear Olive Oil Soap (Life of the Party, North Brunswick, NJ). The gauze pads used for hand odor collection were DUKAL brand, 100\% cotton, sterile, $2 " \times 2 ", 8$ ply, gauze sponges (DUKAL Corporation, Syosset, NY). Hand odor samples were stored in 10-mL clear glass, screw top vials with PTFE/Silicone septa (SUPELCO, Bellefonte, PA). The solvent used for the pretreatment of gauze pads was methanol (HPLC grade, Fisher Scientific, Pittsburgh, PA).

\section{Head Hair}

All participants were given fragrance free shampoo from Jason Natural Products (Culver City, CA). Head hair samples were stored in 2-mL clear glass, screw top vials with PTFE/Silicone septa (SUPELCO, Bellefonte, PA).

\section{Fingernail Clippings}

Subjects washed their hands with Natural, Clear Olive Oil Soap (Life of the Party, North Brunswick, NJ). Plastic manicure brushes were used to clean above and underneath the fingernails (YCC Products Inc., Placentia, CA) and chrome plated steel fingernail clippers were used for the removal of the fingernail clippings (Tweezerman International, 
Port Washington, NY). Fingernail clippings were stored in 2-mL clear glass, screw top vials with PTFE/Silicone septa (SUPELCO, Bellefonte, PA).

\section{Saliva}

The cotton swabs used for saliva collection were 6" in length, wood stem, sterile, cotton tipped applicators (Solon Manufacturing Company, Skowhegan, ME) which were cut to fit inside 10-mL clear glass, screw top vials with PTFE/Silicone septa (SUPELCO, Bellefonte, PA). The solvent used for the pretreatment of cotton swabs was ethanol (AAPER Alcohol and Chemical Co., Shelbyville, KY).

\subsubsection{Chemicals}

The solvents used included: methanol (HPLC grade, Fisher Scientific, Pittsburgh, PA), ethanol (AAPER Alcohol and Chemical Co., Shelbyville, KY), and dichloromethane (HPLC grade, Fisher Scientific, Pittsburgh, PA). Chemical standards used for compound identifications were obtained from Sigma Aldrich (St Louis, MO) or Fisher Scientific (Pittsburgh, PA) and included: dodecanoic acid (Lot\# 13825PB), hexanoic acid (Lot\# 08003HJ), 3,7-dimethyl-1,6-octadien-3-ol (Lot\# 02014DD), benzaldhyde (Lot\# 982126), 1-methyl-naphthalene (Lot\# 04426CJ), hexadecanoic acid, methyl ester (Lot\# 100M1423V), octanoic acid, methyl ester (Lot\# 10514PD), pentacosane (Lot\# 0001386914), squalene (Lot\# 03411MV), 6-methyl-5-hepten-2-one (Lot\# 06723DU), 6,10-dimethyl-5,9-undecadien-2-one (geranylacetone; Lot\# 03906JC), phenol (Lot\# 128K1106), 2-furanmethanol (Lot\#A0290966), dodecanal (Lot\#A0274446), benzyl alcohol (Lot\# 03453EC), nonanal (Lot\# 00407JJ), acetic acid, phenyl methyl ester 
(benzyl acetate; Lot\# 1425791), tetradecane (Lot\# 13401LZ), 3,7-dimethyl-6-octen-1-ol (citronellol; Lot\# 04827PA), 2-ethyl-hexanoic acid (Lot\# MKBF2373V), octanoic acid (Lot\# 02422KO), octadecane (Lot\# A0275841), decanal (Lot\# 119K1535), 2-pentylfuran (Lot\# 13197PJ), hexanal (Lot\#MKBD1396), furfural (Lot\# A0200021001), 2 ethyl-1-hexanol (Lot\#B0072339), 2-octenal (Lot\# 05529EO), acetophenone (Lot\#07404KC), heptanoic acid (Lot\# RA16842), undecane (Lot\# BCBB5844V), 2nonenal (Lot\# MKAA1393), nonanol (Lot\#B02727ED), 2-decanone (Lot\# WA15705), dodecane (00654LC), E,E-2, 4-nondienal (Lot\#06701KO), nonanoic acid, methyl ester (WA12895), tridecane (Lot\# 1427104), undecanal (Lot\# 02915DD), caryophyllene (Lot\# 076K2618), pentadecane (Lot\# 1430810), 1-pentadecene (Lot\# 01310JJ), hexadecane (Lot\# A0290420), heptadecane (Lot\# A0289509), pentadecanoic acid (Lot\# 00713LU), n-hexadecanoic acid (palmitic acid; Lot\# 100M1202V), eicosane (Lot\#02204EH), heneicosane (Lot\# WA12967), and docosane (Lot\# WA12920).

\subsection{Methods}

\subsubsection{Collection of multiple biological specimens}

The procedures for the collection of biological specimens from human subjects were approved by Florida International University Institutional Review Board (IRB) (Approval \# 081805-00). All volunteers utilized in this study signed a written consent form and were compensated for their participation. Sixty volunteers were recruited for this study (30 males, 30 females) ranging in age from 18-60 years old. Four different biological specimens (hand odor, head hair, fingernail clippings and saliva) were collected in a single day from each volunteer under laboratory conditions. Each specimen was 
collected in triplicate and the collection sequence was as follows: Hand odor \#1, hair \#13, hand odor \#2, fingernail clippings \#1-3, hand odor \#3 and saliva \#1-3. The collection procedures corresponding to each specimen are detailed in the subsequent sections.

\subsubsection{Hand odor collection procedures}

The hand odor collection protocol utilized was originally published by Curran et al. (50) and is described here. Each subject washed their hands and forearms with fragrance free, olive oil based soap for 30 seconds, rinsed under cool water for 2 minutes, air dried for 2 minutes and rubbed their hands over the forearms for 5 minutes (in an effort to reconstitute the depleted secretions). A pretreated 2" x 2" cotton gauze pad was then held between the subject's palms for 10 minutes. As a revision to the original collection procedure, in this study all hand odor samples were collected while the subject remained indoors. Once completed, the scented cotton gauze pad was placed into a $10-\mathrm{mL}$ glass vial and allowed 24 hours to equilibrate, at room temperature. Immediately following, volatile extraction and analysis was conducted using headspace solid phase microextraction gas chromatography-mass spectrometry.

\subsection{Pretreatment of cotton gauze}

The cotton gauze pad used for the collection of hand odor was pretreated to remove inherent compounds present in the gauze. The pretreatment step involved spiking the cotton gauze pad with $1 \mathrm{~mL}$ of methanol and subsequently baking it at $105^{\circ} \mathrm{C}$ for 1 hour. The removal of inherent compounds from the pretreated cotton gauze was determined by headspace-solid phase microextraction-gas chromatography-mass spectrometry. 


\subsubsection{Head hair collection procedures}

Hair samples were collected from volunteers. Prior to hair collection, subjects were given a fragrance free shampoo to use on the morning of collection. Subjects were asked to refrain from using personal hair care products (e.g., hair gel, hairspray) 24 hours prior to sample collection. Hair was collected in the laboratory utilizing one of the following techniques: brushing loose strands of hair using a comb, plucking hair using stainless steel tweezers or cutting hair close to the scalp using stainless steel scissors. Approximately $30 \mathrm{mg}$ of head hair was collected from each subject and divided into three portions and weighed. Each portion of hair was transferred into a 2-mL clear glass vial, with a lined screw cap and PTFE/Silicone septum. Prior to volatile extraction, hair samples were given 24 hours to equilibrate in the vial, at a temperature of $28^{\circ} \mathrm{C}$. Immediately following, volatile extraction and analysis was conducted using headspacesolid phase microextraction gas chromatography-mass spectrometry.

\subsubsection{Fingernail collection procedures}

Fingernail samples were collected from volunteers. Prior to fingernail collection, subjects were instructed to wash their hands with fragrance free, olive oil soap for 30 seconds; scrub for 30 seconds using a fingernail brush; rinse under running water for 2 minutes and air dry for 5 minutes (total of 8 minutes). Fingernail samples were obtained by having the subjects clip their fingernails using stainless steel fingernail clippers. Fingernail samples were collected from three different fingers and each fingernail was placed into a 2-mL glass vial, with a lined screw cap and PTFE/Silicone septum. Prior to volatile extraction, fingernail samples were given 24 hours to equilibrate in the vial, at a 
temperature of $28^{\circ}$ Celsius. Immediately following, volatile extraction and analysis was conducted via headspace solid phase microextraction gas chromatography-mass spectrometry.

\subsubsection{Saliva collection procedures}

Saliva samples were collected from volunteers. Subjects were asked to refrain from eating, drinking (water was allowed), chewing gum and/or smoking three hours prior to saliva collection. At the time of collection, subjects rinsed with tap water for one minute, to remove any food debris from their oral cavities. Subjects sampled themselves by swabbing the insides of each cheek for 30 seconds with a pretreated cotton swab, while wearing nitrile gloves. Cotton swabs were transferred to $10-\mathrm{mL}$ clear glass vials, with screw top and septum. Prior to volatile extraction, saliva samples were given 24 hours to equilibrate in the vial, at room temperature. Immediately following, volatile extraction and analysis was conducted via headspace-solid phase microextraction gas chromatography-mass spectrometry.

\subsection{Pretreatment of cotton swabs}

Cotton swabs used for the collection of saliva were pretreated to ensure there were no interfering compounds present in the collection material. The pretreatment step involved spiking each swab with $250 \mu \mathrm{L}$ of ethanol and subsequently baking it at $105^{\circ} \mathrm{C}$ for one hour. The removal of inherent compounds from the pretreated cotton swab was determined by headspace-solid phase microextraction gas chromatography-mass spectrometry. 
3.2.2. Extraction optimization of VOCs from biological specimens using SPME

3.2.2.1. Extraction optimization of VOCs from head hair samples using SPME

The extraction of VOCs from head hair was optimized by evaluating SPME extraction time and the impact of sample mass on the profile of VOCs that were obtained.

\section{Optimization of HS-SPME extraction time for head hair samples}

A series of experiments were conducted to determine the optimal extraction time necessary for the extraction of VOCs from head hair samples. Actual hair samples, collected from a female subject, were used in these experiments. Prior to hair collection, the subject was instructed to wash her hair with fragrance free shampoo. Hair was collected by combing loose strands onto a piece of paper while wearing nitrile gloves. A portion of hair $(9.9 \mathrm{mg} \pm 1.2)$ was transferred to a $2-\mathrm{mL}$ glass vial and was given 24 hours to equilibrate prior to SPME extraction. The experimental extraction times tested were: 7 hours, 15 hours, 21 hours and 24 hours. For each experimental extraction time, triplicate samples were tested. Volatile organic compounds were separated and identified using gas chromatography-mass spectrometry. All experiments were conducted at room temperature. The optimal extraction time was selected based upon which time provided the highest abundance and greatest number of extracted volatile organic compounds. 


\section{Impact of sample mass on the VOCs extracted from head hair}

Additional tests were performed to determine the minimum amount of hair to be collected from an individual, per sample, that will provide the greatest abundance and number of extracted volatile organic compounds. Actual hair samples collected from a female subject were used in these experiments. Prior to hair collection, the subject was instructed to wash her hair with fragrance free shampoo. Hair was collected by combing loose strands onto a piece of paper while wearing nitrile gloves. Varying portions of hair were transferred to $2-\mathrm{mL}$ glass vials. The experimental masses included: $2 \mathrm{mg}, 3 \mathrm{mg}, 5$ $\mathrm{mg}, 6 \mathrm{mg}$ and $8 \mathrm{mg}$ (Table 4).

Table 4-Information pertaining to the samples used during the evaluation of sample mass for hair analysis

\begin{tabular}{|ccccc|}
\hline $\begin{array}{c}\text { Experimental } \\
\text { Mass (mg) }\end{array}$ & $\begin{array}{c}\text { Sample } \\
\text { Number }\end{array}$ & Mass (mg) & $\begin{array}{c}\text { Number of } \\
\text { Strands }\end{array}$ & $\begin{array}{c}\text { Average } \\
\text { Length of } \\
\text { Hair (cm) }\end{array}$ \\
\hline 2 & 1 & 1.6 & 2 & $28.3( \pm 5.1)$ \\
& 2 & 1.7 & 2 & \\
\hline 3 & 3 & 2.3 & 2 & $28.3( \pm 5.1)$ \\
& 1 & 2.9 & 3 & \\
\hline 5 & 2 & 3.5 & 3 & \\
& 3 & 2.9 & 3 & \\
\hline 6 & 1 & 6.2 & 5 & $28.3( \pm 5.1)$ \\
& 2 & 4.8 & 5 & \\
\hline 8 & 3 & 4.7 & 5 & \\
\hline & 1 & 6.7 & 6 & $23.9( \pm 4.9)$ \\
& 2 & 6.3 & 7 & \\
\hline
\end{tabular}


All samples were given 24 hours to equilibrate followed by a 21 hour HS-SPME extraction. VOCs were separated and identified using gas chromatography-mass spectrometry. Triplicate samples were used to test each experimental mass and all testing was conducted at room temperature.

\subsubsection{Extraction optimization of VOCs from fingernail samples using SPME}

The extraction of VOCs from fingernail samples was optimized by evaluating SPME extraction time and fingernail sample type (individual or collective).

\section{Optimization of HS-SPME extraction time for fingernail samples}

Tests were performed to determine the extraction time required for the optimal extraction of VOCs from fingernail samples, using HS-SPME. Actual fingernail samples used in these experiments were collected from a female subject. Prior to fingernail collection, the subject washed her hands and fingernails according to the previously mentioned procedures (Section 3.2.1.3). Fingernails were collected by having the subject clip her nails with stainless steel fingernail clippers. The fingernails collected were the right middle nail, left and right ring nail and pinkie nails and their respective masses are listed in Table 5. Each fingernail was placed into a 2-mL glass vial and given 24 hours to equilibrate. Each extraction time was tested using a single fingernail and the experimental times were 7 hours, 15 hours, 21 hours and 24 hours. Volatile organic compounds were extracted, separated and identified using headspace solid phase microextraction gas chromatography-mass spectrometry. All experiments were conducted at room temperature. The optimal extraction time was selected according to 
the samples that provided the highest abundance and greatest number of extracted volatile organic compounds.

Table 5-Fingernail sample type corresponding to extraction time tested

\begin{tabular}{|c|c|c|c|}
\hline Extraction Time (hrs) & Hand & Nail & $\begin{array}{c}\text { Mass } \\
\text { (mg) }\end{array}$ \\
\hline 7 & Right & Middle & 11.3 \\
\hline 15 & Left & Ring & 8.1 \\
\hline 21 & Right & Ring & 9.0 \\
\hline 24 & -- & Pinkie & 11.4 \\
\hline
\end{tabular}

Impact of fingernail sample type (individual or collective) on the VOCs extracted

Tests were performed to evaluate the profiles of the VOCs obtained from individual fingernails, as well as all fingernails (collectively), in an effort to determine what constitutes a representative fingernail sample. Actual fingernail samples used in these experiments were collected from a female subject. Prior to fingernail collection, the subject washed her hands and fingernails according to the previously mentioned procedures (Section 3.2.1.3.). Fingernails were collected by having the subject clip her nails with stainless steel fingernail clippers. First, all five fingernails from the left hand of a female subject were placed into a single $2-\mathrm{mL}$ glass vial then, thirteen days later, each fingernail from the same hand were placed into their own 2-mL glass vial (Table 6). All of the fingernail samples were given 24 hours to equilibrate and then a 21 hour HSSPME extraction was performed. The extracted VOCs were separated and identified using gas chromatography-mass spectrometry. The optimal fingernail sample was selected according to the samples that provided the highest abundance and greatest number of extracted volatile organic compounds. 
Table 6-Length and mass of fingernails used for the evaluation of optimal sample type

\begin{tabular}{|ccccc|}
\hline Day & Hand & $\begin{array}{c}\text { Sample } \\
\text { Type }\end{array}$ & Length $(\mathbf{m m})$ & Mass (mg) \\
\hline 0 & Left & All Nails & & 57.7 \\
\hline 13 & Left & Thumb & 1.7 & 13.5 \\
& & Index & 1.7 & 8.1 \\
& & Middle & 1.5 & 9.8 \\
& & Ring & 1.0 & 7.2 \\
& & Pinky & 1.2 & 4.1 \\
\hline
\end{tabular}

\subsubsection{Extraction optimization of VOCs from saliva samples using SPME}

A series of experiments were conducted to determine the optimal set time and extraction time when using SPME for the extraction of VOCs from collected saliva samples. Actual saliva samples were collected from a female subject. The female subject sampled herself, while wearing nitrile gloves, by swabbing the inside of each cheek for 30 seconds ( 1 minute total). The swab was cut at the wooden stem using stainless steel scissors and then placed into a 10-mL glass vial. Various set times and extraction times were tested according to the following combinations, seen in Table 7. For each experimental combination of set time and extraction time, triplicate samples were tested. Volatile organic compounds were extracted, separated and identified using headspace solid phase microextraction gas chromatography-mass spectrometry. All experiments were conducted at room temperature. The optimal extraction time was selected according to the samples that provided the highest abundance and greatest number of extracted volatile organic compounds. 
Table 7-The combination of equilibration and extraction times tested for the headspace extraction of VOCs from saliva samples

\begin{tabular}{|c|c|}
\hline $\begin{array}{c}\text { Equilibration Time } \\
\text { (hr) }\end{array}$ & $\begin{array}{c}\text { Extraction Time } \\
\text { (hr) }\end{array}$ \\
\hline 1 & 24 \\
\hline 24 & 7 \\
\hline 24 & 15 \\
\hline 24 & 21 \\
\hline 24 & 24 \\
\hline
\end{tabular}

\subsubsection{Collection of multiple biological specimens over time}

Biological specimens were collected once a month for six months from six volunteers (3 males, 3 females). The specimen collection procedures for hand odor, head hair, fingernail clippings and saliva were the same as those described in the preceding sections. Volatile extraction and analysis was conducted via HS-SPME and GC-MS, respectively.

\subsubsection{Comparison of different types of samples of the same biological specimen type}

\subsubsection{Comparison of head hair to arm hair}

The VOCs released from head hair and arm hair, collected from a male subject, was compared so that similarities/differences can be assessed between the two types of hair samples. Prior to hair collection, the subject was instructed to wash his head hair and arm hair with fragrance free shampoo. Hair was collected by cutting his hair close to the skin using stainless steel scissors while wearing nitrile gloves. Collected head hair and arm hair samples were divided into three portions and each portion was transferred to a $2-\mathrm{mL}$ glass vial and weighed (34.2 $\mathrm{mg} \pm 8.5)$. Hair samples were given 24 hours to equilibrate prior to a 21 hour SPME extraction, at a temperature of $28^{\circ}$ Celsius. Volatile organic compounds were separated and identified using gas chromatography-mass spectrometry. 


\subsubsection{Comparison of fingernails to toe nails}

The VOCs released from fingernails and toe nails, collected from a female subject, were compared so that similarities/differences can be assessed between the two types of nail samples. Prior to fingernail collection, the subject washed her fingernails and toe nails according to the following procedures: lather with fragrance free, olive oil soap for 30 seconds; scrub for 30 seconds using a fingernail brush; rinse under running water for 2 minutes and air dry for 5 minutes. Nails were collected by having the subject clip her nails with stainless steel fingernail clippers. Each fingernail was placed into a 2-mL glass vial and given 24 hours to equilibrate followed by a 21 hours HS-SPME extraction, at a temperature of $28^{\circ}$ Celsius. Volatile organic compounds were separated and identified using gas chromatography-mass spectrometry.

\subsubsection{HS-SPME-GC-MS method}

Headspace solid phase microextraction (HS-SPME) was performed using $50 \mu \mathrm{m} / 30 \mu \mathrm{m}$ Divinylbenzene/Carboxen on Polydimethylsiloxane (DVB/CAR on PDMS) fibers (SUPELCO, Bellefonte, PA). Volatile extractions were conducted for 21 hours at room temperature for hand odor and saliva samples and for 21 hours at $28^{\circ} \mathrm{C}$ for head hair and fingernail clipping samples. The instrumentation used for volatile separation and identification was an Agilent 6890 gas chromatorgraph/5973 mass spectrometer detector. Heat desorption was used to extract the volatiles from the SPME fiber, by placing the fiber into the GC injection port that was held at $250^{\circ}$ Celsius. An HP-5MS column, 30 meters $\mathrm{x} 0.250 \mathrm{~mm}$ (ID) with a $0.25 \mu \mathrm{m}$ phase film thickness, was used for the separation of extracted volatiles. The temperature program was as follows: initial temperature of 
$40^{\circ} \mathrm{C}$ was held for 5 minutes, followed by a ramp of $10^{\circ} \mathrm{C} / \mathrm{min}$ until it reach $290^{\circ} \mathrm{C}$, which was held for 2 minutes. Helium carrier gas was held at a flow rate of $1.0 \mathrm{~mL} / \mathrm{min}$. The operational parameters of the mass spectrometer included maintaining the transfer line temperature at $280^{\circ} \mathrm{C}$ and the source temperature at $230^{\circ} \mathrm{C}$ with a scan range between 40 500 mass-to-charge ratio.

\subsubsection{Statistical Analysis}

Analysis of Variance (ANOVA)

One-way ANOVA was used to evaluate the abundance and number of extracted VOCs for the different experimental factors tested during HS-SPME extraction optimization (alpha value 0.05). Analysis of variance is a parametric technique used to assess whether the difference in sample means is attributed to more than random error. The withinsample variance, or mean squares, and the between-sample variance were calculated using

Equation 4 and Equation 5, respectively, where $h$ is the number of samples and $n$ is the number of measurements acquired (88).

\section{Equation 4-Within sample variations (mean square)

$$
\sigma_{o}^{2}=\sum_{i} \sum_{j}\left(x_{i j}-\overline{x_{j}}\right) / h(n-1)
$$

\section{Equation 5-Between sample variations}

$$
\sigma_{o}^{2}=n \sum_{i}\left(\overline{x_{i}}-\bar{x}\right)^{2} /(h-1)
$$


If the null hypothesis was to be rejected, deeming the sample means were dissimilar, then Tukey's method was used to determine which experimental factors differed. One-way ANOVA and Tukey's method was performed using Minitab software (Minitab Inc., Minitab 16, State College, PA).

\section{Spearman Rank Correlation}

Spearman Rank correlation is a multivariate, non-parametric statistical technique that was used to determine the distinguishability of biological specimens collected from 60 individuals, for each specimen type. The triplicate profiles of the VOCs obtained for each specimen type, per subject, were averaged, normalized and ranked, in ascending order. The correlation between two subject's samples was expressed by a correlation coefficient, $r_{s}$, ranging in value from -1 to 1 , demonstrating a negative or positive correlation respectively. The correlation coefficient was calculated using Equation 6, where $d$ is the differences between the ranked compounds and $n$ represents the number of compounds being ranked (88).

\section{Equation 6-Spearman rank product-moment correlation coefficient}

$$
r_{s}=1-\frac{6 \sum_{i} d_{i}^{2}}{n\left(n^{2}-1\right)}
$$

Once Spearman Rank correlations were determined for all specimens, collected from 60 individuals, assessments were made on the occurrence of matching errors that can be assumed from the correlations coefficients of samples. An example of this type of error 
is claiming that samples from two different subjects are similar due to their high correlation. The occurrences of matching errors were evaluated for each specimen type at three correlation coefficient thresholds: $0.9,0.8$ and 0.7 . Spearman rank correlations were performed using PRIMER 6 software (Clarke et al. PRIMER-E Ltd, Plymouth, United Kingdom).

\section{Principal Component Analysis}

Principal component analysis (PCA) was used to evaluate intra-subject samples (single sample set and six month sample sets), inter-subject samples (six month sample sets) and different types of the same specimen (head hair $v s$. arm hair and fingernails $v s$. toe nails). Principal component analysis is a multivariate analysis technique that reduces data containing correlated variables. The original variables of a data set, which in this case are VOCs and their abundances, are transformed into linear combinations, also known as principal components (PCs), of new uncorrelated variables (88). The first principal component accounts for the greatest amount of variation in the data followed by the second principal component, which accounts for the second greatest amount of variation, and so forth. Mathematically, the principal components are eigenvectors of the covariance matrix that correspond to eigenvalues, which gives the amount of variance in the data set (88). The first two or three principal components of the original data set can be plotted so that differences in the data set can be seen. Principal component analysis makes no assumption about the distribution of the data set, which makes it a nonparametric technique. Principal component analysis was performed and plots of the first three PCs were created using JMP software (SAS Institute Inc., JMP 9.0.2, Cary, NC). 


\section{Cluster Analysis}

Cluster analysis was used to evaluate intra-subject samples (single sample set and six month sample sets), inter-subject samples (six month sample sets) and different types of the same specimen (head hair $v s$. arm hair and fingernails $v s$. toe nails). Cluster analysis is a multivariate, non-parametric statistical method that places objects, within a data set, into classes. Similar objects, determined by the proximity of the two objects, will be grouped together in the same class. The distance between objects is given by the Euclidean distance $(d)$, which is defined as the square root of the sum of the squared differences, and can be seen Equation 7 (88).

\section{Equation 7-Euclidean distance for two samples}

$$
d=\sqrt{\left(x_{1}-y_{1}\right)^{2}+\left(x_{2}-y_{2}\right)^{2}+\ldots+\left(x_{n}-y_{n}\right)^{2}}
$$

Once the distance between objects is determined, clusters can be created using a variety of methods; however, the single linkage method is commonly used. Single linkage uses the minimum distance between two objects to form a cluster. Subsequently, the nearest neighbors (or minimum distance) are then clustered to that cluster which will sort the data into classes. The grouping of classes within the data set can be seen in a dendogram. The vertical axis of the dendogram displays the distance between clusters or similarity. Similarity $\left(\mathrm{s}_{\mathrm{ij}}\right.$ ), which can be seen in Equation 8 , is derived using the distance between two objects $(i, j)$ and the maximum distance $\left(\mathrm{d}_{\max }\right)$ between any two objects. 


\section{Equation 8-Similarity between two samples}

$$
s_{i j}=100\left(\frac{1-d_{i j}}{d_{\max }}\right)
$$

Cluster analysis was performed and dendograms were created using Minitab software (Minitab Inc., Minitab 16, State College, PA).

\subsection{Results}

\subsubsection{Extraction optimization of VOCs from biological samples using SPME}

3.3.1.1. Extraction optimization of VOCs from head hair samples using SPME Optimization of HS-SPME extraction time for head hair samples

Various times were evaluated for the extraction of VOCs from hair samples. The experimental extraction times were 7 hours, 15 hours, 21 hours and 24 hours. The total abundance and the number of VOCs extracted were assessed to determine which extraction time yielded the best response. The total abundance of extracted volatiles was the largest following a 24 hour extraction time which was succeeded by the 21 hour extraction time, as seen in Figure 12. The number of extracted VOCs was also assessed and can be seen in Figure 13. It appears, again, that the 24 hour extraction time extracted the largest number of compounds followed by the 21 hour extraction time. Analysis of Variance (ANOVA), along with Tukey's test, was used to validate these observations as to whether or not the total abundance of extracted volatiles was similar or different. The results of ANOVA revealed that the total abundance of extracted VOCs was significantly 
different for each extraction time; therefore it was determined that the 24 hour extraction time allows for the greatest extraction of volatile organic compounds.

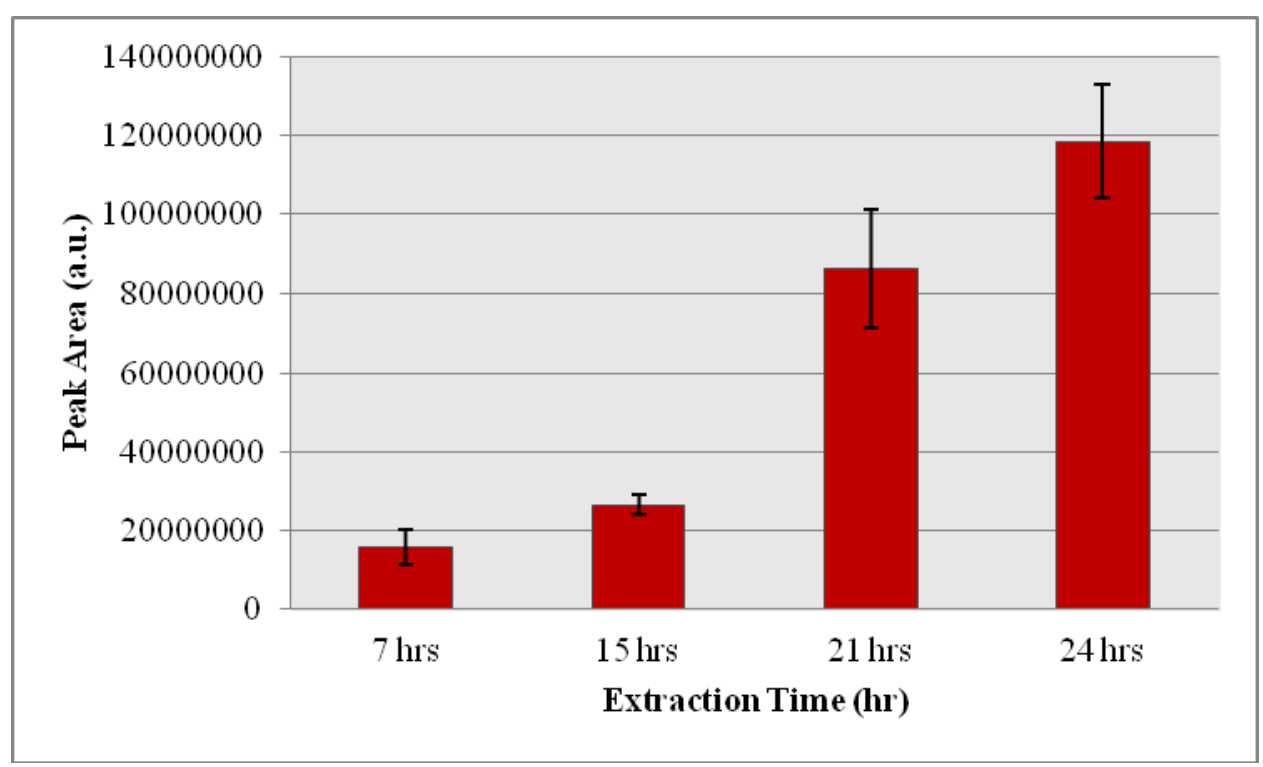

Figure 12-Abundance of VOCs extracted from head hair samples at different extraction times

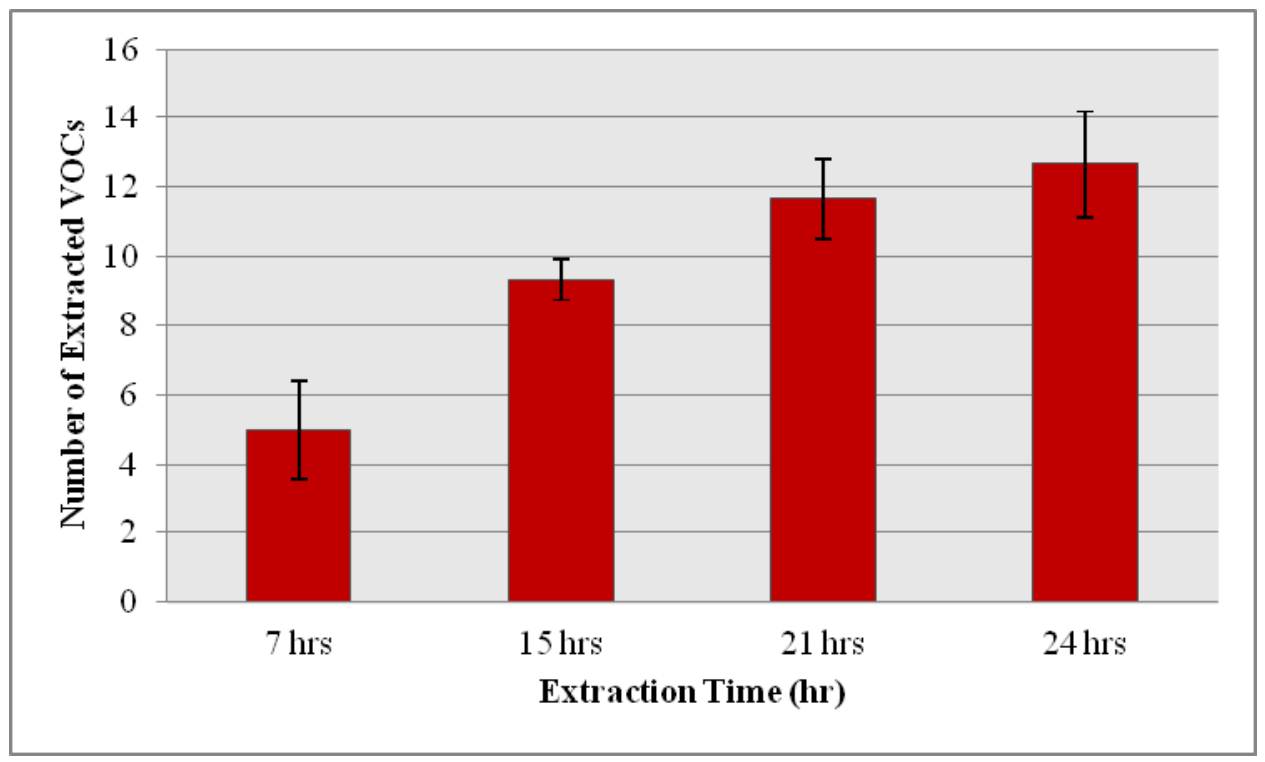

Figure 13- Number of extracted VOCs from head hair at different extraction times 


\section{Impact of sample mass on the VOCs extracted from head hair}

Additionally, the mass of hair to be collected for each of the triplicate hair samples was evaluated. The experimental sample masses considered were $8 \mathrm{mg}, 6 \mathrm{mg}, 5$ $\mathrm{mg}, 3 \mathrm{mg}$ and $2 \mathrm{mg}$ of hair. For a point of reference, the mass of one strand $(\sim 30 \mathrm{~cm})$ of hair has the mass of nearly one milligram. The results of this study are depicted in Figure 14 and Figure 15.

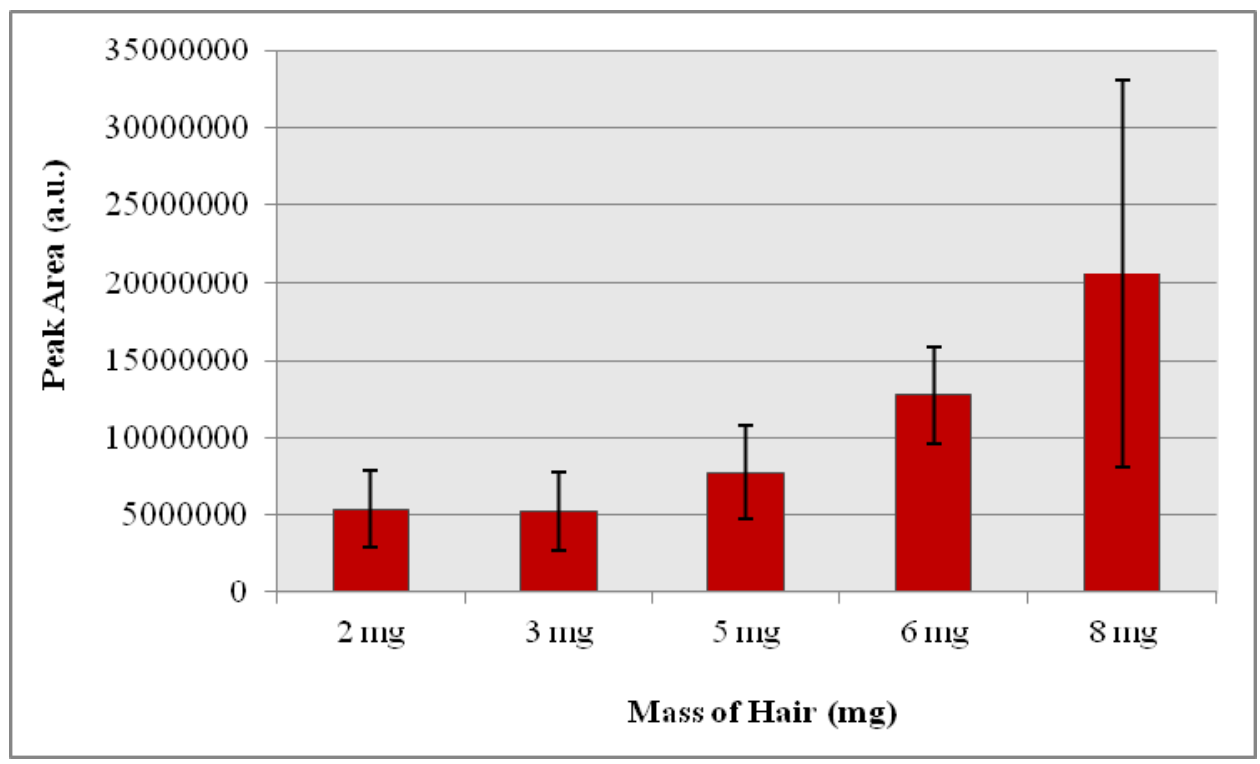

Figure 14-Abundance of VOCs extracted from head hair for various sample masses 


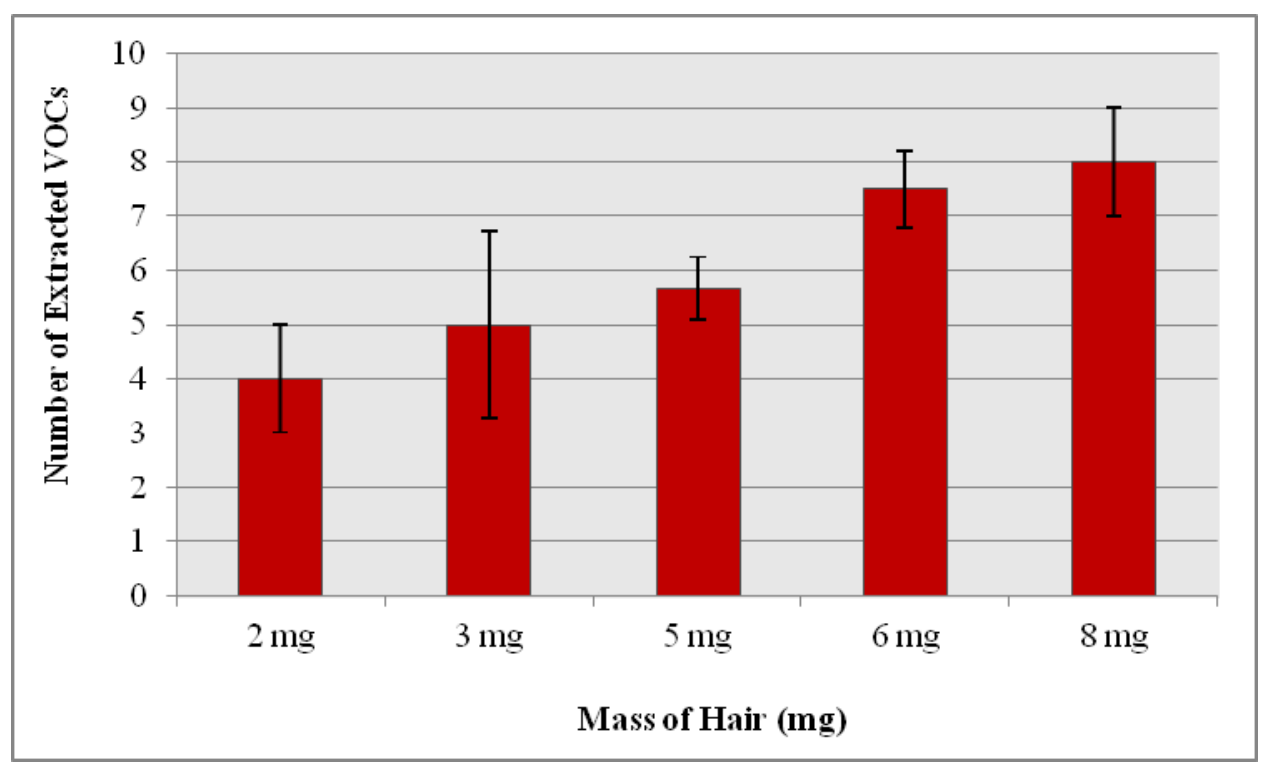

Figure 15-Number of extracted VOCs from head hair for various sample masses

The data revealed that samples with a larger mass provided a higher abundance and a greater number of volatile organic compounds. Statistical evaluation using ANOVA in addition to Tukey's test was performed. Due to the high variation in the $8 \mathrm{mg}$ samples, the average extracted abundance from all of the sample masses was considered to be similar, following significance testing. However, when referring to the number of extracted VOCs the $6 \mathrm{mg}$ and $8 \mathrm{mg}$ samples provided the greatest number of extracted volatile organic compounds. Therefore, the results of this experiment imply that it would be most advantageous to collect a minimum of $6 \mathrm{mg}$ of hair for each of the three hair samples, per person. 


\subsubsection{Extraction optimization of VOCs from fingernail samples using SPME}

\section{Optimization of HS-SPME extraction time for fingernail samples}

SPME extraction times were also evaluated for fingernail samples. The experimental extraction times were 7 hours, 15 hours, 21 hours and 24 hours. Again, the total abundance and number of VOCs extracted were used to determine the optimal extraction time, which can be seen in Figure 16 and Figure 17. The total abundance of extracted volatiles is the largest following a 24 hour extraction. The greatest number of extracted VOCs occurred following a 24 hour extraction, with 14 compounds extracted, which was succeeded by the 21 hour extraction which extracted 9 compounds. Therefore, it was determined that the optimal extraction time of VOCs from fingernail samples would be 24 hours.

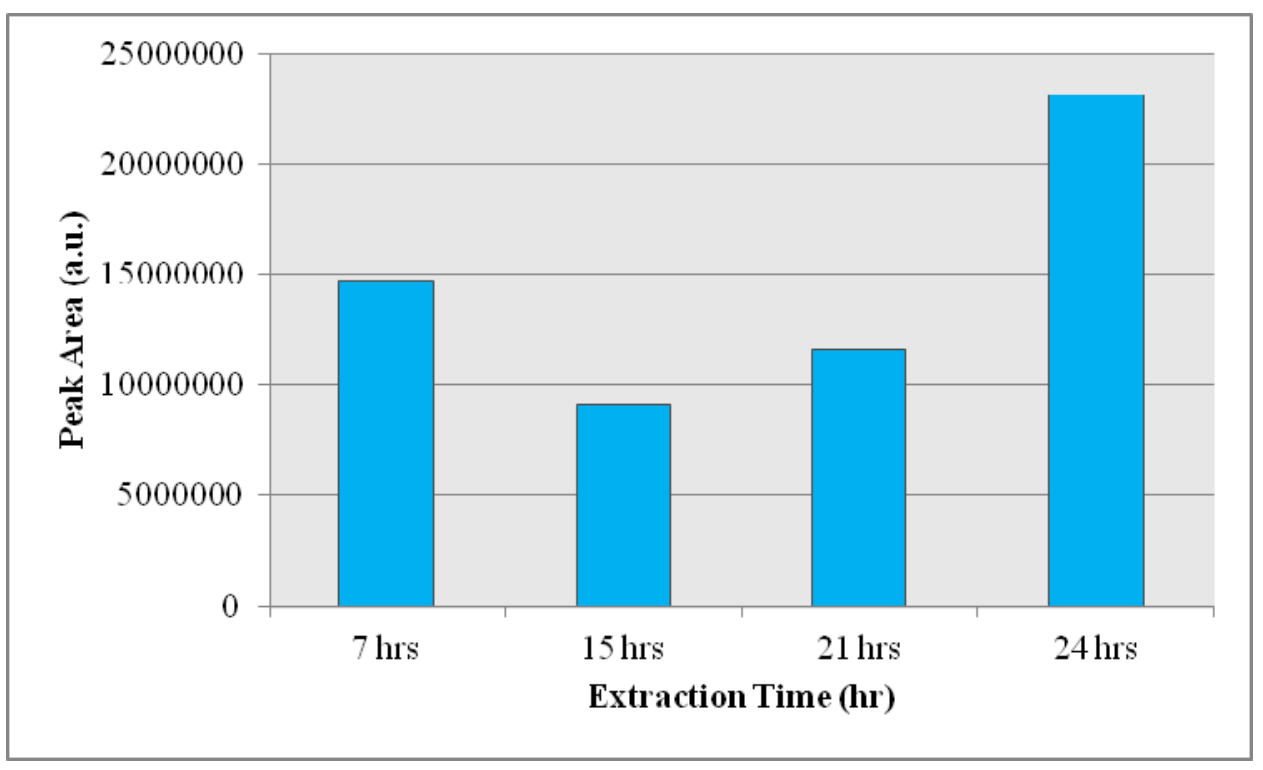

Figure 16- Abundance of VOCs extracted from fingernails at different extraction times 


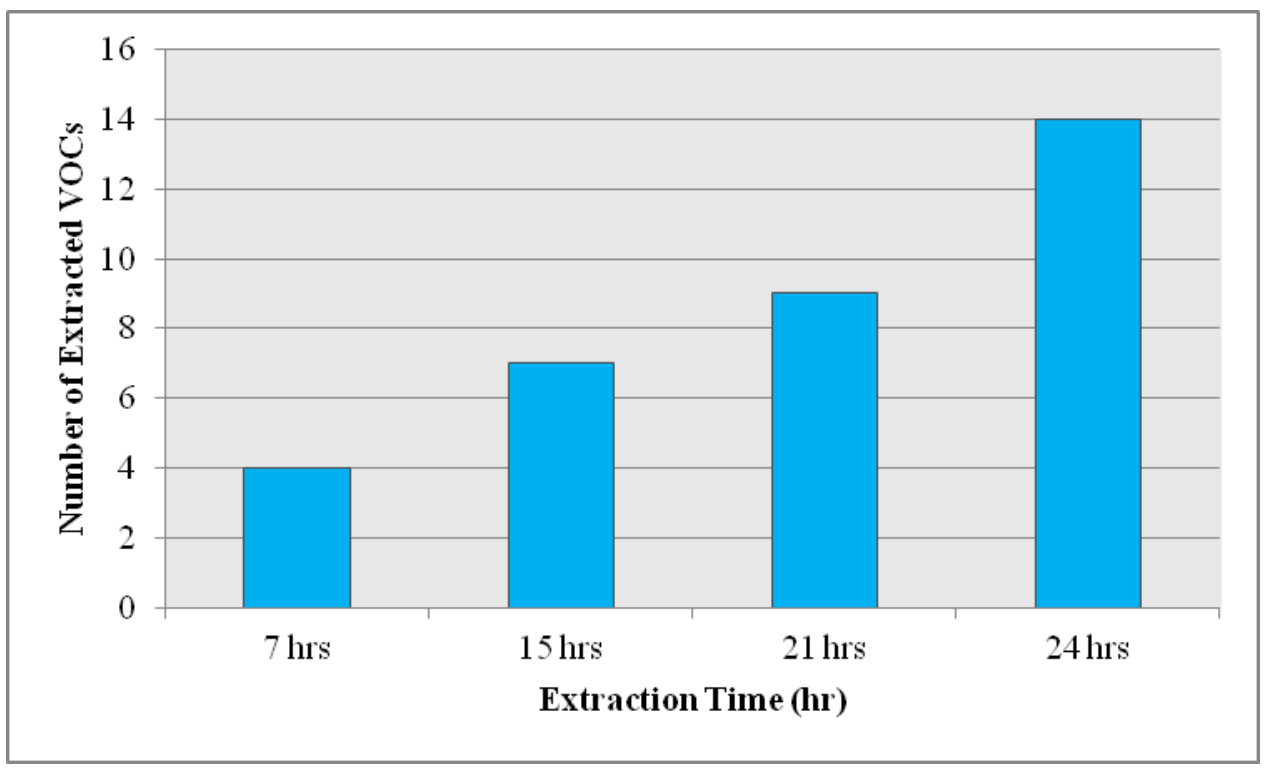

Figure 17- Number of extracted VOCs from fingernails at different extraction times

Impact of fingernail sample type (individual or collective) on the VOCs extracted

Additional tests were performed to evaluate the chemical profiles from individual fingernails, as well as all fingernails collectively, in an effort to determine what constitutes a representative fingernail sample. First, all five fingernails from the left hand of a female subject were placed into a single container and at a later sampling date each fingernail from the same hand was placed into individual containers. The VOCs from these nails were extracted and analyzed using headspace-solid phase microextraction gas chromatography-mass spectrometry. The array of human scent compounds from each sample can be seen in Figure 18. Additionally, the total abundance and number of extracted VOCs from each sample type is displayed in Figure 19 and Figure 20, respectively. 


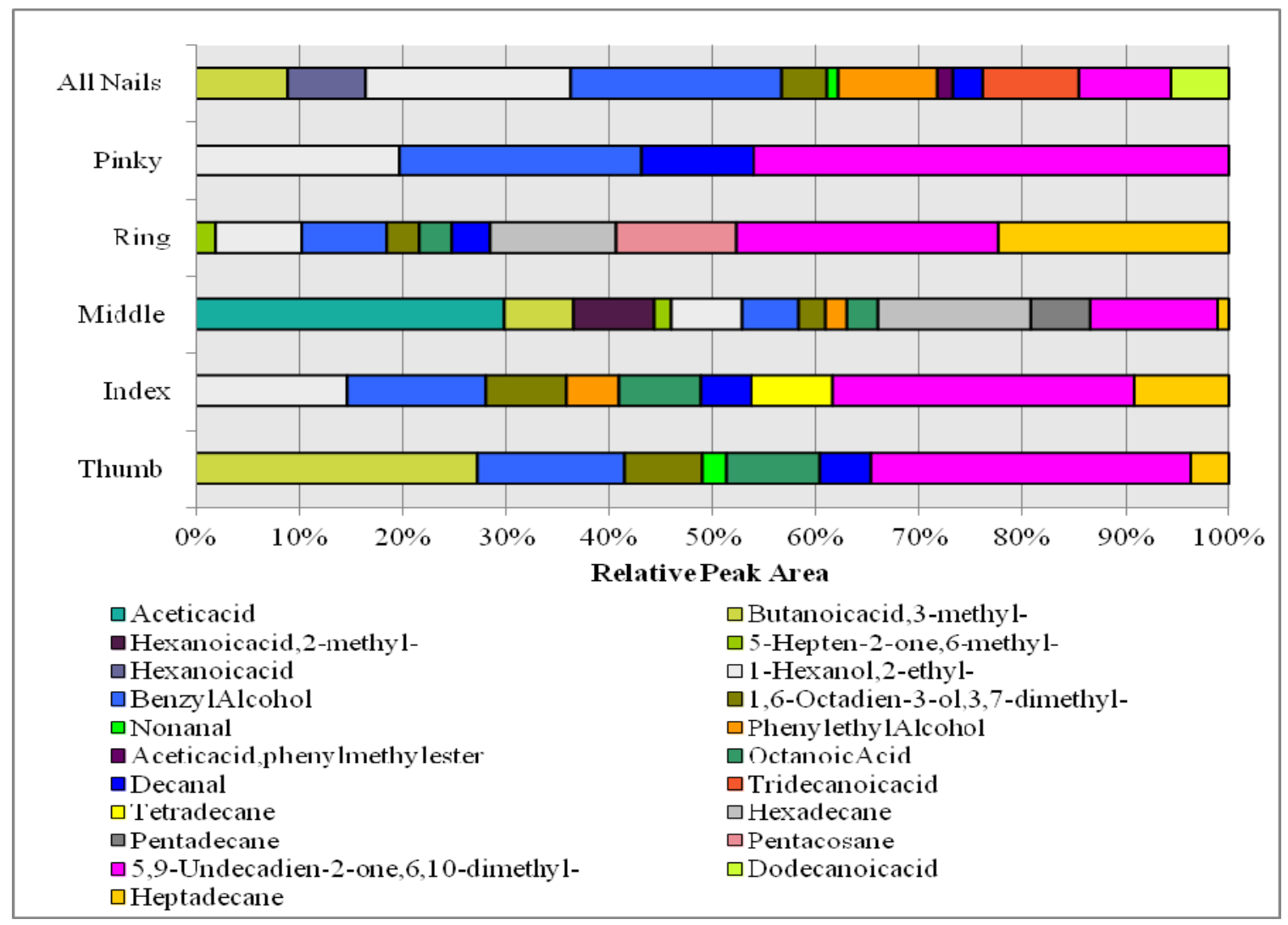

Figure 18-Profile of extracted VOCs from individual and collective fingernail samples 


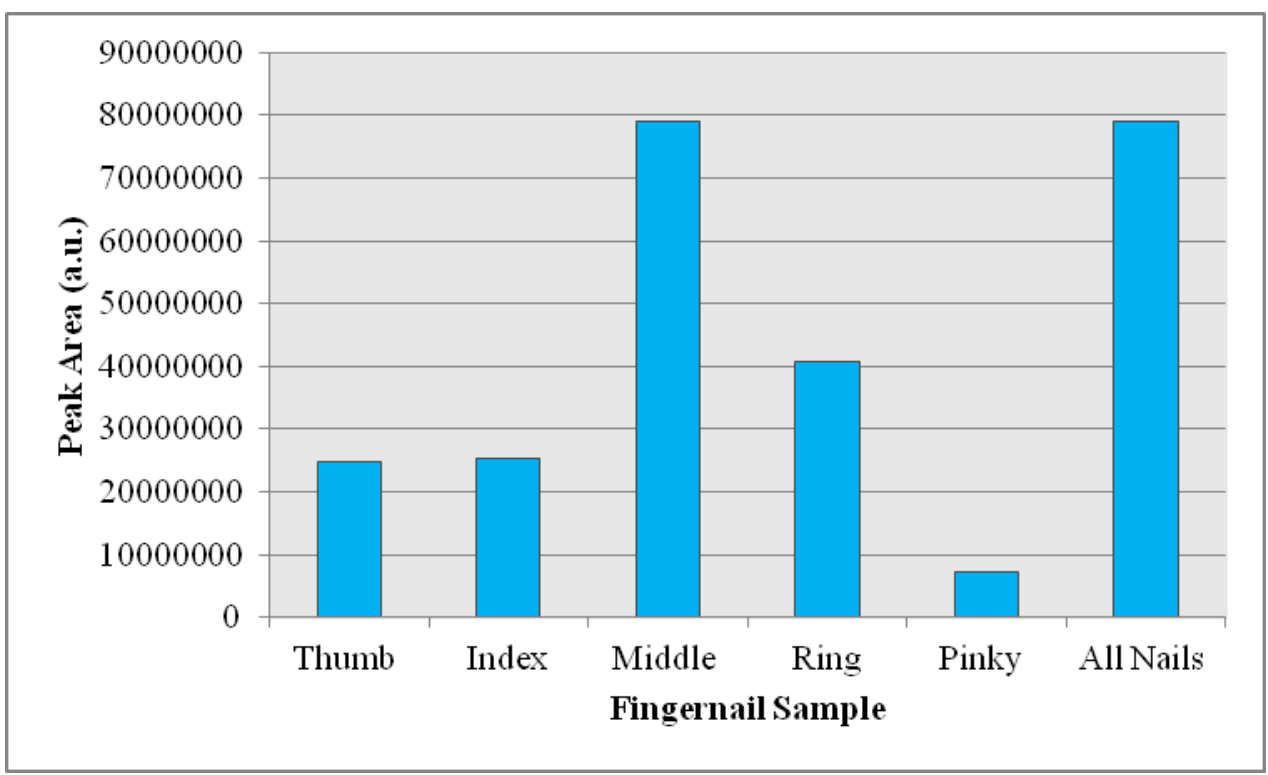

Figure 19-Abundance of VOCs extracted from fingernails for different sample types

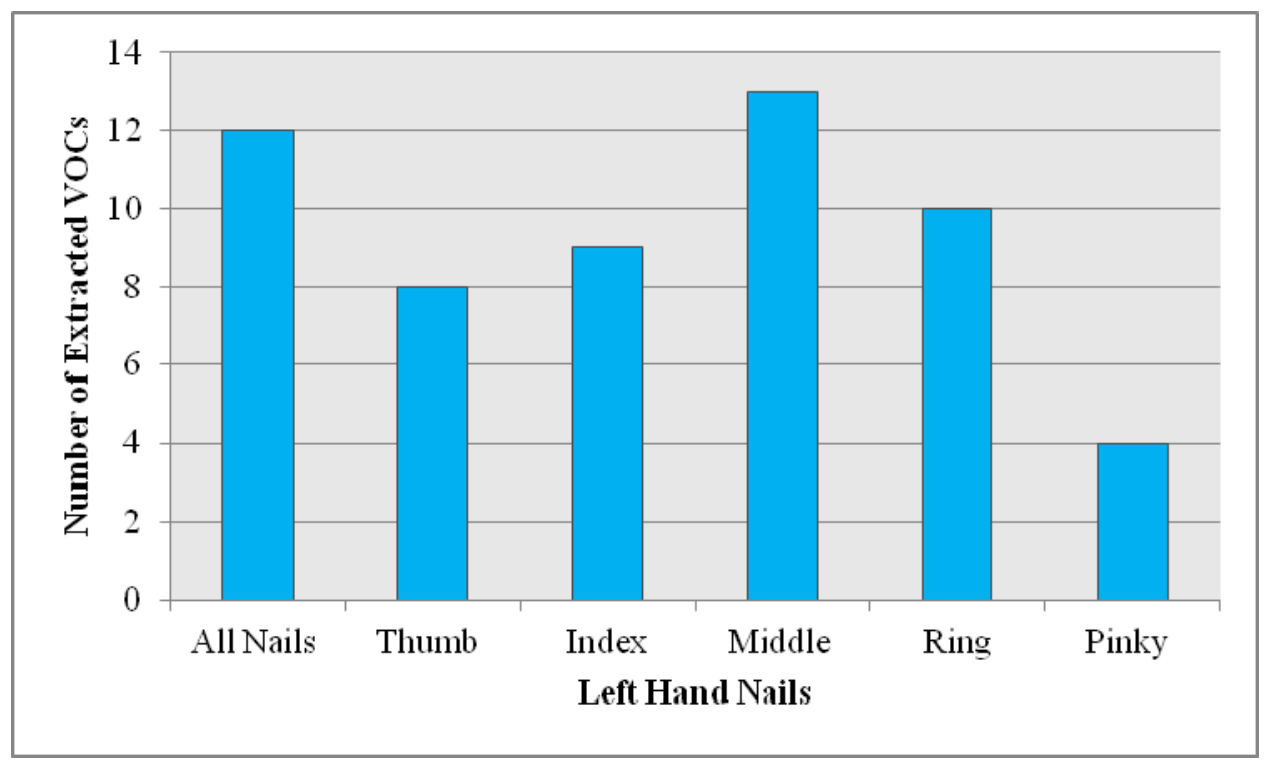

Figure 20-Number of extracted VOCs from fingernails for different sample types

There were many VOCs that were shared by the different fingernail samples. The middle fingernail sample provided the greatest number of compounds $(n=13)$ followed by 
the sample that contained all five fingernails in one container, which provided twelve compounds. The abundance of VOCs from all fingernails combined was comparable to the VOCs from the middle fingernail. The pinkie produced the least amount of VOCs while the abundances from the thumb and index fingernail were similar. Therefore, following this experiment, it was determined that more information, regarding the VOCs from fingernail samples, would be gained from using individual fingernail samples as opposed to a single, combined fingernail sample. Therefore, it was determined that three fingernails would be collected for analysis and would include the index, middle and ring fingernail.

\subsubsection{SPME extraction optimization for VOCs from saliva samples}

Two equilibration (set) and four extraction times were evaluated for the optimal extraction of VOCs from saliva samples. Initially, a set time of 24 hours was used while different extraction times were tested. The experimental extraction times were 7 hours, 15 hours, 21 hours and 24 hours. Results from this study revealed that the total amount of volatiles extracted from saliva were significantly greater than the amount of volatiles extracted from the other biological specimens. Consequently, a secondary set time was included in the study to determine whether it was necessary for a saliva sample to set for 24 hours. Thus, a brief set time of one hour was tested in conjunction with a 24 hour extraction time. The results from this study can be seen in Figure 21. The abundance of extracted VOCs was the largest when a one (1) hour set time was used in conjunction with a 24 hour extraction time. Analysis of Variance (ANOVA), along with Tukey's test, was used to validate these observations as to whether or not the total abundance of 
extracted volatiles was similar or different. The results of ANOVA showed that all of the combinations of set and extraction times yielded a similar total abundance of extracted volatiles.

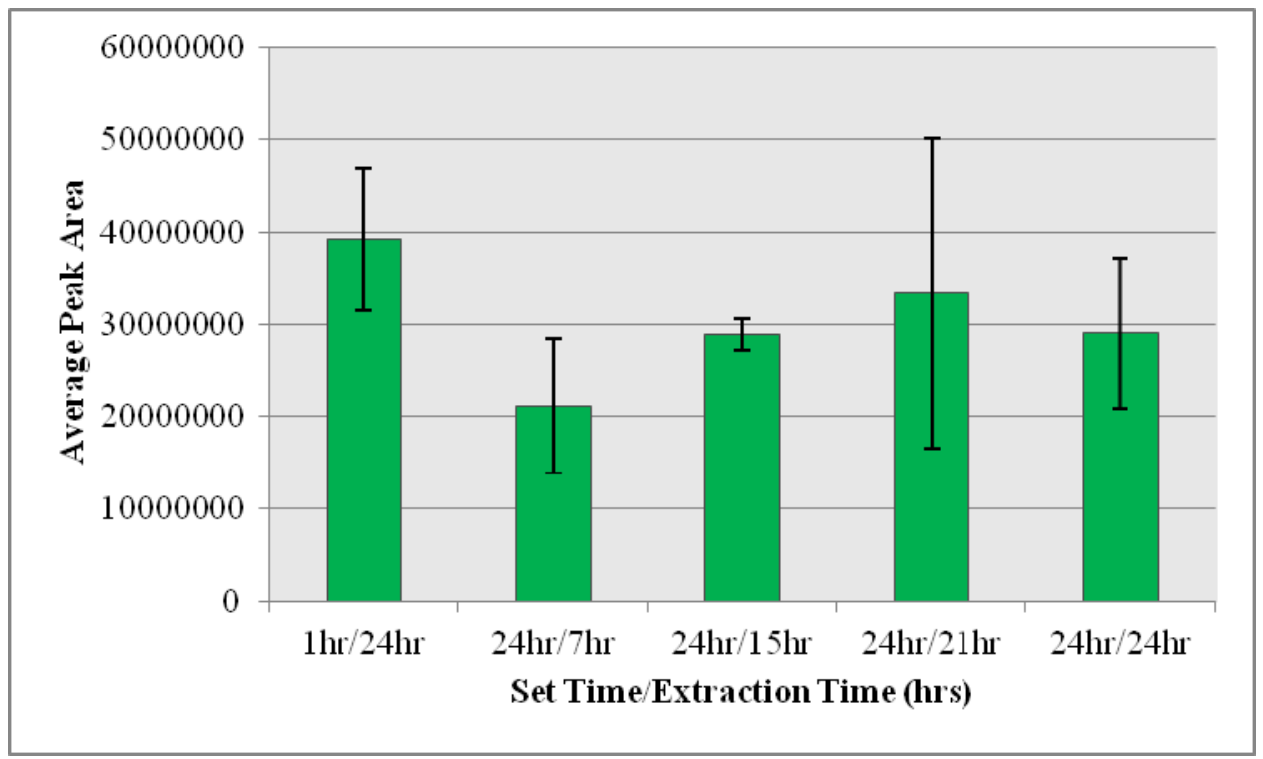

Figure 21-Abundance of VOCs extracted from saliva samples at varying equilibration/extraction times

In addition to monitoring the total extracted abundance, the number of extracted compounds was also assessed and can be seen in Figure 22. The largest number of extracted VOCs occurred when a one (1) hour set time and 24 hour extraction time was used. Analysis of Variance followed by Tukey's test for comparison showed that one hour set and 24 hour extraction time, 24 hour set and 7 hour extraction time and 24 hour set and 15 hour extraction time provided a similar number of extracted compounds. Therefore, it was determined that the optimal set time and extraction time to be used for 
the extraction of VOCs from saliva samples would be a one (1) hour set time and a 24 hour extraction time.

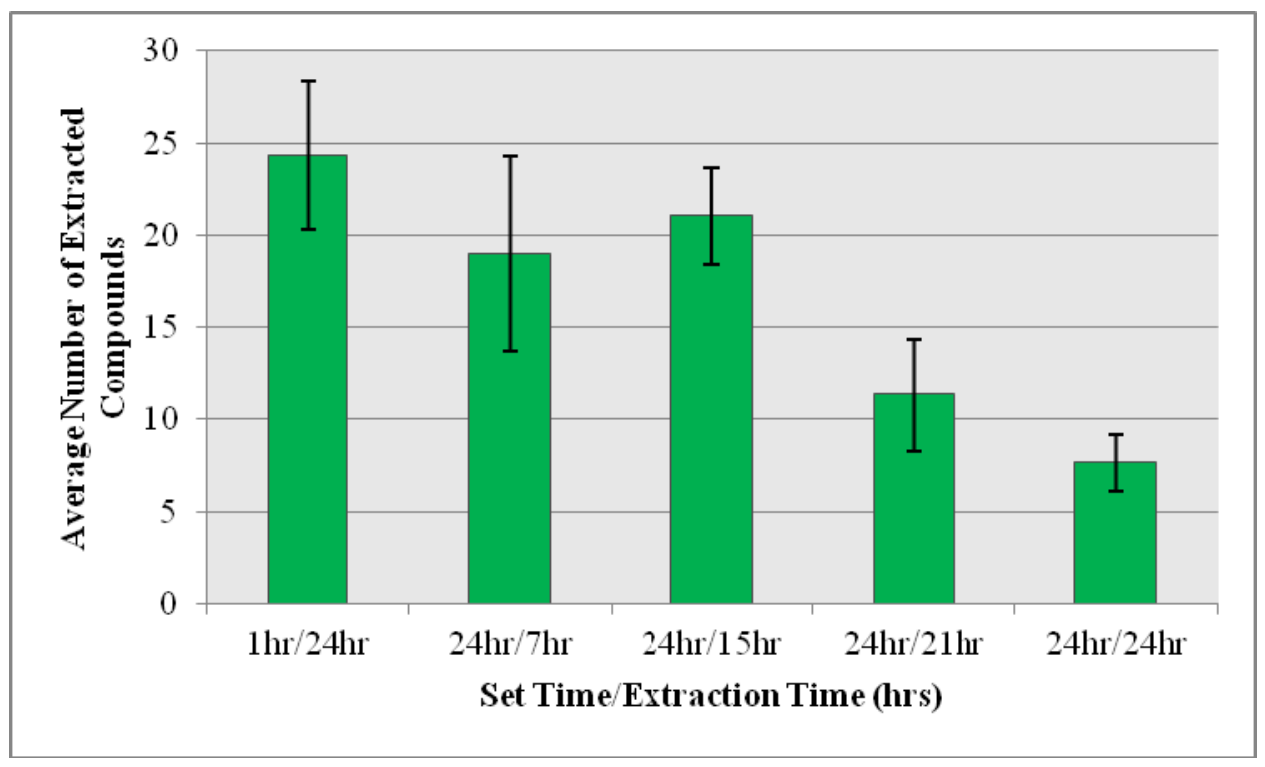

\section{Figure 22-Number of extracted VOCs from saliva samples at different extraction times}

\subsubsection{Collection of multiple biological specimens from a 60 person population}

\subsubsection{Preliminary Assessment}

Biological specimens collected from four individuals (two males and two females) were investigated to provide an initial assessment regarding the VOCs being released by these specimens in addition to the chemical trends which are likely to be observed during the analysis of the remainder of the population. Chromatograms of the VOCs extracted from the headspace of four different biological specimens collected from a male subject can be seen in Figure 23. A comparison of the chromatograms of extracted VOCs from each specimen type revealed the differences between each, such as saliva having the greatest 
abundance of VOCs, fingernails having the smallest abundance and hair producing the fewest number of volatile organic compounds.

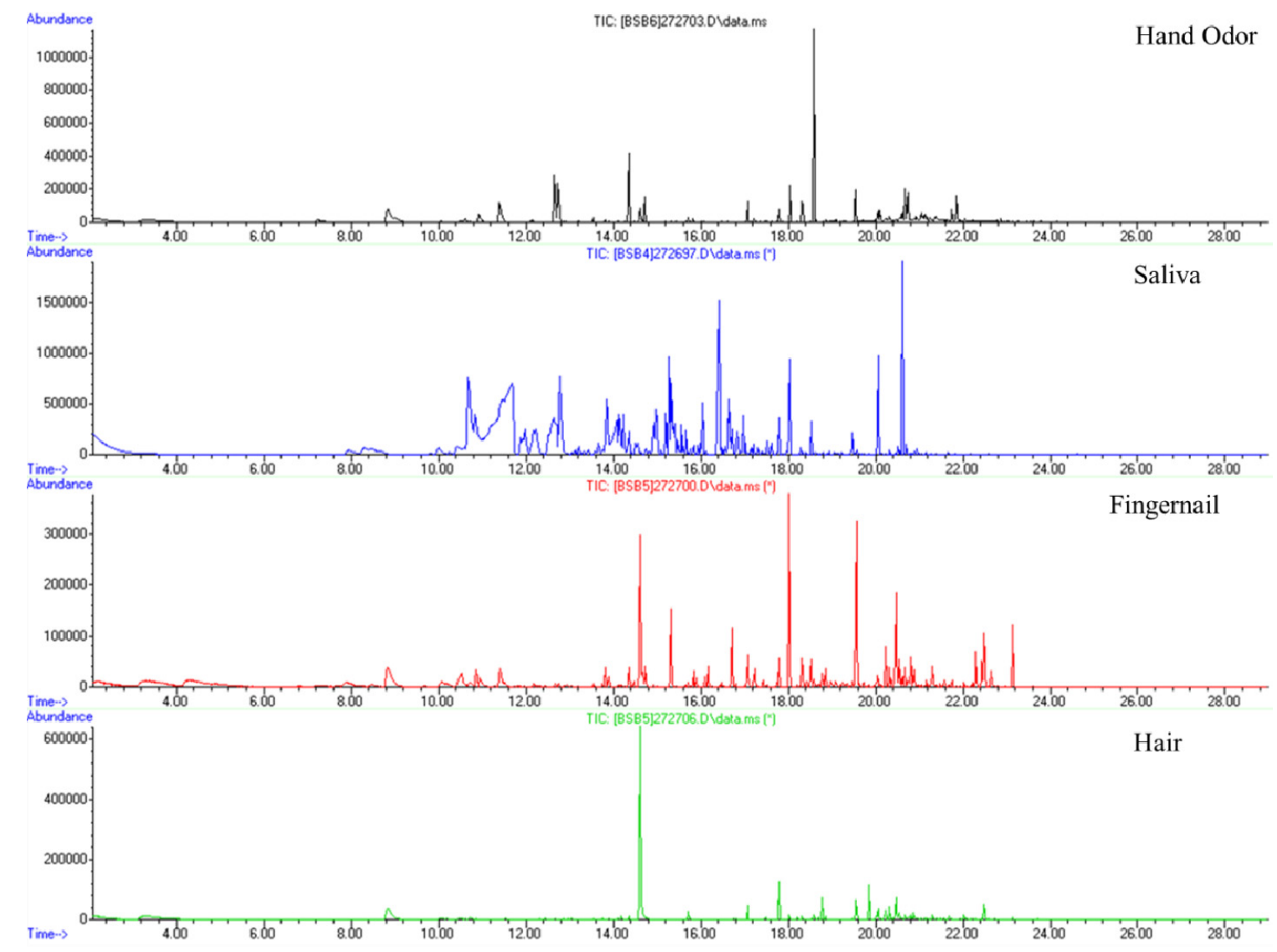

Figure 23-Chromatograms of hand odor, saliva, fingernail and hair from a male subject (13M) 
For data analysis, VOCs which have been previously cited in literature as originating from human specimens, were identified and confirmed for the four subjects. Color charts (as seen in Figure 24 and Figure 25) were used to depict the human scent VOCs extracted from each sample. Each color, in the color chart, corresponds to a specific VOC and the length of the color bar corresponds to its relative abundance (as a percentage of total composition) within the sample. When looking within a specimen type, the reproducibility in the profiles of the VOCs generated among the three samples was easily observed, for each individual. Also, the differences in the profiles of the VOCs between the biological specimen types can also be seen. 

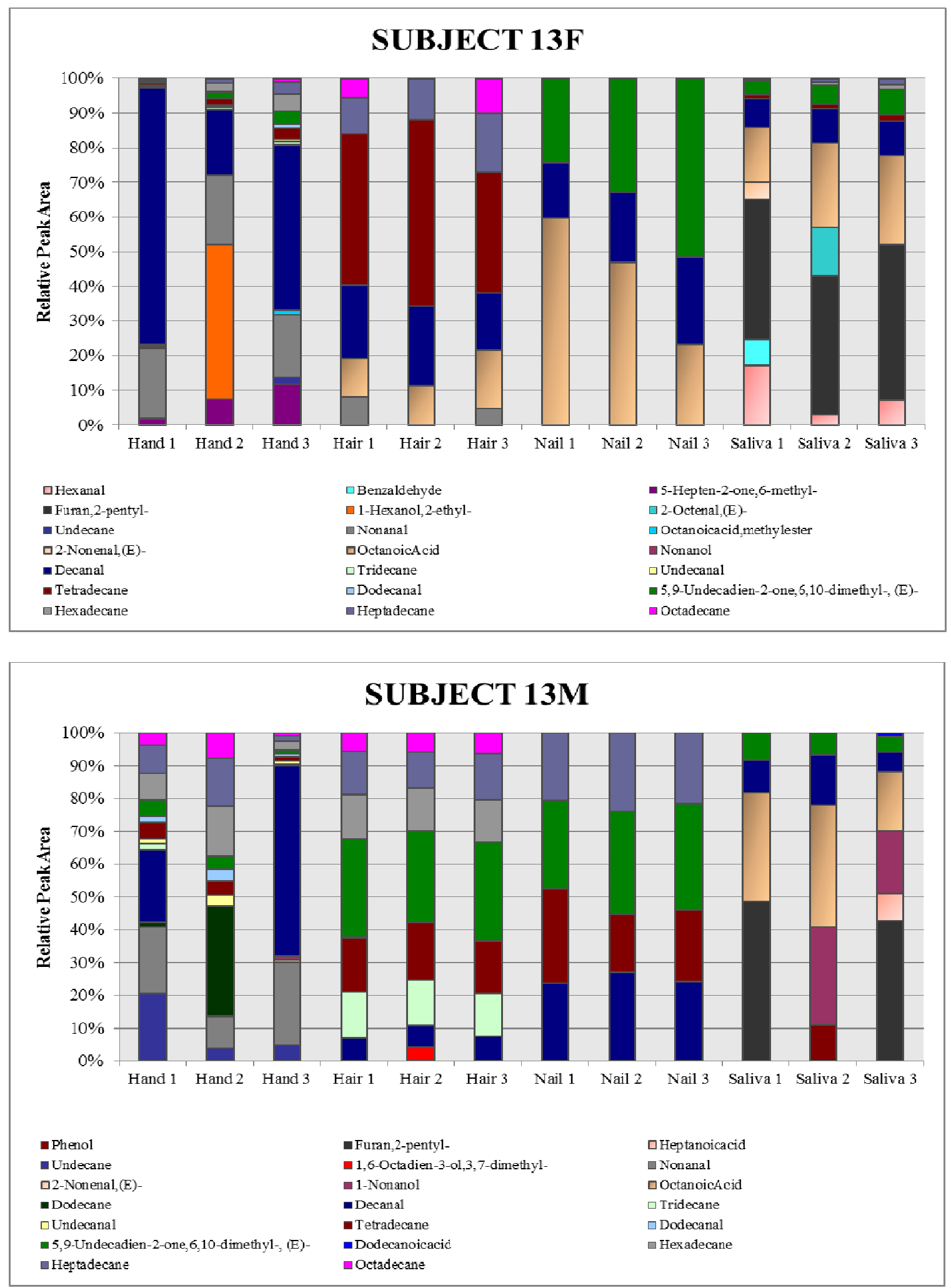

Figure 24-Profiles of the VOCs from triplicate biological specimens for subjects $13 \mathrm{~F}$ and 13M 

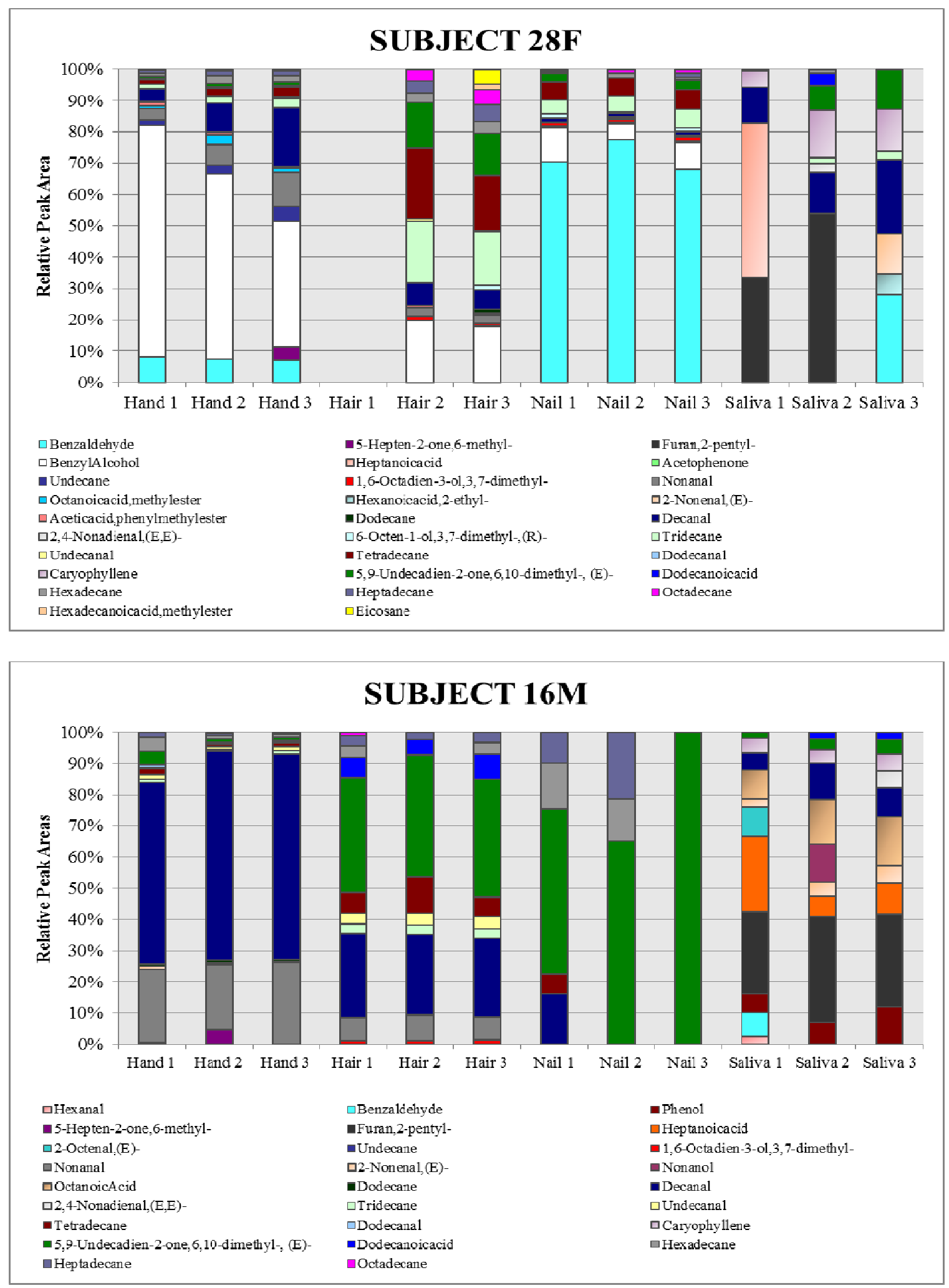

Figure 25-Profiles of the VOCs from triplicate biological specimens for subjects $28 \mathrm{~F}$ and 16M 
The sampling methodology used for this work involved extracting the VOCs from an entirely different sample each time as opposed to performing multiple extractions from the same singular sample. For instance, hair samples \#1-3 are three different portions of hair, from which a single HS-SPME extraction was conducted, which is an alternative to performing three headspace extractions from a single sample of hair. The method of sampling revealed subtle differences in the specimen's chemical composition all while allowing for a greater comprehensive assessment of the VOCs being evolved by the specimen.

In addition to performing a visual inspection of the profiles of the VOCs, statistical techniques, such as Principal Component Analysis (PCA) and cluster analysis, were performed. Principal Component Analysis was used to visualize groupings of the samples. As seen in Figure 26, the triplicate samples of each biological specimen formed its own cluster, separate from the other specimen types. This further supports that the chemicals being released by each specimen type is characteristic of that specimen. 


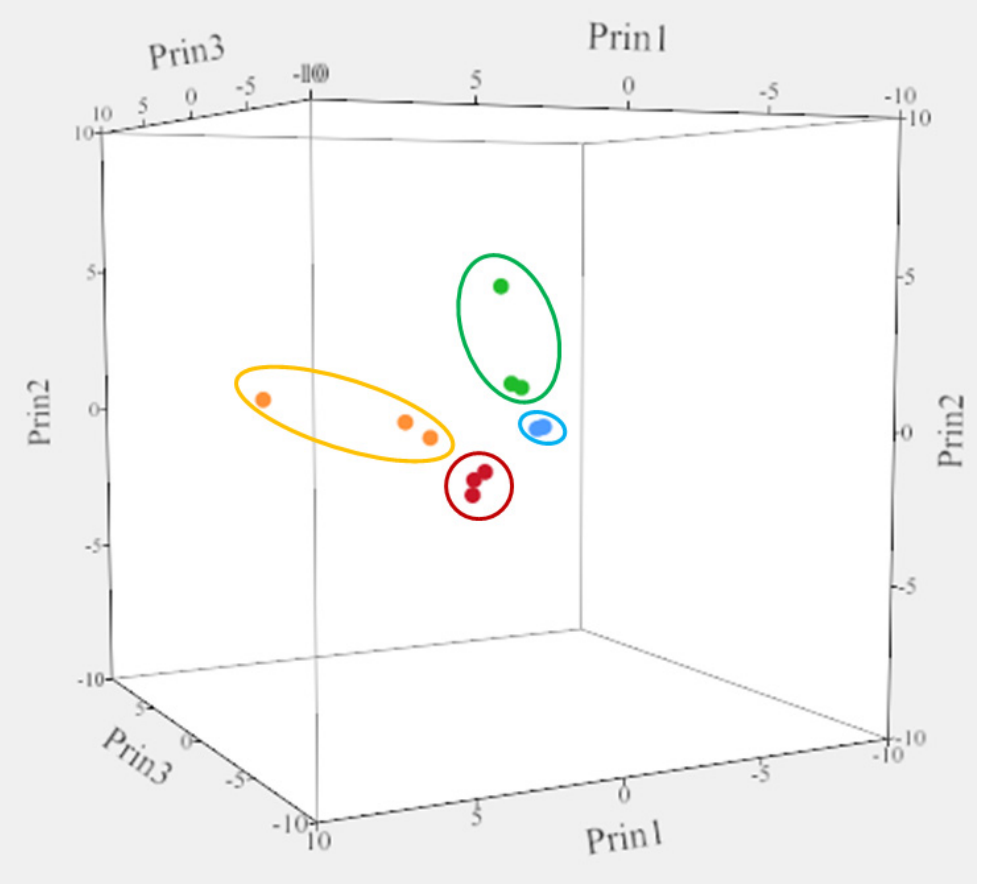

Figure 26-PCA of biological specimens from Subject 13F (hand odor-gold, hair-red, fingernails-blue and saliva-green; 3 PCs cumulative variation $68.8 \%$ )

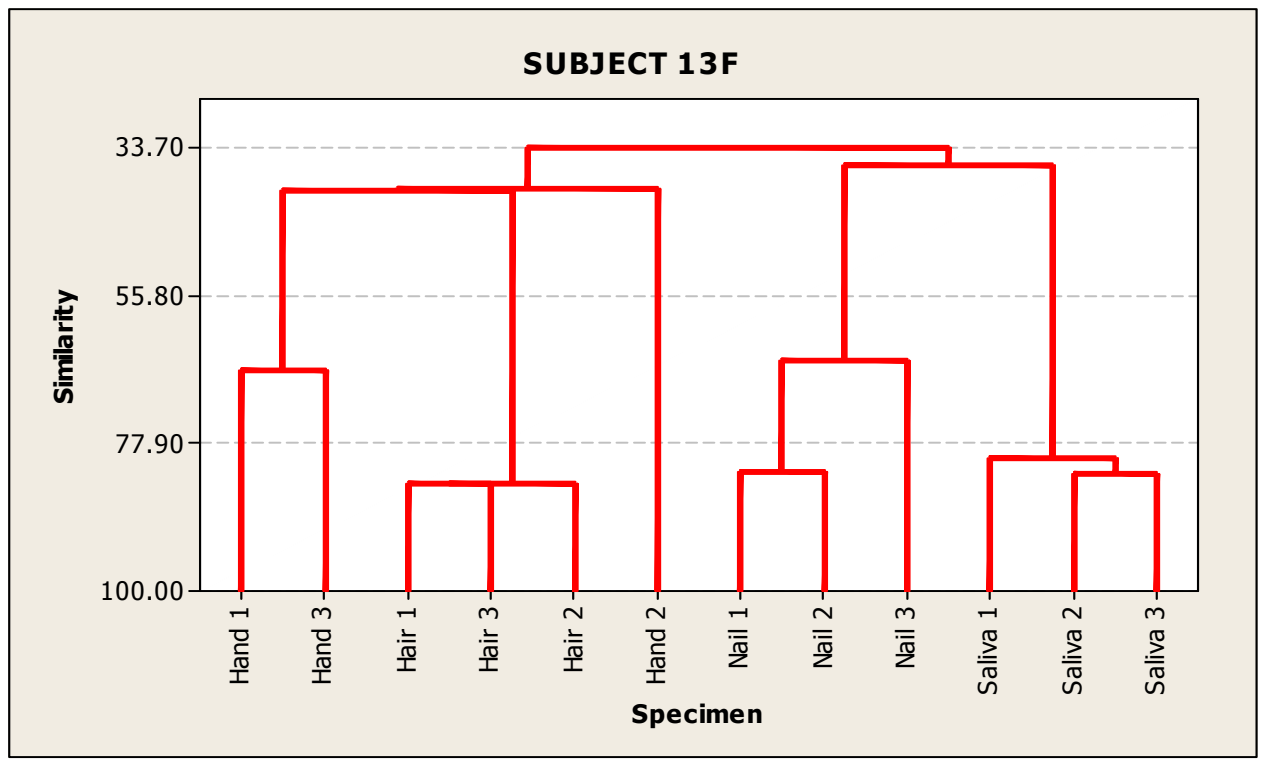

Figure 27-Cluster Analysis of biological specimens from Subject 13F 
Cluster analysis (single linkage, Euclidean distance) can further demonstrate the similarities/differences within and between specimens. The dendogram in Figure 27 displays the results of the cluster analysis. The intra-specimen analysis shows that the triplicate hair and triplicate saliva samples are more similar than the hand odor and fingernail samples. In the PCA plot the three hair samples form a tight cluster of red dots while the dendogram reveals that the hair samples are approximately $83.9 \%$ similar. The PCA plot shows the three hand odor samples, represented by gold dots, create a loose grouping, which can be corroborated by the dendogram. Cluster analysis shows that hand odor samples 1 and 3 are $66.9 \%$ similar while samples 1 and 2 are $39.9 \%$ similar. Similar results were obtained for the other three individuals, such that the PCA displayed a separate cluster for each specimen type.

The similarities/differences between the specimen types can also be assessed using cluster analysis. Two major clusters have been formed between the four specimen types. The hand odor and hair comprise the first cluster while fingernails and saliva comprise the second cluster. The specimens in the first cluster (hand odor and hair) have a similarity of $39.9 \%$ while the specimens in the second cluster (fingernails and saliva) have a similarity of $36.3 \%$. The similarity between the two major clusters is $33.7 \%$ which shows a large dissimilarity among the four specimen types.

The final portion of the preliminary assessment included evaluating the mass of extracted VOCs for each specimen type, which can be seen in Figure 28. It is apparent that there is substantial variation in the extracted mass amounts among specimen types, as well as among individuals. The samples that provided the greatest mass, on average, were saliva (ranging from 39-269 ng) followed by hand odor (ranging from 38-287 ng), 
hair (ranging from 6-162 ng) and fingernails (range 1-733 ng). The mass of extracted VOCs from subject 28F's fingernails were significantly larger than any other sample evaluated. Notes taken while sampling subject $28 \mathrm{~F}$ stated that this female subject removed her artificial nails 36 hours prior to sampling. The large mass of extracted VOCs could have been influenced by the cosmetic procedure, but there is no way to be certain which compounds were endogenous or exogenous; therefore, as previously stated, only the VOCs that have been identified from human specimens in literature were used in this assessment. The assessment of the mass of extracted VOCs reveals that though there is an anticipated trend (saliva provides the greatest mass and fingernails provide the smallest mass) not every sample is going to exhibit predictable behavior (i.e., fingernails from subject 28F). 


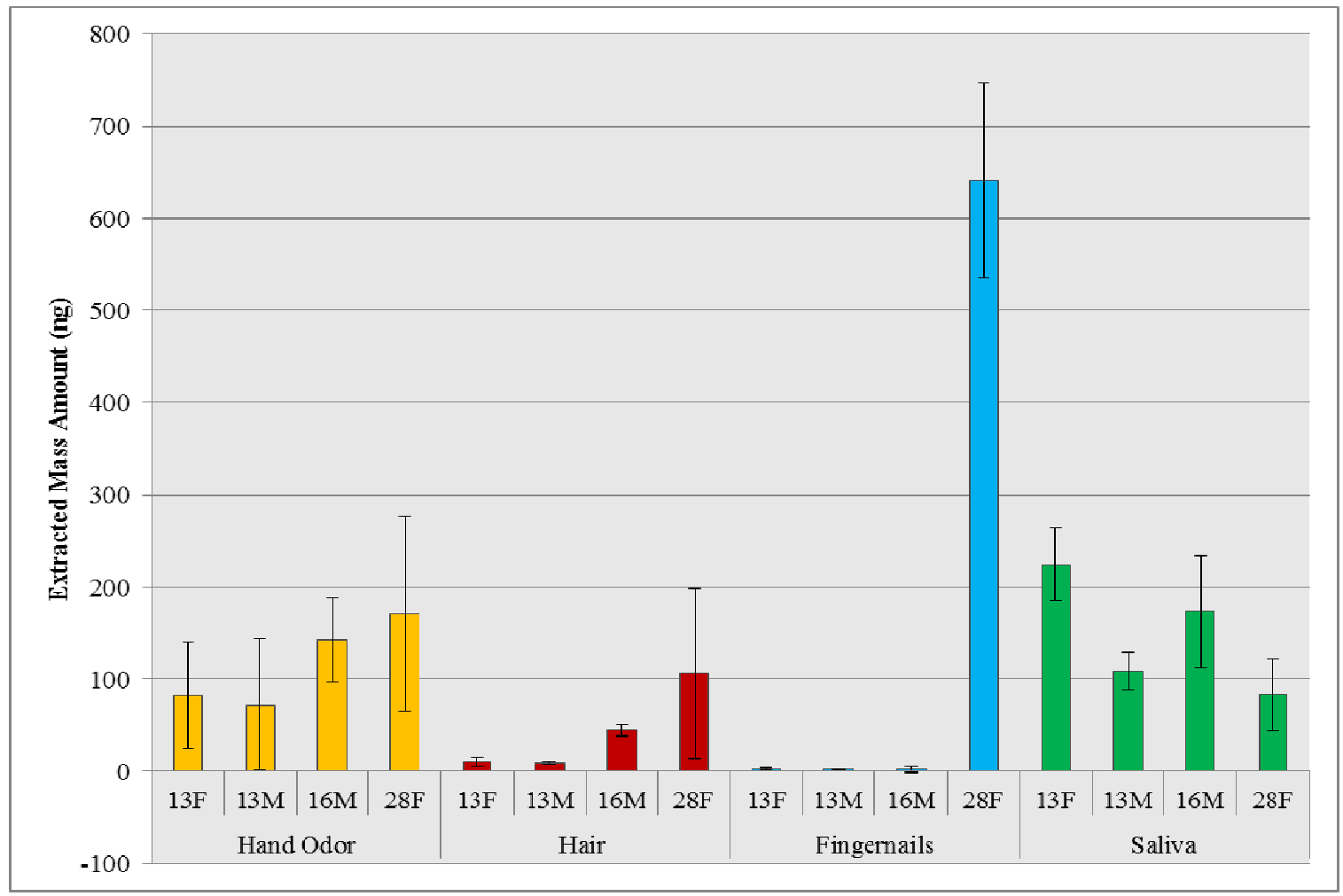

Figure 28-Mass of extracted VOCs from biological specimens collected from four individuals.

Following the results of this preliminary assessment, it was determined that the VOCs emanating from each biological specimen provided a significantly different array of volatile organic compounds. For instance, when comparing hand odor to saliva (which originated from the same person) there is a clear difference between both specimen types and, therefore, any comparisons made between individuals should be performed within each specimen type. 
3.3.2.2. Human scent VOCs of different biological specimens collected from 60 individuals

A total of 714 samples (180 hand odor, 176 hair, 178 fingernail and 180 saliva) were collected from 60 individuals which revealed a combined total of 1,029 chromatographic peaks. The tentative identities of these peaks (when compared to the NIST mass spectral library) produced a long list of compounds that ranged in functionalities from acids, alcohols, aldehydes, aliphatic hydrocarbons (alkane, alkene and alkynes), aromatic hydrocarbons, cyclic hydrocarbons, esters, ethers, halogens, heterocyclics, ketones, and nitrogen- and sulfur-containing compounds among all biological specimen types. 
Table 8-Human scent compounds identified from each biological specimen and frequency of occurrence in collected samples

\begin{tabular}{|c|c|c|c|c|c|c|}
\hline Color & R.T. (min) & Compound Name & Hand Odor & Hair & Finge rnail & Saliva \\
\hline & 6.05 & Hexanal & & & & $37.8 \%$ \\
\hline & 6.95 & Furfural & & & & $5.6 \%$ \\
\hline & 7.68 & 2-Furanmethanol & $8.9 \%$ & & & \\
\hline & 10.10 & Benzaldehyde & $4.4 \%$ & $1.7 \%$ & $2.2 \%$ & $36.1 \%$ \\
\hline & 10.57 & Phenol & $1.7 \%$ & & & $38.9 \%$ \\
\hline & 10.70 & 6-methyl-5-Hepten-2-one & $10.0 \%$ & $5.6 \%$ & $1.1 \%$ & \\
\hline & 10.79 & 2-pentyl-Furan & & & & $91.7 \%$ \\
\hline & 11.44 & 2-ethyl-1-Hexanol & $12.2 \%$ & $12.4 \%$ & $28.5 \%$ & \\
\hline & 11.62 & Benzyl Alcohol & $22.8 \%$ & $31.1 \%$ & $44.7 \%$ & \\
\hline & 12.06 & (E)-2-Octenal & & & & $21.1 \%$ \\
\hline & 12.07 & Acetophenone & $8.9 \%$ & & $1.7 \%$ & $15.6 \%$ \\
\hline & 12.19 & Heptanoic acid & & $0.6 \%$ & & $41.7 \%$ \\
\hline & 12.77 & Undecane & $62.8 \%$ & & & \\
\hline & 12.78 & 3,7-dimethyl-1,6-Octadien-3-ol & $7.8 \%$ & $62.1 \%$ & $38.0 \%$ & \\
\hline & 12.87 & Nonanal & $100.0 \%$ & $63.8 \%$ & $38.5 \%$ & \\
\hline & 13.11 & 2-ethyl-Hexanoic acid & $25.0 \%$ & $1.1 \%$ & $1.1 \%$ & \\
\hline & 13.11 & Octanoic acid, methyl ester & $12.8 \%$ & & & \\
\hline & 13.78 & (E)-2-Nonenal & $32.2 \%$ & $1.1 \%$ & & $33.9 \%$ \\
\hline & 13.82 & Acetic acid, phenyl methyl ester & $4.4 \%$ & $37.3 \%$ & $18.4 \%$ & \\
\hline & 13.87 & Octanoic acid & & $13.0 \%$ & $25.7 \%$ & $55.0 \%$ \\
\hline & 13.94 & Nonanol & $28.9 \%$ & & $1.1 \%$ & \\
\hline & 14.21 & 2-Decanone & $13.3 \%$ & & & \\
\hline & 14.37 & Dodecane & $24.4 \%$ & $11.3 \%$ & & \\
\hline & 14.55 & Decanal & $100.0 \%$ & $95.5 \%$ & $82.1 \%$ & $95.6 \%$ \\
\hline & 14.64 & (E,E)-2,4-Nonadienal & & & & $22.2 \%$ \\
\hline & 14.74 & Nonanoic acid, methyl ester & $6.7 \%$ & & & \\
\hline & 14.81 & (R)-3,7-dimethyl-6-Octen-1-ol & & $21.5 \%$ & $6.1 \%$ & \\
\hline & 15.81 & 1-methyl-Naphthalene & $2.8 \%$ & $2.3 \%$ & & $74.4 \%$ \\
\hline & 15.84 & Tridecane & $71.7 \%$ & $26.0 \%$ & $5.6 \%$ & \\
\hline & 15.96 & Undecanal & $86.7 \%$ & $37.9 \%$ & $4.5 \%$ & \\
\hline & 17.19 & Tetradecane & $98.3 \%$ & $80.8 \%$ & $55.3 \%$ & $42.8 \%$ \\
\hline & 17.34 & Dodecanal & $55.6 \%$ & $14.1 \%$ & $15.1 \%$ & $8.9 \%$ \\
\hline & 17.49 & Caryophyllene & $1.1 \%$ & & $0.6 \%$ & $39.4 \%$ \\
\hline & 17.92 & (E)-6,10-dimethyl-5,9-Undecadien-2-one & $88.3 \%$ & $80.8 \%$ & $86.6 \%$ & $99.4 \%$ \\
\hline & 18.46 & Pentadecane & $2.8 \%$ & $4.0 \%$ & & \\
\hline & 18.54 & 1-Pentadecene & $0.6 \%$ & & & \\
\hline & 19.13 & Dodecanoic acid & $14.4 \%$ & $24.9 \%$ & $5.0 \%$ & $50.0 \%$ \\
\hline & 19.66 & Hexadecane & $98.9 \%$ & $63.3 \%$ & $56.4 \%$ & $28.9 \%$ \\
\hline & 20.80 & Heptadecane & $91.7 \%$ & $75.7 \%$ & $72.1 \%$ & $23.3 \%$ \\
\hline & 21.88 & Octadecane & $61.1 \%$ & $54.2 \%$ & $35.8 \%$ & $7.2 \%$ \\
\hline & 22.41 & Pentadecanoic acid & & $4.0 \%$ & & \\
\hline & 23.11 & Hexadecanoic acid, methyl ester & $3.3 \%$ & $7.9 \%$ & $3.9 \%$ & $6.7 \%$ \\
\hline & 23.33 & n-Hexadecanoic acid & $0.6 \%$ & $7.3 \%$ & $0.6 \%$ & \\
\hline & 23.80 & Eicosane & & $2.8 \%$ & & \\
\hline & 24.67 & Heneicosane & & $2.3 \%$ & & \\
\hline & 25.56 & Docosane & & $0.6 \%$ & & \\
\hline & 28.17 & Pentacosane & $0.6 \%$ & & & \\
\hline
\end{tabular}


From the over one thousand detected compounds, a smaller menu of compounds, which have been previously published in literature as being detected from human specimens $(1,26,28,31,32,36-39,41,42,50,64,80,89-93)$, were confirmed with certified reference standards and were subsequently used for data analysis.

Forty-seven human scent VOCs were used to evaluate the inter-subject differences within each biological specimen and the frequency they were detected from each specimen can be seen in Table 8 . The frequency of occurrence was determined by adding the number of samples each VOC was detected from and dividing by the total number of samples for that specimen type. All replicate samples from each individual were considered. The limit of detection of each human scent VOC is listed in Table 9.

The VOCs used in the data analysis portion of this work included acids, alcohols, aldehydes, aliphatic hydrocarbons, an aromatic hydrocarbon, esters, heterocyclics and ketones. Thirty-five of the human scent VOCs were detected from hand odor samples with the greatest contributions being derived from aliphatic hydrocarbons (31.4\%), aldehydes (17.1\%) and alcohols (17.1\%). Of the four biological specimens evaluated, the highest percentage of esters (11.4\%) was present in hand odor. Thirty-one human scent VOCs were detected from hair samples with the greatest contributions from aliphatic hydrocarbons (32.3\%), aldehydes (19.4\%) and acids (19.4\%). Overall, hair samples provided the highest percentage of aliphatic hydrocarbons and acids of the four collected specimens. The presence of acids from hair samples is expected given that the sebum, secreted by the sebaceous glands in the hair follicle, has been documented to have contained saturated acids (22). 
Twenty-five human scent VOCs were detected from fingernail samples with the greatest contributions from aliphatic hydrocarbons (24.0\%), aldehydes (20.0\%) and alcohols (20.0\%). Of the four biological specimens evaluated, the highest percentage of alcohols, aldehydes, and ketones (12.0\%) were detected in fingernails. The fewest number of human scent VOCs were detected from saliva samples $(n=22)$ with the greatest contributions originating from aldehydes (36.4\%), aliphatic hydrocarbons $(22.7 \%)$ and acids (13.6\%). Though the percentage of aromatic hydrocarbon and heterocyclic VOCs was low (4.5\%) they had the greatest occurrence in saliva than in any of the other biological specimens.

Table 9-Limit of detection (LOD) of human scent VOCs

\begin{tabular}{|l|c|l|}
\hline \multicolumn{1}{|c|}{ Compound Name } & LOD (ng) & \multicolumn{1}{c|}{ Functionality } \\
\hline (E)-2-Nonenal & 6.9 & Aldehyde \\
\hline (E)-2-Octenal & 5.7 & Aldehyde \\
\hline (E)-6,10-dimethyl-5,9-Undecadien-2-one & 7.9 & Ketone \\
\hline (E,E)-2,4-Nonadienal & 6.5 & Aldehyde \\
\hline (R)-3,7-dimethyl-6-Octen-1-ol & 20.2 & Alcohol \\
\hline 1-Pentadecene & 9.7 & Aliphatic Hydrocarbon \\
\hline 2-Decanone & 9.9 & Ketone \\
\hline 2-ethyl-1-Hexanol & 7.7 & Alcohol \\
\hline 2-ethyl-Hexanoic acid & 2.2 & Acid \\
\hline 2-Furanmethanol & 4.1 & Heterocyclic \\
\hline 3,7-dimethyl-1,6-Octadien-3-ol & 6.6 & Alcohol \\
\hline 6-methyl-5-Hepten-2-one & 7.2 & Ketone \\
\hline Acetic acid, phenyl methyl ester & 7.1 & Ester \\
\hline Acetophenone & 6.2 & Ketone \\
\hline Benzaldehyde & 6.6 & Aldehyde \\
\hline Benzyl Alcohol & 7.9 & Alcohol \\
\hline Caryophyllene & 9.8 & Aliphatic Hydrocarbon \\
\hline Decanal & 9.0 & Aldehyde \\
\hline Docosane & 16.4 & Aliphatic Hydrocarbon \\
\hline Dodecanal & 9.5 & Aldehyde \\
\hline Dodecane & 9.8 & Aliphatic Hydrocarbon \\
\hline
\end{tabular}




\begin{tabular}{|l|c|l|}
\hline Dodecanoic acid & 6.8 & Acid \\
\hline Eicosane & 9.8 & Aliphatic Hydrocarbon \\
\hline 2-pentyl-Furan & 8.2 & Heterocyclic \\
\hline Furfural & 10.4 & Heterocyclic \\
\hline Heneicosane & 10.0 & Aliphatic Hydrocarbon \\
\hline Heptadecane & 11.4 & Aliphatic Hydrocarbon \\
\hline Heptanoic acid & 1.0 & Acid \\
\hline Hexadecane & 12.4 & Aliphatic Hydrocarbon \\
\hline Hexadecanoic acid, methyl ester & 8.9 & Ester \\
\hline Hexanal & 5.4 & Aldehyde \\
\hline 1-methyl-Naphthalene & 7.9 & Aromatic Hydrocarbon \\
\hline n-Hexadecanoic acid & 23.2 & Acid \\
\hline Nonanal & 6.1 & Aldehyde \\
\hline Nonanoic acid, methyl ester & 8.6 & Ester \\
\hline Nonanol & 8.5 & Alcohol \\
\hline Octadecane & 9.8 & Aliphatic Hydrocarbon \\
\hline Octanoic acid & 1.7 & Acid \\
\hline Octanoic acid, methyl ester & 8.0 & Ester \\
\hline Pentacosane & 11.1 & Aliphatic Hydrocarbon \\
\hline Pentadecane & 9.8 & Aliphatic Hydrocarbon \\
\hline Pentadecanoic acid & 19.4 & Acid \\
\hline Phenol & 9.1 & Alcohol \\
\hline Tetradecane & 9.9 & Aliphatic Hydrocarbon \\
\hline Tridecane & 9.8 & Aliphatic Hydrocarbon \\
\hline Undecanal & 5.8 & Aldehyde \\
\hline Undecane & 8.7 & Aliphatic Hydrocarbon \\
\hline
\end{tabular}

Many of the human scent VOCs were detected from multiple specimens while others were specific to just one specimen (e.g., nonanoic acid, methyl ester in hand odor). Ten VOCs were shared between all four of the biological specimen types (benzaldehyde, decanal, tetradecane, dodecanal, geranylacetone, dodecanoic acid, hexadecane, heptadecane, octadecane and hexadecanoic acid, methyl ester). In hand odor samples, five VOCs were detected at a frequency greater than $90 \%$, which included nonanal, decanal, tetradecane, hexadecane and heptadecane. Furthermore, nonanal and decanal were present in all of the 180 collected hand odor samples. 
Decanal was the only VOC detected in greater than $90 \%$ of the collected hair samples while no VOCs were present in greater than $90 \%$ of fingernail samples. Three VOCs were detected in greater than $90 \%$ of collected saliva samples, which included 2 pentyl-furan, decanal and geranylacetone. It is also important to note that hexanoic acid, which has been previously identified from human specimens $(36,37,42)$, was detected in $100 \%$ of saliva samples; however, it was excluded from this portion of the data analysis.

The use of the DVB/CAR on PDMS SPME fiber for the headspace extraction of VOCs only provided a glimpse of the different types of compounds being released from these biological specimens. However, the detection of aldehydes and alcohols from hand odor and acids from hair coincides with previous research. Now attention will be given to the occurrence of these compounds from different individuals and assessments will be made as to how these qualitative and quantitative differences between people can be used for differentiation purposes.

\section{VOC Profiles from Biological Specimens}

Forty-seven human scent VOCs were used to create color charts that allowed for the visualization of the chemical profiles for each of the biological specimens collected from 60 individuals. In addition, the similarities and differences between the subjects and the specimen types could be easily identified. As previously mentioned in Section 3.3.2.1, each color in the color chart corresponds to a compound (refer to Table 8) and the length of that color bar corresponds to the relative peak area (abundance) of the compound. Figure 29 displays the profiles of the VOCs obtained from hand odor samples that were 
collected from 60 individuals. Each individual's profile is the average of the triplicate hand odor samples.

Upon visual inspection of the sixty hand odor samples it is easy to identify that nonanal (gray) and decanal (dark blue) were present in every sample. In addition, it is easy to see that these two compounds comprise of approximately $20 \%$ and $30 \%$ of the total abundance, respectively. If these two compounds were not incorporated into these profiles it would be easier to see the contributions from the less abundant VOCs which vary, between individuals, both qualitatively and quantitatively.

The profiles of the VOCs obtained from hair, fingernails and saliva, are displayed in Figure 30, Figure 31 and Figure 32, respectively. The hair and fingernail profiles show greater VOC diversity between the 60 individuals; however, the similarities between the two specimen types are easily observed. Additionally, the profiles of the VOCs from saliva are strikingly different from those of hand odor, hair and fingernails, which were seen in the preliminary assessment (Section 3.3.2.1). Compounds such as 2-pentyl-furan (black), heptanoic acid (shaded orange) and octanoic acid (shaded pink) were present in $91.7 \%, 41.7 \%$ and $55.0 \%$ of the saliva samples, respectively, resulting in a distinct chemical profiles for this specimen.

The analysis of human scent produces large amounts of data consisting of numerous VOCs in varying concentrations. The best representation of these data is through the use of a color chart. From these charts, the chemical differences among individuals and specimen types can quickly be observed. Up until now, little, if any, consideration has been given to the analysis of VOCs produced by fingernails. For the 
first time, it can be seen, through the use of a color chart, the types of compounds being released by fingernails and their similarity to hair volatile organic compounds. 


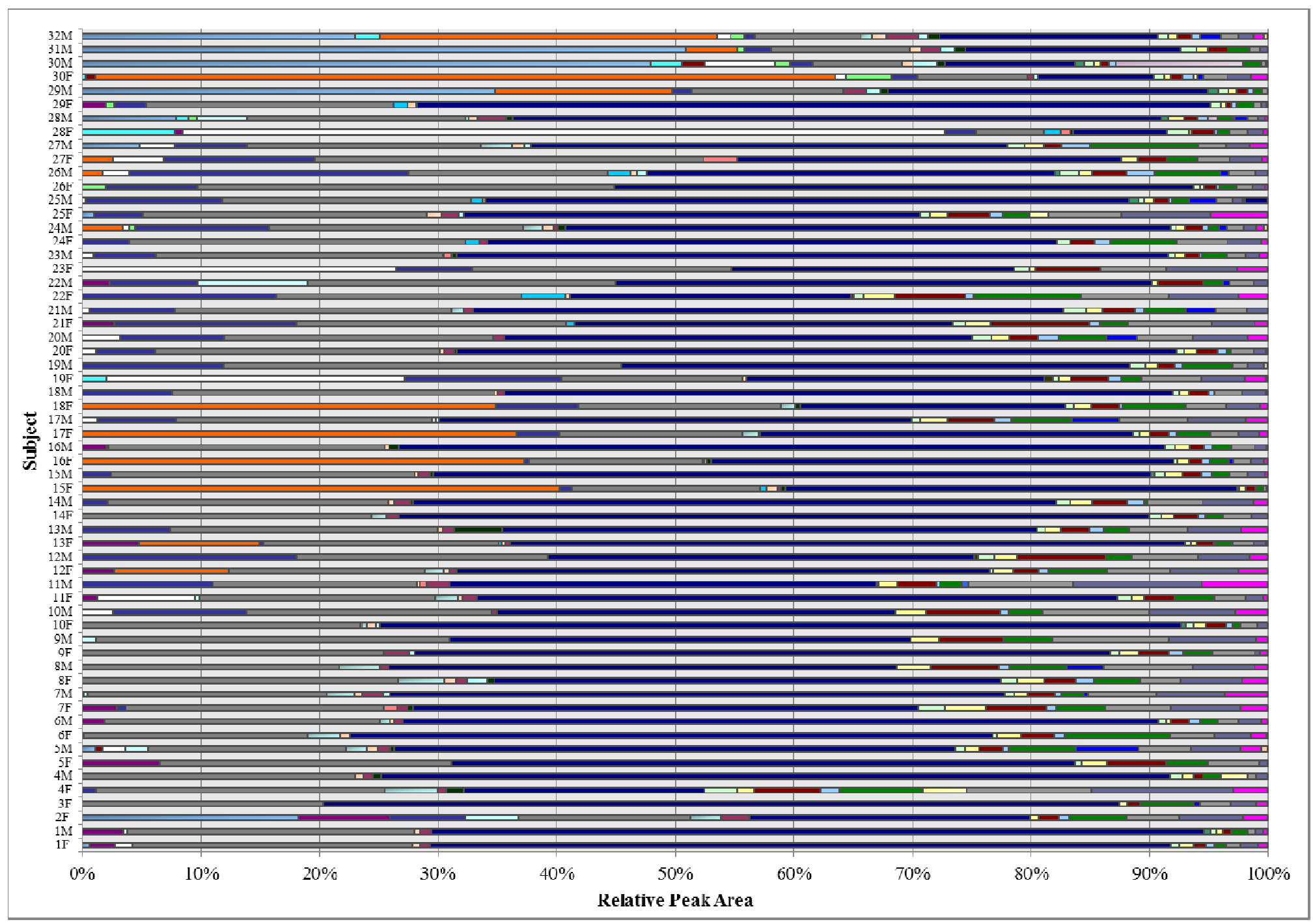

Figure 29-Profile of human scent VOCs from the hand odor samples of 60 individuals [30 males (M) and 30 females (F)] 


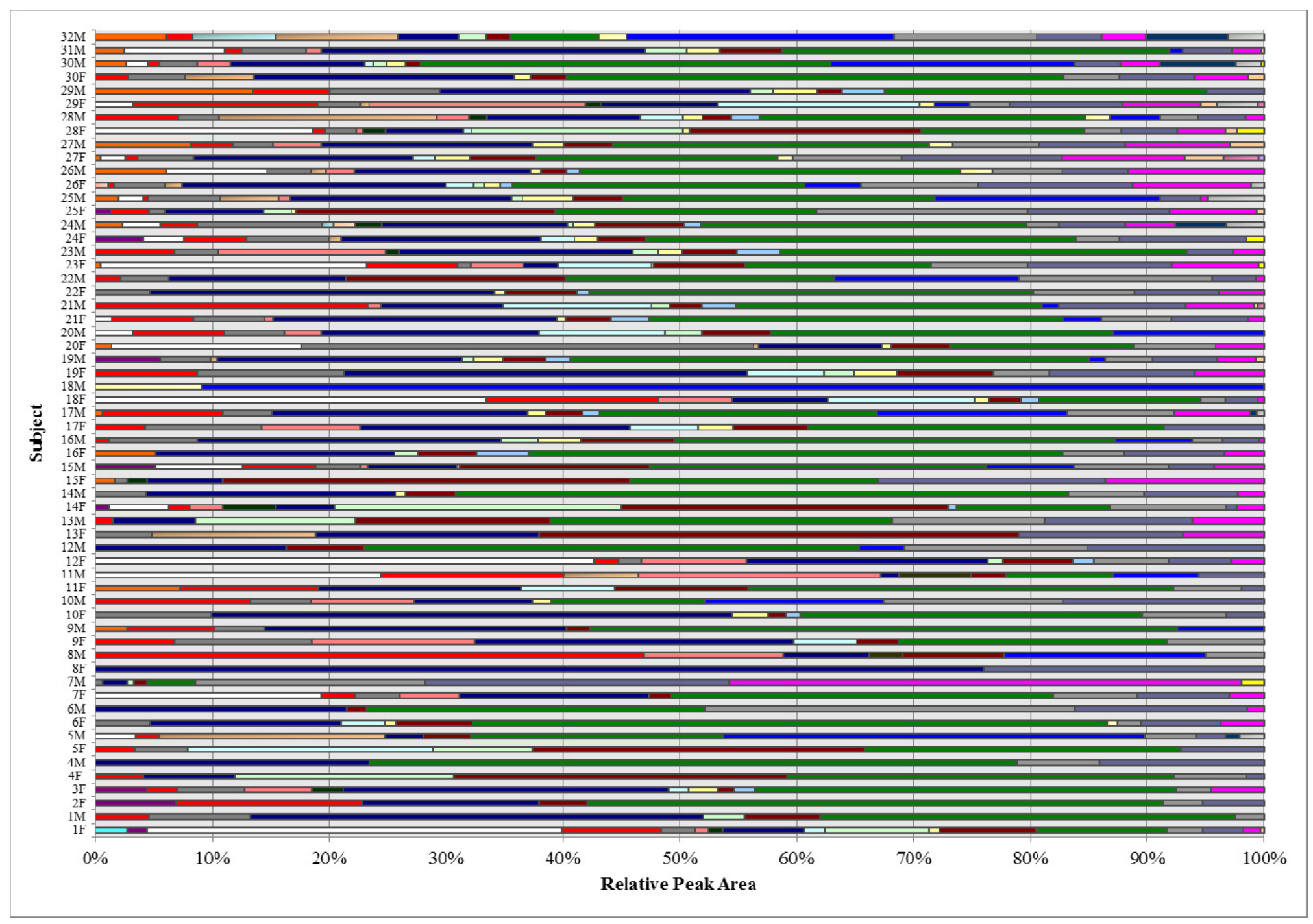

Figure 30-Profile of human scent VOCs from the hair samples of 60 individuals [30 males (M) and 30 females (F)] 


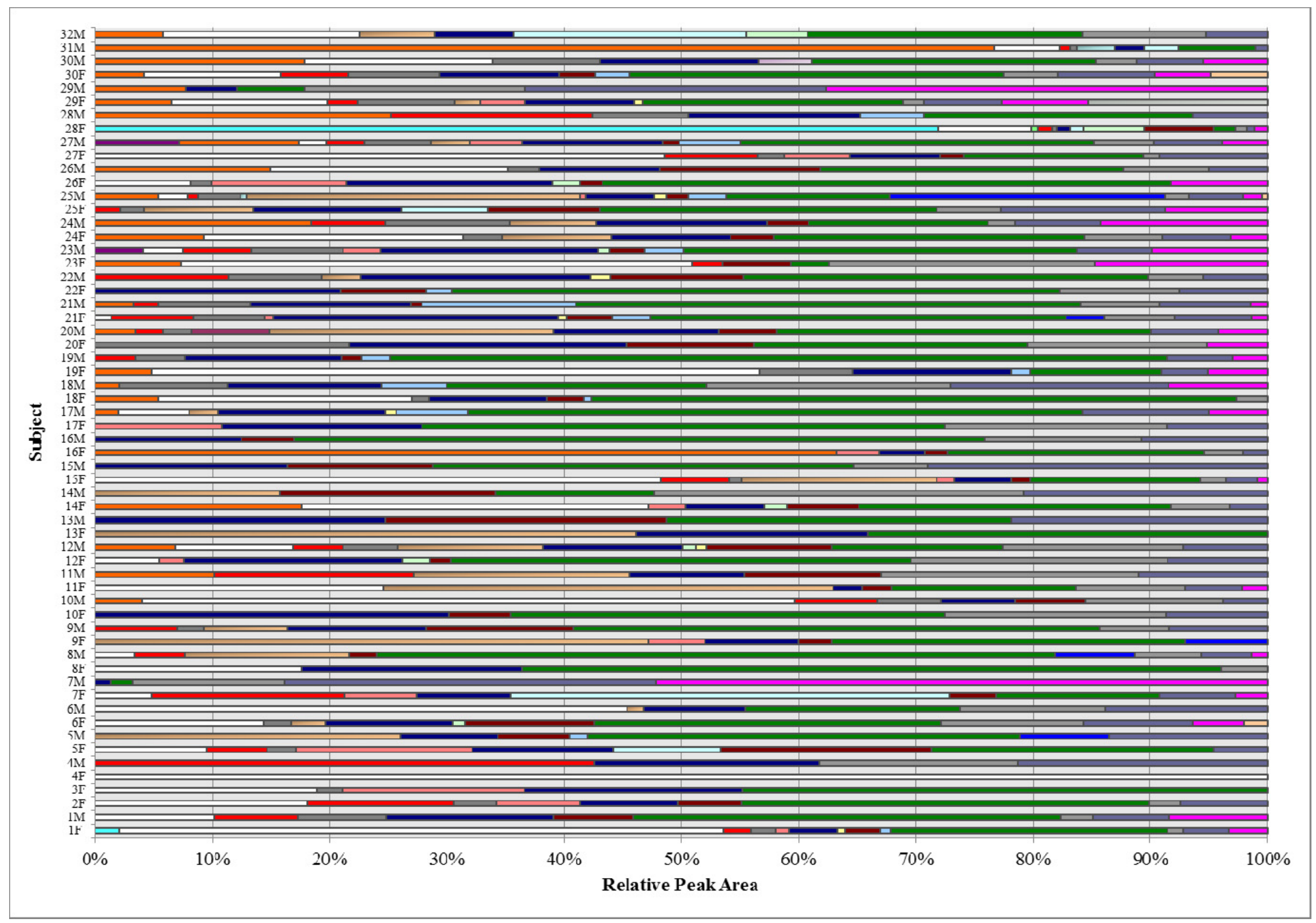

Figure 31-Profile of human scent VOCs from the fingernail samples of 60 individuals [30 males (M) and 30 females (F)] 


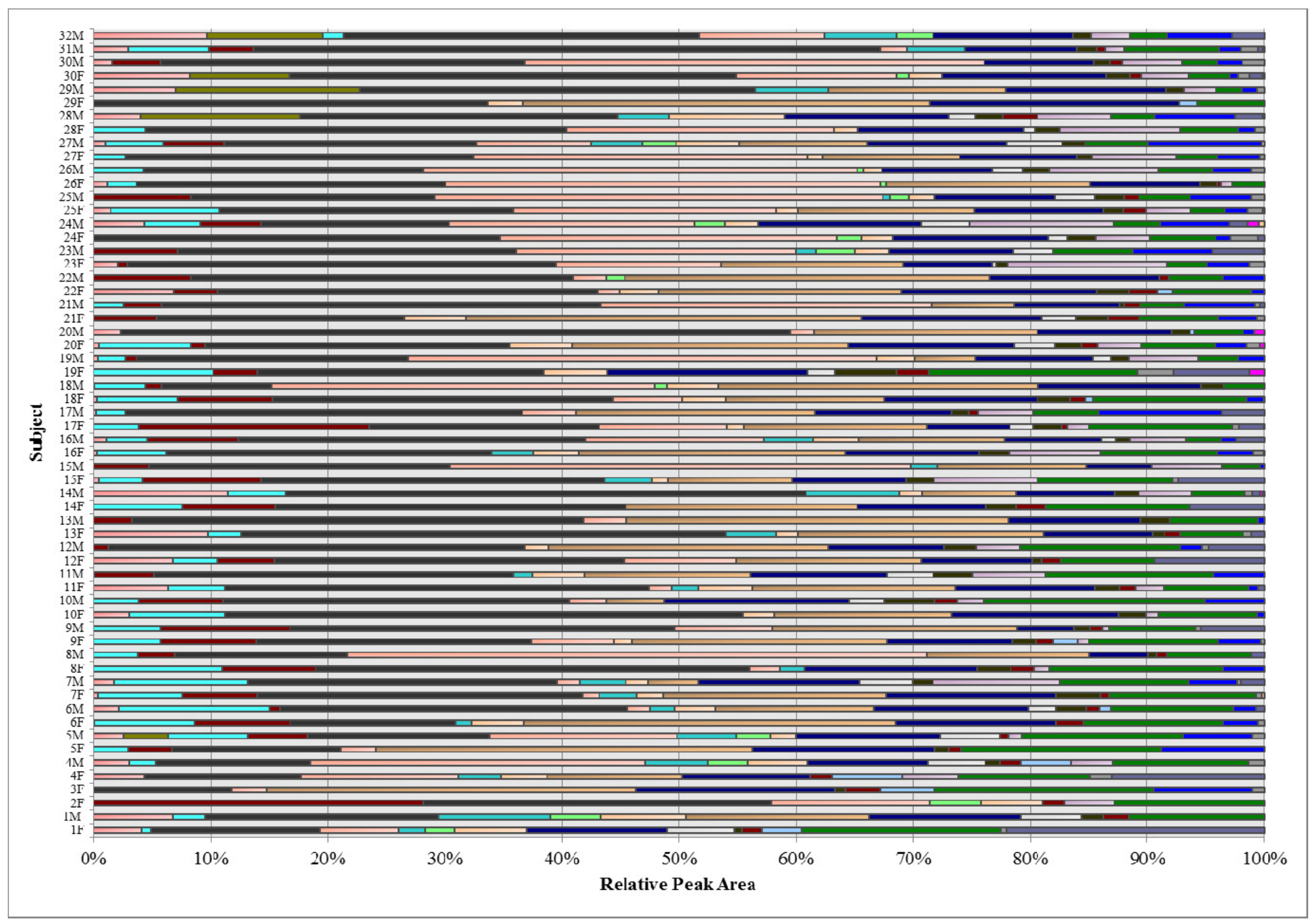

Figure 32-Profile of human scent VOCs from the saliva samples of 60 individuals [30 males (M) and 30 females (F)] 
3.3.2.3. Contributions from male and female subjects to the types of VOCs detected from biological specimens

Assessments were made on the VOCs extracted from biological specimens from male subjects and female subjects. Histograms (seen in Figure 33-Figure 36) display the number of samples from which human scent VOCs were detected, for each specimen type, according to the gender of the subject. Additionally, the frequency of occurrence of VOCs from samples collected from male and female subjects were compared. All replicate samples from each subject (30 males and 30 females) were considered. The frequency of occurrence is given as a percentage of the total samples for each gender per specimen type (Table 10).

For hand odor, twenty-six of the thirty-five detected compounds had a difference in frequency of occurrence of less than $10 \%$, which demonstrates that the occurrence of these compounds in both male and female subjects was similar. For example, undecane was present in $66.7 \%$ of male samples and $58.9 \%$ of female samples which provided a difference in frequency of $7.8 \%$ between the two genders. However, the compounds that differed in frequency by $10 \%$ or greater, in one gender over the other, were further evaluated in an effort to deduce which compounds can be indicative of gender. 
Table 10-Human scent compounds detected from biological samples and the frequency of occurrence from male (M) and female (F) subjects.

\begin{tabular}{|c|c|c|c|c|c|c|c|c|}
\hline \multirow[t]{2}{*}{ Compound Name } & \multicolumn{2}{|c|}{ Hand Odor } & \multicolumn{2}{|c|}{ Hair } & \multicolumn{2}{|c|}{ Fingernails } & \multicolumn{2}{|c|}{ Saliva } \\
\hline & $\mathbf{M}$ & $\mathbf{F}$ & $\mathbf{M}$ & $\mathbf{F}$ & $\mathbf{M}$ & $\mathbf{F}$ & $\mathbf{M}$ & $\mathbf{F}$ \\
\hline 3,7-dimethyl-1,6-Octadien-3-ol & $12.2 \%$ & $3.3 \%$ & $62.1 \%$ & $62.2 \%$ & $45.6 \%$ & $30.3 \%$ & & \\
\hline 2-ethyl-1-Hexanol & $6.7 \%$ & $17.8 \%$ & $18.4 \%$ & $6.7 \%$ & $37.8 \%$ & $19.1 \%$ & & \\
\hline 1-Pentadecene & $1.1 \%$ & & & & & & & \\
\hline$(\mathrm{E}, \mathrm{E})-2,4-$ Nonadienal & & & & & & & $33.3 \%$ & $11.1 \%$ \\
\hline 2-Decanone & $17.8 \%$ & $8.9 \%$ & & & & & & \\
\hline 2-Furanmethanol & $14.4 \%$ & $3.3 \%$ & & & & & & \\
\hline (E)-2-Nonenal & $36.7 \%$ & $27.8 \%$ & $2.3 \%$ & & & & $31.1 \%$ & $36.7 \%$ \\
\hline (E)-2-Octenal & & & & & & & $28.9 \%$ & $13.3 \%$ \\
\hline 6,10-dimethyl-5,9-Undecadien-2-one & $87.8 \%$ & $88.9 \%$ & $88.5 \%$ & $73.3 \%$ & $84.4 \%$ & $88.8 \%$ & $100.0 \%$ & $98.9 \%$ \\
\hline 6-methyl-5-Hepten-2-one & $4.4 \%$ & $15.6 \%$ & $2.3 \%$ & $8.9 \%$ & $2.2 \%$ & & & \\
\hline (R)-3,7-dimethyl-6-Octen-1-ol & & & $10.3 \%$ & $32.2 \%$ & $3.3 \%$ & $9.0 \%$ & & \\
\hline Acetic acid, phenyl methyl ester & $2.2 \%$ & $6.7 \%$ & $37.9 \%$ & $36.7 \%$ & $7.8 \%$ & $29.2 \%$ & & \\
\hline Acetophenone & $11.1 \%$ & $6.7 \%$ & & & & $3.4 \%$ & $22.2 \%$ & $8.9 \%$ \\
\hline Benzaldehyde & $3.3 \%$ & $5.6 \%$ & & $3.3 \%$ & & $4.5 \%$ & $32.2 \%$ & $40.0 \%$ \\
\hline Benzyl Alcohol & $23.3 \%$ & $22.2 \%$ & $26.4 \%$ & $35.6 \%$ & $31.1 \%$ & $57.3 \%$ & & \\
\hline Caryophyllene & $2.2 \%$ & & & & $1.1 \%$ & & $40.0 \%$ & $38.9 \%$ \\
\hline Decanal & $100.0 \%$ & $100.0 \%$ & $96.6 \%$ & $94.4 \%$ & $76.7 \%$ & $85.4 \%$ & $94.4 \%$ & $96.7 \%$ \\
\hline Docosane & & & & $1.1 \%$ & & & & \\
\hline Dodecanal & $55.6 \%$ & $55.6 \%$ & $16.1 \%$ & $12.2 \%$ & $22.2 \%$ & $7.9 \%$ & $4.4 \%$ & $13.3 \%$ \\
\hline Dodecane & $30.0 \%$ & $18.9 \%$ & $5.7 \%$ & $16.7 \%$ & & & & \\
\hline Dodecanoic acid & $25.6 \%$ & $3.3 \%$ & $47.1 \%$ & $3.3 \%$ & $7.8 \%$ & $2.2 \%$ & $61.1 \%$ & $38.9 \%$ \\
\hline Eicosane & & & $2.3 \%$ & $3.3 \%$ & & & & \\
\hline 2-pentyl-Furan & & & & & & & $94.4 \%$ & $88.9 \%$ \\
\hline Furfural & & & & & & & $7.8 \%$ & $3.3 \%$ \\
\hline Heneicosane & & & $1.1 \%$ & $3.3 \%$ & & & & \\
\hline
\end{tabular}




\begin{tabular}{|c|c|c|c|c|c|c|c|c|}
\hline Heptadecane & $92.2 \%$ & $91.1 \%$ & $73.6 \%$ & $77.8 \%$ & $87.8 \%$ & $56.2 \%$ & $22.2 \%$ & $24.4 \%$ \\
\hline Heptanoic acid & & & & $1.1 \%$ & & & $50.0 \%$ & $33.3 \%$ \\
\hline Hexadecane & $98.9 \%$ & $98.9 \%$ & $54.0 \%$ & $72.2 \%$ & $57.8 \%$ & $55.1 \%$ & $22.2 \%$ & $35.6 \%$ \\
\hline Hexadecanoic acid, methyl ester & $4.4 \%$ & $2.2 \%$ & $5.7 \%$ & $10.0 \%$ & $2.2 \%$ & $5.6 \%$ & $8.9 \%$ & $4.4 \%$ \\
\hline Hexanal & & & & & & & $35.6 \%$ & $40.0 \%$ \\
\hline 2-ethyl-Hexanoicacid & $21.1 \%$ & $28.9 \%$ & $2.3 \%$ & & $2.2 \%$ & & & \\
\hline 1-methyl-Naphthalene & $1.1 \%$ & $4.4 \%$ & $4.6 \%$ & & & & $71.1 \%$ & $77.8 \%$ \\
\hline n-Hexadecanoic acid & $1.1 \%$ & & $10.3 \%$ & $4.4 \%$ & & $1.1 \%$ & & \\
\hline Nonanal & $100.0 \%$ & $100.0 \%$ & $60.9 \%$ & $66.7 \%$ & $41.1 \%$ & $36.0 \%$ & & \\
\hline Nonanoic acid, methyl ester & $12.2 \%$ & $1.1 \%$ & & & & & & \\
\hline Nonanol & $34.4 \%$ & $23.3 \%$ & & & $2.2 \%$ & & & \\
\hline Octadecane & $54.4 \%$ & $67.8 \%$ & $49.4 \%$ & $58.9 \%$ & $34.4 \%$ & $37.1 \%$ & $6.7 \%$ & $7.8 \%$ \\
\hline Octanoic Acid & & & $14.9 \%$ & $11.1 \%$ & $32.2 \%$ & $18.0 \%$ & $45.6 \%$ & $64.4 \%$ \\
\hline Octanoic acid, methyl ester & $6.7 \%$ & $18.9 \%$ & & & & & & \\
\hline Pentacosane & $1.1 \%$ & & & & & & & \\
\hline Pentadecane & $2.2 \%$ & $3.3 \%$ & $5.7 \%$ & $2.2 \%$ & & & & \\
\hline Pentadecanoic acid & & & $8.0 \%$ & & & & & \\
\hline Phenol & $2.2 \%$ & $2.2 \%$ & & & & & $38.9 \%$ & $38.9 \%$ \\
\hline Tetradecane & $97.8 \%$ & $98.9 \%$ & $78.2 \%$ & $83.3 \%$ & $50.0 \%$ & $60.7 \%$ & $27.8 \%$ & $57.8 \%$ \\
\hline Tridecane & $70.0 \%$ & $73.3 \%$ & $31.0 \%$ & $21.1 \%$ & $3.3 \%$ & $7.9 \%$ & & \\
\hline Undecanal & $87.8 \%$ & $85.6 \%$ & $36.8 \%$ & $38.9 \%$ & $5.6 \%$ & $3.4 \%$ & & \\
\hline Undecane & $66.7 \%$ & $58.9 \%$ & & & & & & \\
\hline
\end{tabular}


The greatest difference was seen with dodecanoic acid, in hand odor samples, which was detected in $25.6 \%$ of male samples and $3.3 \%$ of female samples, providing a difference of occurrence of $22.2 \%$. Four additional compounds were present more in male samples than female samples which included 2-furanmethanol, nonanol, dodecane and nonanoic acid, methyl ester. Four compounds were present more frequently in female samples, than male samples, which included 6-methyl-5-hepten-2-one, 2-ethyl-1-hexanol, octanoic acid, methyl ester and hexadecanoic acid, methyl ester.

There were twenty-four compounds detected from hair samples that had a difference in frequency of occurrence of less than $10 \%$ between male and female subjects. As seen previously with hand odor, dodecanoic acid had the greatest difference in frequency with detection in $47.1 \%$ of male samples and $3.3 \%$ of female samples, providing a difference of occurrence of $43.8 \%$. Three additional compounds were present more in male samples than female samples which included 2-ethyl-1-hexanol, tridecane and (E)-6,10-dimethyl-5,9-undecadien-2-one. Three compounds were present more frequently in female samples than male samples which included dodecane, (R)-3,7dimethyl-6-octen-1-ol and hexadecane. 


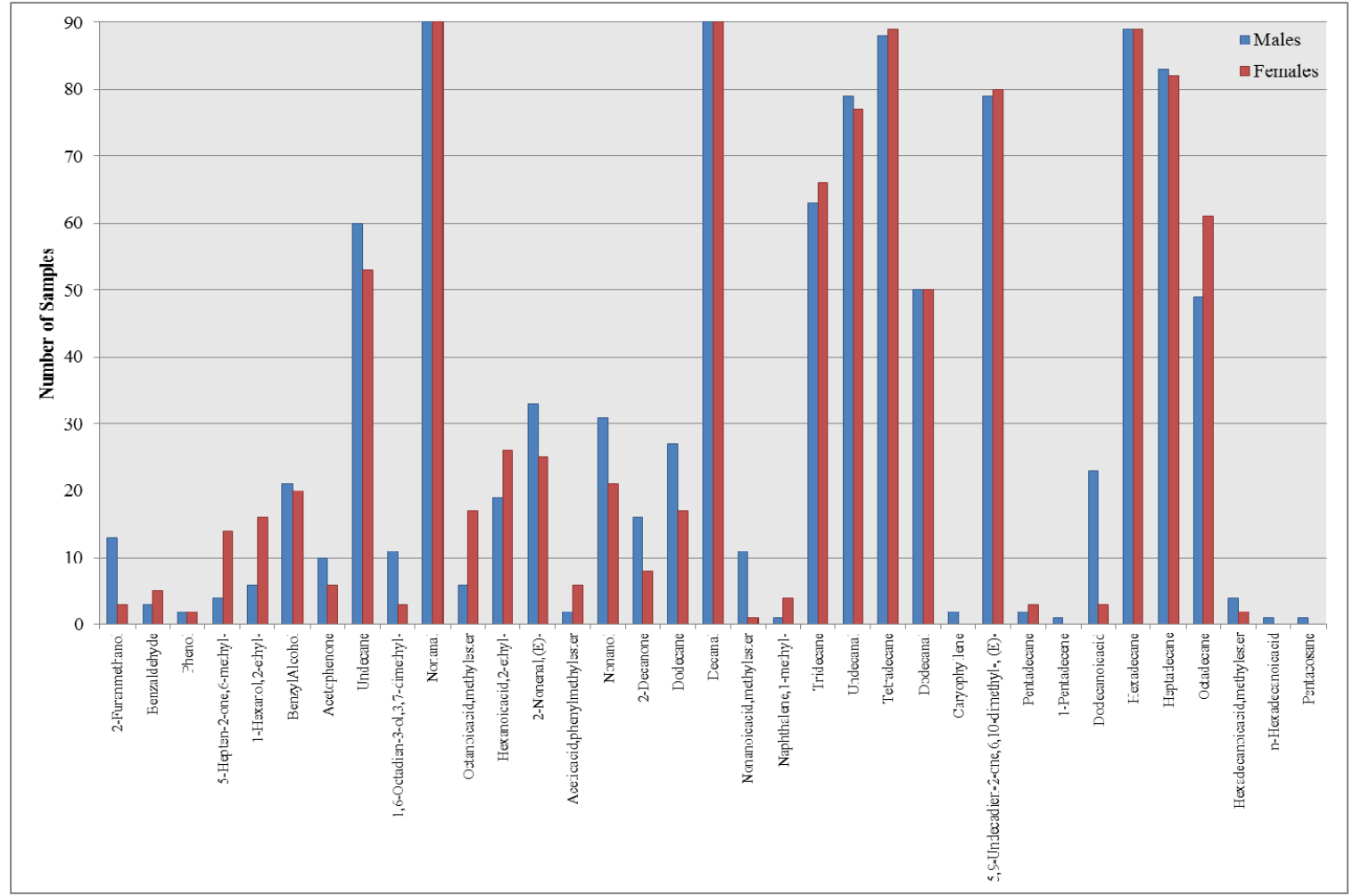

Figure 33-Human scent compounds detected from hand odor samples from male and female subjects.

A total of the thirty-one human scent compounds were detected from fingernails with seventeen of those compounds having a difference in frequency of occurrence of less than $10 \%$ between male and female subjects. The greatest difference in frequency was observed with heptadecane which was detected in $87.8 \%$ of male samples and $56.2 \%$ of female samples, providing a difference of occurrence of $31.6 \%$. Four additional compounds were present more in male samples than female samples which included 2ethyl-1-hexanol, 3,7-dimethyl-1,6-octadien-3-ol, octanoic acid and dodecanal. Three compounds were present more frequently in female samples than male samples which included benzyl alcohol, acetic acid, phenyl methyl ester and tetradecane. 


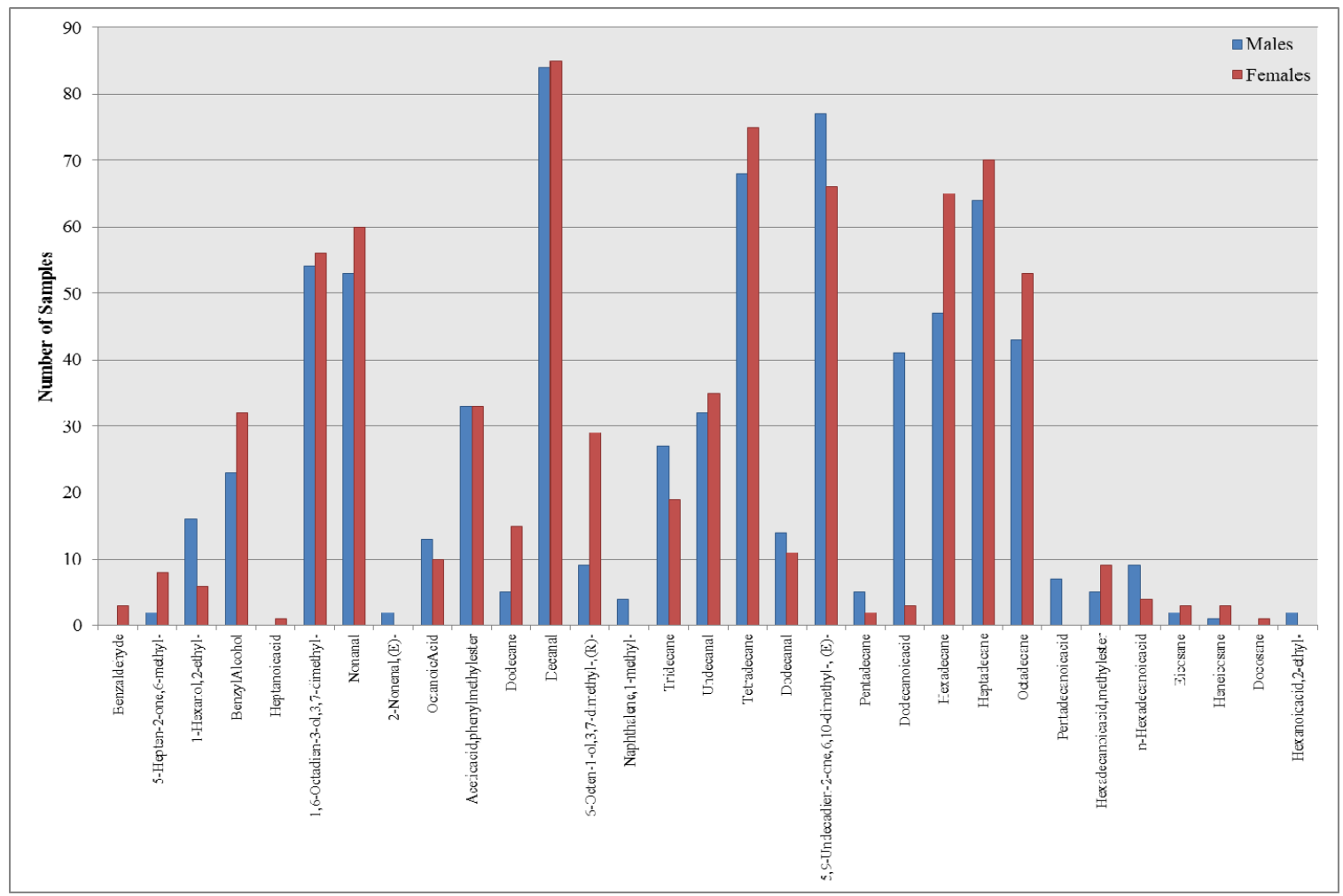

Figure 34-Human scent compounds detected from hair samples from male and female subjects.

For saliva, fourteen compounds had a difference in frequency of occurrence of less than $10 \%$ between male and female subjects. The greatest difference was seen with tetradecane which was detected in $57.8 \%$ of female samples and $27.8 \%$ of male samples, providing a difference in frequency of $30.0 \%$. Two additional compounds were present more in female samples than male samples which included octanoic acid and hexadecane. Five compounds were present more frequently in male samples than female samples which included heptanoic acid, (E)-2-octenal, acetophenone, (E,E)-2,4-nonadienal and dodecanoic acid.

From the VOCs that were characterized as having a large difference in frequency between the genders, only three of those compounds (hexadecane, dodecanoic acid and 
tetradecane) were consistent across the four biological specimen types. Further scrutiny into the occurrence of hexadecane revealed that though it is present at a higher frequency in the hair and saliva samples of female subjects, it has a slightly higher occurrence in the fingernails of males (difference of 2.7\%) and equal occurrence for both genders in hand odor. This demonstrates that hexadecane is not preferentially seen in the samples of female subjects. Contrary to hexadecane, dodecanoic acid was detected more frequently from male subjects and tetradecane was more prevalent from female subjects, across all specimen types.

The presence of dodecanoic acid could be characterized as having a greater probability of originating from a male subject while the same could be said for tetradecane, but for female subjects. These VOCs have the potential of serving as biomarkers to identify the gender of an individual; however, the classification of VOCs as biomarkers is dependent on the specimen type used. For instance, dodecanoic acid has a significantly higher occurrence, in the samples of male subjects, for hand odor $(25.6 \%$ from males and $3.3 \%$ from females) and hair $(47.1 \%$ from males and $3.3 \%$ from females). In contrast, the occurrence of dodecanoic acid in fingernails is low for both genders $(7.8 \%$ from males and $2.2 \%$ from females) and in saliva the frequency of occurrence is high for both male and female subjects $(61.1 \%$ from males and $38.9 \%$ from females). Therefore, if dodecanoic acid was detected instrumentally from a hand odor or hair sample the analyst could conclude with a greater degree of certainty that the sample was contributed by a male then when detected from fingernails or saliva samples. 


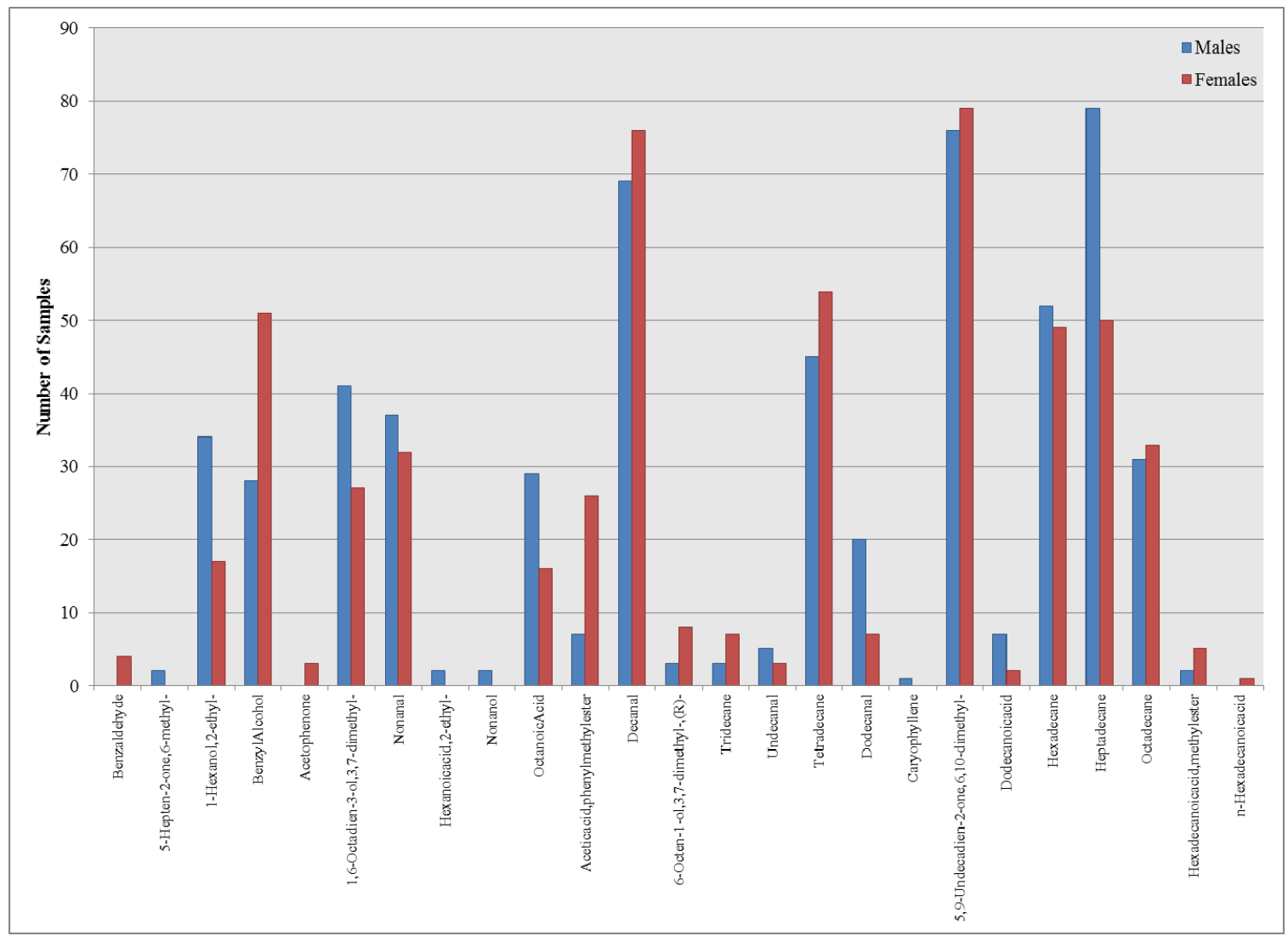

Figure 35-Human scent compounds detected from fingernail samples from male and female subjects. 


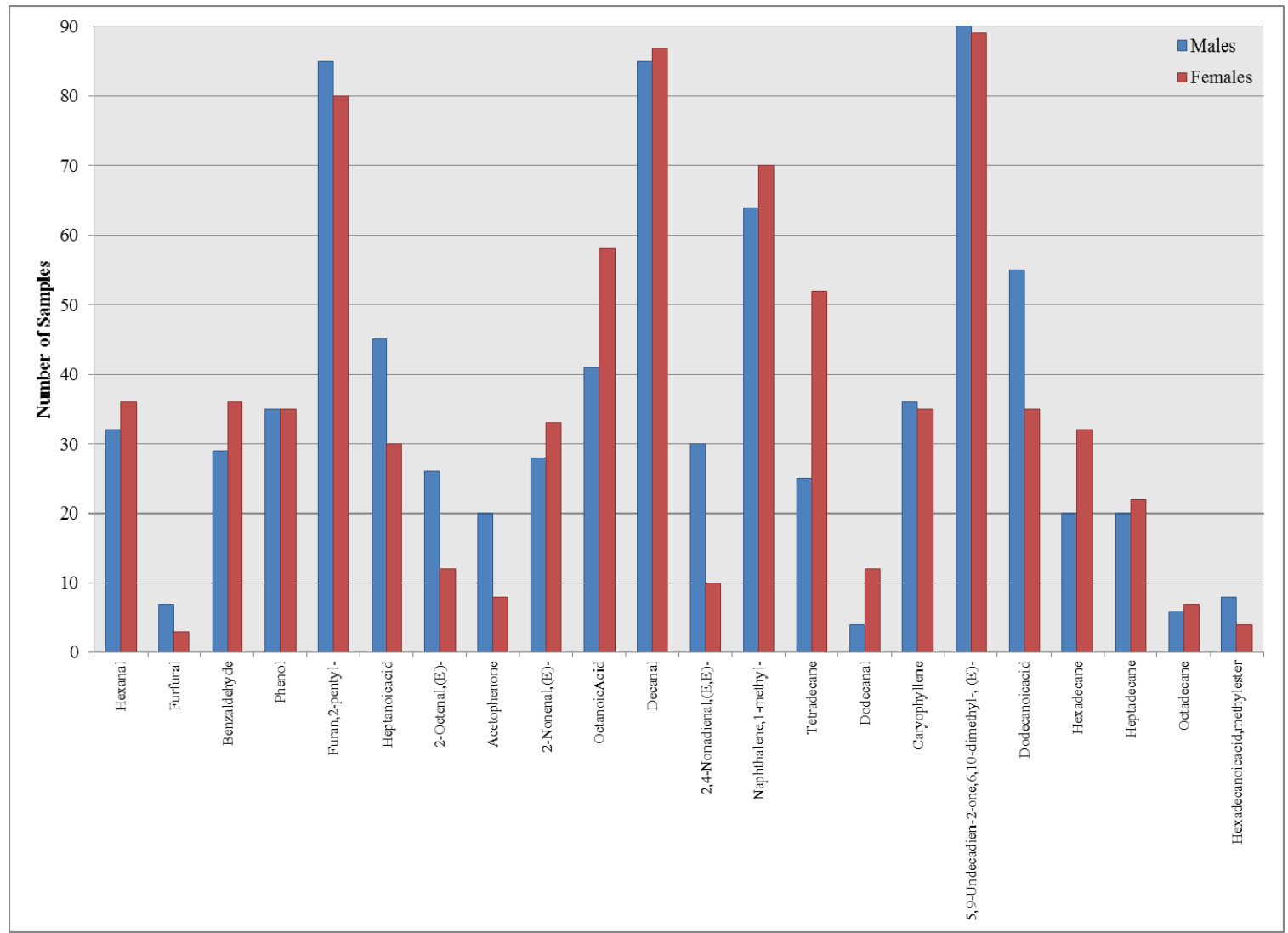

Figure 36-Human scent compounds detected from saliva samples from male and female subjects.

3.3.2.4. Statistical evaluation of VOCs detected from different biological specimens from 60 individuals

The human scent VOCs from each biological specimen were evaluated statistically to determine whether these profiles were different for each of the sixty individuals sampled thereby assessing the discrimination capabilities for each biological specimen type. The replicate profiles of the VOCs for each subject, per a specimen type, were averaged to produce a single profile of volatile organic compounds. The averaged sample from each individual was correlated, in a pair wise fashion, to all of the collected samples using Spearman Rank correlations. The association between two samples was represented by a 
correlation coefficient that ranged in value from -1 to 1 , representing either a negative correlation or a positive correlation, respectively. The comparisons of an averaged sample from sixty individuals provided a total of 1,770 possible pairs between the samples. For this work, the samples that produced a correlation coefficient of 0.7 and greater were assessed. A color map (heat map) was used to represent the samples that correlated at $>0.9,>0.8$ and $>0.7$ which were denoted by a yellow square, blue square and green square, respectively. All of the samples that correlated at $<0.7$ were denoted by a gray square.

The color maps revealed that hand odor and saliva have a large number of indistinguishable pairs at the 0.7 coefficient threshold and above. There are far fewer indistinguishable pairs for the hair and fingernails samples. A trend seen with all of the biological specimens is that the lowest occurrence of indistinguishable pairs (matching errors) occurs at the 0.9 correlation threshold and increases as the threshold is lowered to 0.8 and then 0.7 . For two samples to be considered a match a high degree of similarity must be observed. If Spearman rank were to be used for matching purposes then a high correlation coefficient must be achieved, such as 1 or 0.9 . Fortunately, the number of matching errors is the lowest at the 0.9 threshold.

Table 11-Indistinguishable pairs for each biological specimen at the 0.9 Spearman Rank correlation coefficient threshold (1770 possible pairs)

\begin{tabular}{|l|c|c|c|}
\hline \multicolumn{1}{|c|}{ Specimen } & $\begin{array}{c}\text { Indistinguishable } \\
\text { Pairs }\end{array}$ & $\begin{array}{c}\text { Percent } \\
\text { Indistinguishable }\end{array}$ & $\begin{array}{c}\text { Percent } \\
\text { Distinguishable }\end{array}$ \\
\hline Hand odor & 21 & $1.2 \%$ & $98.8 \%$ \\
\hline Hair & 4 & $0.2 \%$ & $99.8 \%$ \\
\hline Fingernails & 11 & $0.6 \%$ & $99.4 \%$ \\
\hline Saliva & 9 & $0.5 \%$ & $99.5 \%$ \\
\hline
\end{tabular}


Conversely, Spearman Rank correlations were used to determine the percent of distinguished samples for each biological specimen type. By subtracting the number of indistinguishable pairs from the total number of possible pairs (1770), the number of distinguishable pairs was determined. For this portion, only the samples that produced a correlation coefficient of 0.9 or greater were considered indistinguishable. Hand odor produced the greatest number of indistinguishable pairs $(n=21)$, followed by fingernails with eleven, saliva with nine and, lastly, hair with four indistinguishable pairs. Utilizing to the number of indistinguishable pairs for each biological specimen, the number of distinguishable pairs can be determined.

The percentage of distinguishable samples for the four biological specimen types was greater than $98.8 \%$, reaching as high as $99.8 \%$ for hair samples (seen in Table 11). These values demonstrate that though there are qualitative similarities within a specimen type there are significant quantitative differences that allow for a high percentage of discrimination between individuals. These results imply that the VOCs released from biological specimens are specific to the individual they originated from and can be used for differentiation purposes with a low occurrence of matching errors (at a 0.9 correlation coefficient threshold). However, the usefulness of the profiles of the VOCs generated from each of the specimens could diminish if the occurrence of these VOCs is not consistent over time. As a result, the VOCs from biological specimens were evaluated over time (six months) in an effort to assess this condition. 


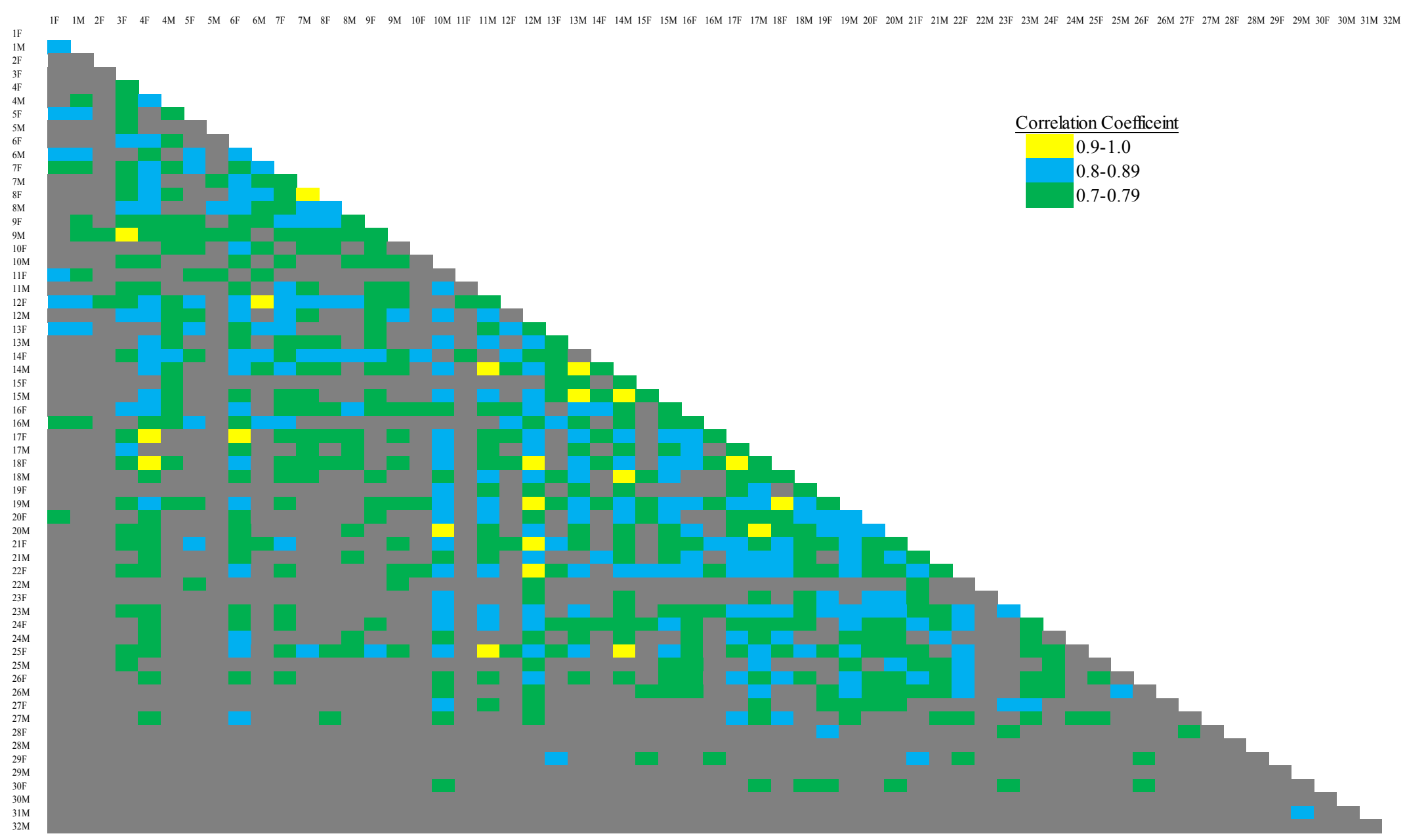

Figure 37-Color map of Spearman Rank correlations for hand odor samples collected from 60 individuals 


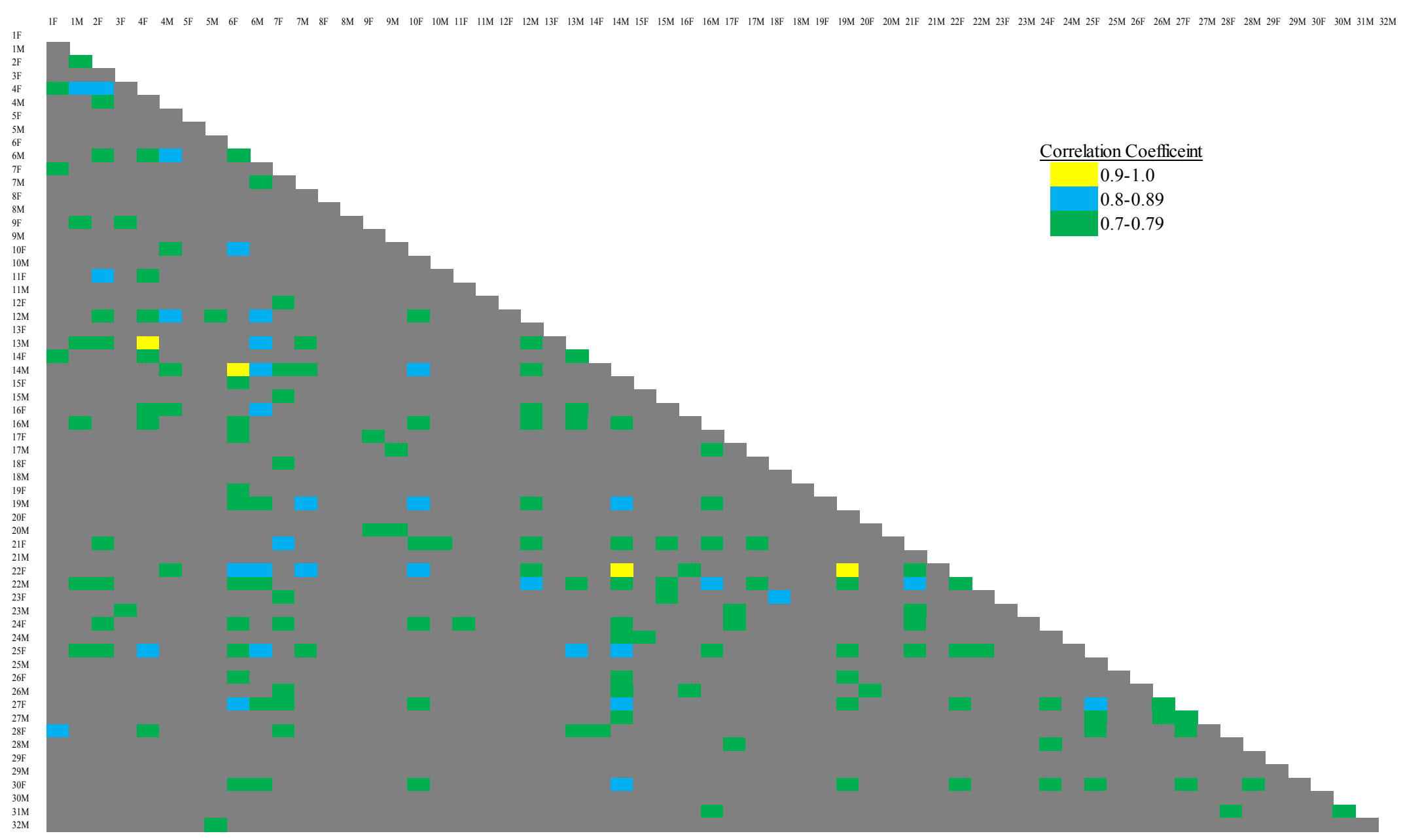

Figure 38-Color map of Spearman Rank correlations for hair samples collected from 60 individuals 


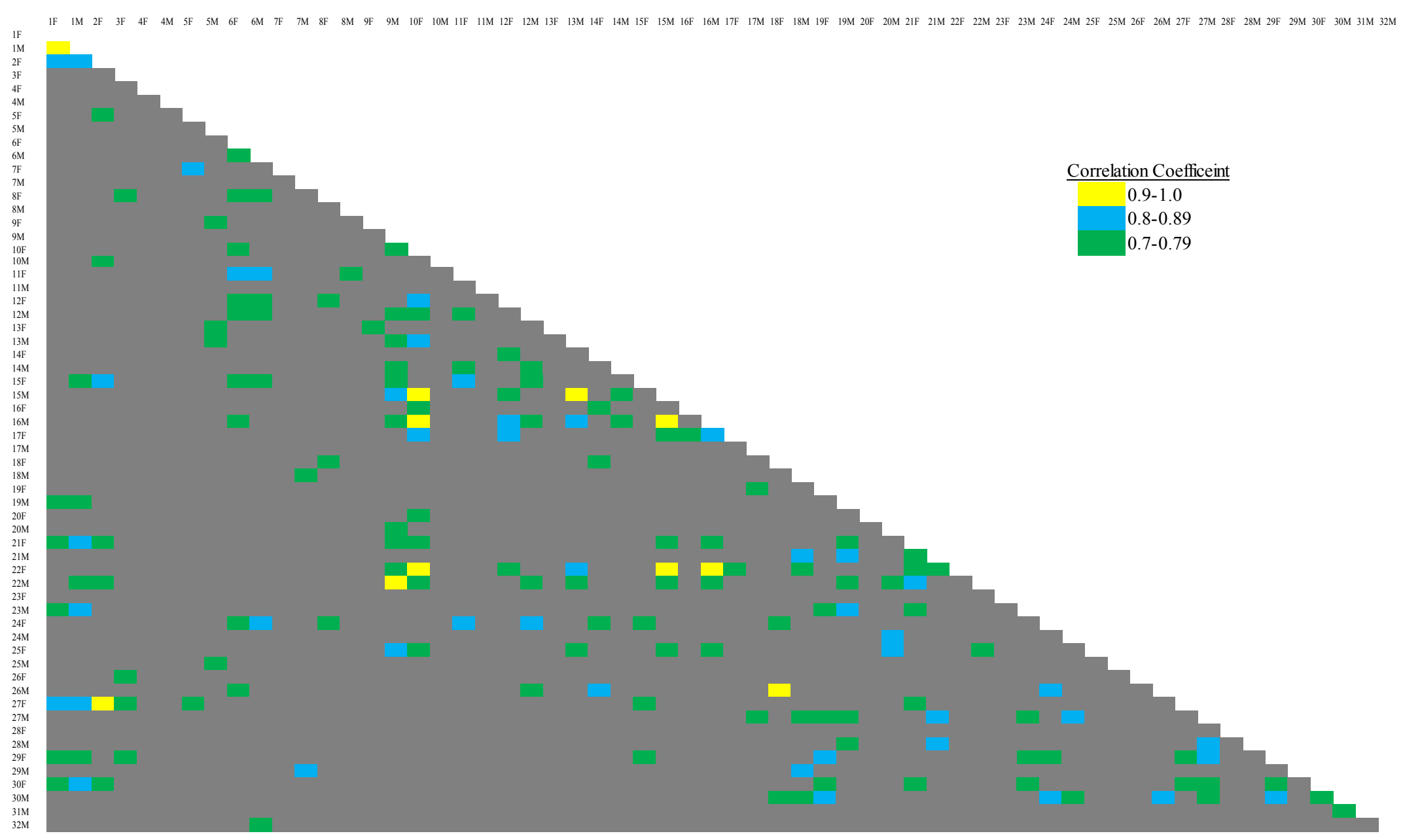

Figure 39-Color map of Spearman Rank correlations for fingernail samples collected from 60 individuals 


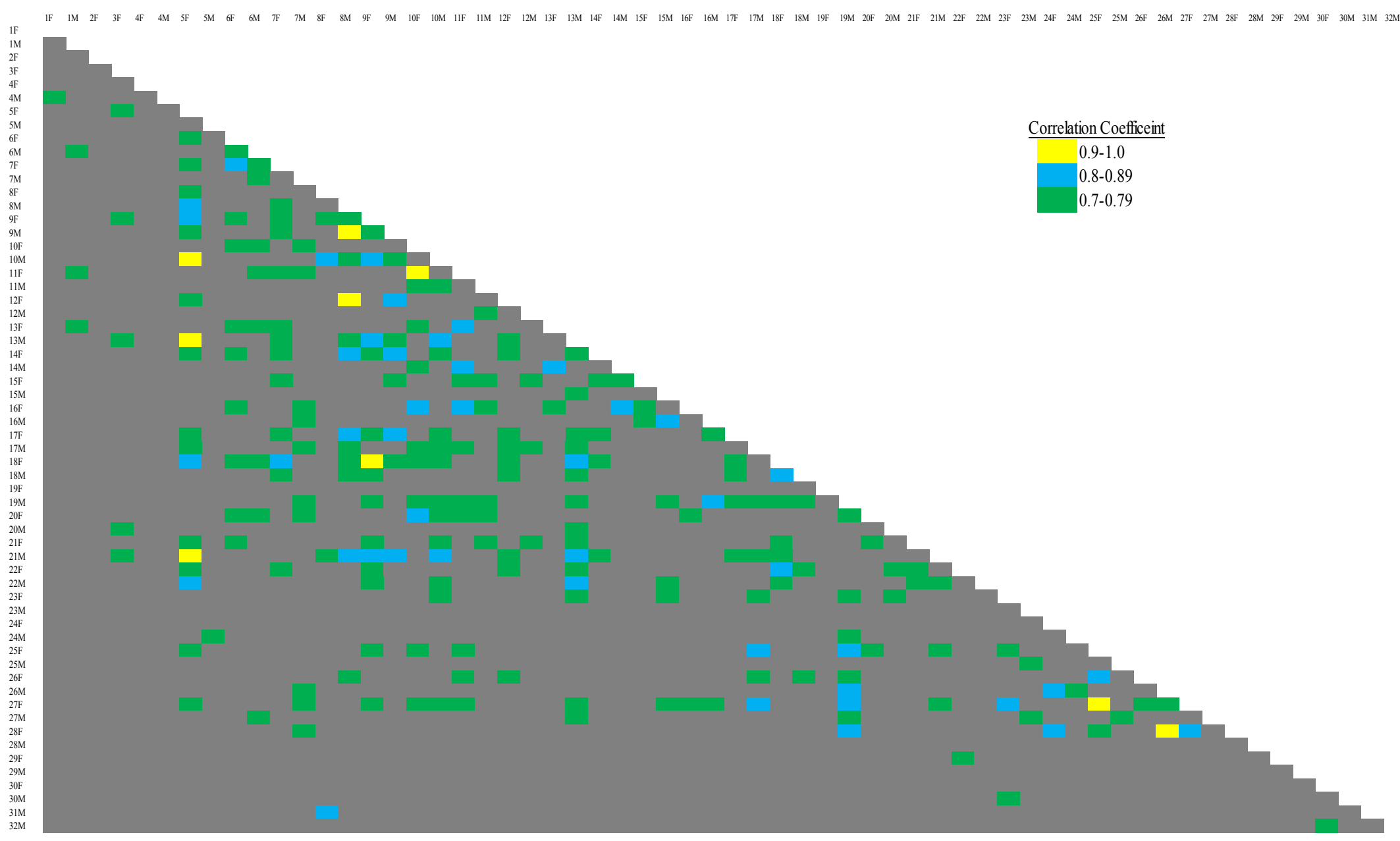

Figure 40-Color map of Spearman Rank correlations for saliva samples collected from 60 individuals 


\subsubsection{Collection of multiple biological specimens over time}

The persistence of VOCs from biological specimens, collected from six individuals, was evaluated. Triplicate samples of hand odor, hair, fingernails and saliva, were collected once a month for six months, consecutively, from each subject. The VOCs released by these biological specimens were extracted using HS-SPME and were separated and identified using GC-MS, according to the same procedures used for the 60 person population. The three profiles of the VOCs obtained for each month, per specimen type, were averaged to produce a single profile of VOCs to be used in monthly comparisons. Following the sampling period, the profiles were reviewed and the VOCs that were detected in five or more months were classified as common human scent VOCs and were used for data analysis. The common human scent VOCs for three female and three male subjects can be seen in Table 12-Table 17. 
Table 12-Common human scent VOCs from Subject 1F following a six month sampling period

\begin{tabular}{|c|c|c|c|c|c|c|c|c|c|c|c|c|c|c|c|c|c|c|c|c|c|c|c|c|c|c|c|c|c|c|}
\hline \multirow[t]{2}{*}{ Compound Name } & \multicolumn{6}{|c|}{ Hand Odor } & \multicolumn{6}{|c|}{ Hair } & \multicolumn{6}{|c|}{ Left Nails } & \multicolumn{6}{|c|}{ Right Nails } & \multicolumn{6}{|c|}{ Saliva } \\
\hline & 1 & 2 & 3 & 4 & 5 & 6 & 1 & 2 & 3 & 4 & 5 & 6 & 1 & 2 & 3 & 4 & 5 & 6 & 1 & 2 & 3 & 4 & 5 & 6 & 1 & 2 & 3 & 4 & 5 & 6 \\
\hline Hexanal & & & & & & & & & & & & & & & & & & & & & & & & & $\mathrm{X}$ & $\mathrm{X}$ & $\mathrm{X}$ & & $\mathrm{X}$ & $\mathrm{X}$ \\
\hline Hexanoicacid & & & & & & & & & & & & & & & & & & & & & & & & & $\mathrm{X}$ & $\mathrm{X}$ & $\mathrm{X}$ & $\mathrm{X}$ & $\mathrm{X}$ & $\mathrm{X}$ \\
\hline Furan,2-pentyl- & & & & & & & & & & & & & & & & & & & & & & & & & $\mathrm{X}$ & $\mathrm{X}$ & $\mathrm{X}$ & $\mathrm{X}$ & $\mathrm{X}$ & $\mathrm{X}$ \\
\hline Heptanoicacid & & & & & & & & & & & & & & & & & & & & & & & & & $\mathrm{X}$ & $\mathrm{X}$ & $\mathrm{X}$ & $\mathrm{X}$ & $\mathrm{X}$ & $\mathrm{X}$ \\
\hline Nonanal & $\mathrm{X}$ & $\mathrm{X}$ & $\mathrm{X}$ & $\mathrm{X}$ & $\mathrm{X}$ & $\mathrm{X}$ & $\mathrm{X}$ & $\mathrm{X}$ & $\mathrm{X}$ & $\mathrm{X}$ & $\mathrm{X}$ & & $\mathrm{X}$ & $\mathrm{X}$ & $\mathrm{X}$ & $\mathrm{X}$ & $\mathrm{X}$ & $\mathrm{X}$ & $\mathrm{X}$ & $\mathrm{X}$ & $\mathrm{X}$ & $\mathrm{X}$ & $\mathrm{X}$ & & & & & & & \\
\hline Decanal & $\mathrm{X}$ & $\mathrm{X}$ & $X$ & $\mathrm{X}$ & $\mathrm{X}$ & $\mathrm{X}$ & $\mathrm{X}$ & $X$ & $\mathrm{X}$ & $\mathrm{X}$ & $\mathrm{X}$ & & $\mathrm{X}$ & $\mathrm{X}$ & $\mathrm{X}$ & $X$ & $\mathrm{X}$ & $\mathrm{X}$ & $\mathrm{X}$ & $\mathrm{X}$ & $\mathrm{X}$ & $\mathrm{X}$ & $\mathrm{X}$ & $\mathrm{X}$ & $\mathrm{X}$ & $\mathrm{X}$ & $\mathrm{X}$ & $\mathrm{X}$ & $\mathrm{X}$ & $\mathrm{X}$ \\
\hline Nonanoicacid & & & & & & & & & & & & & & & & & & & & & & & & & $\mathrm{X}$ & $\mathrm{X}$ & $\mathrm{X}$ & $\mathrm{X}$ & $\mathrm{X}$ & \\
\hline Undecanal & $\mathrm{X}$ & $\mathrm{X}$ & $\mathrm{X}$ & $\mathrm{X}$ & $\mathrm{X}$ & $\mathrm{X}$ & & & & & & & & & & & & & & & & & & & & & & & & \\
\hline Tetradecane & $\mathrm{X}$ & $\mathrm{X}$ & $\mathrm{X}$ & $\mathrm{X}$ & $\mathrm{X}$ & $\mathrm{X}$ & $\mathrm{X}$ & $\mathrm{X}$ & $\mathrm{X}$ & $\mathrm{X}$ & $\mathrm{X}$ & & & & & & & & $\mathrm{X}$ & $\mathrm{X}$ & $\mathrm{X}$ & $\mathrm{X}$ & & $\mathrm{X}$ & & & & & & \\
\hline Dodecanal & $\mathrm{X}$ & $\mathrm{X}$ & $\mathrm{X}$ & $\mathrm{X}$ & $\mathrm{X}$ & $\mathrm{X}$ & & & & & & & & & & & & & & & & & & & & & & & & \\
\hline 5,9-Undecadien-2-one,6,10-dimethyl-, (Z)- & & & & & & & & & & & & & & & & & & & & & & & & & $\mathrm{X}$ & $\mathrm{X}$ & $\mathrm{X}$ & $\mathrm{X}$ & $\mathrm{X}$ & $\mathrm{X}$ \\
\hline 5,9-Undecadien-2-one,6,10-dimethyl- (E) & $\mathrm{X}$ & $\mathrm{X}$ & $\mathrm{X}$ & $\mathrm{X}$ & $\mathrm{X}$ & $\mathrm{X}$ & $\mathrm{X}$ & $\mathrm{X}$ & $\mathrm{X}$ & $\mathrm{X}$ & $\mathrm{X}$ & $\mathrm{X}$ & $\mathrm{X}$ & $\mathrm{X}$ & $\mathrm{X}$ & $X$ & $\mathrm{X}$ & $\mathrm{X}$ & $X$ & $\mathrm{X}$ & $\mathrm{X}$ & $X$ & $X$ & $\mathrm{X}$ & $\mathrm{X}$ & $\mathrm{X}$ & $\mathrm{X}$ & $X$ & $X$ & $\mathrm{X}$ \\
\hline Hexadecane & $\mathrm{X}$ & $\mathrm{X}$ & $X$ & $\mathrm{X}$ & $\mathrm{X}$ & $\mathrm{X}$ & $X$ & $X$ & $\mathrm{X}$ & $\mathrm{X}$ & $\mathrm{X}$ & & & & & & & & & & & & & & $\mathrm{X}$ & $\mathrm{X}$ & $\mathrm{X}$ & $\mathrm{X}$ & $\mathrm{X}$ & \\
\hline Heptadecane & $X$ & $X$ & $X$ & $X$ & $X$ & $\mathrm{X}$ & $X$ & $\mathrm{X}$ & $X$ & $\mathrm{X}$ & $X$ & & $X$ & & $X$ & $X$ & $X$ & $\mathrm{X}$ & $X$ & $\mathrm{X}$ & $\mathrm{X}$ & $X$ & $\mathrm{X}$ & $\mathrm{X}$ & & & & & & \\
\hline Octadecane & $\mathrm{X}$ & $\mathrm{X}$ & $\mathrm{X}$ & $\mathrm{X}$ & $\mathrm{X}$ & $\mathrm{X}$ & & & & & & & & & & & & & $X$ & $\mathrm{X}$ & $\mathrm{X}$ & $\mathrm{X}$ & & $\mathrm{X}$ & & & & & & \\
\hline
\end{tabular}

Table 13-Common human scent VOCs from Subject 2F following a six month sampling period

\begin{tabular}{|c|c|c|c|c|c|c|c|c|c|c|c|c|c|c|c|c|c|c|c|c|c|c|c|c|}
\hline \multirow[t]{2}{*}{ Compound } & \multicolumn{6}{|c|}{ Hand Odor } & \multicolumn{6}{|c|}{ Hair } & \multicolumn{6}{|c|}{ Left Nails } & \multicolumn{6}{|c|}{ Saliva } \\
\hline & 1 & 2 & 3 & 4 & 5 & 6 & 1 & 2 & 3 & 4 & 5 & 6 & 1 & 2 & 3 & 4 & 5 & 6 & 1 & 2 & 3 & 4 & 5 & 6 \\
\hline 1-Hexanol & & & & & & & & & & & & & & & & & & & $\mathrm{X}$ & $\mathrm{X}$ & $\mathrm{X}$ & $X$ & $\mathrm{X}$ & $\mathrm{X}$ \\
\hline Hexanoicacid & & & & & & & & & & & & & & & & & & & $\mathrm{X}$ & $\mathrm{X}$ & $\mathrm{X}$ & $\mathrm{X}$ & $\mathrm{X}$ & $\mathrm{X}$ \\
\hline 5-Hepten-2-one,6-methyl- & & & & & & & $\mathrm{X}$ & $\mathrm{X}$ & $\mathrm{X}$ & & $\mathrm{X}$ & $\mathrm{X}$ & & & & & & & & & & & & \\
\hline Furan,2-pentyl- & & & & & & & & & & & & & & & & & & & $\mathrm{X}$ & $\mathrm{X}$ & $\mathrm{X}$ & $\mathrm{X}$ & $\mathrm{X}$ & $\mathrm{X}$ \\
\hline Phenol & & & & & & & & & & & & & & & & & & & $\mathrm{X}$ & $\mathrm{X}$ & $\mathrm{X}$ & $\mathrm{X}$ & $\mathrm{X}$ & $\mathrm{X}$ \\
\hline BenzylAlcohol & & & & & & & & & & & & & $\mathrm{X}$ & $\mathrm{X}$ & $\mathrm{X}$ & $\mathrm{X}$ & $\mathrm{X}$ & $\mathrm{X}$ & & & & & & \\
\hline 1,6-Octadien-3-ol,3,7-dimethyl- & & & & & & & $\mathrm{X}$ & $\mathrm{X}$ & $\mathrm{X}$ & $\mathrm{X}$ & $\mathrm{X}$ & $\mathrm{X}$ & $\mathrm{X}$ & $\mathrm{X}$ & $\mathrm{X}$ & $\mathrm{X}$ & $\mathrm{X}$ & $\mathrm{X}$ & & & & & & \\
\hline Nonanal & $\mathrm{X}$ & $\mathrm{X}$ & $\mathrm{X}$ & $\mathrm{X}$ & $\mathrm{X}$ & $\mathrm{X}$ & & & & & & & $\mathrm{X}$ & $\mathrm{X}$ & $\mathrm{X}$ & $\mathrm{X}$ & $\mathrm{X}$ & $\mathrm{X}$ & & & & & & \\
\hline PhenylethylAlcohol & & & & & & & & & & & & & & $\mathrm{X}$ & $\mathrm{X}$ & $\mathrm{X}$ & $\mathrm{X}$ & $\mathrm{X}$ & & & & & & \\
\hline 2-Nonenal,(E)- & & & & & & & & & & & & & & & & & & & $\mathrm{X}$ & $\mathrm{X}$ & $\mathrm{X}$ & $\mathrm{X}$ & $\mathrm{X}$ & $\mathrm{X}$ \\
\hline Aceticacid,phenylmethylester & & & & & & & & & & & & & $\mathrm{X}$ & $\mathrm{X}$ & $\mathrm{X}$ & $\mathrm{X}$ & $\mathrm{X}$ & $\mathrm{X}$ & & & & & & \\
\hline OctanoicAcid & & & & & & & & & & & & & & & & & & & & $\mathrm{X}$ & $\mathrm{X}$ & $\mathrm{X}$ & $\mathrm{X}$ & $\mathrm{X}$ \\
\hline Nonanol & & & & & & & & & & & & & & & & & & & $\mathrm{X}$ & $\mathrm{X}$ & $\mathrm{X}$ & $\mathrm{X}$ & $\mathrm{X}$ & \\
\hline Dodecane & & $\mathrm{X}$ & $\mathrm{X}$ & $\mathrm{X}$ & $\mathrm{X}$ & $\mathrm{X}$ & & & & & & & & & & & & & & & & & & \\
\hline Decanal & $\mathrm{X}$ & $\mathrm{X}$ & $\mathrm{X}$ & $\mathrm{X}$ & $\mathrm{X}$ & $\mathrm{X}$ & $\mathrm{X}$ & $\mathrm{X}$ & $\mathrm{X}$ & $\mathrm{X}$ & $\mathrm{X}$ & $\mathrm{X}$ & $\mathrm{X}$ & $\mathrm{X}$ & $\mathrm{X}$ & $\mathrm{X}$ & $\mathrm{X}$ & $\mathrm{X}$ & & & & & & \\
\hline Nonanoicacid & & & & & & & & & & & & & & & & & & & $\mathrm{X}$ & $\mathrm{X}$ & $\mathrm{X}$ & $\mathrm{X}$ & $\mathrm{X}$ & $\mathrm{X}$ \\
\hline Undecanal & $\mathrm{X}$ & $\mathrm{X}$ & $\mathrm{X}$ & $\mathrm{X}$ & $\mathrm{X}$ & $\mathrm{X}$ & & & & & & & & & & & & & & & & & & \\
\hline Tetradecane & $\mathrm{X}$ & $\mathrm{X}$ & $\mathrm{X}$ & $\mathrm{X}$ & $\mathrm{X}$ & $\mathrm{X}$ & $\mathrm{X}$ & $\mathrm{X}$ & $\mathrm{X}$ & $\mathrm{X}$ & $\mathrm{X}$ & $\mathrm{X}$ & $\mathrm{X}$ & $\mathrm{X}$ & $\mathrm{X}$ & $\mathrm{X}$ & $\mathrm{X}$ & $\mathrm{X}$ & $\mathrm{X}$ & $\mathrm{X}$ & $\mathrm{X}$ & $\mathrm{X}$ & & $\mathrm{X}$ \\
\hline Dodecanal & $\mathrm{X}$ & $X$ & $\mathrm{X}$ & $\mathrm{X}$ & $\mathrm{X}$ & $\mathrm{X}$ & & & & & & & & & & & & & & & & & & \\
\hline Caryophyllene & & & & & & & & & & & & & & & & & & & $\mathrm{X}$ & $\mathrm{X}$ & & $\mathrm{X}$ & $\mathrm{X}$ & $\mathrm{X}$ \\
\hline 5,9-Undecadien-2-one,6,10-dimethyl-, (Z)- & & & & & & & & & & & & & & & & & & & $\mathrm{X}$ & $\mathrm{X}$ & & $\mathrm{X}$ & $\mathrm{X}$ & $\mathrm{X}$ \\
\hline 5,9-Undecadien-2-one,6,10-dimethyl-, (E)- & $\mathrm{X}$ & $\mathrm{X}$ & $X$ & $\mathrm{X}$ & $\mathrm{X}$ & $\mathrm{X}$ & $\mathrm{X}$ & $\mathrm{X}$ & $\mathrm{X}$ & $\mathrm{X}$ & $\mathrm{X}$ & $\mathrm{X}$ & $\mathrm{X}$ & $\mathrm{X}$ & $\mathrm{X}$ & $X$ & $\mathrm{X}$ & $\mathrm{X}$ & $\mathrm{X}$ & & $\mathrm{X}$ & $\mathrm{X}$ & $\mathrm{X}$ & $\mathrm{X}$ \\
\hline Hexadecane & $\mathrm{X}$ & $\mathrm{X}$ & $\mathrm{X}$ & $\mathrm{X}$ & $\mathrm{X}$ & $\mathrm{X}$ & $\mathrm{X}$ & $\mathrm{X}$ & $\mathrm{X}$ & $\mathrm{X}$ & $\mathrm{X}$ & $\mathrm{X}$ & & & & & & & & & & & & \\
\hline Heptadecane & $\mathrm{X}$ & $\mathrm{X}$ & $\mathrm{X}$ & $\mathrm{X}$ & $\mathrm{X}$ & $\mathrm{X}$ & $\mathrm{X}$ & $\mathrm{X}$ & $\mathrm{X}$ & $\mathrm{X}$ & $\mathrm{X}$ & $\mathrm{X}$ & $\mathrm{X}$ & $\mathrm{X}$ & $\mathrm{X}$ & X & $\mathrm{X}$ & $\mathrm{X}$ & & & & & & \\
\hline Octadecane & $\mathrm{X}$ & $\mathrm{X}$ & $X$ & $X$ & $X$ & $X$ & & & & & & & & & & & & & & & & & & \\
\hline
\end{tabular}




\section{Table 14-Common human scent VOCs from Subject 8F following a six month sampling period}

\begin{tabular}{|c|c|c|c|c|c|c|c|c|c|c|c|c|c|c|c|c|c|c|c|c|c|c|c|c|}
\hline \multirow[t]{2}{*}{ Compounds } & \multicolumn{6}{|c|}{ Hand Odor } & \multicolumn{6}{|c|}{ Hair } & \multicolumn{6}{|c|}{ Fingernails } & \multicolumn{6}{|c|}{ Saliva } \\
\hline & 1 & 2 & 3 & 4 & 5 & 6 & 1 & 2 & 3 & 4 & 5 & 6 & 1 & 2 & 3 & 4 & 5 & 6 & 1 & 2 & 3 & 4 & 5 & 6 \\
\hline Benzaldehyde & & & & & & & & & & & & & & & & & & & $\mathrm{X}$ & $\mathrm{X}$ & $\mathrm{X}$ & $\mathrm{X}$ & $\mathrm{X}$ & \\
\hline Hexanoicacid & & & & & & & & & & & & & & & & & & & $\mathrm{X}$ & $\mathrm{X}$ & $\mathrm{X}$ & $\mathrm{X}$ & $\mathrm{X}$ & $\mathrm{X}$ \\
\hline Furan,2-pentyl- & & & & & & & & & & & & & & & & & & & $\mathrm{X}$ & $\mathrm{X}$ & $\mathrm{X}$ & $\mathrm{X}$ & $\mathrm{X}$ & $\mathrm{X}$ \\
\hline BenzylAlcohol & & $\mathrm{X}$ & $\mathrm{X}$ & $\mathrm{X}$ & $\mathrm{X}$ & $\mathrm{X}$ & & & & & & & $\mathrm{X}$ & & $\mathrm{X}$ & $\mathrm{X}$ & $\mathrm{X}$ & $\mathrm{X}$ & & & & & & \\
\hline 1,6-Octadien-3-ol,3,7-dimethyl- & & & & & & & & & & & & & & $\mathrm{X}$ & $\mathrm{X}$ & $\mathrm{X}$ & $\mathrm{X}$ & $\mathrm{X}$ & & & & & & \\
\hline Undecane & & $\mathrm{X}$ & $\mathrm{X}$ & $\mathrm{X}$ & $X$ & X & & & & & & & & & & & & & & & & & & \\
\hline Heptanoicacid & & & & & & & & & & & & & & & & & & & $\mathrm{X}$ & & $\mathrm{X}$ & $\mathrm{X}$ & $\mathrm{X}$ & $\mathrm{X}$ \\
\hline Nonanal & $\mathrm{X}$ & $\mathrm{X}$ & $\mathrm{X}$ & $\mathrm{X}$ & $\mathrm{X}$ & $\mathrm{X}$ & & & & & & & & $X$ & $\mathrm{X}$ & $\mathrm{X}$ & $X$ & $\mathrm{X}$ & & & & & & \\
\hline 2-Nonenal,(E)- & $\mathrm{X}$ & & $\mathrm{X}$ & $\mathrm{X}$ & $\mathrm{X}$ & $\mathrm{X}$ & & & & & & & & & & & & & & & & & & \\
\hline Decanal & $\mathrm{X}$ & $\mathrm{X}$ & $\mathrm{X}$ & $\mathrm{X}$ & $\mathrm{X}$ & $\mathrm{X}$ & $\mathrm{X}$ & $\mathrm{X}$ & $\mathrm{X}$ & $\mathrm{X}$ & $\mathrm{X}$ & $\mathrm{X}$ & $\mathrm{X}$ & $X$ & $\mathrm{X}$ & $\mathrm{X}$ & $\mathrm{X}$ & $\mathrm{X}$ & $\mathrm{X}$ & $\mathrm{X}$ & $X$ & $\mathrm{X}$ & $X$ & $\mathrm{X}$ \\
\hline Tridecane & $\mathrm{X}$ & $\mathrm{X}$ & $\mathrm{X}$ & $\mathrm{X}$ & $\mathrm{X}$ & $\mathrm{X}$ & & & & & & & & & & & & & & & & & & \\
\hline Undecanal & $\mathrm{X}$ & $\mathrm{X}$ & $\mathrm{X}$ & $\mathrm{X}$ & $\mathrm{X}$ & $\mathrm{X}$ & & & & & & & & & & & & & & & & & & \\
\hline Tetradecane & $\mathrm{X}$ & $\mathrm{X}$ & $\mathrm{X}$ & $\mathrm{X}$ & $\mathrm{X}$ & $\mathrm{X}$ & & & & & & & & $X$ & $\mathrm{X}$ & $\mathrm{X}$ & $\mathrm{X}$ & $\mathrm{X}$ & $\mathrm{X}$ & $X$ & $\mathrm{X}$ & $\mathrm{X}$ & $X$ & $\mathrm{X}$ \\
\hline Dodecanal & $\mathrm{X}$ & $\mathrm{X}$ & & $\mathrm{X}$ & $\mathrm{X}$ & $\mathrm{X}$ & & & & & & & & & & & & & & & & & & \\
\hline Caryophyllene & & & & & & & & & & & & & & & & & & & $\mathrm{X}$ & $\mathrm{X}$ & $\mathrm{X}$ & $\mathrm{X}$ & $\mathrm{X}$ & $\mathrm{X}$ \\
\hline 5,9-Undecadien-2-one,6,10-dimethyl- & $\mathrm{X}$ & $\mathrm{X}$ & $\mathrm{X}$ & $\mathrm{X}$ & $\mathrm{X}$ & $\mathrm{X}$ & & & & & & & $\mathrm{X}$ & $\mathrm{X}$ & $\mathrm{X}$ & $\mathrm{X}$ & $\mathrm{X}$ & $\mathrm{X}$ & $\mathrm{X}$ & $\mathrm{X}$ & $\mathrm{X}$ & $\mathrm{X}$ & $\mathrm{X}$ & $\mathrm{X}$ \\
\hline Hexadecane & $\mathrm{X}$ & $\mathrm{X}$ & $\mathrm{X}$ & $\mathrm{X}$ & $\mathrm{X}$ & $\mathrm{X}$ & & & & & & & & & & & & & & & & & & \\
\hline Heptadecane & $\mathrm{X}$ & $\mathrm{X}$ & $\mathrm{X}$ & $\mathrm{X}$ & $\mathrm{X}$ & $\mathrm{X}$ & $\mathrm{X}$ & $\mathrm{X}$ & $\mathrm{X}$ & $\mathrm{X}$ & $\mathrm{X}$ & $\mathrm{X}$ & & & & & & & & & & & & \\
\hline Octadecane & & & & & & & & $\mathrm{X}$ & $\mathrm{X}$ & $\mathrm{X}$ & $\mathrm{X}$ & $\mathrm{X}$ & & $\mathrm{X}$ & $\mathrm{X}$ & $\mathrm{X}$ & $\mathrm{X}$ & $\mathrm{X}$ & & & & & & \\
\hline
\end{tabular}

\section{Table 15-Common human scent VOCs from Subject 4M following a six month}

sampling period

\begin{tabular}{|c|c|c|c|c|c|c|c|c|c|c|c|c|c|c|c|c|c|c|c|c|c|c|c|c|c|c|c|c|c|c|}
\hline \multirow[t]{2}{*}{ Compound } & \multicolumn{6}{|c|}{ Hand Odor } & \multicolumn{6}{|c|}{ Hair } & \multicolumn{6}{|c|}{ Left Nails } & \multicolumn{6}{|c|}{ Right Nails } & \multicolumn{6}{|c|}{ Saliva } \\
\hline & 1 & 2 & 3 & 4 & 5 & 6 & 1 & 2 & 3 & 4 & 5 & 6 & 1 & 2 & 3 & 4 & 5 & 6 & 1 & 2 & 3 & 4 & 5 & 6 & 1 & 2 & 3 & 4 & 5 & 6 \\
\hline 1-Hexanol & & & & & & & & & & & & & & & & & & & & & & & & & $\mathrm{X}$ & $\mathrm{X}$ & $\mathrm{X}$ & $\bar{X}$ & $\bar{X}$ & \\
\hline Benzaldehyde & & & & & & & & & & & & & & & & & & & & & & & & & $\mathrm{X}$ & $X$ & $\mathrm{X}$ & $\mathrm{X}$ & $\mathrm{X}$ & $X$ \\
\hline Hexanoicacid & & & & & & & & & & & & & & & & & & & & & & & & & $\mathrm{X}$ & $\mathrm{X}$ & $\mathrm{X}$ & $\mathrm{X}$ & $\mathrm{X}$ & X \\
\hline Furan,2-pentyl- & & & & & & & & & & & & & & & & & & & & & & & & & $\mathrm{x}$ & $\mathrm{X}$ & $\mathrm{X}$ & $\mathrm{X}$ & $\mathrm{X}$ & $X$ \\
\hline Nonanal & $X$ & $X$ & $\mathrm{X}$ & $X$ & $\mathrm{X}$ & $\mathrm{X}$ & & & & & & & & & & & & & & & & & & & & & & & & \\
\hline 2-Nonenal,(E)- & & & & & & & & & & & & & & & & & & & & & & & & & $\mathrm{X}$ & $\mathrm{X}$ & $\mathrm{X}$ & $\mathrm{X}$ & $X$ & \\
\hline Decanal & $\mathrm{X}$ & $\mathrm{X}$ & $\mathrm{X}$ & $X$ & $\mathrm{X}$ & $\mathrm{X}$ & $\mathrm{X}$ & $\mathrm{X}$ & $\mathrm{X}$ & $\mathrm{X}$ & $\mathrm{X}$ & $\mathrm{X}$ & $\mathrm{X}$ & $\mathrm{X}$ & $\mathrm{X}$ & $\mathrm{X}$ & $\mathrm{X}$ & $\mathrm{X}$ & $\mathrm{X}$ & $\mathrm{X}$ & $\mathrm{X}$ & $\mathrm{X}$ & $\mathrm{X}$ & $\mathrm{X}$ & $\mathrm{x}$ & $\mathrm{X}$ & $\mathrm{X}$ & $\mathrm{X}$ & $\mathrm{X}$ & $\mathrm{X}$ \\
\hline Nonanoicacid & & & & & & & & & & & & & & & & & & & & & & & & & $\mathrm{X}$ & $\mathrm{X}$ & $\mathrm{X}$ & $\mathrm{X}$ & $\mathrm{X}$ & $\mathrm{X}$ \\
\hline Tridecane & $X$ & $X$ & $\mathrm{X}$ & $\mathrm{X}$ & $\mathrm{X}$ & & & & & & & & & & & & & & & & & & & & & & & & & \\
\hline Undecanal & $X$ & $\mathrm{X}$ & $\mathrm{X}$ & $\mathrm{X}$ & $\mathrm{X}$ & $\mathrm{X}$ & & & & & & & & & & & & & & & & & & & & & & & & \\
\hline Tetradecane & $\mathrm{X}$ & $\mathrm{X}$ & $\mathrm{X}$ & $\mathrm{X}$ & $\mathrm{X}$ & $\mathrm{X}$ & & & & & & & & & & & & & & & & & & & $\mathrm{X}$ & $\mathrm{X}$ & $\mathrm{X}$ & $\mathrm{X}$ & $\mathrm{X}$ & \\
\hline Dodecanal & & & & & & & & & & & & & & & & & & & & & & & & & $\mathrm{X}$ & $\mathrm{X}$ & $\mathrm{X}$ & $\mathrm{X}$ & $\mathrm{X}$ & \\
\hline Caryophyllene & & & & & & & & & & & & & & & & & & & & & & & & & $\mathrm{X}$ & $\mathrm{X}$ & $\mathrm{X}$ & $\mathrm{X}$ & $\mathrm{X}$ & $\mathrm{X}$ \\
\hline 5,9-Undecadien-2-one,6,10-dimethyl-, (Z)- & & & & & & & & & & & & & & & & & & & & & & & & & $\mathrm{X}$ & $\mathrm{X}$ & $\mathrm{X}$ & $\mathrm{X}$ & $\mathrm{X}$ & $\mathrm{X}$ \\
\hline 5,9-Undecadien-2-one,6,10-dimethyl-, (E)- & $\mathrm{X}$ & $\mathrm{X}$ & $\mathrm{X}$ & $\mathrm{X}$ & $\mathrm{X}$ & $\mathrm{X}$ & $\mathrm{X}$ & $\mathrm{X}$ & $\mathrm{X}$ & $\mathrm{X}$ & $X$ & $\mathrm{X}$ & & $\mathrm{X}$ & $\mathrm{X}$ & $\mathrm{X}$ & $X$ & $\mathrm{X}$ & & $X$ & $X$ & $\mathrm{X}$ & $\mathrm{X}$ & $\mathrm{X}$ & $\mathrm{X}$ & $\mathrm{X}$ & $X$ & $\mathrm{X}$ & $X$ & X \\
\hline Hexadecane & $\mathrm{X}$ & $\mathrm{X}$ & $X$ & $X$ & $\mathrm{X}$ & $\mathrm{X}$ & $\mathrm{X}$ & $\mathrm{X}$ & $\mathrm{X}$ & $\mathrm{X}$ & $X$ & & & & & & & & & & & & & & & & & & & \\
\hline Heptadecane & $\mathrm{X}$ & $\mathrm{X}$ & & $\mathrm{X}$ & $\mathrm{X}$ & $X$ & $\mathrm{X}$ & $\mathrm{X}$ & $\mathrm{X}$ & $\mathrm{X}$ & $\mathrm{X}$ & $\mathrm{X}$ & & & & & & & $\mathrm{X}$ & & $\mathrm{X}$ & $\mathrm{X}$ & $\mathrm{X}$ & $\mathrm{X}$ & & & & & & \\
\hline
\end{tabular}


Table 16-Common human scent VOCs from Subject $16 \mathrm{M}$ following a six month sampling period

\begin{tabular}{|c|c|c|c|c|c|c|c|c|c|c|c|c|c|c|c|c|c|c|c|c|c|c|c|c|}
\hline \multirow[t]{2}{*}{ Compound } & \multicolumn{6}{|c|}{ Hand Odor } & \multicolumn{6}{|c|}{ Hair } & \multicolumn{6}{|c|}{ Fingernails } & \multicolumn{6}{|c|}{ Saliva } \\
\hline & 1 & 2 & 3 & 4 & 5 & 6 & 1 & 2 & 3 & 4 & 5 & 6 & 1 & 2 & 3 & 4 & 5 & 6 & 1 & 2 & 3 & 4 & 5 & 6 \\
\hline Hexanoic acid & & & & & & & & & & & & & & & & & & & $\mathrm{X}$ & $\mathrm{X}$ & $\mathrm{X}$ & $\mathrm{X}$ & $\mathrm{X}$ & $\mathrm{X}$ \\
\hline Furan,2-pentyl- & & & & & & & & & & & & & & & & & & & $X$ & $\mathrm{X}$ & $\mathrm{X}$ & $\mathrm{X}$ & $\mathrm{X}$ & $\mathrm{X}$ \\
\hline Nonanal & $\mathrm{X}$ & $\mathrm{X}$ & $\mathrm{X}$ & $X$ & $\mathrm{X}$ & $\mathrm{X}$ & $\mathrm{X}$ & $\mathrm{X}$ & $\mathrm{X}$ & $\mathrm{X}$ & $\mathrm{X}$ & $\mathrm{X}$ & & & & & & & & & & & & \\
\hline OctanoicAcid & & & & & & & & & & & & & & $\mathrm{X}$ & $\mathrm{X}$ & $\mathrm{X}$ & $\mathrm{X}$ & $\mathrm{X}$ & & & & & & \\
\hline Decanal & $\mathrm{X}$ & $\mathrm{X}$ & $\mathrm{X}$ & $\mathrm{X}$ & $\mathrm{X}$ & $\mathrm{X}$ & $\mathrm{X}$ & $\mathrm{X}$ & $\mathrm{X}$ & $\mathrm{X}$ & $\mathrm{X}$ & $\mathrm{X}$ & & & & & & & $\mathrm{X}$ & $\mathrm{X}$ & $\mathrm{X}$ & $\mathrm{X}$ & $\mathrm{X}$ & $\mathrm{X}$ \\
\hline Nonanoicacid & & & & & & & & & & & & & & & & & & & $X$ & $\mathrm{X}$ & $\mathrm{X}$ & $\mathrm{X}$ & & $\mathrm{X}$ \\
\hline Tridecane & X & $X$ & X & X & $\mathrm{X}$ & & & & & & & & & & & & & & & & & & & \\
\hline Naphthalene,1-methyl- & & & & & & & & & & & & & & & & & & & $\mathrm{X}$ & & $\mathrm{X}$ & $X$ & $\mathrm{X}$ & $\mathrm{X}$ \\
\hline Tetradecane & $X$ & $\mathrm{X}$ & $\mathrm{X}$ & $\mathrm{X}$ & & $\mathrm{X}$ & $\mathrm{X}$ & X & $\mathrm{X}$ & $\mathrm{X}$ & $\mathrm{X}$ & $\mathrm{X}$ & & & & & & & & & & & & \\
\hline 5,9-Undecadien-2-one,6,1-dimethyl-, (E)- & $\mathrm{X}$ & $\mathrm{X}$ & $\mathrm{X}$ & & $\mathrm{X}$ & $\mathrm{X}$ & $\mathrm{X}$ & $\mathrm{X}$ & $\mathrm{X}$ & $\mathrm{X}$ & $\mathrm{X}$ & $\mathrm{X}$ & $\mathrm{X}$ & $\mathrm{X}$ & $\mathrm{X}$ & $\mathrm{X}$ & $\mathrm{X}$ & $\mathrm{X}$ & $\mathrm{X}$ & $\mathrm{X}$ & $\mathrm{X}$ & $X$ & $\mathrm{X}$ & $\mathrm{X}$ \\
\hline Dodecanoicacid & & & & & & & $\mathrm{X}$ & X & $X$ & & $\mathrm{X}$ & X & & & & & & & & & & & & \\
\hline Hexadecane & $\mathrm{X}$ & $\mathrm{X}$ & $\mathrm{X}$ & $\mathrm{X}$ & $\mathrm{X}$ & $\mathrm{X}$ & $\mathrm{X}$ & $\mathrm{X}$ & $\mathrm{X}$ & $\mathrm{X}$ & & $\mathrm{X}$ & & & & & & & & & & & & \\
\hline Heptadecane & $\mathrm{X}$ & $\mathrm{X}$ & $\mathrm{X}$ & & $\mathrm{X}$ & $\mathrm{X}$ & $\mathrm{X}$ & $\mathrm{X}$ & $\mathrm{X}$ & $\mathrm{X}$ & $\mathrm{X}$ & $\mathrm{X}$ & & & & & & & & & & & & \\
\hline Octadecane & & & & & & & $\mathrm{X}$ & $\mathrm{X}$ & $\mathrm{X}$ & $\mathrm{X}$ & $\mathrm{X}$ & $\mathrm{X}$ & & & & & & & & & & & & \\
\hline
\end{tabular}

\section{Table 17-Common human scent VOCs from Subject 28M following a six month} sampling period

\begin{tabular}{|c|c|c|c|c|c|c|c|c|c|c|c|c|c|c|c|c|c|c|c|c|c|c|c|c|}
\hline \multirow[t]{2}{*}{ Compound } & \multicolumn{6}{|c|}{ Hand Odor } & \multicolumn{6}{|c|}{ Hair } & \multicolumn{6}{|c|}{ Fingernails } & \multicolumn{6}{|c|}{ Saliva } \\
\hline & 1 & 2 & 3 & 4 & 5 & 6 & 1 & 2 & 3 & 4 & 5 & 6 & 1 & 2 & 3 & 4 & 5 & 6 & 1 & 2 & 3 & 4 & 5 & 6 \\
\hline Hexanal & & & & & & & & & & & & & & & & & & & $\mathrm{X}$ & $X$ & $\mathrm{X}$ & & $\mathrm{X}$ & $\mathrm{X}$ \\
\hline Furan,2-pentyl- & & & & & & & & & & & & & & & & & & & $\mathrm{X}$ & $\mathrm{X}$ & $\mathrm{X}$ & $\mathrm{X}$ & $\mathrm{X}$ & $\mathrm{X}$ \\
\hline Hexanoicacid & & & & & & & & & & & & & & & & & & & $\mathrm{X}$ & $\mathrm{X}$ & $\mathrm{X}$ & $\mathrm{X}$ & $\mathrm{X}$ & $\mathrm{X}$ \\
\hline Nonanal & $\mathrm{X}$ & $\mathrm{X}$ & $\mathrm{X}$ & $\mathrm{X}$ & $\mathrm{X}$ & $\mathrm{X}$ & $\mathrm{X}$ & $\mathrm{X}$ & $\mathrm{X}$ & $\mathrm{X}$ & $\mathrm{X}$ & $\mathrm{X}$ & & & & & & & & & & & & \\
\hline Decanal & $X$ & $X$ & $X$ & $\mathrm{X}$ & $X$ & $X$ & $\mathrm{X}$ & X & $X$ & $X$ & $X$ & $X$ & $\mathrm{X}$ & X & $X$ & & X & $X$ & $X$ & $\mathrm{X}$ & $\mathrm{X}$ & $X$ & X & $X$ \\
\hline Undecanal & $\mathrm{X}$ & $X$ & $\mathrm{X}$ & & $\mathrm{X}$ & $X$ & & & & & & & & & & & & & & & & & & \\
\hline Naphthalene,1-methyl- & & & & & & & & & & & & & & & & & & & $\mathrm{X}$ & $\mathrm{X}$ & $X$ & & $\mathrm{X}$ & $X$ \\
\hline Tetradecane & $X$ & $X$ & $X$ & & X & X & & & & & & & & & & & & & & & & & & \\
\hline Dodecanal & $\mathrm{X}$ & $X$ & $\mathrm{X}$ & & $\mathrm{X}$ & $\mathrm{X}$ & & & & & & & & & & & & & & & & & & \\
\hline Caryophyllene & & & & & & & & & & & & & & & & & & & $\mathrm{X}$ & $\mathrm{X}$ & $\mathrm{X}$ & & $\mathrm{X}$ & $\mathrm{X}$ \\
\hline 5,9-Undecadien-2-one,6,10-dimethyl-, (E)- & $\mathrm{X}$ & $\mathrm{X}$ & $\mathrm{X}$ & & $\mathrm{X}$ & $\mathrm{X}$ & $\mathrm{X}$ & $\mathrm{X}$ & $\mathrm{X}$ & & $\mathrm{X}$ & $\mathrm{X}$ & & & & & & & $\mathrm{X}$ & $\mathrm{X}$ & $\mathrm{X}$ & $\mathrm{X}$ & $\mathrm{X}$ & \\
\hline Dodecanoicacid & & & & & & & & & & & & & & & & & & & $\mathrm{X}$ & $\mathrm{X}$ & $\mathrm{X}$ & $\mathrm{X}$ & $\mathrm{X}$ & \\
\hline Hexadecane & $\mathrm{X}$ & $\mathrm{X}$ & $\mathrm{X}$ & $\mathrm{X}$ & $\mathrm{X}$ & $\mathrm{X}$ & & & & & & & & & & & & & & & & & & \\
\hline Heptadecane & $\mathrm{X}$ & $\mathrm{X}$ & $\mathrm{X}$ & $\mathrm{X}$ & $\mathrm{X}$ & $\mathrm{X}$ & $\mathrm{X}$ & $\mathrm{X}$ & & $\mathrm{X}$ & $\mathrm{X}$ & $X$ & & & & & & & & & & & & \\
\hline
\end{tabular}




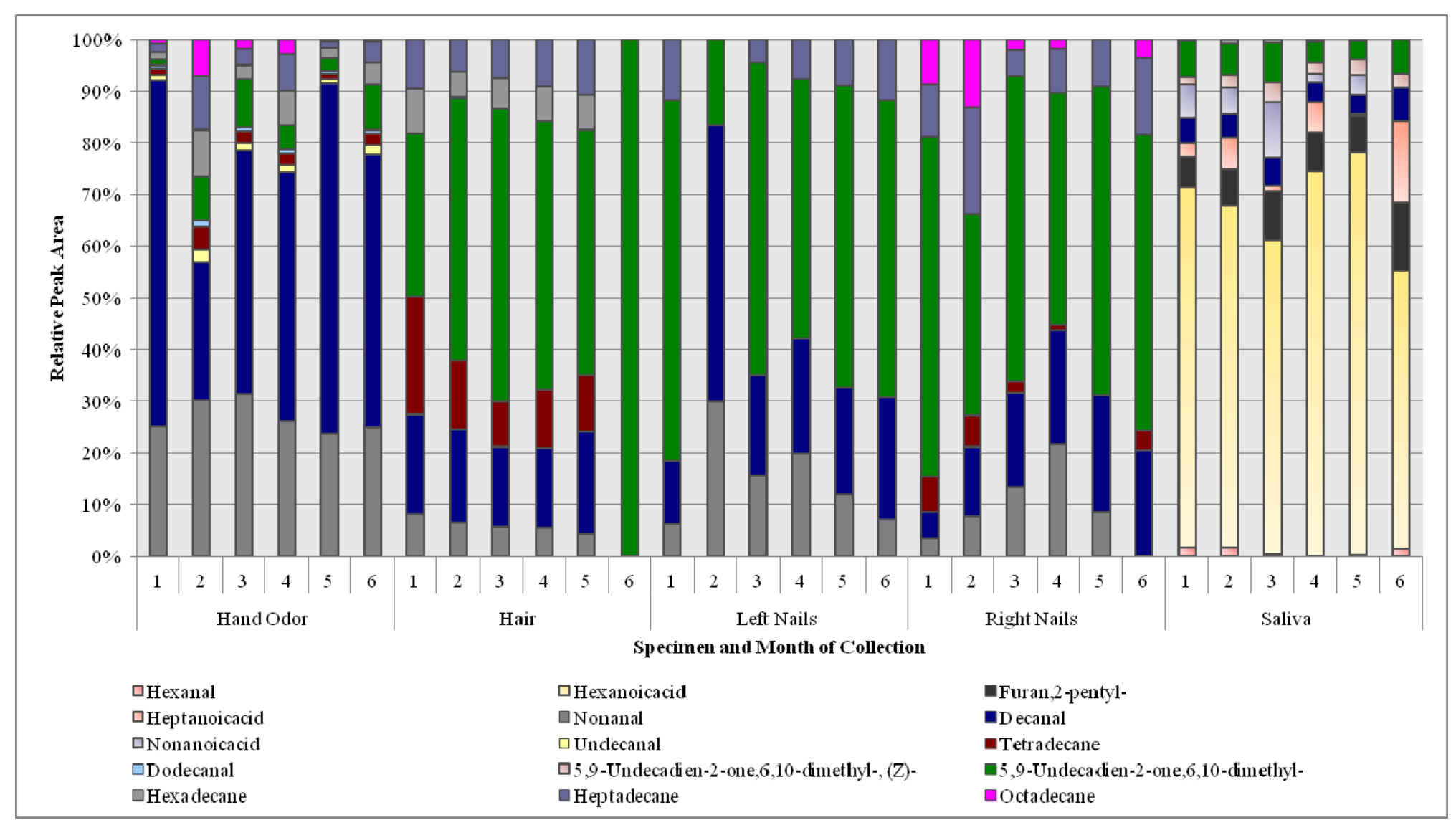

Figure 41-Chemical profiles of biological specimens from Subject 1F over a six month period 
The average number of common human scent VOCs detected from each subject were, in descending order, 9 for saliva (ranging from 6-12), 9 for hand odor (ranging from 7-12), 5 for hair (ranging from 4-8) and 4 for fingernails (ranging from 1-9). Referring to Table 12, Subject 1F has nine common human scent VOCs from hand odor, six from hair, four from left hand fingernails, six from right hand fingernails and nine from saliva. From this table it can be noted that all of the common VOCs present in left hand fingernails were also present in right hand fingernails; however, the right hand nails contained two additional common VOCs (tetradecane and octadecane). Additionally, the six common human scent VOCs present in saliva (hexanal, hexanoic acid, 2-pentyl-furan, heptanoic acid, nonanoic acid, and cis-geranylacetone) were not detected in the other three specimen types. Using a color chart, the common VOCs, and their relative abundance, for each specimen collected from Subject 1F can be visualized (Figure 41). The color charts of the other five subjects can be seen in Appendix A.

A statistical evaluation, using principal component analysis (PCA), was performed so groupings could be visualized from the six months of collected data. For Subject 1F, a plot of the first three principal components (Figure 42) revealed that each specimen formed its own distinct cluster (cumulative variation of $76.0 \%$ ); however, the clusters of hair (red dots) and fingernails (blue dots) grouped very closely together. These trends could also be seen with the remaining five subjects (Figure 42). To expand on the results of the PCA, cluster analysis (Euclidean distance, single linkage) was performed which provided a similarity value (in percentage) for each specimen type. 

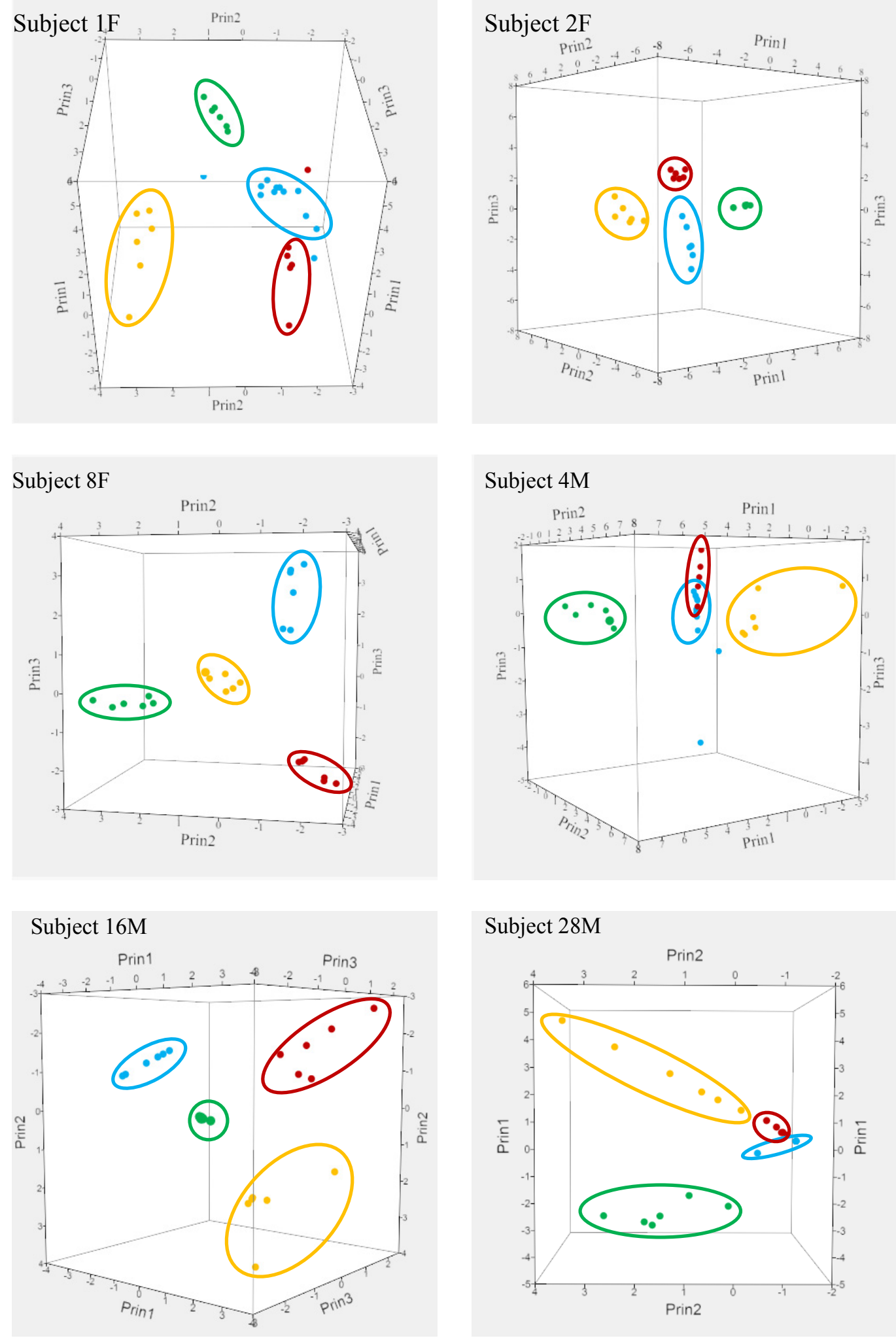

Figure 42- PCA of biological specimens six individuals (gold-hand odor, red-hair, bluefingernails and green-saliva) 
The results of the cluster analysis are displayed in the form of a dendogram which depicts groupings within the data. For Subject 1F, three major clusters were formed with the first cluster (left side) consisting of hand odor, the second cluster (middle) consisting of hair and fingernails and the third cluster consisting of saliva (Figure 43). With regards to percent similarity, the six month saliva samples were the most similar $(85.8 \%)$ of the four specimen types. Succeeding saliva, hand odor was the next most consistent specimen with a similarity of $81.5 \%$ among the six month samples, followed by hair $(71.7 \%)$ and, lastly, fingernails (69.4\%). Small groupings of hair and fingernail samples were seen in the dendogram which produced a higher percentage of similarity than all of the months combined. For instance, hair samples from months 2, 3, 4 and 5 were $94.6 \%$ similar; however, that value decreased to $71.7 \%$ as months 1 and 6 were added to the evaluations. The dendograms of the remaining subjects can be seen in Appendix B. 


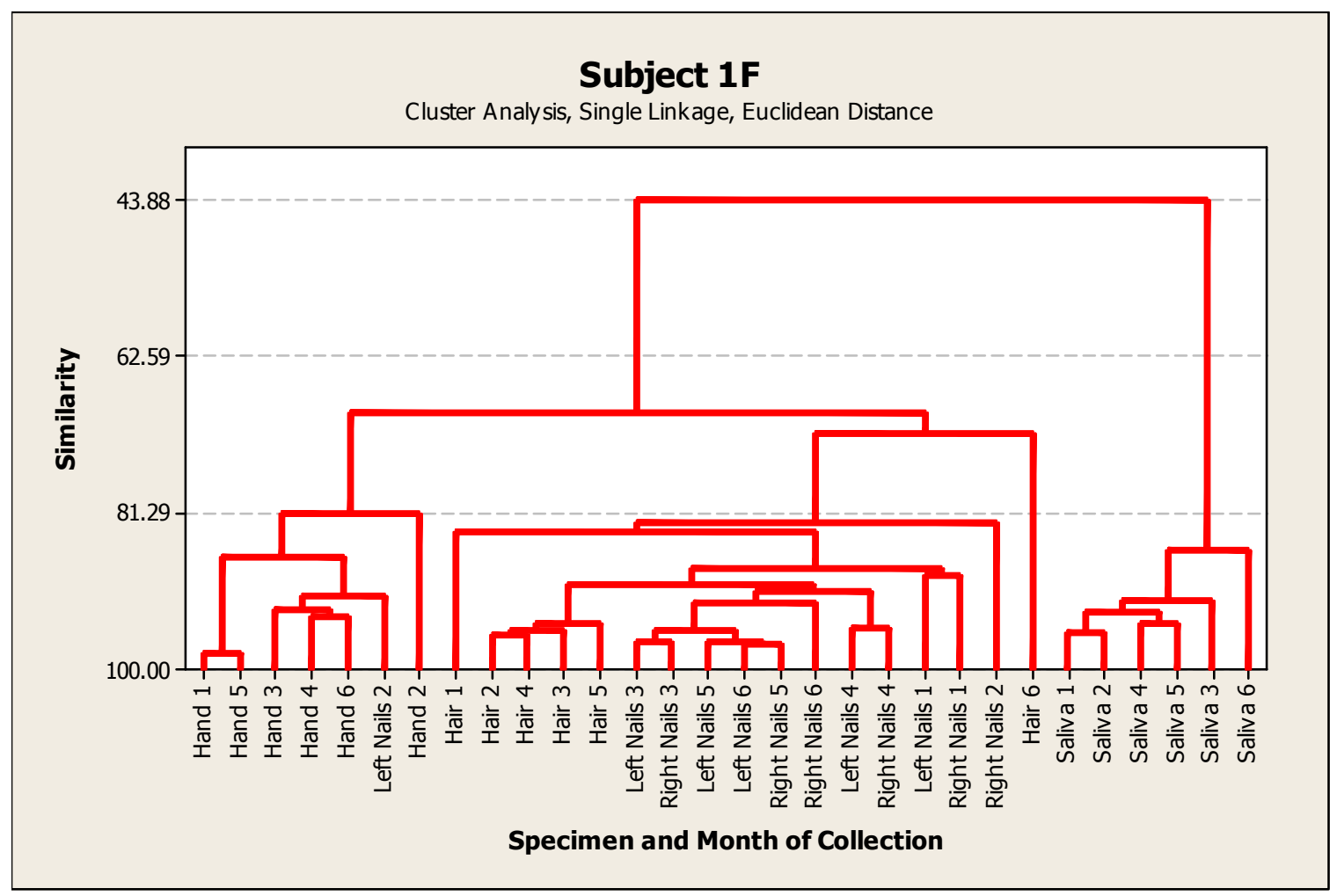

Figure 43-Dendogram of biological specimens from Subject $1 \mathrm{~F}$ collected over a six month period

Similarities, derived from cluster analysis, for the biological specimens collected from all six individuals can be seen in Table 18. Similarities were recorded for all six months (1-6) of the collected samples, as well as for smaller clusters (e.g. Months 2-5 hair samples from Subject $1 \mathrm{~F}$ are $94.6 \%$ similar) providing a thorough assessment on how each month's sample associated with the rest. For instance, the saliva samples collected from Subject 16M on months 1, 2, 3, 4 and 6 were 91.8\% similar; however, when the saliva sample from month 5 was included in the assessment, the overall similarity for the saliva samples dropped to $50.2 \%$. This scenario reveals subtle variations in the profiles of the VOCs over time. 
Table 18-Similarities among biological specimens collected over a six month period

\begin{tabular}{|c|c|c|c|c|c|c|c|c|}
\hline & \multicolumn{2}{|c|}{ Hand odor } & \multicolumn{2}{|c|}{ Hair } & \multicolumn{2}{|c|}{ Fingernails } & \multicolumn{2}{|c|}{ Saliva } \\
\hline & Months & $\begin{array}{c}\text { Similarity } \\
(\%)\end{array}$ & Months & $\begin{array}{c}\text { Similarity } \\
(\%)\end{array}$ & Months & $\begin{array}{c}\text { Similarity } \\
(\%)\end{array}$ & Months & $\begin{array}{c}\text { Similarity } \\
(\%)\end{array}$ \\
\hline \multirow[t]{3}{*}{ Subject 1F } & $1,3-6$ & 86.6 & $2-5$ & 94.6 & $3-6$ & 90.7 & $1-6$ & 85.8 \\
\hline & $1-6$ & 81.5 & $1-5$ & 83.5 & $1,3-6$ & 88.0 & & \\
\hline & & & $1-6$ & 71.7 & $1-6$ & 69.4 & & \\
\hline Subject 2F & $1-6$ & 90.8 & $1-6$ & 89.8 & $1-6$ & 78.1 & $1-6$ & 86.7 \\
\hline Subject $8 \mathrm{~F}$ & $1-6$ & 82.3 & $1-6$ & 76.8 & $1-6$ & 71.8 & $1-6$ & 82.7 \\
\hline \multirow[t]{2}{*}{ Subject 4M } & $1-6$ & 82.3 & $1-6$ & 92.6 & $2-6$ & 92.6 & $1-6$ & 89.4 \\
\hline & & & & & $1-6$ & 39.4 & & \\
\hline \multirow[t]{2}{*}{ Subject 16M } & $1-6$ & 86.8 & $1-6$ & 90.0 & $1-4$ & 76.4 & $1-4,6$ & 91.8 \\
\hline & & & & & $1-6$ & 58.0 & $1-6$ & 50.2 \\
\hline \multirow[t]{3}{*}{ Subject 28M } & $2-4,6$ & 89.4 & $1-2,5-6$ & 89.1 & $1-3,5-6$ & 100.0 & $1-3,5-6$ & 84.2 \\
\hline & $1-4,6$ & 87.2 & $1-6$ & 80.9 & $1-6$ & 66.4 & $1-6$ & 52.6 \\
\hline & $1-6$ & 79.8 & & & & & & \\
\hline
\end{tabular}

Summarizing the values listed in the chart, hand odor, on average, was $83.9 \%$ similar (ranging from 79.8-90.8\%) over time, making it the most consistent specimen over time. The second most consistent specimen was hair which had an average similarity of $83.6 \%$ (ranging from $71.7-92.6 \%$ ), followed by saliva with $74.6 \%$ (ranging from 50.2-89.4\%) and fingernails with $63.9 \%$ similarity (ranging from 39.4-78.1\%). The time study revealed that VOCs from hand odor and hair remain consistent over time; however, there was a greater variation in saliva which depicted by, on two occasions (Subject $16 \mathrm{M}$ and $28 \mathrm{M}$ ), a similarity as low as $50 \%$. Fingernails fared the worst, over time, with four out of six subjects having a similarity less than $70 \%$. A low value of similarity could suggest that the VOCs from fingernails are not persistent (potentially because of exogenous chemicals) making it a less than ideal specimen for distinguishing individuals, especially when matching an aged sample to a fresh sample. It has been 
previously demonstrated that scent samples collected in the same day are more reproducible than those collected over time (25). Therefore, a decreased level of similarity (average of $76.5 \%$ across all subjects and specimen types) is not alarming and is somewhat expected. The results of this study provided insight into the reproducibility of the profiles of the VOCs generated from each of the different specimen types, over time, which will have the greatest impact when known and questioned scent samples cannot be compared immediately.

3.3.3.1. Discrimination of individuals using VOCs from biological specimens collected over time

In addition to assessing the persistence of VOCs from biological specimens over time, the discrimination of individuals was also evaluated. Table 19 lists the 14 common human scent VOCs from hand odor, across the six individuals sampled. Two pieces of information can be gained from this table. First, there are many common human scent VOCs shared among the six subjects. The hand odor of all six subjects contained nonanal, decanal, tetradecane, geranylacetone, hexadecane and heptadecane. It will be important to assess whether the presence of these similar VOCs makes these samples indistinguishable or does the abundance at which these VOCs are detected allow for distinguishability? 
Table 19-Common human scent VOCs from hand odor samples of six individuals

\begin{tabular}{|l|c|c|c|c|c|c|}
\hline \multicolumn{1}{|c}{ Hand Odor VOCs } & \multicolumn{1}{c}{ 1F } & \multicolumn{1}{c}{$\mathbf{4 M}$} & $\mathbf{8 F}$ & \multicolumn{1}{c|}{$\mathbf{2 0}$ 28M } \\
\hline BenzylAlcohol & & & & $\mathrm{X}$ & & \\
\hline Undecane & & & & $\mathrm{X}$ & & \\
\hline Nonanal & $\mathrm{X}$ & $\mathrm{X}$ & $\mathrm{X}$ & $\mathrm{X}$ & $\mathrm{X}$ & $\mathrm{X}$ \\
\hline 2-Nonenal,(E)- & & & & $\mathrm{X}$ & & \\
\hline Dodecane & & $\mathrm{X}$ & & & & \\
\hline Decanal & $\mathrm{X}$ & $\mathrm{X}$ & $\mathrm{X}$ & $\mathrm{X}$ & $\mathrm{X}$ & $\mathrm{X}$ \\
\hline Tridecane & & & $\mathrm{X}$ & $\mathrm{X}$ & $\mathrm{X}$ & \\
\hline Undecanal & $\mathrm{X}$ & $\mathrm{X}$ & $\mathrm{X}$ & $\mathrm{X}$ & & $\mathrm{X}$ \\
\hline Tetradecane & $\mathrm{X}$ & $\mathrm{X}$ & $\mathrm{X}$ & $\mathrm{X}$ & $\mathrm{X}$ & $\mathrm{X}$ \\
\hline Dodecanal & $\mathrm{X}$ & $\mathrm{X}$ & & $\mathrm{X}$ & & $\mathrm{X}$ \\
\hline 5,9-Undecadien-2-one,6,10-dimethyl-, (E)- & $\mathrm{X}$ & $\mathrm{X}$ & $\mathrm{X}$ & $\mathrm{X}$ & $\mathrm{X}$ & $\mathrm{X}$ \\
\hline Hexadecane & $\mathrm{X}$ & $\mathrm{X}$ & $\mathrm{X}$ & $\mathrm{X}$ & $\mathrm{X}$ & $\mathrm{X}$ \\
\hline Heptadecane & $\mathrm{X}$ & $\mathrm{X}$ & $\mathrm{X}$ & $\mathrm{X}$ & $\mathrm{X}$ & $\mathrm{X}$ \\
\hline Octadecane & $\mathrm{X}$ & $\mathrm{X}$ & & & & \\
\hline
\end{tabular}

Secondly, there are common human scent VOCs that are specific to a single individual which can be identified. For instance, Subject $8 \mathrm{~F}$ had two common VOCs (benzyl alcohol and undecane) which were not detected from the other five subjects. The same can be said for Subject 2F, dodecane was present in this subject's hand odor which was absent from the rest. These distinct common VOCs are likely to distinguish these subjects from the rest due to the presence of what appears to be "subject specific" compounds. Again, PCA was used to visualize the groupings of each subjects' specimens to evaluate the distinctiveness of these VOCs over time. The plot of the first three principal components for hand odor samples (cumulative variation of $59.5 \%$ ) can be seen in Figure 44. 


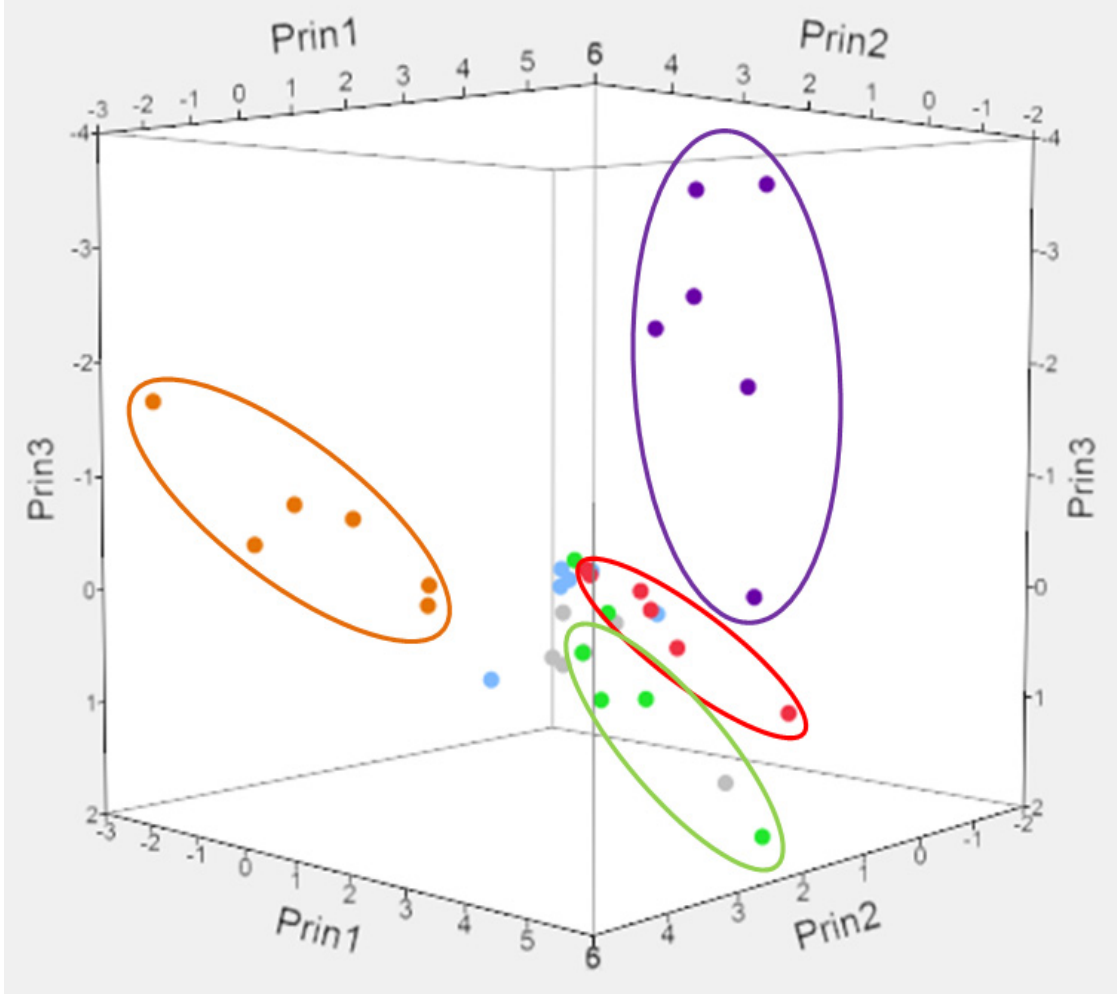

Figure 44-Hand odor samples collected over six months for six individuals (PurpleSubject 1F, red-Subject $2 \mathrm{~F}$, orange-Subject $8 \mathrm{~F}$, blue-Subject $4 \mathrm{M}$, gray-Subject $16 \mathrm{M}$, lime green-Subject 28M)

As previously noted, the groupings of Subject $2 \mathrm{~F}$ (purple) and Subject 8F's (orange) hand odor were positioned well away from the other hand odor samples. The remainder of the subject's hand odor samples was relatively close, yet each formed their own cluster. A few monthly samples could be seen grouping near the others, but as seen with the 60 person population, there were a small percentage of samples which were considered indistinguishable between two individuals.

Table 20 lists the 10 VOCs classified as common human scent for hair samples. There were three common VOCs that appear in only one subject (5-Hepten-2-one,6- 
methyl- and 1,6-Octadien-3-ol,3,7-dimethyl- from Subject 2F and dodecanoic acid from Subject 16M). Furthermore, there were fewer VOCs shared among all six subjects (such as decanal and heptadecane) than with hand odor. As a result, the PCA of hair samples (cumulative variation 69.4\%) revealed that each subject's sample formed their own cluster with fewer clusters overlapping.

Table 20-Common human scent VOCs from hair samples of six individuals

\begin{tabular}{|l|c|c|c|c|c|c|}
\hline \multicolumn{1}{|c}{ Hair VOCs } & \multicolumn{1}{c}{$\mathbf{1 F}$} & \multicolumn{2}{c}{$\mathbf{2 F}$} & \multicolumn{1}{l}{$\mathbf{4 M}$} & \multicolumn{1}{l}{$\mathbf{1 6 M}$} & $\mathbf{2 8 M}$ \\
\hline 5-Hepten-2-one,6-methyl- & & $\mathrm{X}$ & & & & \\
\hline 1,6-Octadien-3-ol,3,7-dimethyl- & & $\mathrm{X}$ & & & & \\
\hline Nonanal & $\mathrm{X}$ & & & & $\mathrm{X}$ & $\mathrm{X}$ \\
\hline Decanal & $\mathrm{X}$ & $\mathrm{X}$ & $\mathrm{X}$ & $\mathrm{X}$ & $\mathrm{X}$ & $\mathrm{X}$ \\
\hline Tetradecane & $\mathrm{X}$ & $\mathrm{X}$ & & & $\mathrm{X}$ & \\
\hline 5,9-Undecadien-2-one,6,10-dimethyl-, (E)- & $\mathrm{X}$ & $\mathrm{X}$ & & $\mathrm{X}$ & $\mathrm{X}$ & $\mathrm{X}$ \\
\hline Dodecanoicacid & & & & & $\mathrm{X}$ & \\
\hline Hexadecane & $\mathrm{X}$ & $\mathrm{X}$ & & $\mathrm{X}$ & $\mathrm{X}$ & \\
\hline Heptadecane & $\mathrm{X}$ & $\mathrm{X}$ & $\mathrm{X}$ & $\mathrm{X}$ & $\mathrm{X}$ & $\mathrm{X}$ \\
\hline Octadecane & & & $\mathrm{X}$ & & $\mathrm{X}$ & \\
\hline
\end{tabular}




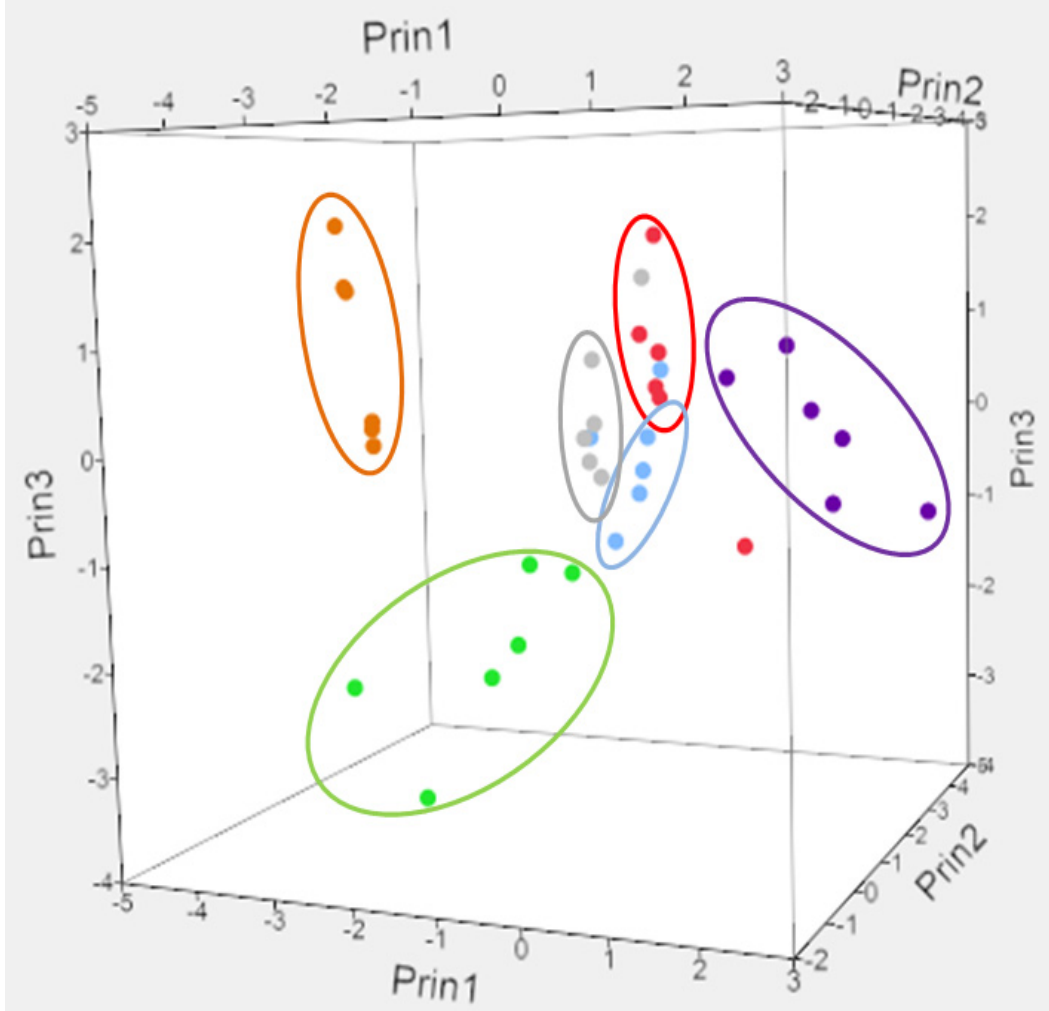

Figure 45-Hair samples collected over six months for six individuals (Purple-Subject $1 \mathrm{~F}$, red-Subject $2 \mathrm{~F}$, orange-Subject $8 \mathrm{~F}$, blue-Subject $4 \mathrm{M}$, gray-Subject 16M, lime green-Subject 28M)

A total of eleven common VOCs were detected from fingernails (Table 21); however, there were no VOCs that were shared by all of the subjects. There were, on the contrary, three VOCs that were specific to one individual which included phenyl ethyl alcohol and acetic acid, phenyl methyl ester from Subject 2F and octanoic acid from Subject 16M. Referring to the PCA of fingernails (cumulative variation 58.7\%), some of the clusters from the different subjects were more superimposed than with the previous two specimens (Figure 58). The irreproducibility of the profiles of the VOCs, over time, has led to greater matching errors from among the subjects. 
Table 21-Common human scent VOCs from fingernail samples of six individuals

\begin{tabular}{|c|c|c|c|c|c|c|c|c|}
\hline Fingernail VOCs & $\begin{array}{l}\text { 1F, } \\
\mathbf{L N}\end{array}$ & $\begin{array}{l}\text { 1F, } \\
\text { RN }\end{array}$ & $2 F$ & $8 F$ & $\begin{array}{l}\text { 4M, } \\
\text { LN }\end{array}$ & $\begin{array}{l}\text { 4M, } \\
\text { RN }\end{array}$ & $\begin{array}{l}16 \\
\text { M }\end{array}$ & 28M \\
\hline BenzylAlcohol & & & $\mathrm{X}$ & $\mathrm{X}$ & & & & \\
\hline 1,6-Octadien-3-ol,3,7-dimethyl- & & & $\mathrm{X}$ & $\mathrm{X}$ & & & & \\
\hline Nonanal & $\mathrm{X}$ & $\mathrm{X}$ & $\mathrm{X}$ & $\mathrm{X}$ & & & & \\
\hline OctanoicAcid & & & & & & & $\mathrm{X}$ & \\
\hline PhenylethylAlcohol & & & $\mathrm{X}$ & & & & & \\
\hline Aceticacid,phenylmethylester & & & $\mathrm{X}$ & & & & & \\
\hline Decanal & $\mathrm{X}$ & $\mathrm{X}$ & $\mathrm{X}$ & $\mathrm{X}$ & $\mathrm{X}$ & $\mathrm{X}$ & & $\mathrm{X}$ \\
\hline Tetradecane & & $\mathrm{X}$ & $\mathrm{X}$ & $\mathrm{X}$ & & & & \\
\hline 5,9-Undecadien-2-one,6,10-dimethyl-, (E)- & $\mathrm{X}$ & $\mathrm{X}$ & $\mathrm{X}$ & $\mathrm{X}$ & $\mathrm{X}$ & $\mathrm{X}$ & $\mathrm{X}$ & \\
\hline Heptadecane & $\mathrm{X}$ & $\mathrm{X}$ & $\mathrm{X}$ & & & $\mathrm{X}$ & & \\
\hline Octadecane & & $\mathrm{X}$ & & $X$ & & & & \\
\hline
\end{tabular}




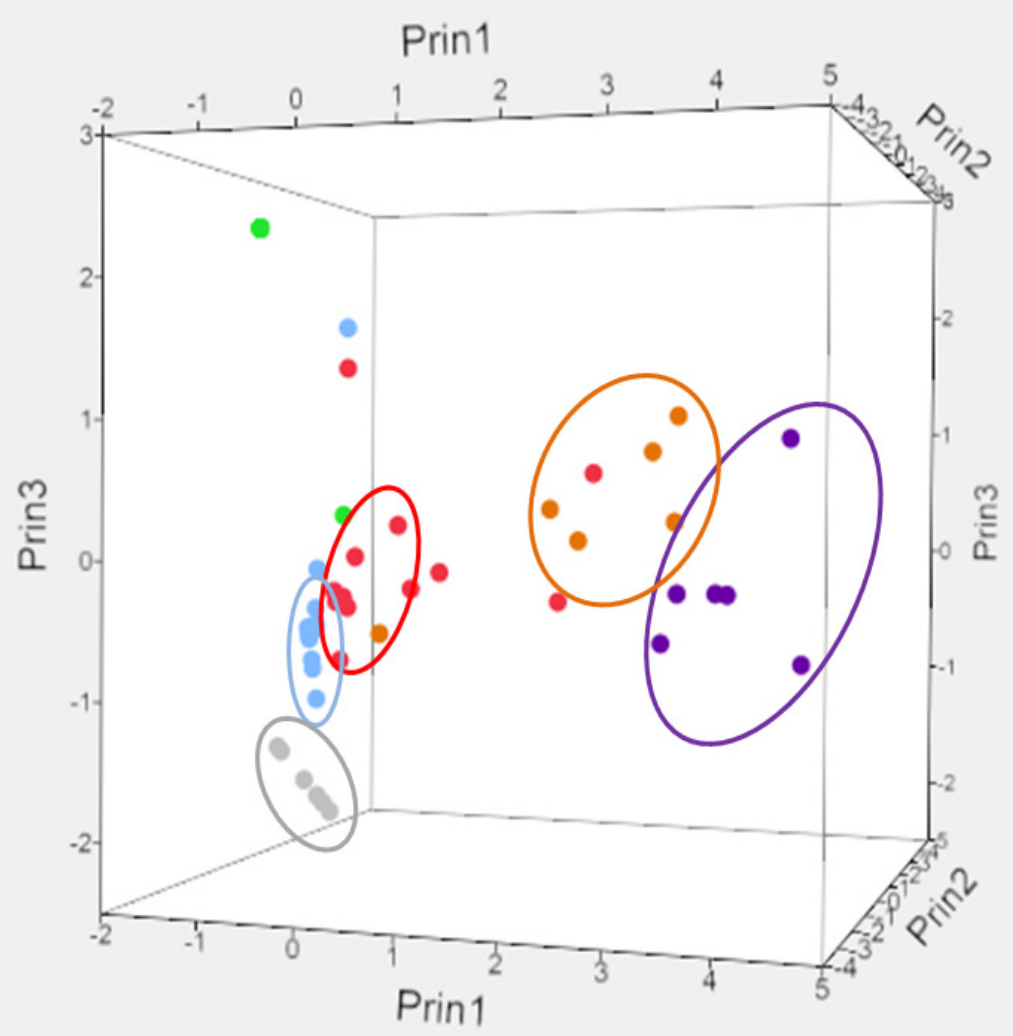

Figure 46-Fingernail samples collected over six months for six individuals (PurpleSubject 1F, red-Subject $2 \mathrm{~F}$, orange-Subject $8 \mathrm{~F}$, blue-Subject $4 \mathrm{M}$, gray-Subject $16 \mathrm{M}$, lime green-Subject 28M)

A total of twenty common VOCs were detected from saliva (Table 22). There were three common VOCs shared by all of the subjects which included 2-pentyl-furan, hexanoic acid and (E)-6,10-dimethyl- 5,9-undecadien-2-one. There were four VOCs that were specific to one individual which included nonanol and octanoic acid from Subject 2F, hexadecane from subject $1 \mathrm{~F}$ and dodecanal from Subject 4M. The PCA of saliva samples (cumulative variation 50.3\%) form distinct clusters for each subject (Figure 58). 
Table 22-Common human scent VOCs from saliva samples of six individuals

\begin{tabular}{|l|l|l|l|l|l|l|}
\hline \multicolumn{1}{|c}{ Saliva VOCs } & $\mathbf{1 F}$ & $\mathbf{2 F}$ & $\mathbf{8 F}$ & $\mathbf{4 M}$ & $\mathbf{1 6 M}$ & $\mathbf{2 8 M}$ \\
\hline Hexanal & $\mathrm{X}$ & & & & & $\mathrm{X}$ \\
\hline 1-Hexanol & & $\mathrm{X}$ & & $\mathrm{X}$ & & \\
\hline Benzaldehyde & & & $\mathrm{X}$ & $\mathrm{X}$ & & \\
\hline Phenol & & $\mathrm{X}$ & & & & \\
\hline Furan,2-pentyl- & $\mathrm{X}$ & $\mathrm{X}$ & $\mathrm{X}$ & $\mathrm{X}$ & $\mathrm{X}$ & $\mathrm{X}$ \\
\hline Hexanoicacid & $\mathrm{X}$ & $\mathrm{X}$ & $\mathrm{X}$ & $\mathrm{X}$ & $\mathrm{X}$ & $\mathrm{X}$ \\
\hline Heptanoicacid & $\mathrm{X}$ & & $\mathrm{X}$ & & & \\
\hline 2-Nonenal,(E)- & & $\mathrm{X}$ & & $\mathrm{X}$ & & \\
\hline Nonanol & & $\mathrm{X}$ & & & & \\
\hline OctanoicAcid & & $\mathrm{X}$ & & & & \\
\hline Decanal & $\mathrm{X}$ & & $\mathrm{X}$ & $\mathrm{X}$ & $\mathrm{X}$ & $\mathrm{X}$ \\
\hline Nonanoicacid & $\mathrm{X}$ & $\mathrm{X}$ & & $\mathrm{X}$ & $\mathrm{X}$ & \\
\hline Naphthalene,1-methyl- & & & & & $\mathrm{X}$ & $\mathrm{X}$ \\
\hline Tetradecane & & $\mathrm{X}$ & $\mathrm{X}$ & $\mathrm{X}$ & & \\
\hline Dodecanal & & & & $\mathrm{X}$ & & \\
\hline Caryophyllene & & $\mathrm{X}$ & $\mathrm{X}$ & $\mathrm{X}$ & & $\mathrm{X}$ \\
\hline 5,9-Undecadien-2-one,6,10-dimethyl-, (Z)- & $\mathrm{X}$ & $\mathrm{X}$ & & $\mathrm{X}$ & & \\
\hline 5,9-Undecadien-2-one,6,10-dimethyl-, (E)- & $\mathrm{X}$ & $\mathrm{X}$ & $\mathrm{X}$ & $\mathrm{X}$ & $\mathrm{X}$ & $\mathrm{X}$ \\
\hline Dodecanoicacid & & & & & & $\mathrm{X}$ \\
\hline Hexadecane & $\mathrm{X}$ & & & & & \\
\hline
\end{tabular}




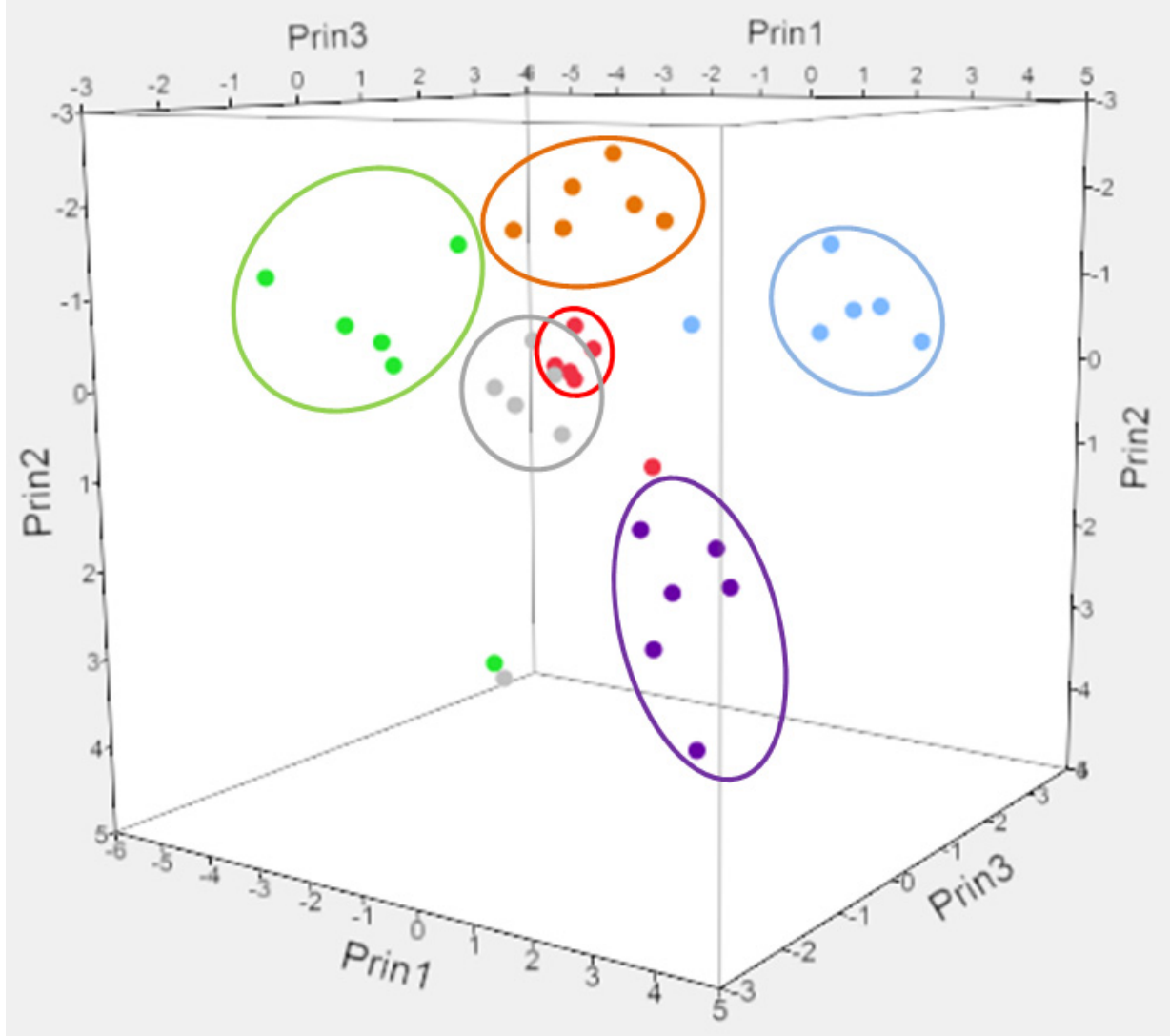

Figure 47- Saliva samples collected over six months for six individuals (PurpleSubject 1F, red-Subject $2 \mathrm{~F}$, orange-Subject 8F, blue-Subject $4 \mathrm{M}$, gray-Subject $16 \mathrm{M}$, lime green-Subject 28M)

Supporting the results from Section 3.3.2.4 (differentiating 60 individuals sampled once), the biological specimens collected over time can be used to differentiate individuals. As seen before, there were some samples that were indistinguishable between subjects, as deemed by the small distances between samples when using PCA; however, nearly all of the samples collected from the six subjects were distinguishable following a six month sampling period. 
3.3.4. Comparison of different types of samples of the same biological specimen type The profiles of the VOCs from the different types of biological specimens were evaluated to determine if the compounds being released from these specimens were specimenspecific or location-specific. Data collected have shown that each specimen produced its own profile of VOCs that was different from the other specimen types. However, what had not been addressed was whether the differences were, either, inherent to the specimens or attributed to the location of the body from which it was collected. Therefore, head hair and arm hair collected from a male subject were compared, as well as the fingernails and toe nails collected from a female subject.

\subsubsection{Comparison of head hair to arm hair}

Volatile organic compounds (VOCs) from three head hair samples and three arm hair samples (collected from a male subject) were extracted and identified using headspace solid phase microextraction gas chromatography-mass spectrometry. The identities of sixteen human scent VOCs were confirmed and their relative peak areas (abundance) can be seen in a color chart in Figure 48. The two types of hair had 10 VOCs in common which included 3,7-dimethyl-1,6-octadien-3-ol, nonanal, decanal, undecanal, tetradecane, (E)-6,10-dimethyl-5,9-undecadien-2-one, dodecanoic acid, hexadecane, heptadecane and octadecane. Three VOCs were only detected from head hair (2-ethyl-1-hexanol, pentadecane and pentadecanoic acid) and three VOCs were only detected from arm hair (2-ethyl-hexanoic acid, dodecanal and hexadecanoic acid, methyl ester). All of the VOCs detected in either type of hair sample have been previously detected in head hair samples 
from the 60 individuals sampled in 3.3.2.2, indicating there are no VOCs in this sample set that were specific to one type of hair.

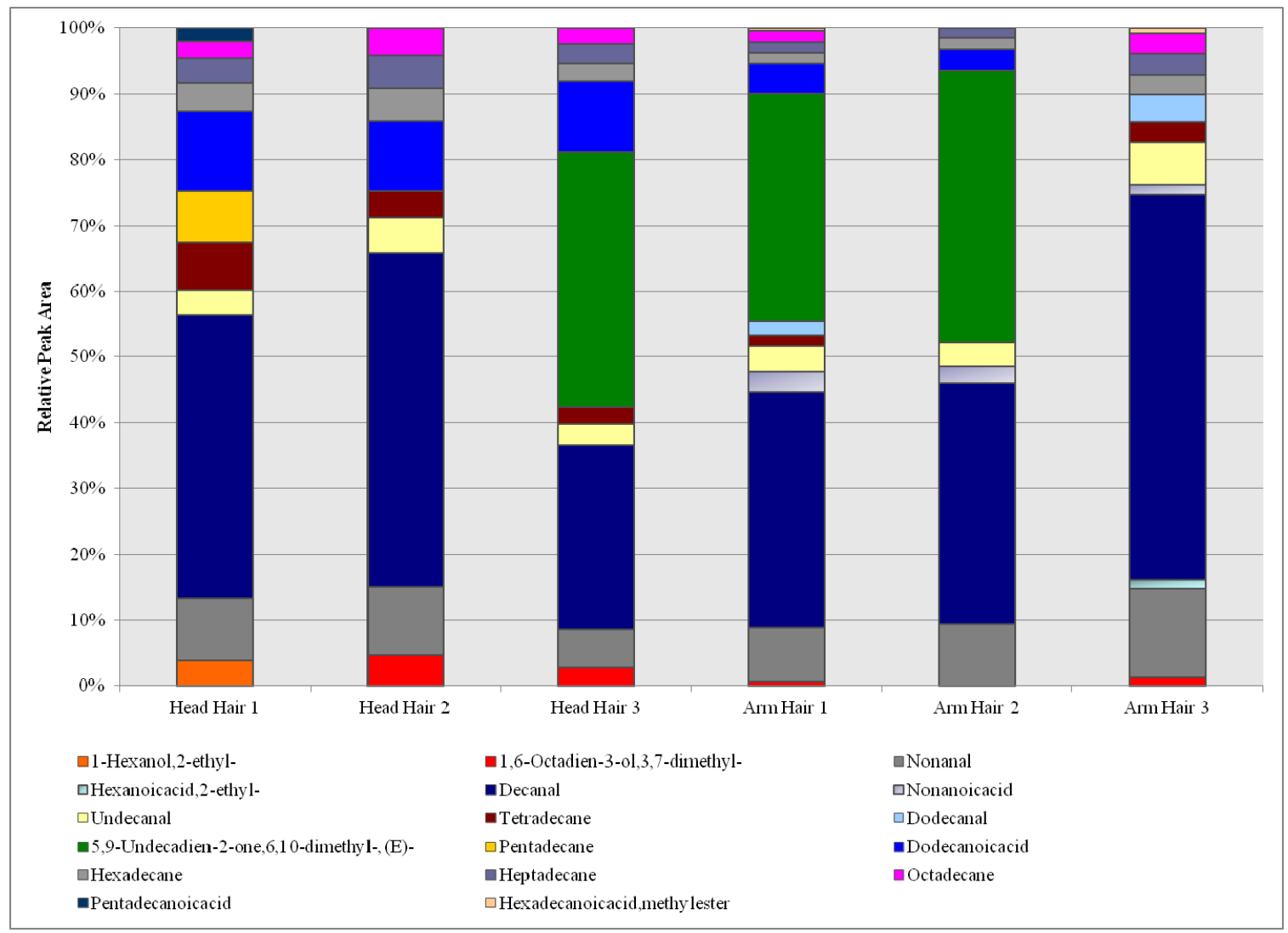

Figure 48-Profile of the VOCs generated from head hair and arm hair collected from a male subject (16M).

A statistical evaluation, using PCA, was performed on the hair types and a plot of the first three principal components can be seen in Figure 49 (cumulative variation 94.26\%). The three head hair (circles) and three arm hair (triangles) created diffuse clusters, emphasizing the variation within the specimen type. In addition, the two clusters were positioned far apart, which represented the variation between the specimen types. The initial assumption was that these two types of hair were dissimilar; however, 
maybe this assessment was a narrow one. Therefore, data from hand odor, hair, fingernails and saliva, previously acquired from the same subject, were incorporated during statistical evaluations so that a broader view can be given to the true similarities/differences of these hair types. In this situation, the newly collected head hair and arm hair samples were compared to previously collected head hair samples, along with the remaining three biological specimens, to provide a good standard for comparison.

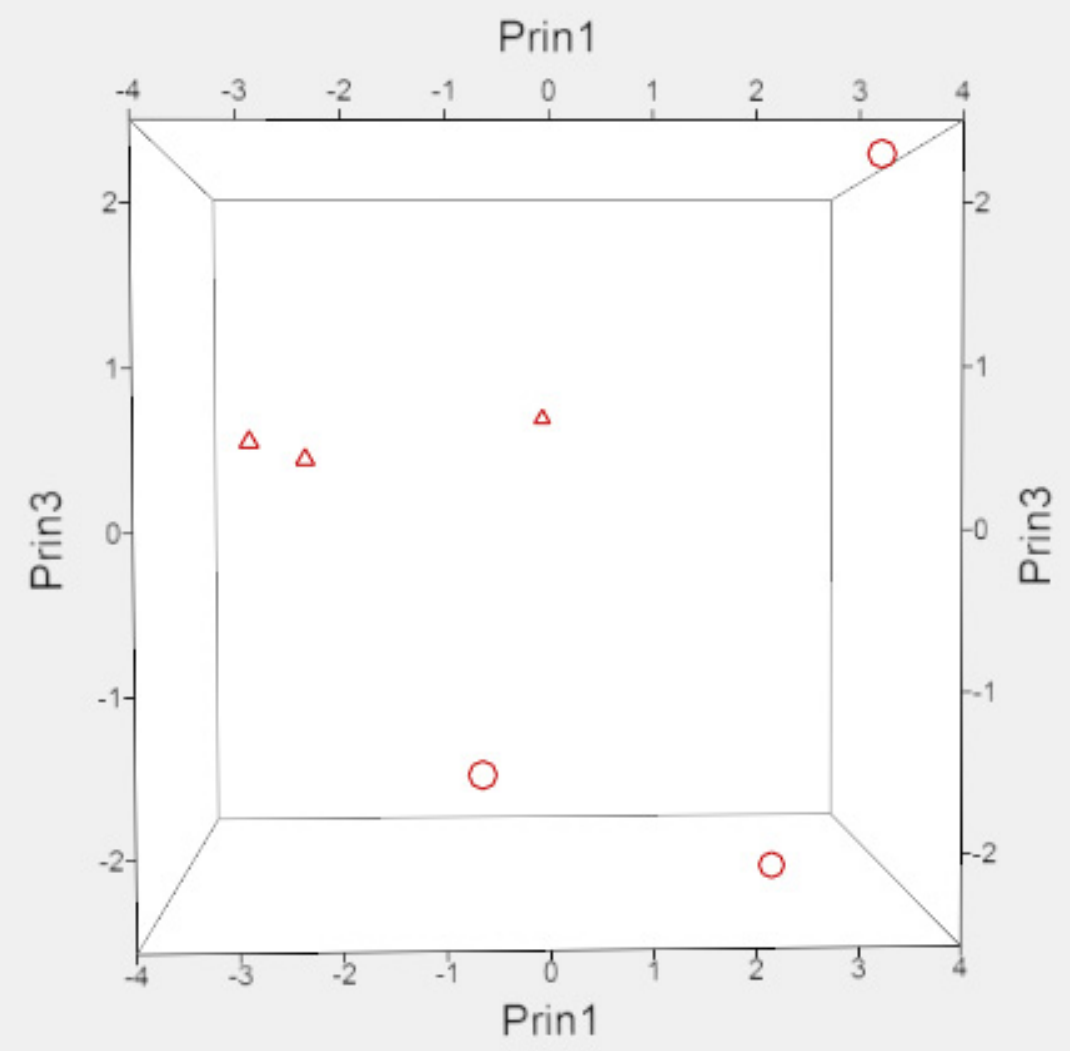

Figure 49-PCA of head hair (circles) and arm hair (triangles) collected from a male subject (16M) 
Replicate samples of hand odor, hair, fingernails and saliva were collected from the male subject fifteen days prior to the collection of the three head hair and three arm hair samples, previously seen in this section. Confirmed human scent VOCs from all specimens were identified and can be seen in Table 23, as well as in Figure 50 in the form of a color chart. Eight VOCs were shared between the three types of head hair samples (head hair \#1-3 (Day 0), head hair \#4-6 (Day 15) and arm hair) which included nonanal, decanal, tetradecane, geranylacetone, dodecanoic acid, hexadecane, heptadecane and octadecane. Two additional VOCs were present in the originally collected head hair (\#1-3) and the arm hair samples (dodecanal and hexadecanoic acid, methyl ester); however, no additional VOCs were shared between the originally collected head hair (\#13) and the head hair collected 15 days later (\#4-6). 
Table 23-VOCs detected from biological specimens from Subject 16M

\begin{tabular}{|c|c|c|c|c|c|c|c|c|c|c|c|c|c|c|c|c|c|}
\hline \multirow[t]{2}{*}{ Compound } & \multicolumn{3}{|c|}{ Hand } & \multicolumn{3}{|c|}{ Hair } & \multicolumn{3}{|c|}{ Hair* } & \multicolumn{3}{|c|}{ Arm hair } & \multicolumn{3}{|c|}{ Nails } & \multicolumn{2}{|c|}{ Saliva } \\
\hline & 1 & 2 & 3 & 1 & 2 & 3 & 4 & 5 & 6 & 1 & 2 & 3 & 1 & 2 & 3 & 1 & 2 \\
\hline Hexanal & & & & & & & & & & & & & & & & & $\mathrm{X}$ \\
\hline Hexanoic acid & & & & & & & & & & & & & & & & $\mathrm{X}$ & $\mathrm{X}$ \\
\hline Phenol & & & & & & & & & & & & & & & & $\mathrm{X}$ & $\mathrm{X}$ \\
\hline Furan,2-pentyl- & & & & & & & & & & & & & & & & $\mathrm{X}$ & $\mathrm{X}$ \\
\hline 1-Hexanol,2-ethyl- & $\mathrm{X}$ & $\mathrm{X}$ & $\mathrm{X}$ & & & & $\mathrm{X}$ & & & & & & & & & & \\
\hline Acetophenone & $\mathrm{X}$ & $\mathrm{X}$ & & & & & & & & & & & & & & $\mathrm{X}$ & \\
\hline 1,6-Octadien-3-ol,3,7-dimethyl- & & & & & & & & $\mathrm{X}$ & $\mathrm{X}$ & $\mathrm{X}$ & & $\mathrm{X}$ & & & & & \\
\hline Heptanoicacid & & & & & & & & & & & & & & & & & $\mathrm{X}$ \\
\hline Nonanal & $\mathrm{X}$ & $\mathrm{X}$ & $\mathrm{X}$ & $\mathrm{X}$ & $\mathrm{X}$ & $\mathrm{X}$ & $\mathrm{X}$ & $\mathrm{X}$ & $\mathrm{X}$ & $\mathrm{X}$ & $\mathrm{X}$ & $\mathrm{X}$ & & & & & \\
\hline Hexanoicacid,2-ethyl- & & & & & & & & & & & & $\mathrm{X}$ & & & & & \\
\hline 2-Nonenal,(E)- & & & & & & & & & & & & & & & & & $\mathrm{X}$ \\
\hline OctanoicAcid & & & & & & & & & & & & & & & $\mathrm{X}$ & & \\
\hline Decanal & $\mathrm{X}$ & $\mathrm{X}$ & $\mathrm{X}$ & $\mathrm{X}$ & $\mathrm{X}$ & $\mathrm{X}$ & $\mathrm{X}$ & $\mathrm{X}$ & $\mathrm{X}$ & $\mathrm{X}$ & $\mathrm{X}$ & $\mathrm{X}$ & & & & $\mathrm{X}$ & $\mathrm{X}$ \\
\hline Nonanoicacid & & & & & & & & & & & & & & & & $\mathrm{X}$ & $\mathrm{X}$ \\
\hline Undecanal & $\mathrm{X}$ & & & & & & $\mathrm{X}$ & $\mathrm{X}$ & $\mathrm{X}$ & $\mathrm{X}$ & $\mathrm{X}$ & $\mathrm{X}$ & & & & & \\
\hline Naphthalene,1-methyl- & & & & & & & & & & & & & & & & $\mathrm{X}$ & \\
\hline Tetradecane & $X$ & X & $\mathrm{X}$ & $\mathrm{X}$ & $\mathrm{X}$ & X & X & $X$ & $\mathrm{X}$ & $\mathrm{X}$ & & $X$ & & & & & \\
\hline Dodecanal & $\mathrm{X}$ & & & $X$ & & $\mathrm{X}$ & & & & $\mathrm{X}$ & & $\mathrm{X}$ & & & & & \\
\hline 5,9-Undecadien-2-one,6,10-dimethyl-, (E)- & $\mathrm{X}$ & $\mathrm{X}$ & $\mathrm{X}$ & $\mathrm{X}$ & $\mathrm{X}$ & $\mathrm{X}$ & & & $\mathrm{X}$ & $\mathrm{X}$ & $\mathrm{X}$ & & $\mathrm{X}$ & $\mathrm{X}$ & $\mathrm{X}$ & $\mathrm{X}$ & $\mathrm{X}$ \\
\hline Pentadecane & & & & & & & $\mathrm{X}$ & & & & & & & & & & \\
\hline Dodecanoicacid & $\mathrm{X}$ & & & $\mathrm{X}$ & $\mathrm{X}$ & $\mathrm{X}$ & $\mathrm{X}$ & $\mathrm{X}$ & $\mathrm{X}$ & $\mathrm{X}$ & $\mathrm{X}$ & & & & & & \\
\hline Hexadecane & $\mathrm{X}$ & $\mathrm{X}$ & $\mathrm{X}$ & $\mathrm{X}$ & $\mathrm{X}$ & $\mathrm{X}$ & $\mathrm{X}$ & $\mathrm{X}$ & $\mathrm{X}$ & $\mathrm{X}$ & $\mathrm{X}$ & $\mathrm{X}$ & & & & & \\
\hline Heptadecane & $\mathrm{X}$ & $\mathrm{X}$ & $\mathrm{X}$ & $\mathrm{X}$ & & & $\mathrm{X}$ & $\mathrm{X}$ & $\mathrm{X}$ & $\mathrm{X}$ & $\mathrm{X}$ & $\mathrm{X}$ & & & & & \\
\hline Octadecane & & & & $\mathrm{X}$ & & $\mathrm{X}$ & $\mathrm{X}$ & $\mathrm{X}$ & $\mathrm{X}$ & $\mathrm{X}$ & & $\mathrm{X}$ & & & & & \\
\hline Pentadecanoicacid & & & & & & & $\mathrm{X}$ & & & & & & & & & & \\
\hline Hexadecanoicacid,methylester & $\mathrm{X}$ & & & $\mathrm{X}$ & & $\mathrm{X}$ & & & & $\mathrm{X}$ & & $\mathrm{X}$ & & & & & \\
\hline
\end{tabular}

*-Head hair samples collected along with arm hair samples on Day 15. 


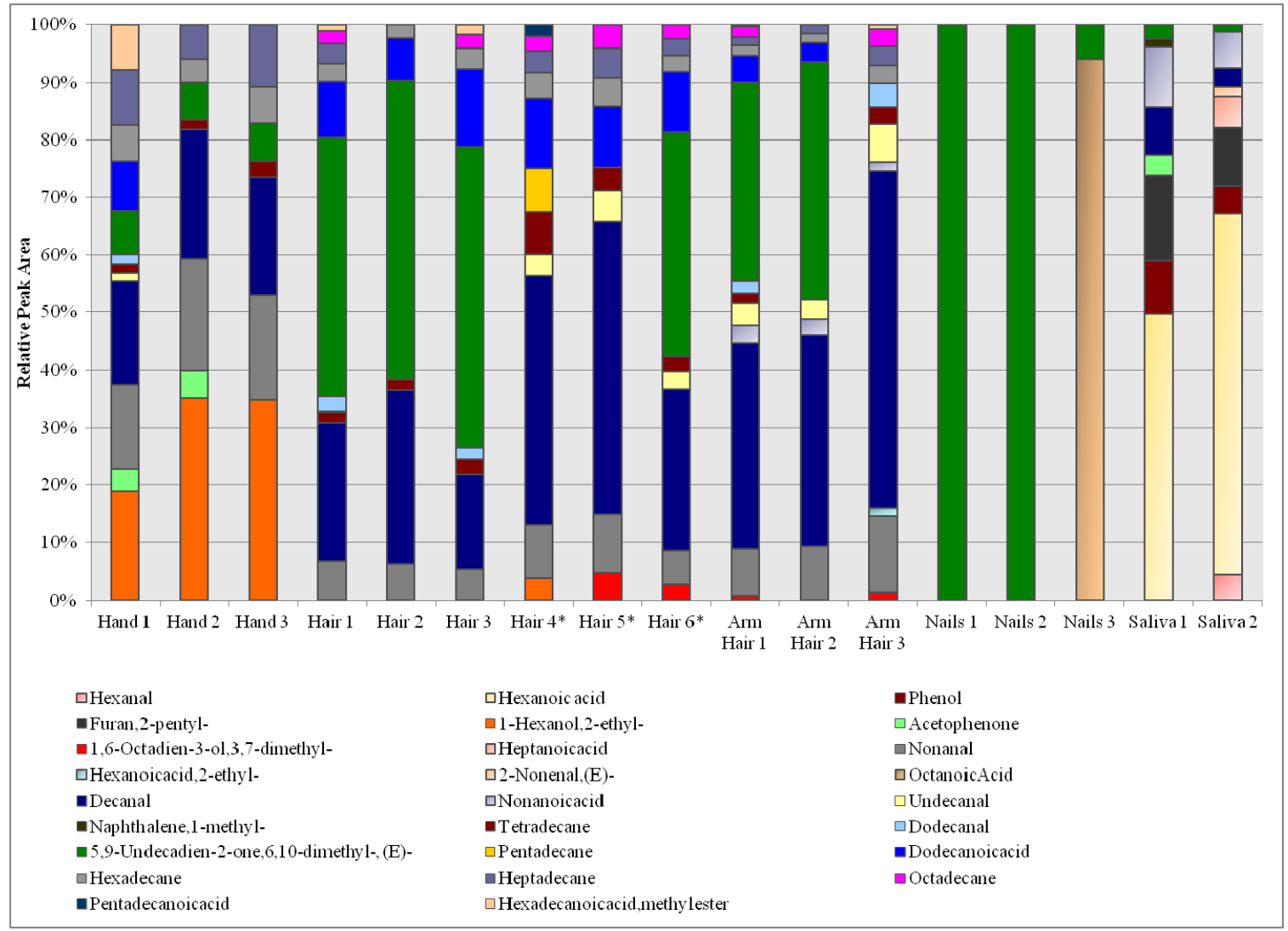

Figure 50-Profile of the VOCs generated from the biological specimens for Subject $16 \mathrm{M}$

Again, PCA was performed which now included the data from hand odor, hair (\#1-3), fingernails and saliva. A plot of the first three principal components can be seen in Figure 51 (cumulative variation $60.39 \%$ ). A cluster of all of the hair samples was observed in the middle of the plot in red. The originally collected hair (squares) was seen to be grouping with two arm hair (triangles) and one head hair (circles; collected on Day 15). Though they are still close to the main cluster of hair, one arm hair and two head hair samples (collected on Day 15) are further away from the remaining samples. In this scenario, the arm hair was grouping more frequently with the originally collected head 
hair (Day 0) because of the presence of dodecanal and hexadecanoic acid, methyl ester in both of the samples.

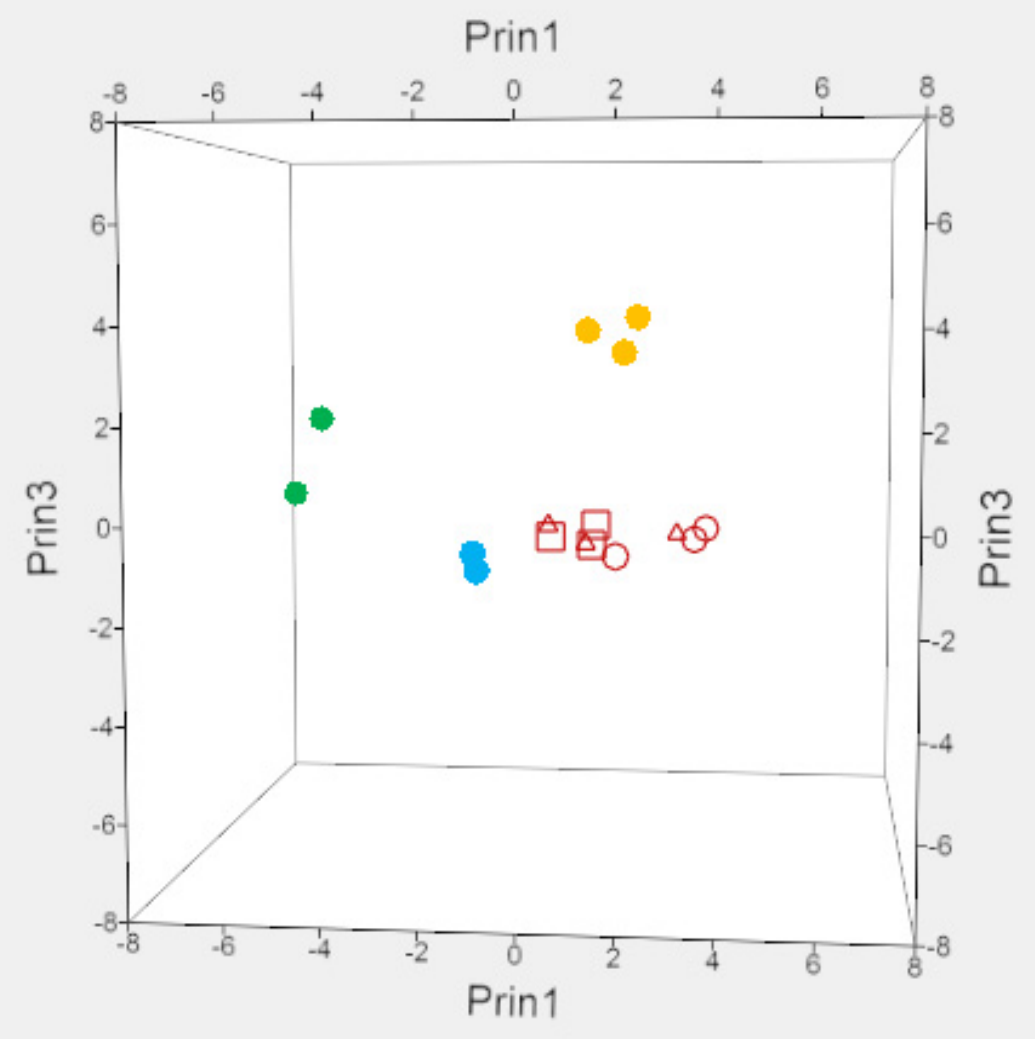

-Hand odor

- Fingernails

- Saliva

口-Ilead IIair (ุinay 0$)$

O-Head Hair (Day 1.5)

$\triangle$-Arm Hair

Figure 51-PCA of biological specimens from Subject 16M

The similarity of the specimen types was evaluated using Cluster Analysis (Euclidean distance, single linkage). The similarity between head hair (Day 0,\#1-3), arm hair (\#1-2) and head hair (Day 15,\#6) was 90.922\% (Figure 52). The cluster of the three hair samples (head hair \#4-\#5 and arm hair \#3) were positioned further away from the main hair cluster with an $88.65 \%$ similarity. All of the hair samples were $74.15 \%$ similar. These results indicate that there was no profound difference between the two 
types of hair (head hair and arm hair) which signifies that the VOCs released from biological specimens is specimen-specific, as opposed to location-specific.

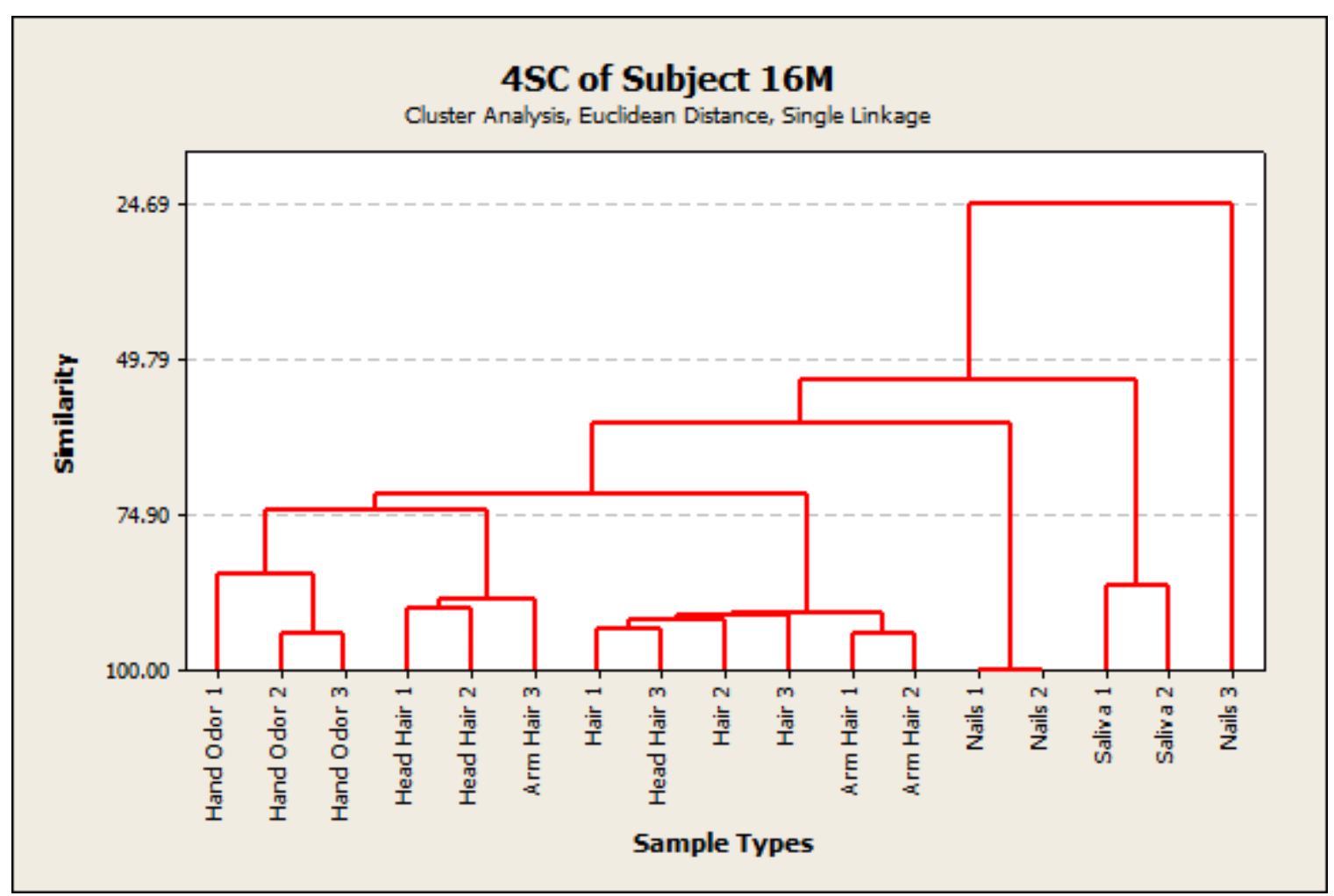

Figure 52-Dendogram of biological specimens from Subject 16M 


\subsubsection{Comparison of fingernails to toe nails}

Volatile organic compounds (VOCs) from ten fingernail (left and right hands) and ten toe nail (left and right foot) samples (collected from a female subject) were extracted and identified using headspace solid phase microextraction gas chromatography-mass spectrometry. The identities of fifteen human scent VOCs were confirmed and their relative peak areas (abundance) can be seen in a color chart in Figure 53. The two types of nails shared nine VOCs which included benzyl alcohol, 3,7-dimethyl-1,6-octadien-3ol, nonanal, octanoic acid, decanal, (E)-6,10-dimethyl-5,9-undecadien-2-one, hexadecane, heptadecane and octadecane. Five VOCs were detected only from fingernails (6-methyl-5-hepten-2-one, acetic acid, phenyl methyl ester, 3,7-dimethyl-6octen-1-ol, undecanal and tetradecane) and one VOC was detected only from toe nail samples (n-hexadecanoic acid). All of the VOCs detected in either type of nail sample have been previously detected in fingernail samples of the 60 individuals sampled in Section 3.3.2.2, indicating that there were no VOCs in this sample set that were specific to one type of nail. 


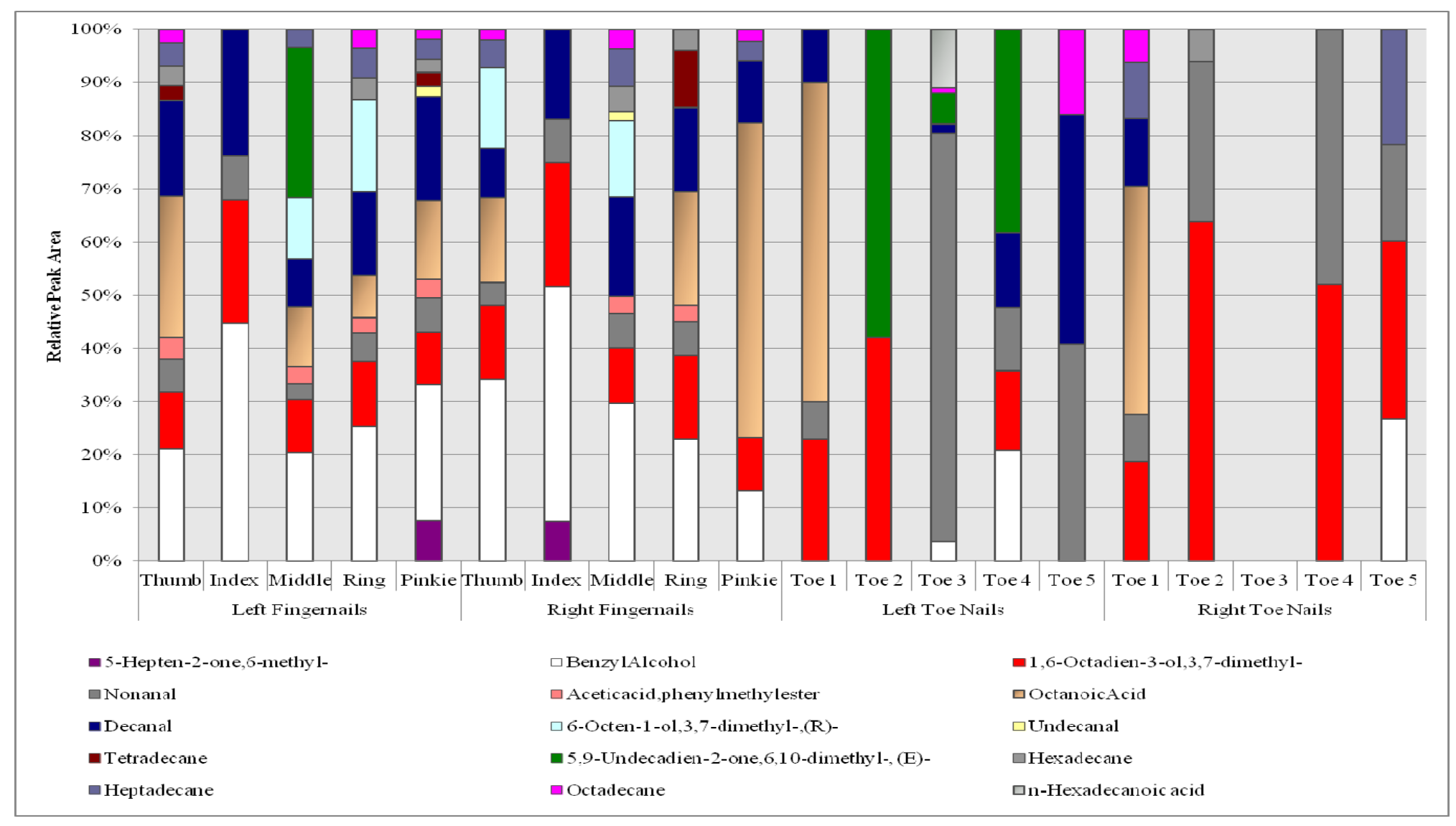

Figure 53-VOCs profile for fingernails and toe nails collected from a female subject (2F) 
Just as with the evaluation of different types of hair, PCA was performed for the different fingernail types and a plot of the first three principal components can be seen in Figure 54 (cumulative variation 50.1\%). The fingernail (open diamonds) and toe nail (closed triangles) samples created two separate clusters, with no distinction regarding which side of the body the samples were obtained from (i.e., left or right). The initial assessment of these two specimen types was that these two types of nails were distinct; therefore, these data were combined with the data of hand odor, hair, fingernails and saliva, previously acquired from the same subject, for a second look at the statistical interpretation of these volatile organic compounds.

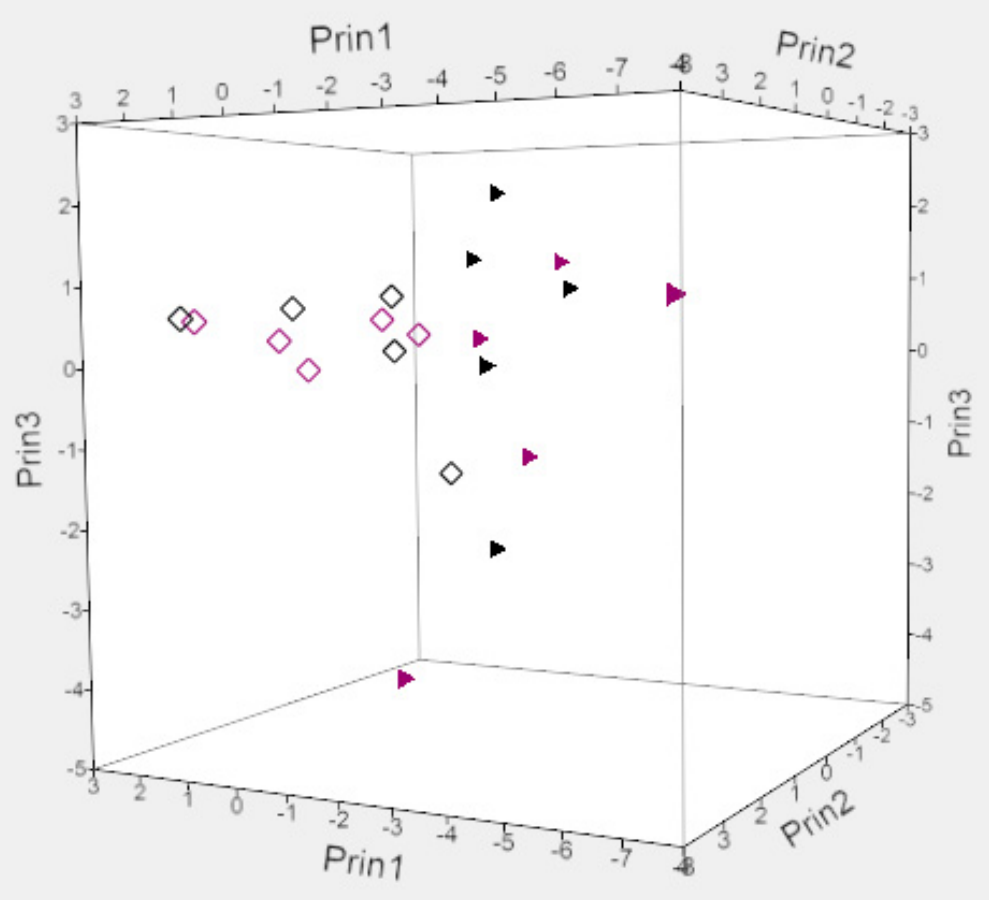

Figure 54-PCA of fingernails (open diamonds) and toe nails (triangles) collected from a female subject (2F) (Left side samples-black, Right side samples-purple) 
Triplicate samples of hand odor, hair, fingernails and saliva were collected, from a female subject, prior to the collection of the ten fingernail and ten toe nail samples, previously mentioned in this section. Confirmed human scent VOCs from all specimens were identified and can be seen in Table 24, as well as in Figure 55, in the form of a color chart. Seven VOCs were shared between the three types of fingernail samples (nails \#13, right hand and left hand nails and right and left toe nails) which included benzyl alcohol, 3,7-dimethyl-1,6-octadien-3-ol, nonanal, octanoic acid, decanal, geranylacetone and heptadecane. Two additional VOCs were present in the originally collected nails (\#1-3) and the left hand and right hand nails (acetic acid, phenyl methyl ester and tetradecane); however, no additional VOCs were shared between the originally collected nails (\#1-3) and toe nails. 
Table 24-VOCs detected from biological specimens from Subject 2 F

\begin{tabular}{|c|c|c|c|c|c|c|c|c|c|c|c|c|c|c|c|c|c|c|c|c|c|c|c|c|c|c|c|c|c|c|c|c|}
\hline \multirow[t]{2}{*}{ Compound } & \multicolumn{3}{|c|}{$\begin{array}{l}\text { Hand } \\
\text { odor }\end{array}$} & \multicolumn{3}{|c|}{ Hair } & \multicolumn{3}{|c|}{ Nails } & \multicolumn{5}{|c|}{$\begin{array}{c}\text { Left } \\
\text { hand nails }\end{array}$} & \multicolumn{5}{|c|}{$\begin{array}{c}\text { Right } \\
\text { hand nails }\end{array}$} & \multicolumn{6}{|c|}{$\begin{array}{c}\text { Left } \\
\text { toe nails }\end{array}$} & \multicolumn{4}{|c|}{$\begin{array}{l}\text { Right } \\
\text { toe nails }\end{array}$} & \multicolumn{3}{|c|}{ Saliva } \\
\hline & 1 & 2 & 3 & 1 & 2 & 3 & 1 & 2 & 3 & $\mathbf{T}$ & I & M & $\mathbf{R}$ & $\mathbf{P}$ & $\mathbf{T}$ & I & M & $\mathbf{R}$ & $\mathbf{P}$ & 1 & 2 & 3 & 4 & 5 & 1 & 2 & 3 & 4 & 5 & 1 & 2 & 3 \\
\hline 1-Hexanol & & & & & & & & & & & & & & & & & & & & & & & & & & & & & & $\mathrm{X}$ & & \\
\hline Benzaldehyde & & & & & & & & & & & & & & & & & & & & & & & & & & & & & & & $\mathrm{X}$ & \\
\hline Hexanoicacid & & & & & & & & & & & & & & & & & & & & & & & & & & & & & & $\mathrm{X}$ & $\mathrm{X}$ & $\mathrm{X}$ \\
\hline 5-Hepten-2-one,6-methyl- & & & & $\mathrm{X}$ & & $\mathrm{X}$ & & & & & & & & $\mathrm{X}$ & & $\mathrm{X}$ & & & & & & & & & & & & & & & & \\
\hline Furan,2-pentyl- & & & & & & & & & & & & & & & & & & & & & & & & & & & & & & & $\mathrm{X}$ & $\mathrm{X}$ \\
\hline Phenol & & & & & & & & & & & & & & & & & & & & & & & & & & & & & & $\mathrm{X}$ & $\mathrm{X}$ & $\mathrm{X}$ \\
\hline BenzylAlcohol & & & & & $\mathrm{X}$ & $\mathrm{X}$ & $\mathrm{X}$ & $\mathrm{X}$ & $\mathrm{X}$ & $\mathrm{X}$ & $\mathrm{X}$ & $\mathrm{X}$ & $\mathrm{X}$ & $\mathrm{X}$ & $\mathrm{X}$ & $\mathrm{X}$ & $\mathrm{X}$ & $\mathrm{X}$ & $\mathrm{X}$ & & & $\mathrm{X}$ & $\mathrm{X}$ & & & & & & $\mathrm{X}$ & & & \\
\hline Undecane & & & $\mathrm{X}$ & & & & & & & & & & & & & & & & & & & & & & & & & & & & & \\
\hline Heptanoicacid & & & & & & & & & & & & & & & & & & & & & & & & & & & & & & & $\mathrm{X}$ & \\
\hline $\begin{array}{l}\text { 1,6-Octadien-3-ol,3,7- } \\
\text { dimethyl- }\end{array}$ & & & & $\mathrm{X}$ & $\mathrm{X}$ & $\mathrm{X}$ & $\mathrm{X}$ & $\mathrm{X}$ & $\mathrm{X}$ & $\mathrm{X}$ & $\mathrm{X}$ & $\mathrm{X}$ & $\mathrm{X}$ & $\mathrm{X}$ & $\mathrm{X}$ & $\mathrm{X}$ & $X$ & $\mathrm{X}$ & $\mathrm{X}$ & $\mathrm{X}$ & $\mathrm{X}$ & & $\mathrm{X}$ & & $\mathrm{X}$ & $\mathrm{X}$ & & $\mathrm{X}$ & $\mathrm{X}$ & & & \\
\hline Nonanal & $\mathrm{X}$ & $\mathrm{X}$ & $\mathrm{X}$ & & $\mathrm{X}$ & $\mathrm{X}$ & $\mathrm{X}$ & $\mathrm{X}$ & $\mathrm{X}$ & $\mathrm{X}$ & $\mathrm{X}$ & $\mathrm{X}$ & $\mathrm{X}$ & $\mathrm{X}$ & $\mathrm{X}$ & $\mathrm{X}$ & $\mathrm{X}$ & $\mathrm{X}$ & & $X$ & & $\mathrm{X}$ & $\mathrm{X}$ & $\mathrm{X}$ & $\mathrm{X}$ & $\mathrm{X}$ & & $\mathrm{X}$ & $\mathrm{X}$ & & & \\
\hline Hexanoicacid,2-ethyl- & $\mathrm{X}$ & $\mathrm{X}$ & $\mathrm{X}$ & & & $\mathrm{X}$ & & & & & & & & & & & & & & & & & & & & & & & & $\mathrm{X}$ & & \\
\hline 2-Nonenal,(E)- & $\mathrm{X}$ & $\mathrm{X}$ & $\mathrm{X}$ & & & & & & & & & & & & & & & & & & & & & & & & & & & $\mathrm{X}$ & $\mathrm{X}$ & \\
\hline Aceticacid,phenylmethylester & & & & $\mathrm{X}$ & $\mathrm{X}$ & $\mathrm{X}$ & $X$ & $\mathrm{X}$ & $X$ & $\mathrm{X}$ & & $\mathrm{X}$ & $\mathrm{X}$ & $\mathrm{X}$ & & & $\mathrm{X}$ & $X$ & & & & & & & & & & & & & & \\
\hline OctanoicAcid & & & & & & & & $\mathrm{X}$ & & $\mathrm{X}$ & & $\mathrm{X}$ & $\mathrm{X}$ & $\mathrm{X}$ & $\mathrm{X}$ & & & $\mathrm{X}$ & $\mathrm{X}$ & $\mathrm{X}$ & & & & & $\mathrm{X}$ & & & & & $\mathrm{X}$ & $\mathrm{X}$ & $\mathrm{X}$ \\
\hline Decanal & $\mathrm{X}$ & $\mathrm{X}$ & $\mathrm{X}$ & $\mathrm{X}$ & $\mathrm{X}$ & $\mathrm{X}$ & $X$ & $\mathrm{X}$ & $\mathrm{X}$ & $\mathrm{X}$ & $\mathrm{X}$ & $\mathrm{X}$ & $\mathrm{X}$ & $\mathrm{X}$ & $\mathrm{X}$ & $\mathrm{X}$ & $\mathrm{X}$ & $\mathrm{X}$ & $\mathrm{X}$ & $\mathrm{X}$ & & $\mathrm{X}$ & $\mathrm{X}$ & $\mathrm{X}$ & $\mathrm{X}$ & & & & & $\mathrm{X}$ & $\mathrm{X}$ & $\mathrm{X}$ \\
\hline $\begin{array}{l}\text { 6-Octen-1-ol,3,7-dimethyl- } \\
\text {,(R)- }\end{array}$ & & & & $\mathrm{X}$ & $\mathrm{X}$ & $\mathrm{X}$ & & & & & & $X$ & $\mathrm{X}$ & & $\mathrm{X}$ & & $X$ & & & & & & & & & & & & & & & \\
\hline Tridecane & $\mathrm{X}$ & $\mathrm{X}$ & $\mathrm{X}$ & & & & & & & & & & & & & & & & & & & & & & & & & & & & & \\
\hline Naphthalene,2-methyl- & & & & & & & & & & & & & & & & & & & & & & & & & & & & & & $\mathrm{X}$ & & \\
\hline Undecanal & $\mathrm{X}$ & $\mathrm{X}$ & $\mathrm{X}$ & & & & & & & & & & & $\mathrm{X}$ & & & $\mathrm{X}$ & & & & & & & & & & & & & & & \\
\hline Tetradecane & $\mathrm{X}$ & $\mathrm{X}$ & $\mathrm{X}$ & $\mathrm{X}$ & $\mathrm{X}$ & $\mathrm{X}$ & & $\mathrm{X}$ & $\mathrm{X}$ & $\mathrm{X}$ & & & & $\mathrm{X}$ & & & & $\mathrm{X}$ & & & & & & & & & & & & & $\mathrm{X}$ & $\mathrm{X}$ \\
\hline Dodecanal & $\mathrm{X}$ & $\mathrm{X}$ & $\mathrm{X}$ & & & & & & & & & & & & & & & & & & & & & & & & & & & & & \\
\hline Caryophyllene & & & & & & & & & & & & & & & & & & & & & & & & & & & & & & $\mathrm{X}$ & $\mathrm{X}$ & \\
\hline 5,9-Undecadien-2-one,6,10- & & & & & & & & & & & & & & & & & & & & & & & & & & & & & & $\mathrm{X}$ & $\mathrm{X}$ & $\mathrm{X}$ \\
\hline
\end{tabular}




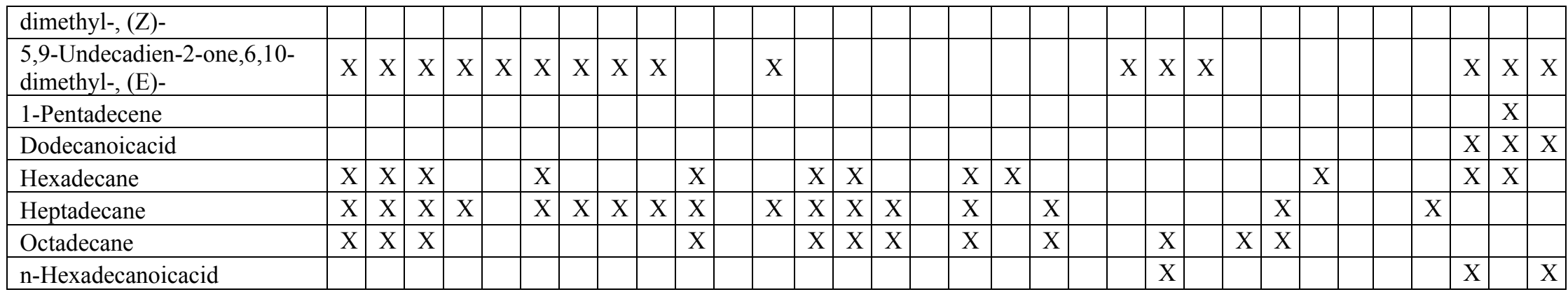




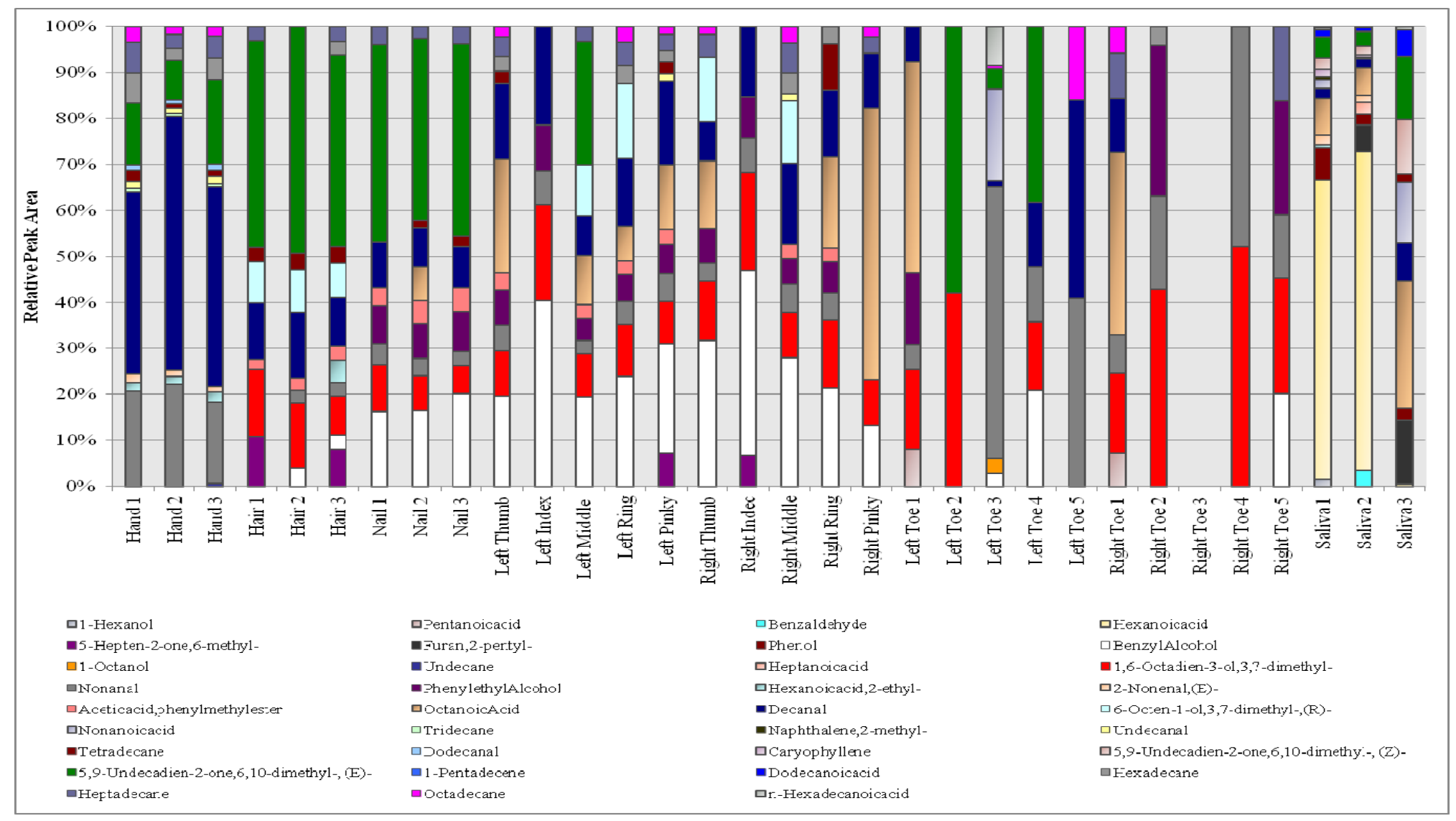

Figure 55-Profile of the VOCs generated from the biological specimens for Subject 2F 
Principal component analysis was performed a second time. A plot of the first three principal components can be seen in Figure 56 (cumulative variation 45.1\%). A cluster of nail samples \#1-3, left and right hand nails, left and right toe nails and hair samples can be seen in the middle of the plot. The originally collected nail samples (blue dots) cluster closely with the left and right hand nails; while nearby, the left and right toe nails are slightly further away.

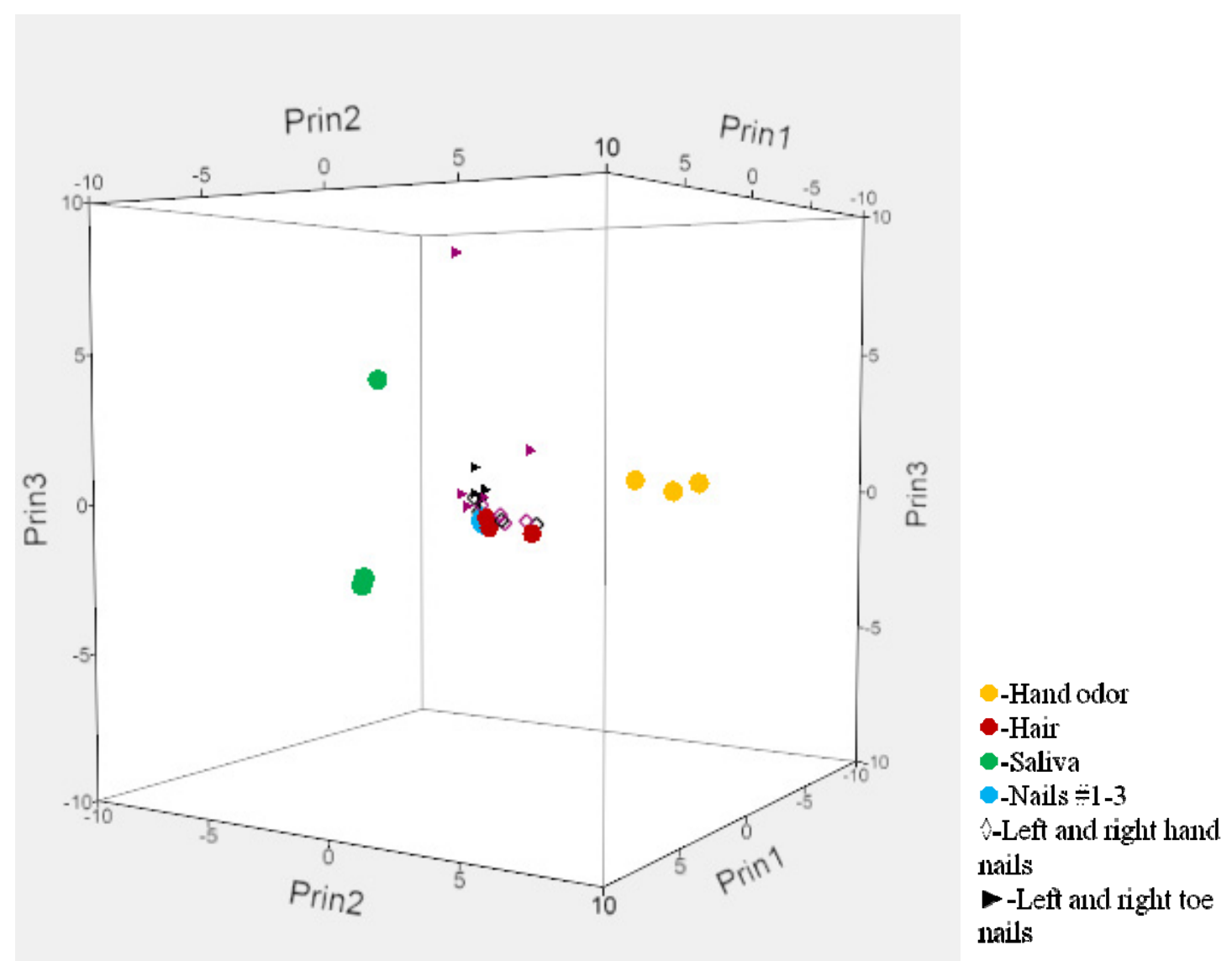

Figure 56-PCA of biological specimens from Subject 2F

The similarity of the specimen types was also evaluated using Cluster Analysis (Euclidean distance, single linkage). The originally collected nails (\#1-3) had a similarity 
value of $91.2 \%$ (Figure 57). All of the left hand and right hand nails (excluding the left middle and right pinky nail) were $75.8 \%$ similar. When comparing the originally collected nails (\#1-3) to the ten left and right hand nails a similarity value of $70.2 \%$ was obtained. A low percentage of similarity has been seen before with fingernails collected over time, which produced an average similarity of $63.9 \%$ over a six month period. The similarity between the left and right hand nails and the original nail samples, collected over two and a half years prior, was well above the expected similarity value for this specimen type.

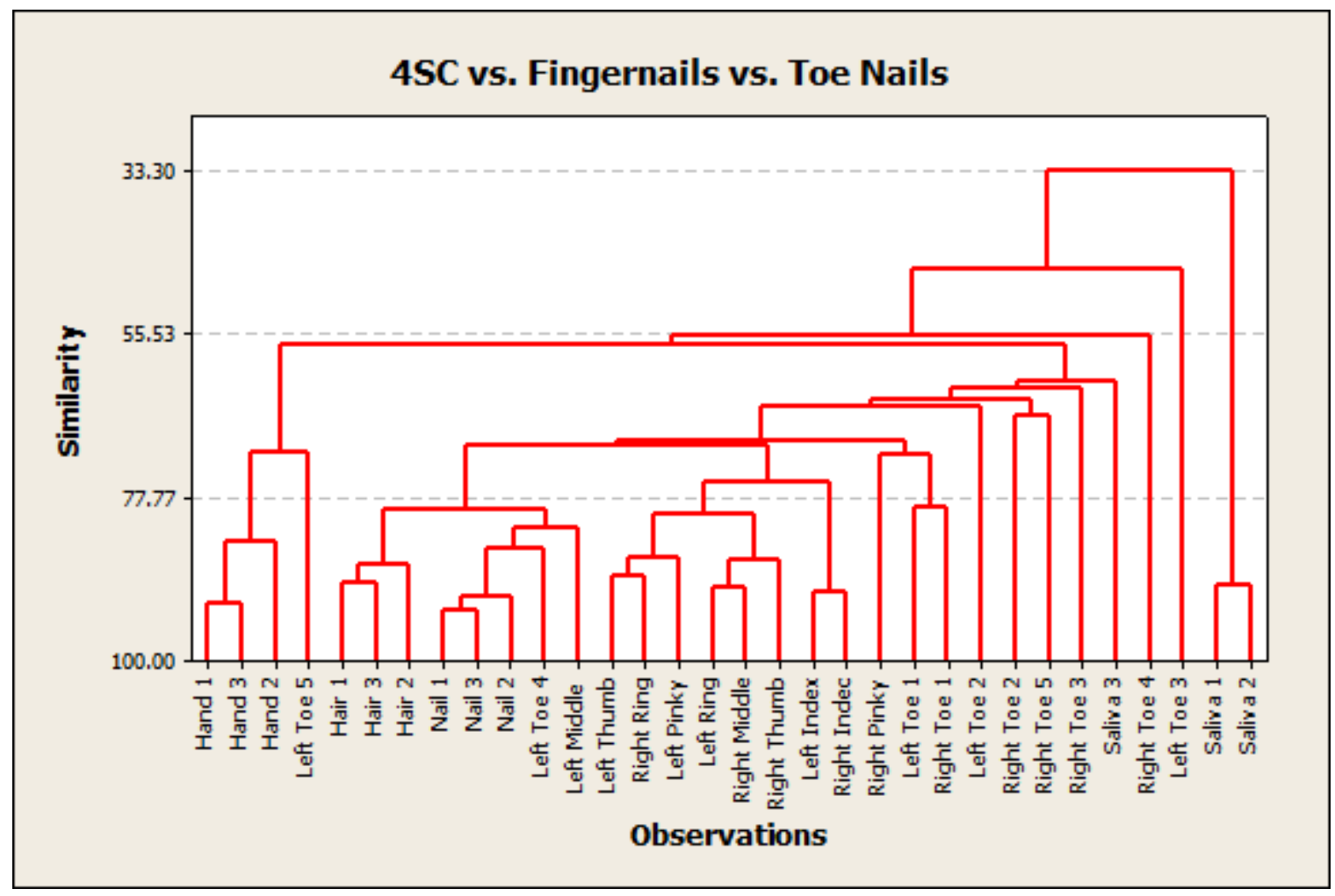

Figure 57-Dendogram of biological specimens from Subject 2F 
Now turning the attention to toe nails, when all of the nail types were considered, a similarity value of $46.8 \%$ was obtained. This work was the first to identify the VOCs from toe nails and compared the VOCs to fingernail samples. It appears, on the basis of the low similarity between the samples that though toe nails have some VOCs in common with fingernails, their quantitative differences make these the two specimen types dissimilar. Perhaps as a result of the low reproducibility of the VOCs being released by this specimen type, it is not best to use it for the evaluation of specimen vs. location specific volatile organic compounds. However, the results seen here indicate that fingernails and toe nails are sufficiently different which contradicts the results acquired during the evaluation of different hair types. 


\section{CANINE EVALUATIONS OF BIOLOGICAL SPECIMENS}

\subsection{Materials}

The Human Scent Collection System (Battelle Memorial Institute, Columbus, OH) and the Scent Transfer Unit 100 (Big 'T' LLC, Haw River, NC) were the dynamic airflow devices used for scent collection. Human scent was collected onto 2" x 2" or 4" x 4" gauze pads DUKAL brand, 100\% cotton, sterile, 8 ply, gauze sponges (DUKAL Corporation, Syosset, NY). The solvent used for the pretreatment of gauze pads was methanol (HPLC grade, Fisher Scientific, Pittsburgh, PA). Chrome plated steel fingernail clippers were used for the collection of fingernail clippings (Tweezerman International, Port Washington, NY). The cotton swabs used for saliva collection were 6" in length, wood stem, sterile, cotton tipped applicators (Solon Manufacturing Company, Skowhegan, ME), which were cut to fit inside $10-\mathrm{mL}$ or $40-\mathrm{mL}$ clear glass, screw top vials with PTFE/Silicone septa (SUPELCO, Bellefonte, PA). The solvent used for the pretreatment of cotton swabs was ethanol (AAPER Alcohol and Chemical Co., Shelbyville, KY). All scent samples were stored in 10-mL clear glass, screw top vials with PTFE/Silicone septa (SUPELCO, Bellefonte, PA). Scent samples collected from one target were stored in its own small Pelican Case (The Pelican Store, Milwaukee, WI) to prevent cross contamination of scents. 


\subsection{Methods}

\subsubsection{Canine evaluation of collected biological specimens}

Canine response to human scent originating from head hair, fingernail clippings and saliva, were evaluated and compared to hand odor in a series of field tests. The objective of this task was to evaluate the utility of these alternative biological specimens as scent sources for human scent discriminating canines. Biological specimens were evaluated by observing canine response when presented with the scent collected from a biological specimen in the presence of the corresponding target's scent trail. Canine teams used in these field tests were located in Long Beach, California, which is also where testing was conducted. All field tests were double-blind which means neither the handlers nor the trail monitors knew which sample was presented to the canine or the direction of the scent trails.

\subsubsection{Evaluation of head hair}

\section{Creation of Scent Trails}

Volunteers were recruited to serve as targets and were compensated for their participation. Scent trails were created when a target walked a path depositing their scent into the environment. For these field tests, scent trails were created by having a target walk away from a predetermined starting point and make two decisions (i.e., left turn, right turn, or continue straight) at alleyways or intersections. The direction of the decisions made along the path of the target was randomly selected by the test coordinators and the target was informed as to which route to take. A total of three trail layers produced a scent trail at each starting point, but each with a different path. Four 
test locations were used for these field tests, such that each location was used to test a different experimental variable. The scent trails made by the targets can be seen in Figure 58 for each of the test locations.
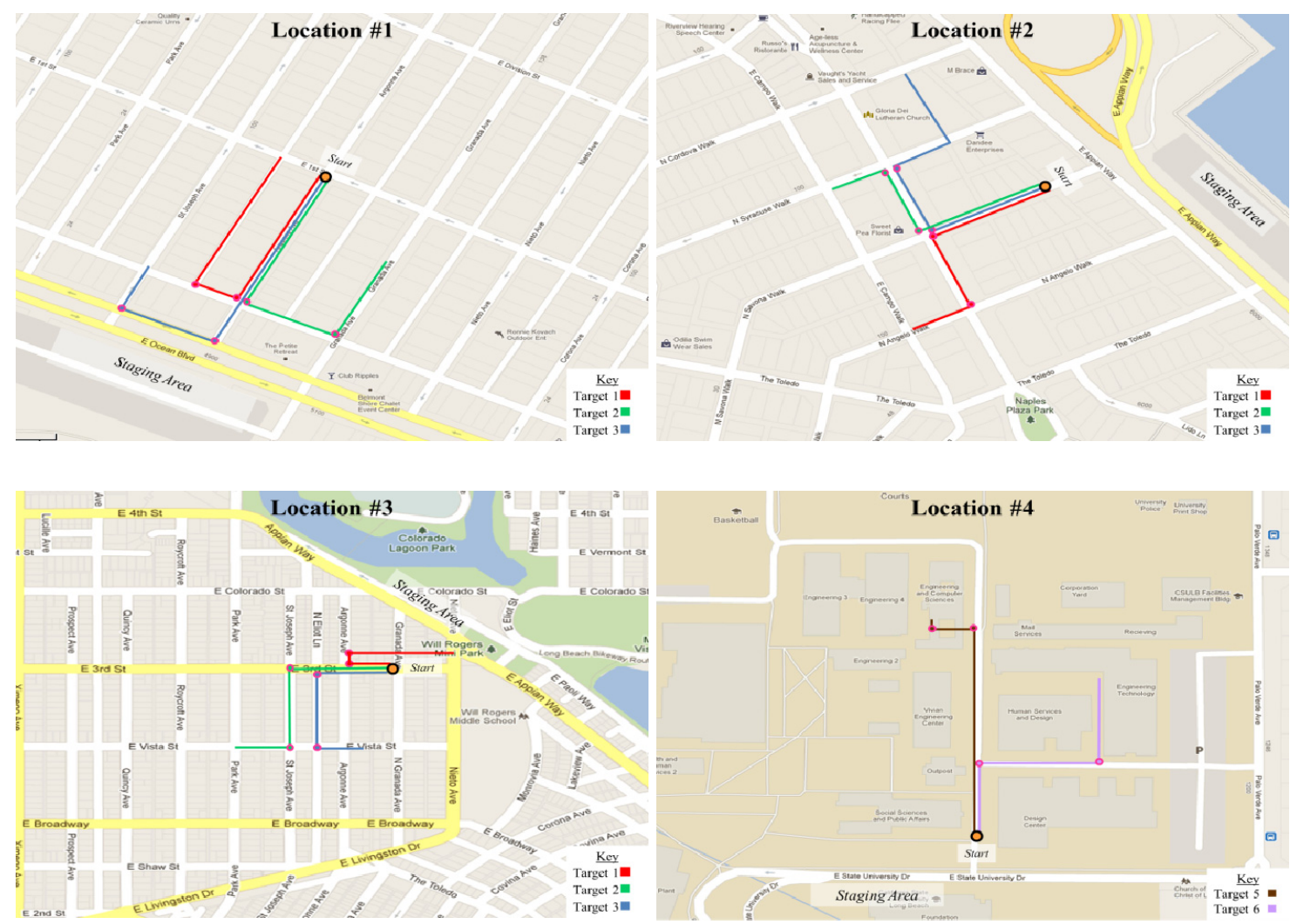

Figure 58-Maps of scent trails created by targets for the evaluation of head hair

Test locations included residential areas and a local university. The temperature, relative humidity and wind speed at the time the trails were laid (1) and at the time of the canine evaluations (2) were collected and are listed in Table 25. 
Table 25- Environmental conditions at each test location, for the evaluation of head hair, at the times the 1) trails were laid and 2) when canine testing was conducted.

\begin{tabular}{|c|c|c|c|c|c|c|c|}
\hline & & \multicolumn{2}{|c|}{ Temperature $\left({ }^{\circ} \mathbf{C}\right)$} & \multicolumn{2}{c|}{ Relative Humidity (\%) } & \multicolumn{2}{c|}{ Wind Speed (m/s) } \\
\cline { 2 - 8 } Test Location & Trail Age (hrs) & $\mathbf{1}$ & $\mathbf{2}$ & $\mathbf{1}$ & $\mathbf{2}$ & $\mathbf{1}$ & $\mathbf{2}$ \\
\hline 1 & 24 & 21.6 & 20.4 & 60.7 & 67.1 & 0.3 & 0.1 \\
\hline 2 & 24 & 24.8 & 24.2 & 51.0 & 56.3 & 0.0 & 1.5 \\
\hline 3 & 48 & 24.1 & 21.6 & 44.5 & 60.8 & 0.8 & 1.3 \\
\hline 4 & 1 & 22.4 & & 59.1 & & 2.0 & \\
\hline
\end{tabular}

\section{Collection of Scent Samples}

On the same day the scent trails were created, scent samples were collected from the targets using both the Scent Transfer Unit 100 (STU-100) and the Human Scent Collection System (HSCS); therefore, ensuring that the scent on the trail was the same age as the scent sample. Scent was collected from the hands and head hair of targets onto a piece of cotton gauze. Scent was collected by holding the device approximately one inch away from the scent source and running it on the high airflow setting. The scent collection times used were 30 seconds or 60 seconds. The scent collection device, scent source and collection time were evaluated at each location listed in Table 26. Following scent collection, the collection material was placed into a $10-\mathrm{mL}$ clear glass vial and stored in a small pelican case. Scent samples from the same target were stored together, to prevent cross contamination from the scent of another target. 
Table 26-Listing of which collection device, specimen type and collection time was used to create scent samples at each test location.

\begin{tabular}{|c|c|c|c|}
\hline Test Location & Collection Device & Specimen Type & Collection Time \\
\hline 1 & STU-100 & Hand/Hair & 30 seconds \\
\hline 2 & HSCS & Hand/Hair & 30 seconds \\
\hline 3 & STU-100/ HSCS & Hand & 30 seconds \\
\hline 4 & HSCS & Hair & 60 seconds \\
\hline
\end{tabular}

\section{Canine Evaluations}

Seven (7) canine teams were used for canine evaluations. Information pertaining to each canine team that participated in the canine field tests is listed in Table 27. At each test location, a canine team was taken to a start point of a scent trail and the handler was given a scent sample to present to the canine. Following the presentation of a scent sample, three types of canine responses were recorded by the trail monitor: 1) does the canine begin to trail; 2) the canine's first decision and 3) the canine's second decision. The role of the trail monitor was to follow the canine teams and document any observations. Trail monitors did not know what sample was being presented to the canine nor did they know the path of any of the targets' scent trails. Trail monitors were volunteers and they were compensated for their participation. Targets were not present at the end of a scent trail, except for location \#4. All of the canine teams completed two tests at each location. In addition to scent samples, blanks were randomly incorporated into testing. 
Table 27-Canine teams used for the evaluation of head hair and their corresponding information

\begin{tabular}{|c|c|c|c|c|c|}
\hline Team \# & Age & B reed & $\begin{array}{c}\text { Years of } \\
\text { Training }\end{array}$ & Certified & $\begin{array}{c}\text { Certification } \\
\text { Date }\end{array}$ \\
\hline 1 & 16 months & German Shepard & 8 weeks & No & N/A \\
\hline 2 & 4.5 years & Blue Tick Coon Hound & 4.5 years & Yes & 2006 \\
\hline 3 & 2 years & German Shepard & 8 weeks & No & N/A \\
\hline 4 & 7 years & Bloodhound & 7 years & Yes & \\
\hline 5 & 3.5 years & Bloodhound & 3.5 years & Yes & Nov. 2008 \\
\hline 6 & 8.5 years & Bloodhound & 8 years & Yes & $2003 / 2004$ \\
\hline 7 & 3 years & Bloodhound & 3 years & No & \\
\hline
\end{tabular}

\subsubsection{Evaluation of fingernail clippings}

\section{Creation of Scent Trails}

Volunteers were recruited to serve as targets and were compensated for their participation. For these field tests, scent trails were created in two manners. One manner of laying a trail of scent, which was used at test location \#1, involved having a target walk away from an initial point and incorporating a variety of decisions (i.e., left turn, right turn or continue straight) for a total distance of 0.33-0.87 miles. Multiple starting points were utilized along this type of scent trail. The other manner of laying a trail of scent, which was used at test location \#2, was created by having a target walk away from a pre-selected starting point and making only two decisions (i.e., left turn, right turn, or continue straight) which ended the scent trail. This type of trail ranged from 0.1-0.3 miles in length. The direction of the decisions made along the path of a target's scent trail was randomly selected by the test coordinators and the target was informed as to which route to take. A total of three trail layers produced a scent trail at each test 
location and each with a different path. Two test locations were used for these field tests. The scent trails made by the targets at each of the test locations can be seen in Figure 59 .
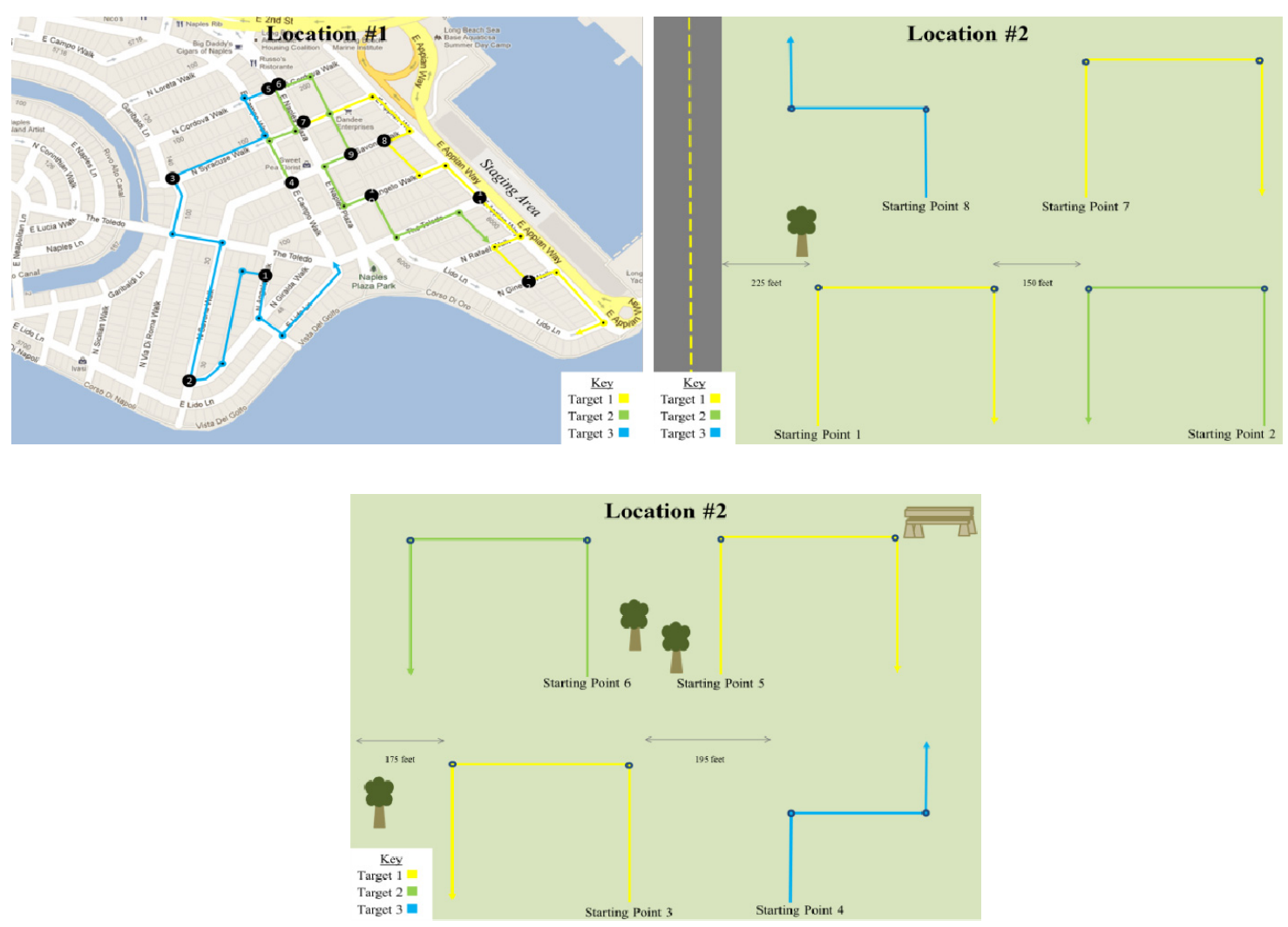

Figure 59-Maps of scent trail created by targets for the evaluation of fingernails

All scent trails were created one hour prior to testing. Test locations included residential areas and a park. The temperature, relative humidity and wind speed at each test location was collected and are listed in Table 28. 


\section{Table 28-Environmental conditions at each test location for the evaluation of fingernails}

\begin{tabular}{|c|c|c|c|}
\hline Test Location & Temperature $\left({ }^{\circ} \mathbf{C}\right)$ & Relative Humidity $\mathbf{( \% )}$ & Wind Speed $(\mathbf{m} / \mathbf{s})$ \\
\hline 1 & 18.9 & 70.0 & 0.6 \\
\hline 2 & 29.9 & 50.4 & 3.5 \\
\hline
\end{tabular}

\section{Collection of Scent Samples}

Fingernail samples were collected from the participating targets 24 hours prior to the start of field testing. Hand odor was collected on the day of testing. Each target clipped the excess portion of all ten fingernails using stainless steel fingernail clippers (which were cleaned with isopropyl alcohol wipes). The total mass of fingernails collected from each target was $36.6 \mathrm{mg}, 35.9 \mathrm{mg}$, and $50.3 \mathrm{mg}$ for Targets 1, 2 and 3, respectively. The fingernail clippings were gathered and placed into a $10-\mathrm{mL}$ glass vial. The cap was replaced on the vial and it was stored in a pelican case until the day of testing.

Scent samples were created using the Scent Transfer Unit 100 (STU-100). Scent was collected from the palms of the hands and from the fingernails of the targets onto a 2" x 2" cotton gauze. Scent was collected by holding the STU-100 approximately one inch away from the scent source and running it on high airflow setting for 30 seconds. Following scent collection, the cotton gauze was placed into a new $10-\mathrm{mL}$ clear glass vial and stored in the respective target's pelican case to prevent cross contamination from other target's scent. 


\section{Canine Evaluations}

Four (4) canine teams were used for canine evaluations. Information pertaining to each canine team that participated in the canine field tests is listed in Table 29. At each test location, a canine team was taken to a start point and the handler was given a scent sample to present to the canine. Following the presentation of a scent sample, three types of canine responses were recorded by the trail monitor: 1) does the canine begin to trail; 2) the canine's first decision and 3) the canine's second decision. Targets were not present at the end of a scent trail. All of the canine teams completed two tests at each location.

\section{Table 29- Canine teams used for the evaluation of fingernails and their corresponding information}

\begin{tabular}{|c|c|c|c|}
\hline Team & Age (years) & Breed of Dog & Year of Training \\
\hline 1 & 3 & German Shepard & 2 \\
\hline 2 & 5 & Bloodhound & 4.5 \\
\hline 3 & 4 & German Shepard & 1 \\
\hline 4 & 10 & Bloodhound & 9.5 \\
\hline
\end{tabular}

\subsubsection{Evaluation of saliva}

\section{Creation of Scent Trails}

Volunteers were recruited to serve as targets and were compensated for their participation. For these field tests, scent trails were created in two fashions. One manner of laying the scent trail, which was used at test locations \#1 and \#3, involved having a target walk away from a starting point and incorporating a variety of decisions (i.e., left turn, right turn or continue straight) for a total distance of 0.8-1.2 miles. Multiple starting 
points were utilized along this type of scent trail. The other manner of laying the scent trail, which was used at test location $\# 2$ and \#4, was created by having a target walk away from a pre-selected starting point and making one or two decisions (i.e., left turn, right turn, or continue straight) at alleyways or intersections. The trails used for these evaluations ranged from 0.1-0.3 miles in length. The direction of the decisions made along the path of the target was randomly selected by the test coordinators and the target was informed as to which route to take. A total of three trail layers produced a scent trail at each test location and each with a different path. Four test locations were used for these field tests. The scent trails made by the targets at each of the test locations can be seen in Figure .

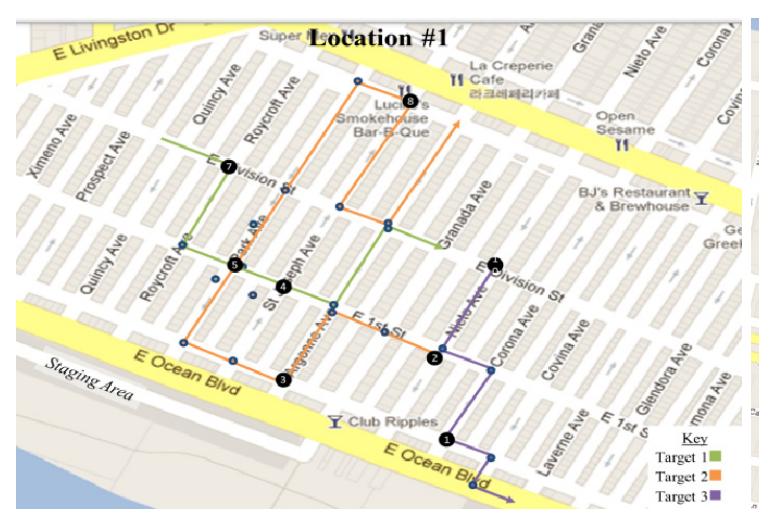

Location \#2:Lot A

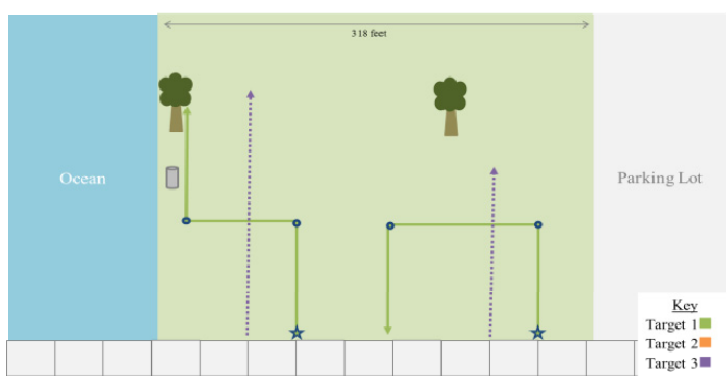

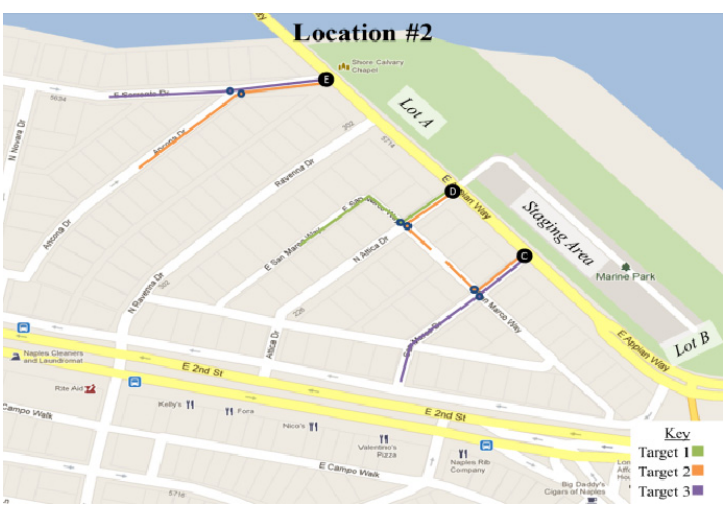

Location 2 :Lot B

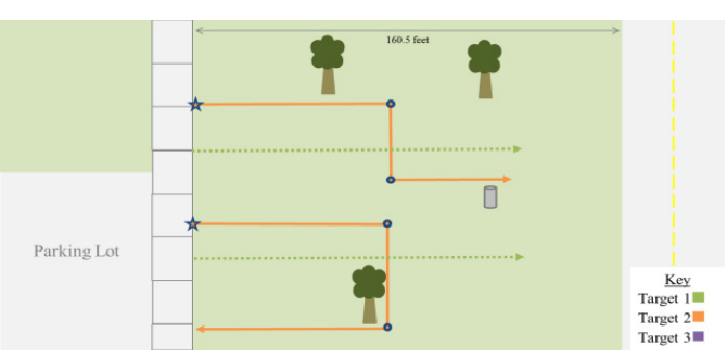

Figure 60-Maps of scent trails created by targets for the evaluation of saliva 

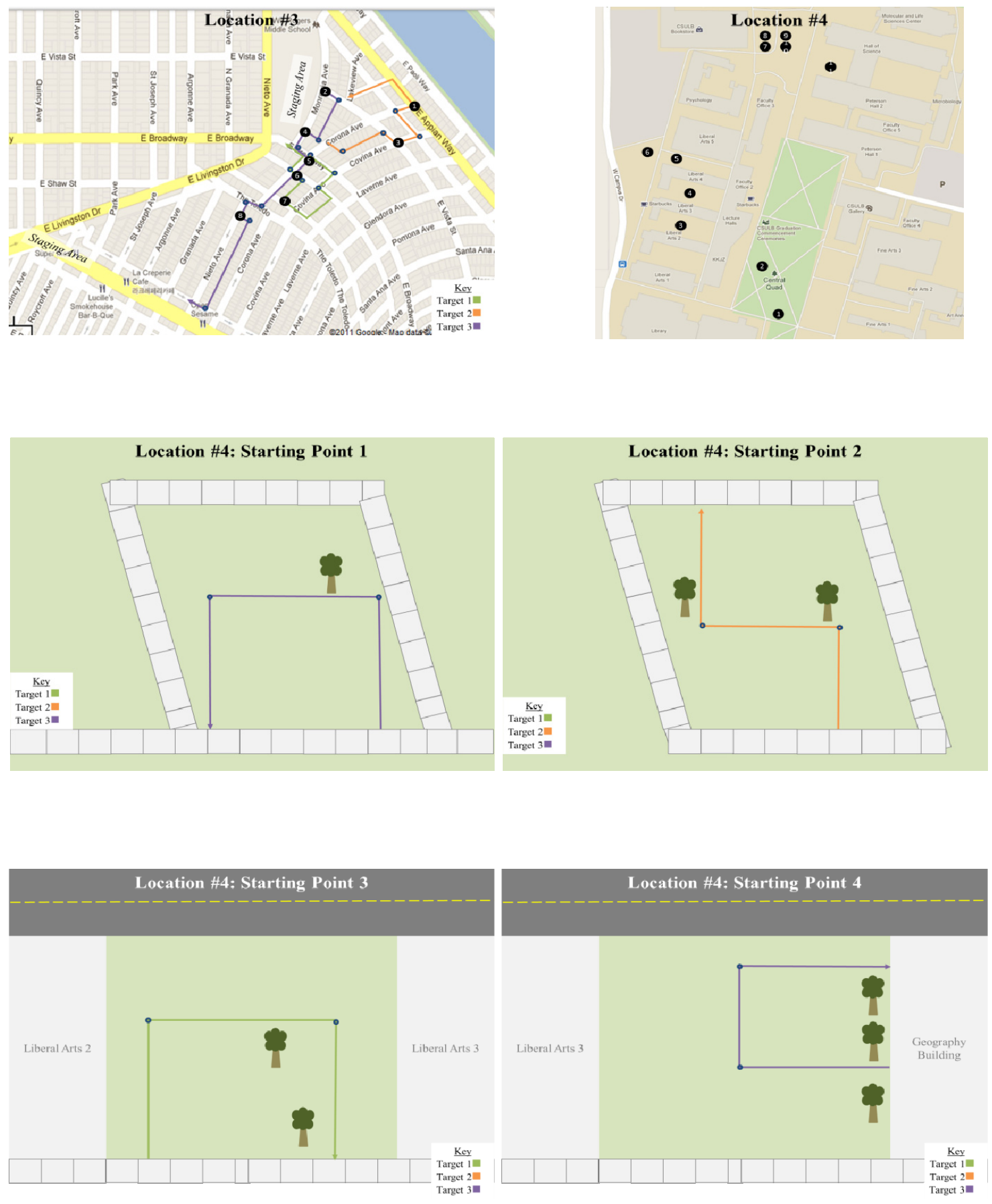

Figure 60 (continued)-Maps of scent trails created by targets for the evaluation of saliva 

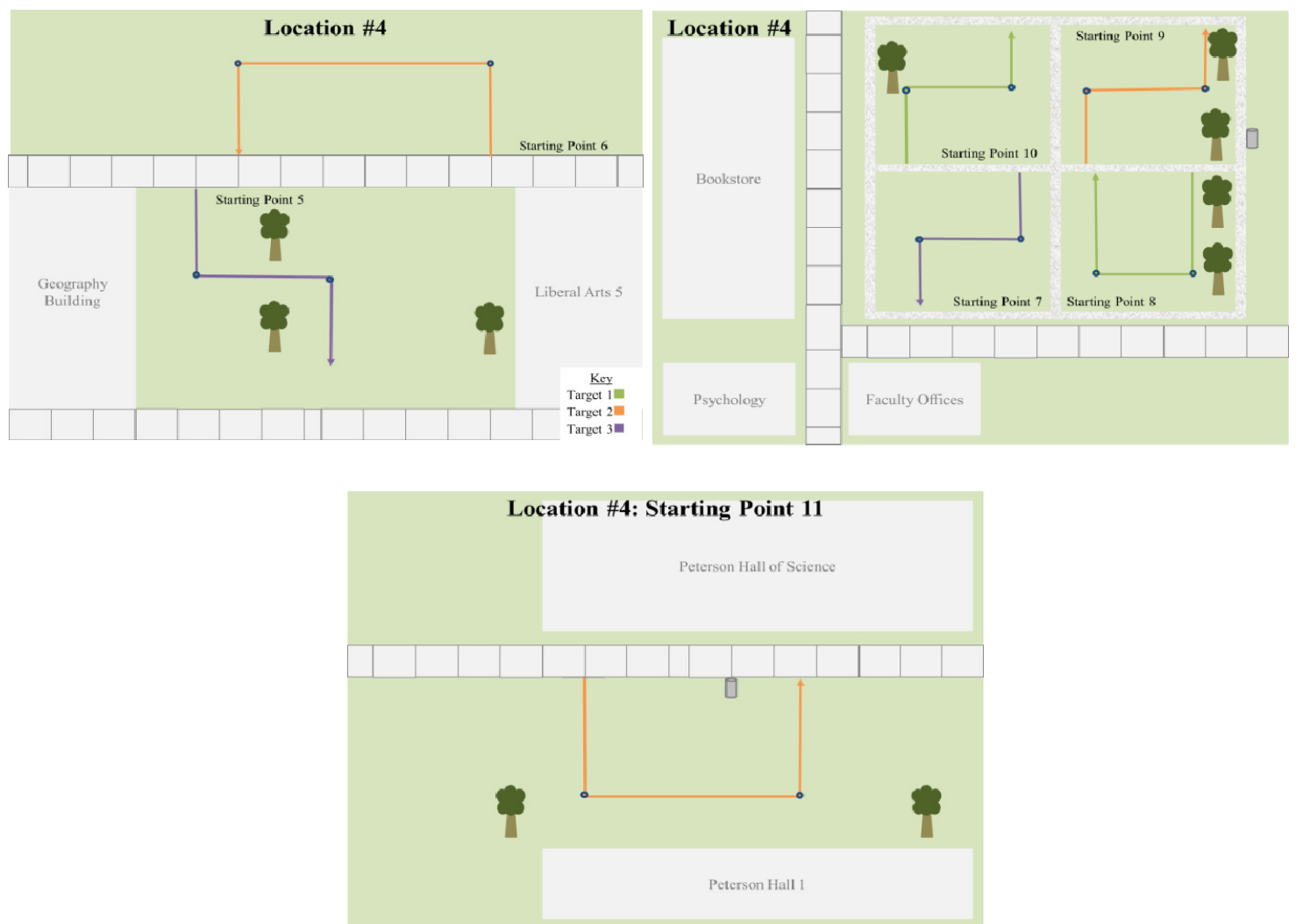

Figure 60 (continued)-Maps of scent trails created by targets for the evaluation of saliva

All scent trails were created one hour prior to testing. Test locations included residential areas and a local university. The temperature, relative humidity and wind speed at each test location were collected and are listed in Table 30.

Table 30- Environmental conditions at each test location for the evaluation of saliva \begin{tabular}{|l|l|l|l}
\hline Test Location & Temperature $\left({ }^{\circ} \mathrm{C}\right)$ & Relative Humidity $(\%)$ & Wind Speed $(\mathrm{m} / \mathrm{s})$ \\
\hline
\end{tabular}

\begin{tabular}{|c|c|c|c|}
\hline 1 & 20.3 & $54 \%$ & 1.83 \\
\hline 2 & 21.8 & & 1.83 \\
\hline 3 & 18.5 & $66 \%$ & 1.29 \\
\hline 4 & 24.1 & $37 \%$ & 0.61 \\
\hline
\end{tabular}




\section{Collection of Scent Samples}

Scent samples were collected from the targets using the Scent Transfer Unit 100 (STU100). Scent was collected from the palms of the hands and the saliva samples from the targets onto a 2" x 2" cotton gauze. Targets provided saliva samples by swabbing the inside of each cheek for 30 seconds ( 1 min total) with a pretreated cotton swab. The swab was then placed into a $10-\mathrm{mL}$ glass vial until it was time for indirect sampling with the STU-100. Scent samples were created by holding the STU-100 approximately one inch away from the scent source and running it on the high airflow setting for 30 seconds. Following scent collection, the cotton gauze was placed into a new $10-\mathrm{mL}$ glass vial and stored in a pelican case. Scent samples from the same target were stored together, to prevent cross contamination with another target's scent. Canine response to hand odor and saliva were evaluated at all four test locations.

\section{Canine Evaluations}

Five (5) canine teams were used for canine evaluations. Information pertaining to each canine team that participated in the canine field tests is listed in

Table 31. At each test location, a canine team was taken to a start point and the handler was given a scent sample to present to the canine. Following the presentation of a scent sample, three types of canine responses were recorded by the trail monitor: 1) does the canine begin to trail; 2) the canine's first decision and 3) the canine's second decision. Targets were not present at the end of a scent trail. All of the canine teams completed two tests at each location. In addition to scent samples, blanks were randomly incorporated into testing. 


\section{Table 31- Canine teams used for the evaluation of saliva and their corresponding information}

\begin{tabular}{|c|c|c|c|}
\hline Team \# & Age (ye ars) & Breed of Dog & Year of Training \\
\hline 1 & 4 & German Shepard & 1 \\
\hline 2 & 5 & Bloodhound & 4.5 \\
\hline 3 & 3 & German Shepard & 2 \\
\hline 4 & 10 & Bloodhound & 9.5 \\
\hline 5 & & Belgium Malonis & \\
\hline
\end{tabular}

\subsubsection{Canine evaluation of scent collection systems}

Canine response to human scent collected using two different scent collection devices were evaluated in a series of field tests. The goal of this task was to evaluate whether these scent collection devices transferred a sufficient amount of scent from a source to a sorbent material which would subsequently be provided to human scent discriminating canines. Scent collection systems were evaluated by observing canine response after being presented with scent samples created by a scent collection device while in the presence of the corresponding target's scent trail. The biological specimens used as sources of human scent were hand odor and saliva. Canine teams used in these field tests were located in Long Beach, CA and Alameda, CA, which is also where testing was conducted. All field tests were double-blind which means neither the handlers nor the trail monitors knew which sample was being presented to the canine or the direction of the scent trails. 
4.2.2.1. Evaluation of the operational parameters of the Human Scent Collection System (HSCS)

\section{Creation of Scent Trails}

Volunteers were recruited to serve as targets and were compensated for their participation. For these field tests scent trails, were created in the following manner. A target walked away from an initial point and incorporated a variety of decisions (i.e., left turn, right turn or continue straight) for a total distance of 0.8-1.2 miles. Multiple starting points were utilized along this type of scent trail. The direction of the decisions made along the path of the target was randomly selected by the test coordinators and the target was informed as to which route to take. A total of three targets were used for these field tests, however, only two targets produced a scent trail at each test location. Four test locations were used for these field tests. The scent trails made by the targets at each of the test locations in Long Beach and Alameda can be seen in Figure 61 and Figure 62, respectively. 

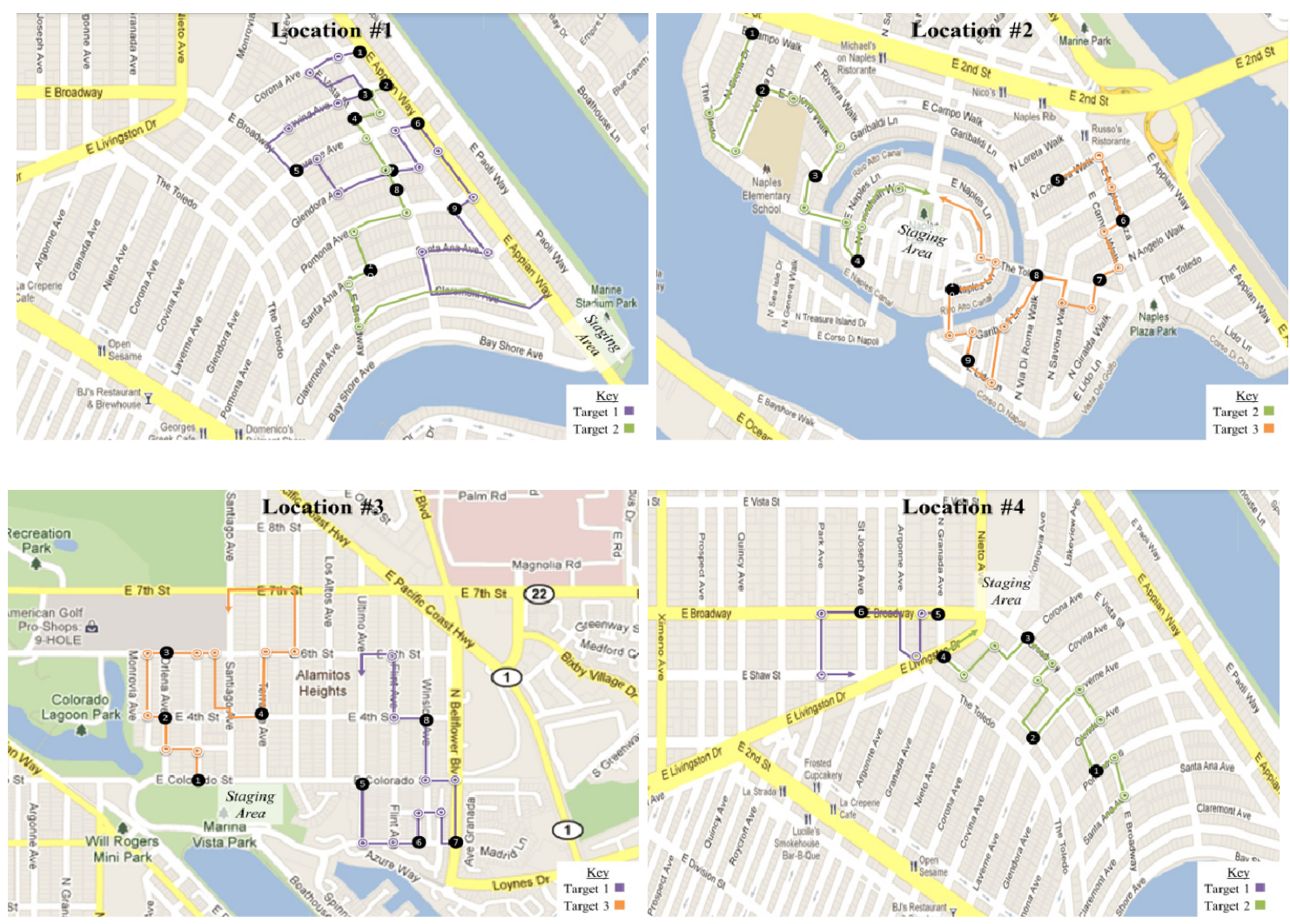

Figure 61-Maps of scent trails created by targets at Long Beach test locations 

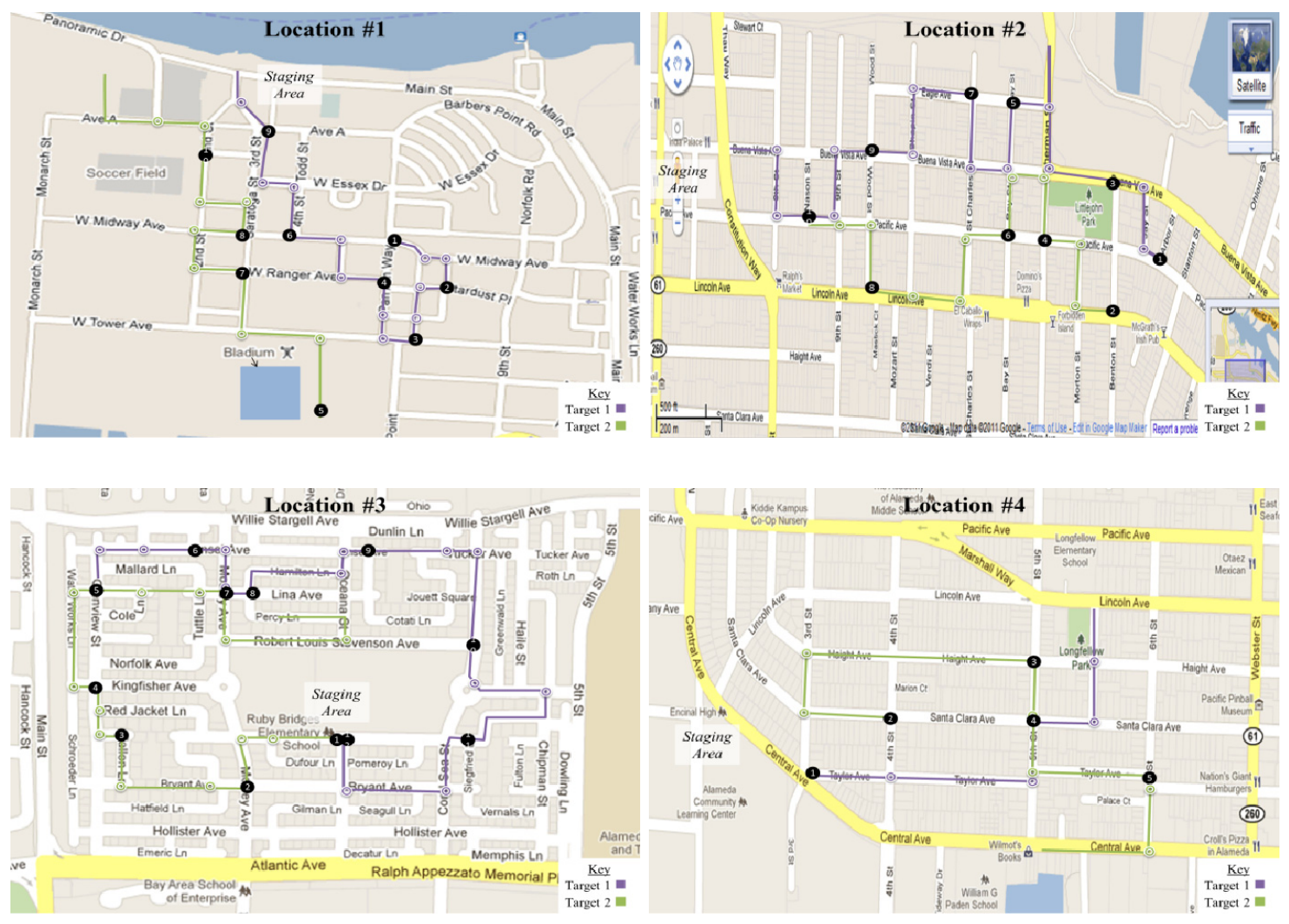

Figure 62-Maps of scent trails created by targets at Alameda test locations

All scent trails were created one hour prior to testing. Test locations included residential and industrial areas. The temperature, relative humidity and wind speed at each test location in Long Beach and Alameda were collected and are listed in Table 32. 
Table 32-HSCS parameters: Environmental conditions at each test location

\begin{tabular}{|c|c|c|c|c|}
\hline Site & Test Location & Temperature $\left({ }^{\circ} \mathbf{C}\right)$ & Relative Humidity (\%) & Wind Speed (m/s) \\
\hline Long Beach & 1 & 25.5 & 65.0 & 1.0 \\
\hline & 2 & 26.0 & 54.0 & 1.3 \\
\hline & 3 & 18.8 & 76.5 & 0.0 \\
\hline & 4 & 23.8 & 59.7 & 2.0 \\
\hline \multirow{2}{*}{ Alameda } & 1 & 20.0 & 55.3 & 5.2 \\
\hline & 2 & 22.6 & -- & 2.1 \\
\hline & 3 & 22.5 & 48.6 & 2.8 \\
\hline & 4 & 23.9 & 46.7 & 2.7 \\
\hline
\end{tabular}

\section{Collection of Scent Samples}

Scent samples were collected from the targets using the Human Scent Collection System (HSCS). Scent was collected from the palms of the hands and saliva samples (collected onto a cotton swab) from each of targets onto a 4" x 4" cotton gauze. Scent was collected by holding the HSCS approximately one inch away from the scent source and running it on the experimental airflow setting for an experimental collection time. The collection parameters used for the creation of scent samples at each test location is listed in Table 33. Following scent collection, the cotton gauze was placed into a $40-\mathrm{mL}$ clear glass vial and stored in a pelican case. All of the scent samples obtained from the same target were stored together, to prevent cross contamination with another target's scent. 
Table 33-HSCS Parameters: Collection time, airflow speed and specimen type tested at each test location

\begin{tabular}{|c|c|c|c|}
\hline Test Location & $\begin{array}{c}\text { Collection } \\
\text { Time }\end{array}$ & $\begin{array}{c}\text { Collection } \\
\text { Airflow Speed }\end{array}$ & Specimen \\
\hline 1 & $30 \mathrm{~s} / 60 \mathrm{~s}$ & Medium & Hand \\
\hline 2 & $30 \mathrm{~s} / 60 \mathrm{~s}$ & Medium & Saliva \\
\hline 3 & $30 \mathrm{~s}$ & Low & Hand/Saliva \\
\hline 4 & $30 \mathrm{~s}$ & High & Hand/Saliva \\
\hline
\end{tabular}

\section{Canine Evaluations}

A total of eleven (11) canine teams were used for canine evaluations with five teams from Long Beach and 6 teams from Alameda. Information pertaining to each canine team that participated in the canine field tests is listed in Table 34. At each test location, a canine team was taken to a starting point and the handler was given a scent sample to present to the canine. Following the presentation of a scent sample, three types of canine responses were recorded by the trail monitor: 1) does the canine begin to trail; 2) the canine's first decision and 3) the canine's second decision. Targets were not present at the end of a scent trail. All of the canine teams completed two tests at each location (except for test location \#4 at the Alameda test site where each team completed one test). In addition to scent samples, blanks were randomly incorporated into testing. 
Table 34-HSCS parameters: Information pertaining to each participating canine team

\begin{tabular}{|c|c|c|c|c|c|c|}
\hline Site & Canine \# & Age & Breed & Years of Training & Certified & $\begin{array}{c}\text { Certification } \\
\text { Date }\end{array}$ \\
\hline \multirow[t]{5}{*}{ Long Beach } & 1 & $4+$ year & German Shepard & 3 year & Yes & Mar-10 \\
\hline & 2 & 7 year & Bloodhound & 6.5 year & Yes & Jan-11 \\
\hline & 3 & 4 years & German Shepard & 2 year & No & \\
\hline & 4 & 7 year & Blue Tick Coon Hound & 7 year & Yes & 2006 \\
\hline & 5 & 4 years & German Shepard & 3 years & Yes & Mar-10 \\
\hline \multirow[t]{6}{*}{ Alameda } & 1 & 19 months & English Shepard & 17 months & Yes & Feb-11 \\
\hline & 2 & 2.5 years & Lab/Golden Retriever & 2.5 years & Yes & Sep-09 \\
\hline & 3 & 7 years & Gordon Setter & 6 years & Yes & May-11 \\
\hline & 4 & 3.5 years & German Shepard & 3 years & Yes & Nov-09 \\
\hline & 5 & 12 years & Yellow Lab & 10 years & Yes & May-09 \\
\hline & 6 & 4 years & Boxer & 4 years & Yes & Mar-11 \\
\hline
\end{tabular}

\subsubsection{Evaluation of the HSCS and the Scent Transfer Unit 100 (STU-100)}

\section{Creation of Scent Trails}

Volunteers were recruited to serve as targets and were compensated for their participation. For these field tests, scent trails were created by the targets in the following manner. A target walked away from a selected starting point and incorporated a variety of decisions (i.e., left turn, right turn or continue straight) for a total distance of 0.8-1.2 miles. Multiple starting points were utilized along the scent trail. The direction of each decision made along the path was randomly selected by the test coordinators and the target was informed as to which route to take. Three targets created scent trails at the Long Beach test locations and two targets created scent trails in Alameda. Four test locations were used in Long Beach and two test locations were used in Alameda. The scent trails made by the targets at each of the test locations at each test site can be seen in Figure 63 and Figure 64, respectively. 

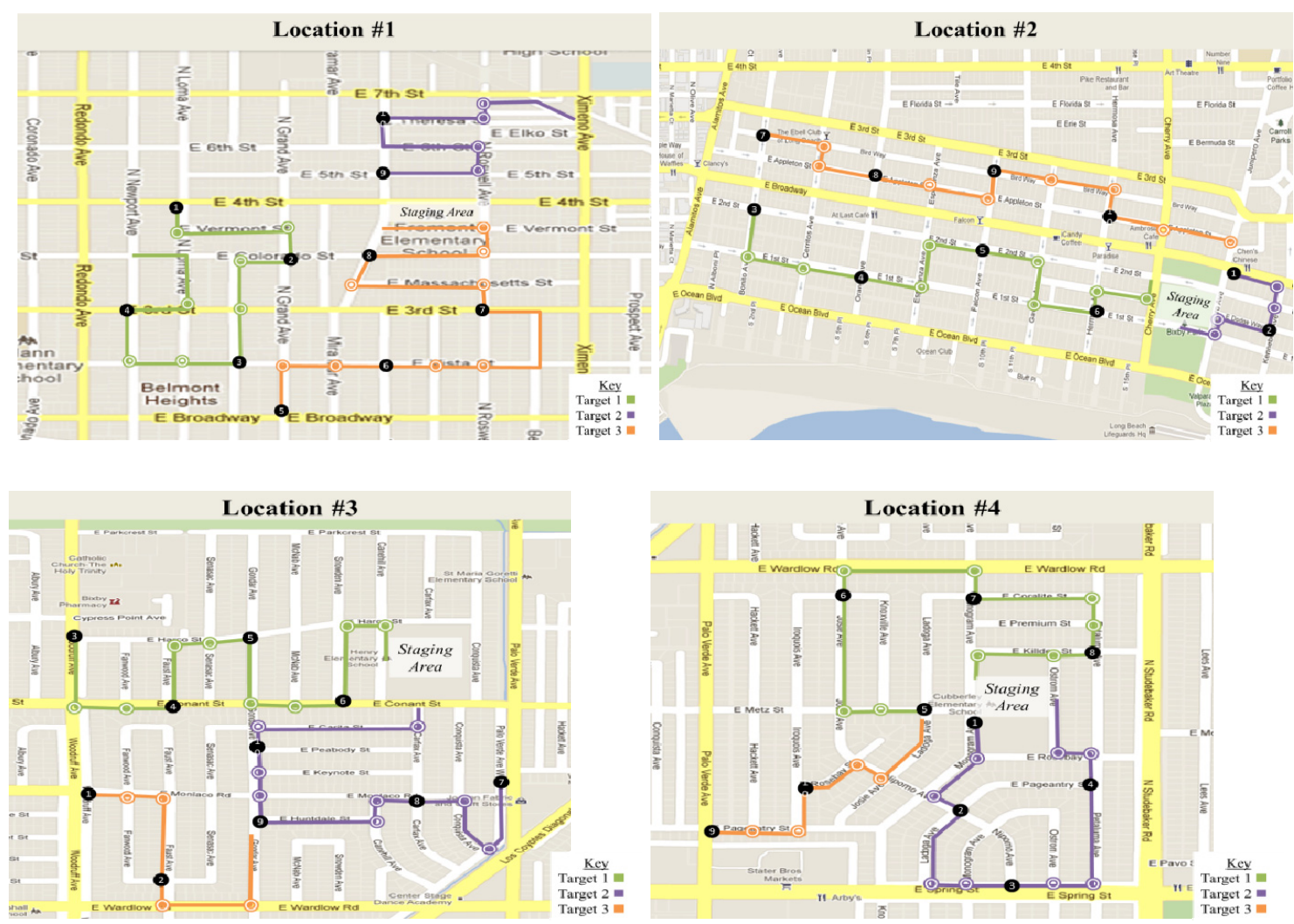

Figure 63-Maps of scent trails created by targets at Long Beach test locations

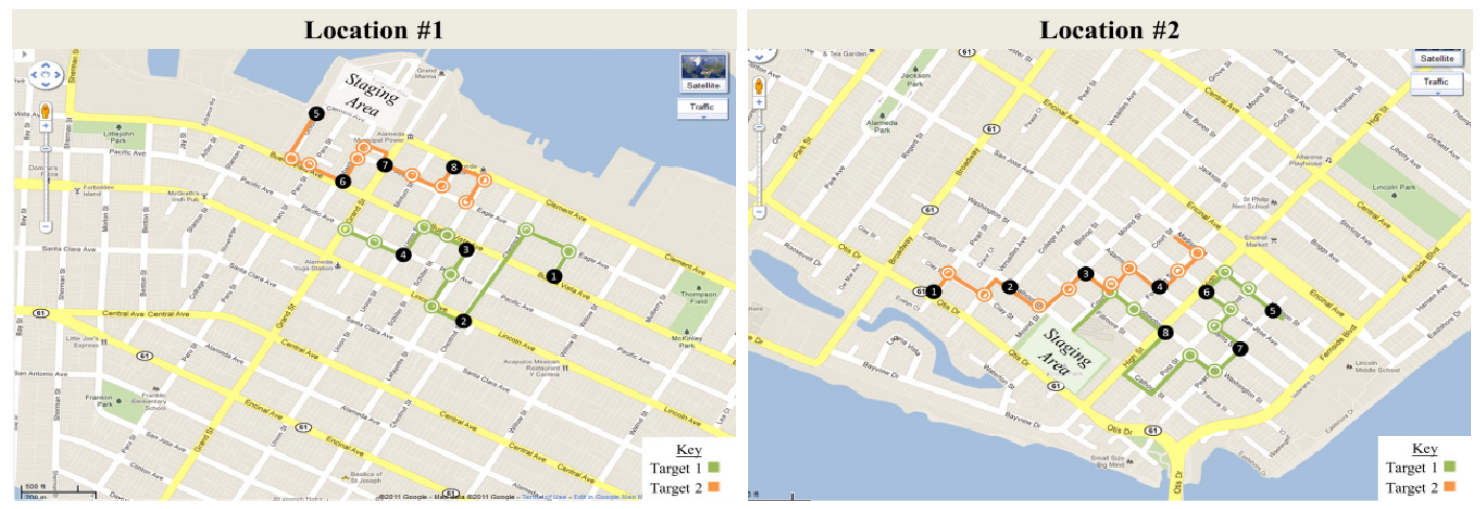

Figure 64-Maps of scent trails created by targets at Alameda test locations 
All scent trails were created one hour prior to testing. All test locations at each test site were residential areas. The temperature and wind speed at each test location in Long Beach and Alameda were collected and are listed in Table 35.

Table 35-Device comparison: Environmental conditions at each test location

\begin{tabular}{|c|c|c|c|}
\hline Site & Test Location & Temperature $\left({ }^{\circ} \mathbf{C}\right)$ & Wind Speed $(\mathbf{m} / \mathbf{s})$ \\
\hline Long Beach & 1 & 22.7 & 0.7 \\
\hline & 2 & 27.5 & 1.5 \\
\hline & 3 & 23.3 & 0.3 \\
\hline & 4 & 24.9 & 1.8 \\
\hline Alameda & 1 & 18.9 & 0.9 \\
\hline & 2 & 21.4 & 2.1 \\
\hline
\end{tabular}

\section{Collection of Scent Samples}

Scent samples were collected from the targets using the Human Scent Collection System (HSCS) and Scent Transfer Unit 100 (STU-100). Scent was collected from saliva and the palms of the hands from each target onto cotton gauze. Targets provided saliva samples by swabbing the inside of each cheek for 30 seconds ( 1 min total) with a pretreated cotton swab. The swab was then placed into a $10-\mathrm{mL}$ glass vial until it was indirectly sampled with the HSCS or STU-100. Scent samples were created by holding the scent collection device one inch away from the scent source and running it on the high airflow setting for 60 seconds. Following scent collection, the cotton gauze was placed into a new $10-\mathrm{mL}$ or 40-mL clear glass vial (depending on which collection device was used) and stored in a pelican case. Scent samples from the same target were stored together, to prevent cross contamination with another target's scent. Hand odor samples were used at test locations $\# 1$ and \#3 and saliva samples were used at test locations \#2 and \#4. 


\section{Canine Evaluations}

A total of nine (9) canine teams were used for canine evaluations with five teams from Long Beach and four teams from Alameda. Information pertaining to each canine team that participated in the canine field tests is listed in Table 36. At each test location, a canine team was taken to a starting point and the handler was given a scent sample to present to the canine. Following the presentation of a scent sample, three types of canine responses were recorded by the trail monitor: 1) whether the canine begins to trail; 2) the canine's first decision and 3) the canine's second decision. Targets were not present at the end of the scent trails. All of the canine teams completed two tests at each location. In addition to scent samples, blanks were randomly incorporated into testing.

Table 36-Device comparison: Information pertaining to each participating canine team

\begin{tabular}{|l|c|c|c|c|c|c|}
\hline \multicolumn{1}{|c|}{ Site } & Canine $\#$ & Age & Breed & Year of Training & Certified & Date \\
\hline Long Beach & 1 & 4 years & German Shepard & 3 years & Yes & Mar-10 \\
\hline & 2 & 7 year & Bloodhound & 6.5 year & Yes & Jan-11 \\
\hline & 3 & 4 years & German Shepard & 2 year & No & \\
\hline & 4 & 7 year & Blue Tick Coon Hound & 7 year & Yes & 2006 \\
\hline & 5 & $4+$ year & German Shepard & 3 year & Yes & Mar-10 \\
\hline Alameda & 1 & 4 years & Boxer & 4 years & Yes & Mar-11 \\
\hline & 2 & 3.5 years & German Shepard & 3 years & Yes & Nov-09 \\
\hline & 3 & 11 months & Laborador/Terrier Mix & 8 months & No & Feb-11 \\
\hline
\end{tabular}




\subsection{Results}

\subsubsection{Canine evaluation of collected biological specimens}

\subsubsection{Evaluation of head hair}

Canine response to an alternative biological specimen, such as hair, was evaluated in comparison to hand odor. In addition to a biological specimen experimental variable, additional variables were also evaluated, which included the type of collection device and the age of the scent trail. Canine teams performed a total of thirty eight (38) tests and of those tests, 34 included actual scent samples and four included blank samples. The evaluation for biological specimens was comprised of twelve hand odor tests and 22 hair tests and the results are displayed in Figure 65. The graph includes the percentage of canine teams that correctly began trailing after smelling the scent sample and properly completed the first and second decision point, respectively. One additional component incorporated into the results is the percentage for chance at each decision.

When a canine was presented with a scent sample the canine had a choice to begin trailing or not to begin trailing. Therefore, the chance that a canine would begin trailing a scent trail, correctly, was greater than $50 \%$. If a canine began trailing it would walk to the first decision point where it could make one of three decisions, proceed straight, turn left or turn right. Since the proper completion of the first decision point was dependent on whether the canine began trailing, the chance that the canine would properly execute the first decision point was greater than $16.7 \%$. Once a canine completed the first decision point, the canine would encounter the second decision point which also included one of three choices, proceed straight, turn right or turn left. The chance that a canine would begin trailing and complete the first and second decision point 
correctly was greater than $5.6 \%$. These values for chance are represented by the black bars with white dots.

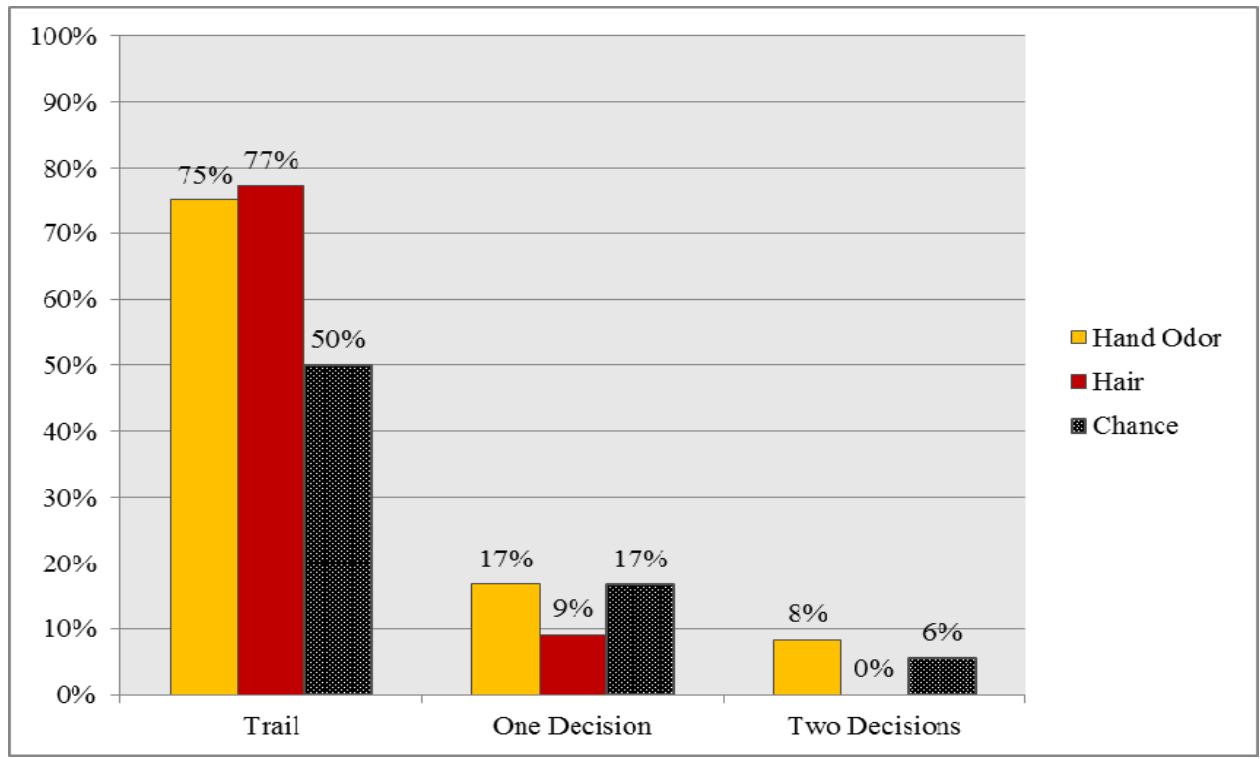

Figure 65- Canine response to hand odor and hair samples

Canine response to hand odor and hair was similar with differences in response being no greater than $8 \%$ for all three decision points. Canine response was also compared to chance for each of the observed behaviors (begin to trail, first decision and second decision). When presented with a scent sample, canines began trailing at a rate that was better than chance $(50.0 \%)$ for both hand odor and hair. However, canines responded at a frequency at or below the chance level for both the first decision point $(16.7 \%)$ and the second decision point (5.6\%) for both specimen types.

Additional variables, such as the scent collection device and the age of the scent trail, were incorporated into the field trials and could have also influenced canine response. The two collection devices used for scent collection were the Scent Transfer 
Unit 100 (STU-100) and the Human Scent Collection System (HSCS). The evaluation of the two different collection devices was comprised of 23 HSCS tests and 11 STU-100 tests. Canine response to scent collected from the two different systems is displayed in Figure 66. Again, the response to the STU-100 and the HSCS was similar with differences in response being no greater than $9 \%$ for all three decision points. However, the difference in canine response was to the two scent collection devices was most noticeable when comparing these responses to chance. Canines performed better than chance for all three observed behaviors (begin to trail, first decision and second decision) when presented with a sample collected using the STU-100.

Lastly, the data was evaluated to determine whether the age of the scent trail influenced a canine's ability to accurately complete the three decision points, which can be seen in Figure 67. Trails were aged for 1 hour, 24 hours and 48 hours which were comprised of 10 tests, 16 tests and 8 tests, respectively. The greatest difference in canine response was observed for trailing such that the difference in response varied by $18 \%$ between 1 hour and 48 hours aged trails. At the subsequent decisions, canine response was similar with differences in response being no greater than $6 \%$ for the first and second decision point. When comparing these responses to chance, canines could not correctly maneuver the first and second decision point at a rate greater than chance, regardless of the age of the scent trail. 


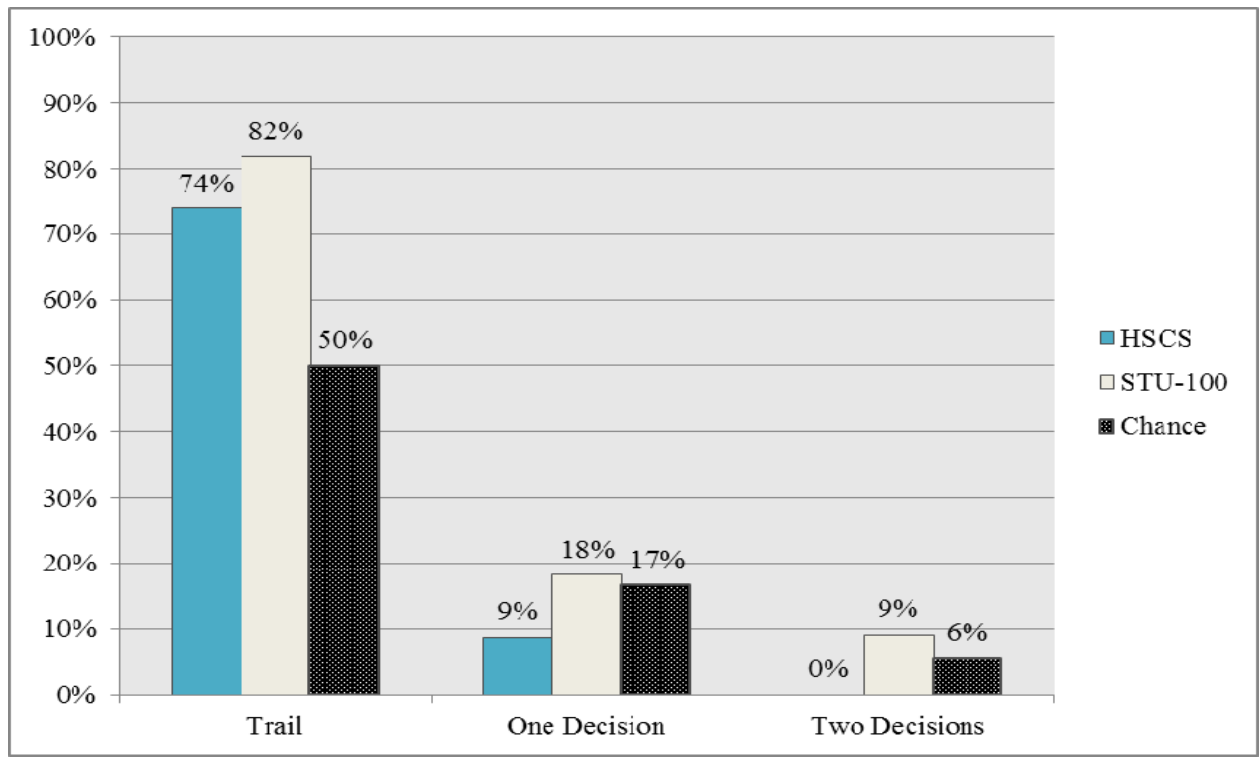

Figure 66- Canine response to two different scent collection systems

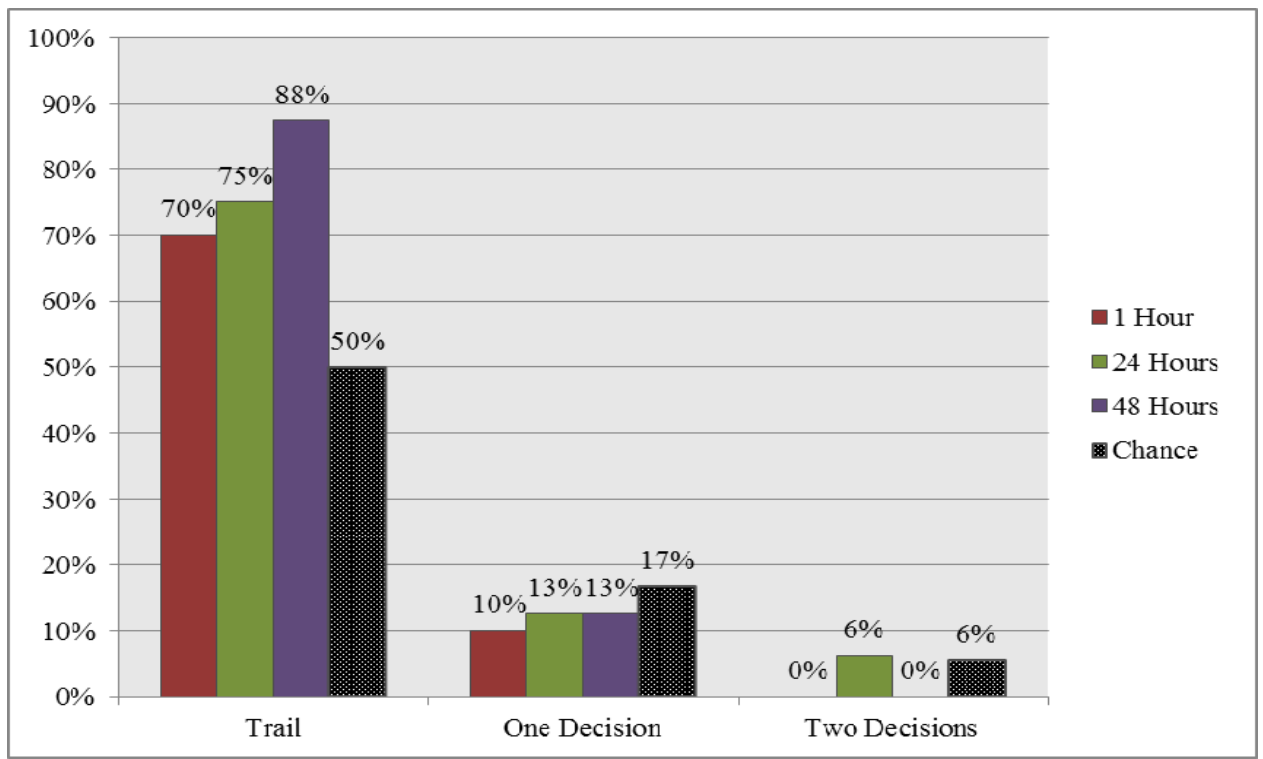

Figure 67- Canine response to aged scent trails

When testing the three experimental variables, canine response was similar for the different conditions within that particular variable type. However, there was one circumstance where canine response to scent was better than chance, when the STU-100 
was used. Because two scent collection devices were used during field testing it is possible that poor results were obtained when samples were collected using the HSCS, and as a result it became difficult to effectively evaluate whether hair can be used as a scent source for trained canines. Consequently, the protocol for field testing was redesigned to eliminate the influence of the scent collection device and the age of the trail, so the STU-100 and one (1) hour aged trails were used for the remainder of the field tests.

\subsubsection{Evaluation of fingernail clippings}

Canine response to fingernails was evaluated in comparison to hand odor. Contrary to the evaluation of hair, many of the experimental variables (i.e. collection device and the age of the scent trail) were held constant which allowed for the evaluation of only the biological specimen. Canine teams completed a total of fifteen tests. The evaluation of biological specimens was comprised of eight hand odor tests and seven fingernail tests. The results from this field test are displayed in Figure 68 and refer to the percentage of canine teams that correctly began trailing and completed the first and second decisions in addition to the levels of chance for each decision.

Canine response to hand odor and fingernails was similar with differences in response being no greater than $8 \%$ for all three decision points. Canines performed better than chance when beginning to trail and at the first decision point. No canines were able to correctly complete the second decision for either of the specimen types. Field tests conducted previously by Dr. Furton's research group (unpublished work) has shown that canines respond well to hand odor; therefore, poor canine response to hand odor, as well as fingernails, during this trial could be attributed to the working condition (i.e. moral) of 
the participating canines on that particular day of testing and not due to the biological specimen. The results of this field test did not clearly indicate whether canine teams can use fingernail clippings as scent sources; however, they were able to respond to the scent of fingernails just as effectively as they did to hand odor.

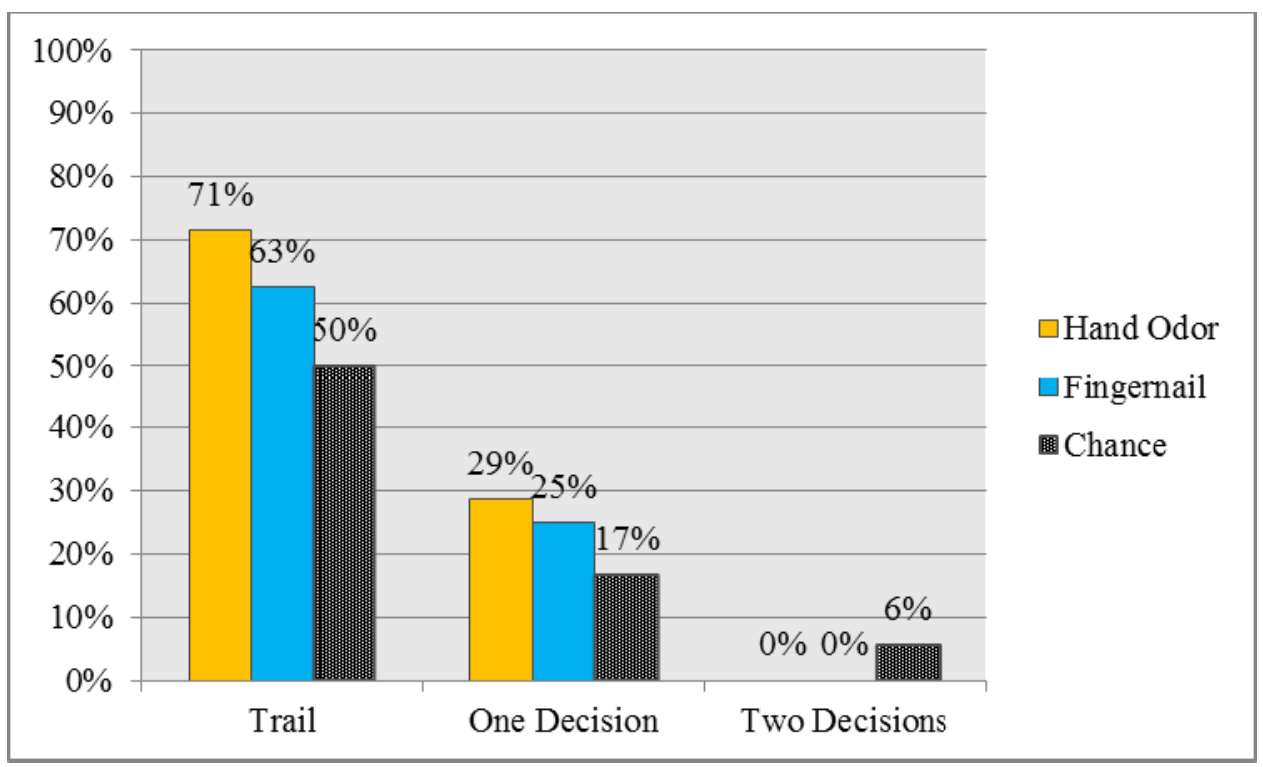

Figure 68-Canine response to hand odor and fingernail samples

\subsubsection{Evaluation of saliva}

Canine response to saliva was evaluated in comparison to hand odor. Again, for this field trial experimental variables such as collection device and the age of the scent trail were held constant, which allowed for the evaluation of only the biological specimen. Canine teams completed a total of thirty three (33) tests and of those tests, 32 included actual scent samples, and one included blank samples. The evaluation of biological specimens was comprised of sixteen hand odor tests and sixteen saliva tests and the results are displayed in Figure 69. The graph includes the percentage of canine 
that correctly completed the three observed responses, such as whether the canine began trailing after smelling the scent sample and the proper completion of the first and second decision point, in addition to the level of chance that a canine would respond correctly at those decisions.

Canine response to hand odor and saliva was similar for two of the three decisions. The greatest difference in canine response was observed at the first decision point, which varied by $19 \%$. For the remaining decisions, canine response was similar with differences in response being no greater than $6 \%$ for beginning to trail and the second decision point. Canines performed better than chance at all three decisions for both specimen types, which did not occur at any of the other canine trials (hair or fingernail). Typically, tracking/trailing canines will use human scent that is released from the surface of the skin (e.g. hands, back); however, these tests indicate that canine teams can also use human scent from saliva samples and are likely to perform in the same manner as when working with skin sources of scent, such as hand odor.

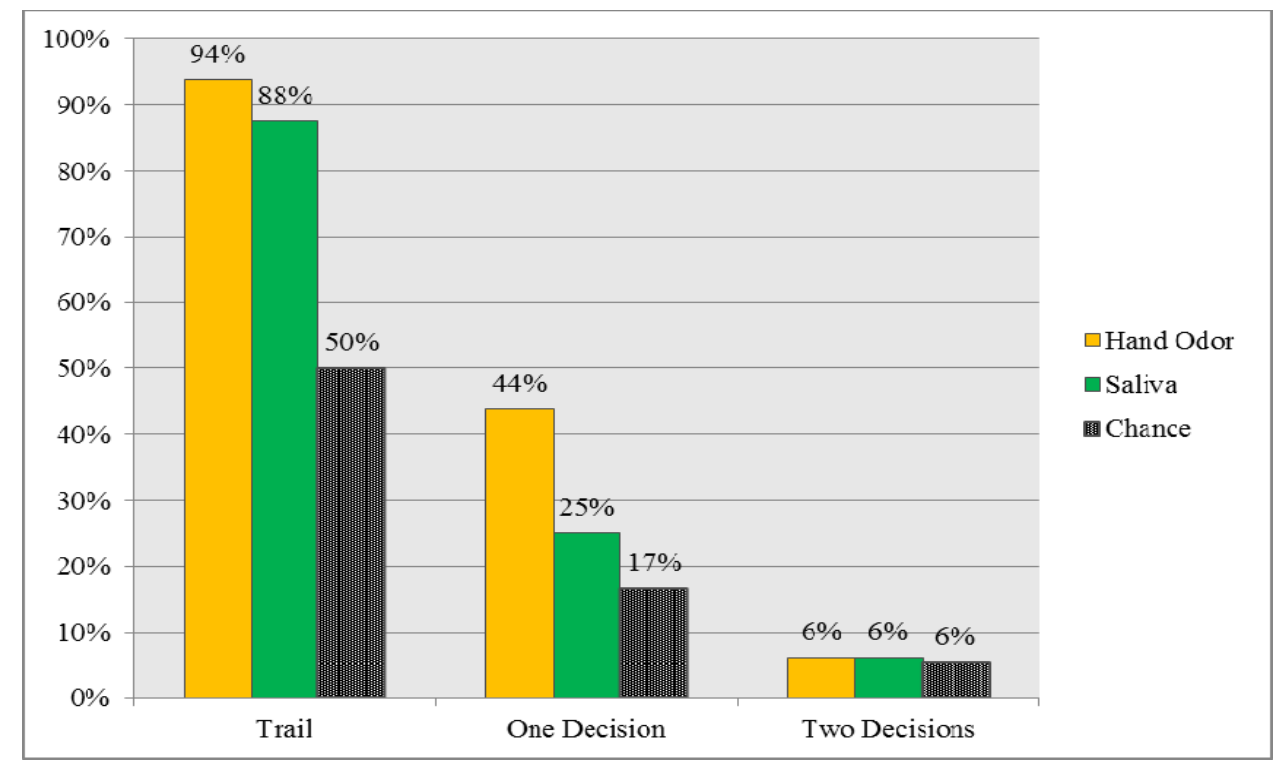

Figure 69-Canine response to hand odor and saliva samples 


\subsubsection{Canine response to blank samples}

In addition to providing samples from biological specimens, blank samples were also incorporated into canine field testing. Blank samples were the collection material, i.e., a cotton gauze pad, which does not contain human scent. When presenting a blank sample to a canine, theoretically the canine would not detect human scent and would remain still, or not begin to trail. When a canine begins trailing after presented with a blank sample it could represent two things: 1) the collection material was contaminated with human scent and the canine responded correctly, or 2) the collection material was not contaminated with human scent and the canine did not respond correctly. During field testing of biological specimens, $36 \%$ of the canines did not begin to trail, when presented with a blank sample, and $64 \%$ of the canines did begin trailing. Of the canines that began trailing when presented with a blank sample, not one canine followed the path of a target meaning that the blanks were not likely to have been contaminated with human scent and the canines were not responding correctly.

An explanation for nearly two-thirds of the canines responding incorrectly is that blanks are not commonly incorporated into training practices for the canines used in these tests. Traditionally, human scent discriminating canines are presented with a scent sample and are trained to identify and match the scent to the person it originated from. As a result, instinctively these canines will begin trailing when presented with any type of sample. The results of this work emphasize the importance of incorporating blanks into routine training regimens, so canines can become increasingly familiar between human scent samples and blanks samples, which only contain odors from the local environment. 
When canines can accurately decipher between human scent and blanks then their reliability, in the field, can be better assessed. 


\subsubsection{Canine evaluation of scent collection systems}

4.3.2.1. Evaluation of the operation parameters of the Human Scent Collection System (HSCS)

Canine response was used to evaluate the operational parameters (collection time and collection airflow) of the Human Scent Collection System for the collection of human scent from biological specimens. For this field test, canine teams completed a total of seventy (70) tests and of those tests, 65 included actual scent samples, and five included blank samples. The evaluation of collection time was comprised of 16 tests for 30 second collection and 18 tests for 60 second collection, and the results are displayed in Figure 70. The graph includes the percentage of canine teams that responded correctly to the three observed responses, in addition to the chance level for each response. Because the success rate for each response is contingent on the previous, the chance level that a canine will begin to trail when presented with a scent sample is $50.0 \%$, complete the first decision point is $16.7 \%$ and complete the second decision point is $5.6 \%$. The airflow speed used for this portion of the trial was the medium airflow speed, which is the default airflow speed setting of the HSCS.

The evaluation of collection time resulted in a canine response that was better than chance for all three of the observed responses, for both the 30s and 60s time. Canine response to scent samples created using the 60 second collection time lead to $16 \%$ more canine teams beginning to trail when presented with the sample than when presented with samples created using the 30 second collection time. This result infers that a 60 second collection time provides for a greater amount of scent to be collected onto the sorbent material which allowed the canine to perceive the scent and begin trailing. For the 
remaining decisions, canine response was similar, with differences in response being no greater than $4 \%$ for the first and second decision points.

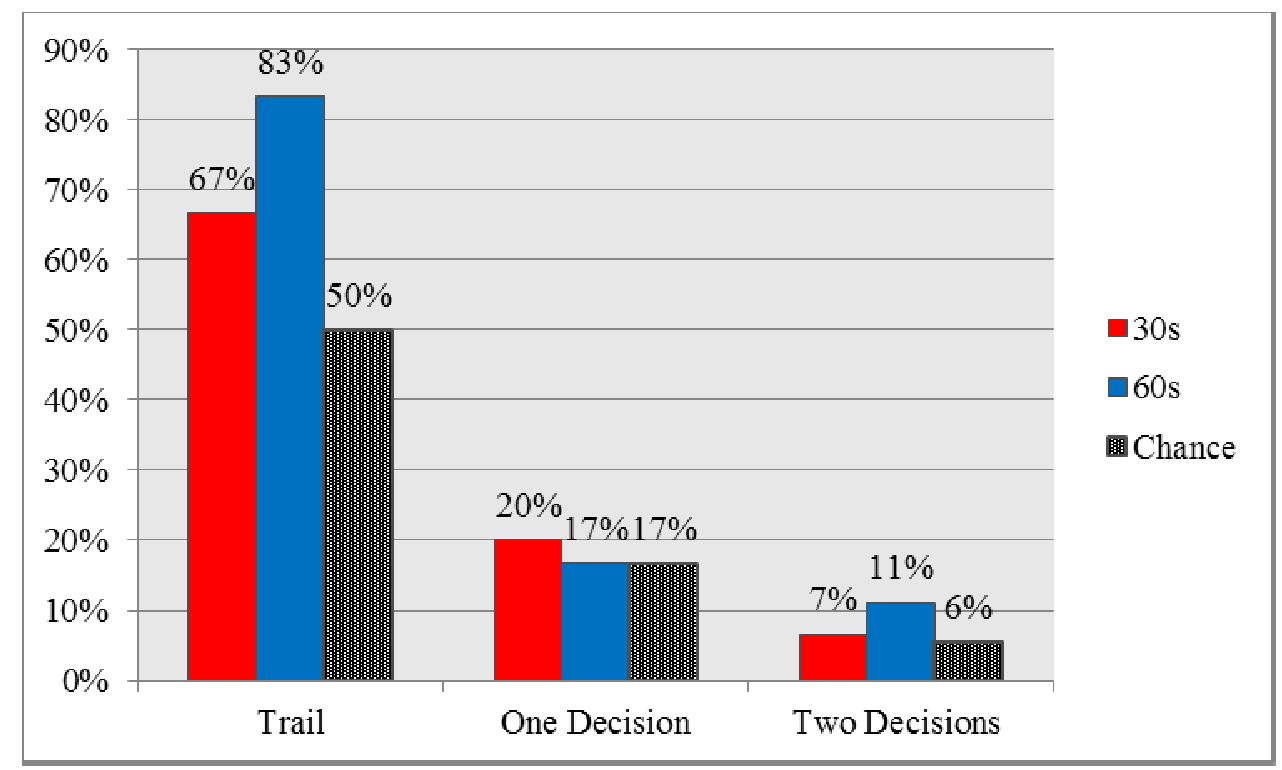

Figure 70-Canine response to scent samples collected using the HSCS at two different collection times

The second portion of the field test was dedicated to evaluating the airflow speed of the HSCS. The assessment of airflow speed was comprised of 17 tests for the low airflow, 16 tests for the medium airflow and 13 tests for the high airflow and the results, and chance level, are displayed in Figure 71. The collection time used for this portion of the trial was 30 seconds, which is the default collection time of the HSCS. 


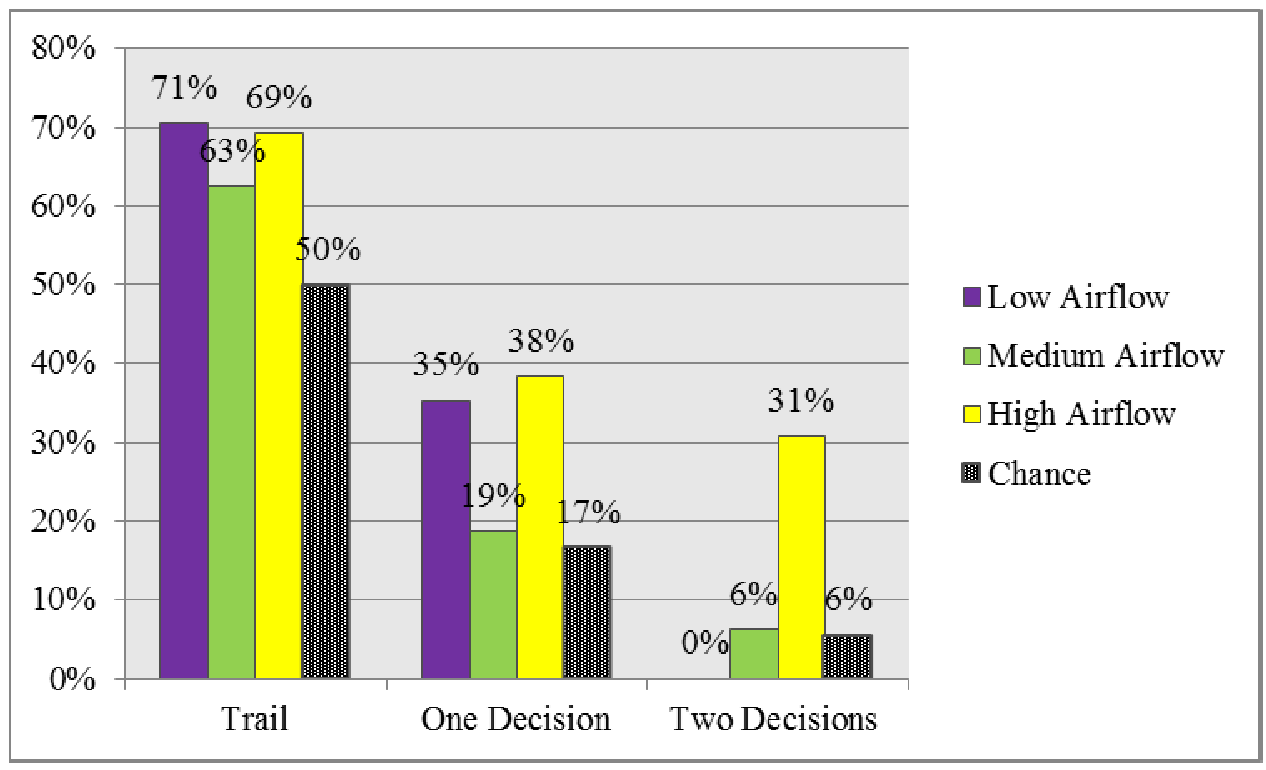

\section{Figure 71-Canine response to scent samples collected using the HSCS at three different airflow speeds}

The percentage of canine teams that began trailing after being presented with a scent sample was similar for all three collection airflow speeds with a response better than chance for all speeds. However, canine response at the first and second decision point revealed larger differences among the airflow speeds. The percentage of canine teams which were able to correctly complete the first and second decision point occurred when the scent sample was collected at the high airflow speed. At the low airflow speed, no canine teams were able to correctly complete the second decision point. Though canines were able to complete the second decision point better than chance when using the medium airflow, a greater number of canines $(31 \%)$ were able to complete the second decision point when the high airflow speed was used. These results reflect that the use of a high airflow speed, for the collection of scent, will collect a sufficient amount of scent to allow canines to follow a scent trail further (or the second decision point in this test). 
Canine response was used in the selection of the optimal operational parameters of the Human Scent Collection System. The results of the field tests show that the use of a 60 second collection time and a high airflow speed will elicit a better response from human scent discriminating canines. The selection of the operational settings for scent collection devices is extremely important due to the fact that the manner in which human scent evidence is collected can impact canine performance. If an insufficient amount of scent has been transferred from a source to the sorbent material then the canine will not be able to perceive it and is thus, unlikely to locate and follow a person's scent trail.

\subsubsection{Evaluation of the HSCS and the Scent Transfer Unit 100 (STU-100)}

Canine response was used to compare the performance of two scent collection systems (the HSCS and the STU-100). For this field test, canine teams completed a total of 50 tests and of those tests, 47 included actual scent samples and 3 blank samples. A summary of canine response to the two scent collection systems is displayed in Figure 72 and the graph portrays the percentage of canine teams that correctly completed the three observed responses and the chance level for each response.

Canine response to both collection devices was better than chance for each of the observed responses. The percentage of canine teams that began trailing when presented with a scent sample was similar for both of the devices. However, canine response at the first and second decision point was noticeably greater when the STU-100 was used to create the scent sample. To understand why canines respond better to scent samples created using the STU-100, rather than the HSCS, a closer look was given to the airflow speed of each device. As seen in Figure 73, the airflow speed of the STU-100 (average 
$1.00 \mathrm{~m} / \mathrm{s}$ ) is significantly greater than the airflow speed of the HSCS (average $0.59 \mathrm{~m} / \mathrm{s}$ ), when performing a One-way ANOVA $(\mathrm{p}=0.05)$. Canine response to scent samples created using the STU-100 can be attributed to the higher the airflow speed of the device, which draws in a larger volume of air thereby allowing for a greater accumulation of scent onto the gauze pad.

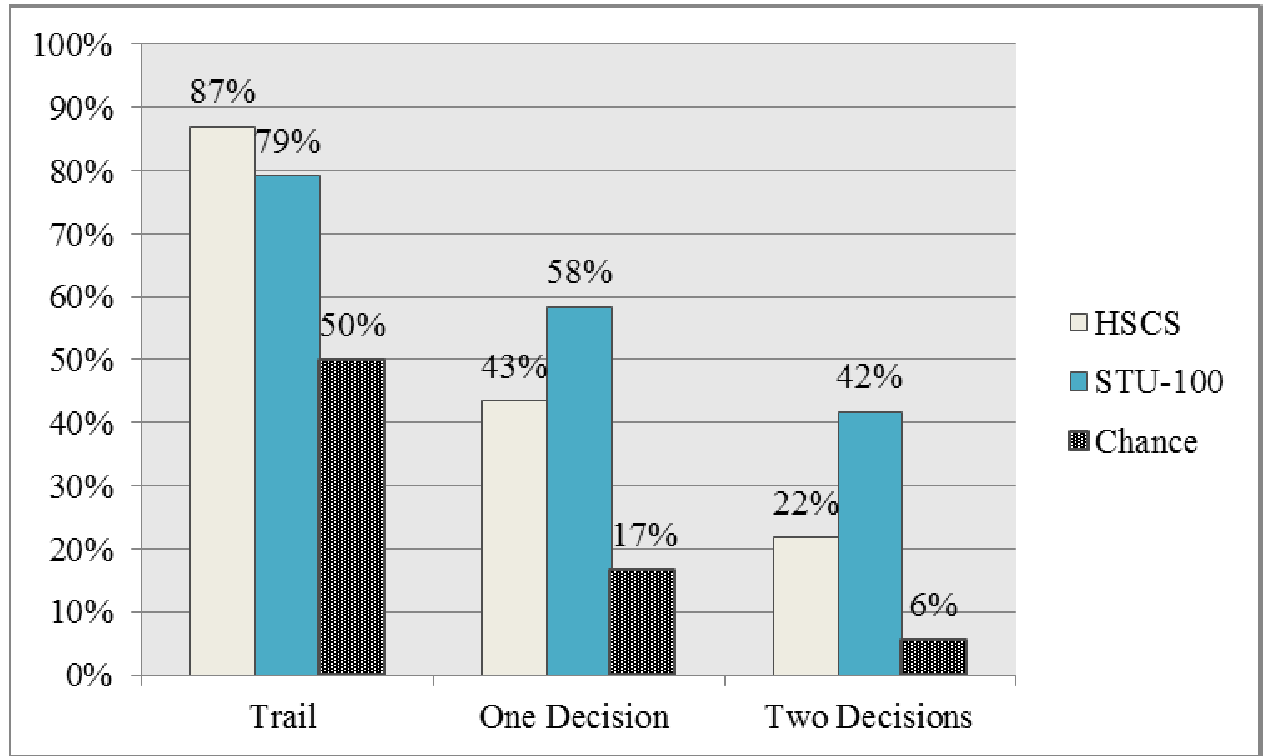

Figure 72-Canine response to scent samples collected using the HSCS and the STU100 


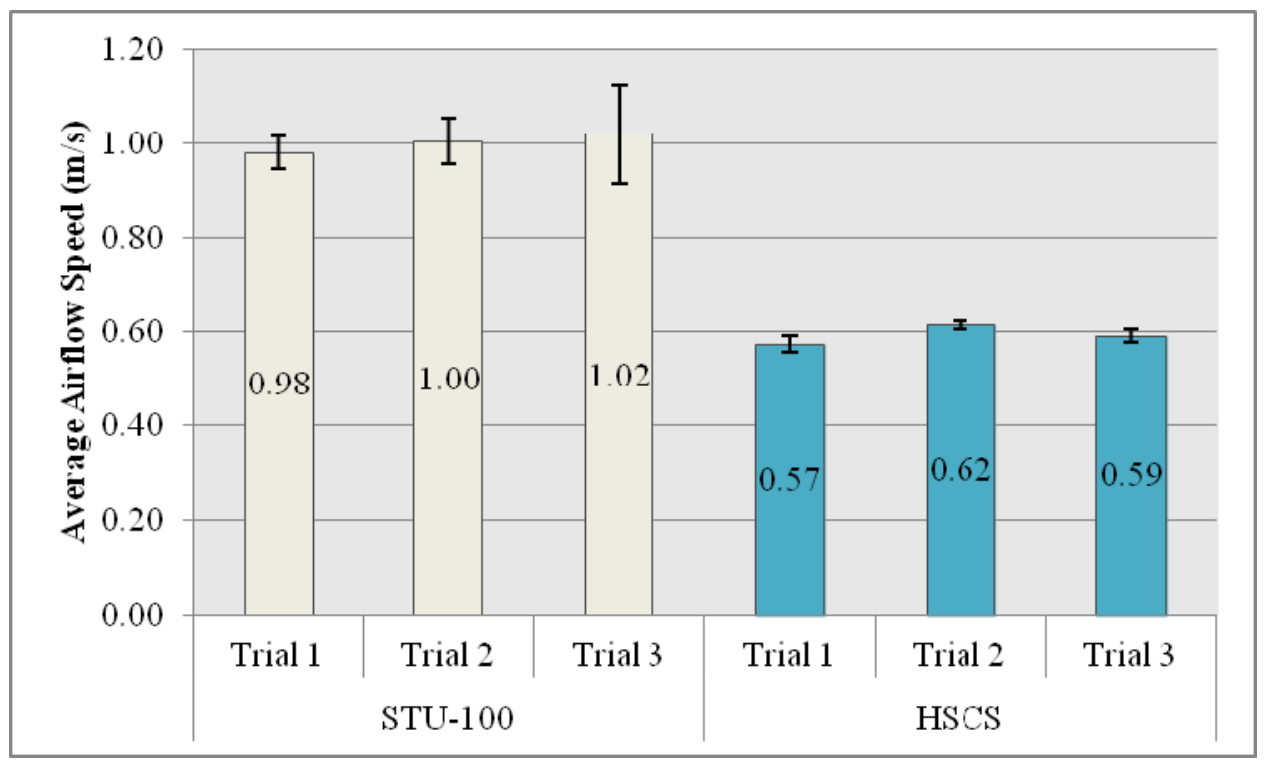

Figure 73-Airflow speeds of the STU-100 and the HSCS while running at the highest airflow setting for $60 \mathrm{~s}$

Additionally, canine response to the two biological specimens (hand odor and saliva) was also assessed. The evaluation of biological specimens was comprised of 24 tests for hand odor and 23 tests for saliva and the results and chance levels for each decision are displayed in Figure 74. The airflow speed and the collection time used for this portion of the trial were the high airflow speed and 60 second collection time, respectively. 


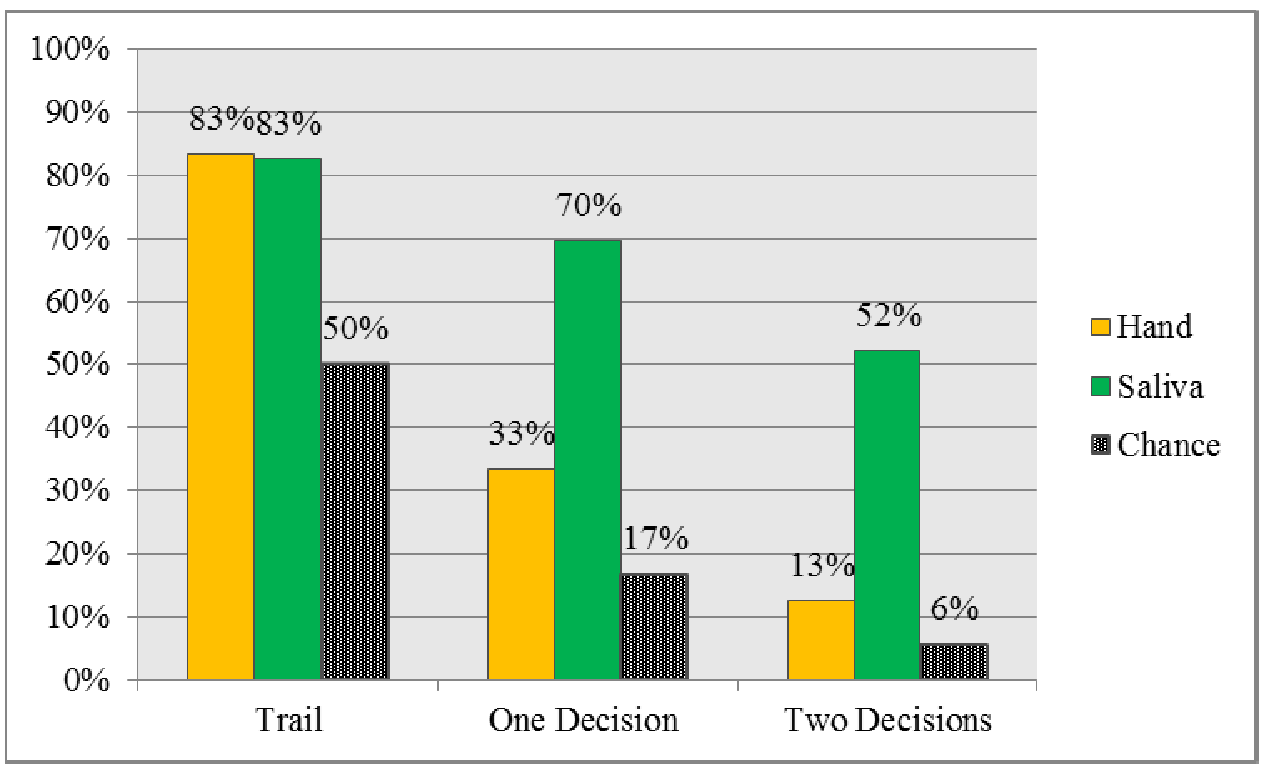

Figure 74- Canine response to scent samples of hand odor and saliva

Canine response to both biological specimens was better than chance for each of the observed responses. The percentage of canine teams that began trailing after being presented with a scent sample was the same for both biological specimens. More than double the amount of canine teams were able to complete the first decision point and triple the amount of canine teams were able to complete the second decision point when provided with a saliva sample, as opposed to a hand odor sample. To better understand these results an instrumental approach can be used to explain the canine response seen in the field.

In the laboratory, HS-SPME-GC-MS has revealed two things regarding hand odor and saliva: 1) the spectrum of VOCs from hand odor is different from saliva and 2) the total abundance of the VOCs in the headspace of saliva samples is significantly greater than in hand odor samples. An example of these two occurrences can be seen in Figure 76 and 77 which show the chemical profiles of hand odor and saliva samples, collected 
from a female subject, as well as the abundance of the extracted volatiles from those specimens, respectively. The qualitative and quantitative differences in the VOCs from these two specimens could lead someone to speculate that canines could not use the scent from saliva to properly identify and trail the scent of a person, but the results from this field test reveals that canines can use saliva as a scent source and providing a better response than when using hand odor.

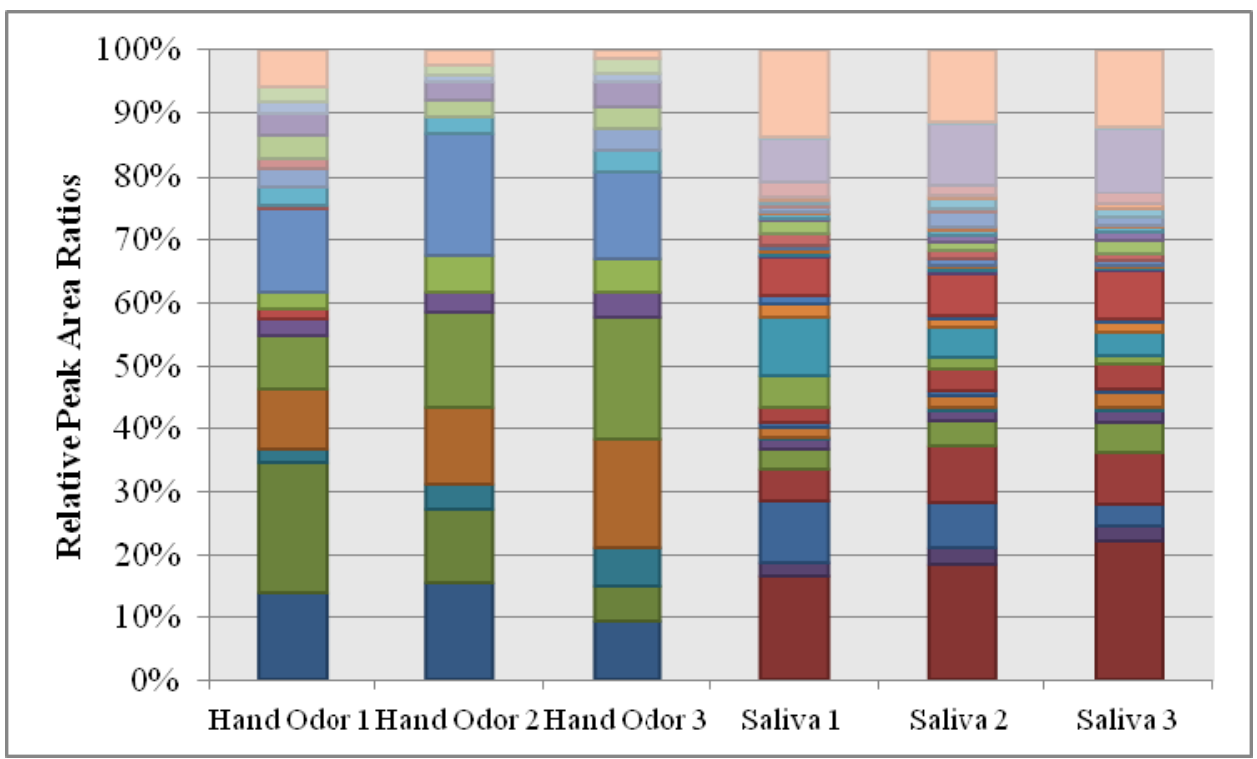

Figure 75-Chemical profile of VOCs extracted from hand odor and saliva from Subject 23F 


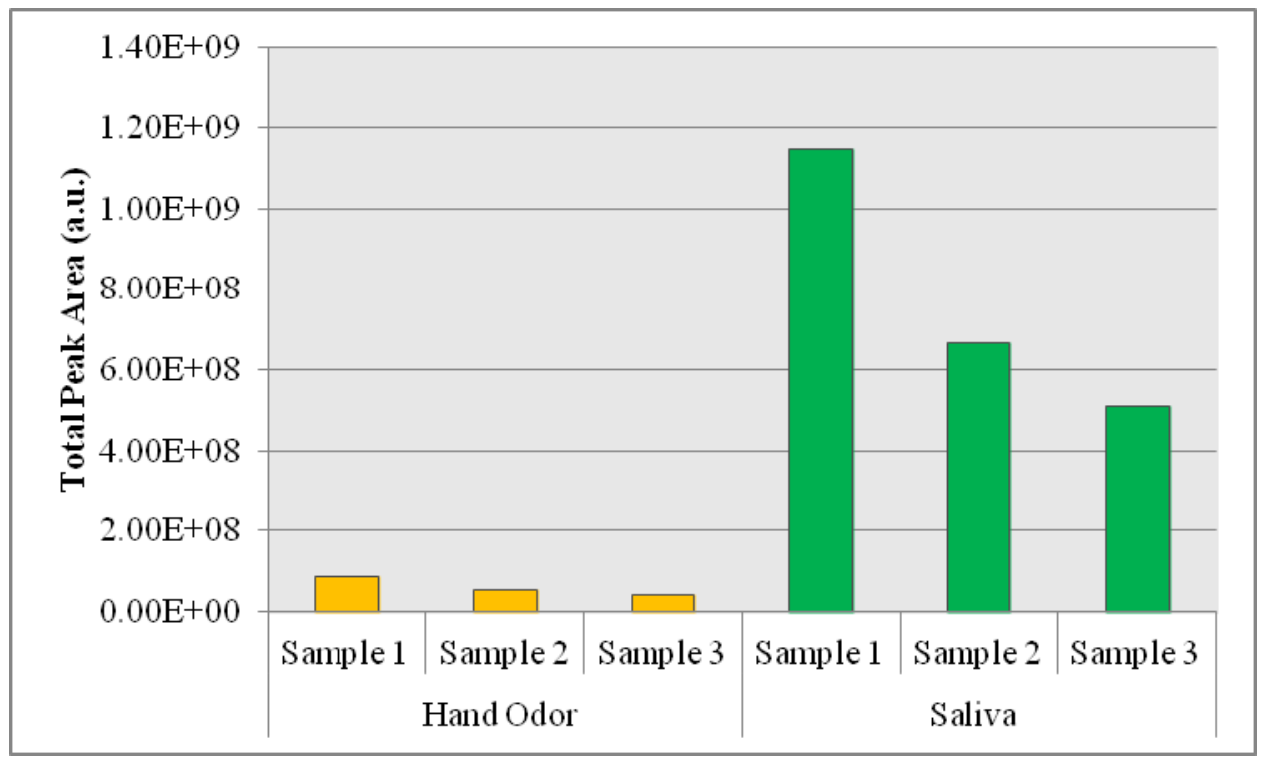

\section{Figure 76-Total abundance (peak area) of VOCs extraction from hand odor and saliva from Subject $23 F$}

When performing a side-by-side analysis it becomes apparent that there were eight VOCs which were present in both hand odor and saliva samples, while four of those compounds (decanal, butylated hydroxytoluene (BHT), hexadecane and homomenthyl salicylate) were present in the three hand odor and three saliva samples. When comparing the abundance of these compounds in both specimens (Figure 77), the abundance of decanal and homomenthyl salicylate is significantly larger in saliva. The abundance of BHT in hand odor is significantly larger than in saliva. The abundance of hexadecance is statistically similar in both hand odor and saliva. These four compounds could be an example of what the canines are sensing allowing them to match different specimens, such as hand odor and saliva, from the same person. Furthermore, when using saliva, some of these compounds that are common to both specimens, are more abundant in 
saliva, than in hand odor, which can be easily detected by the canine and provide a better response.

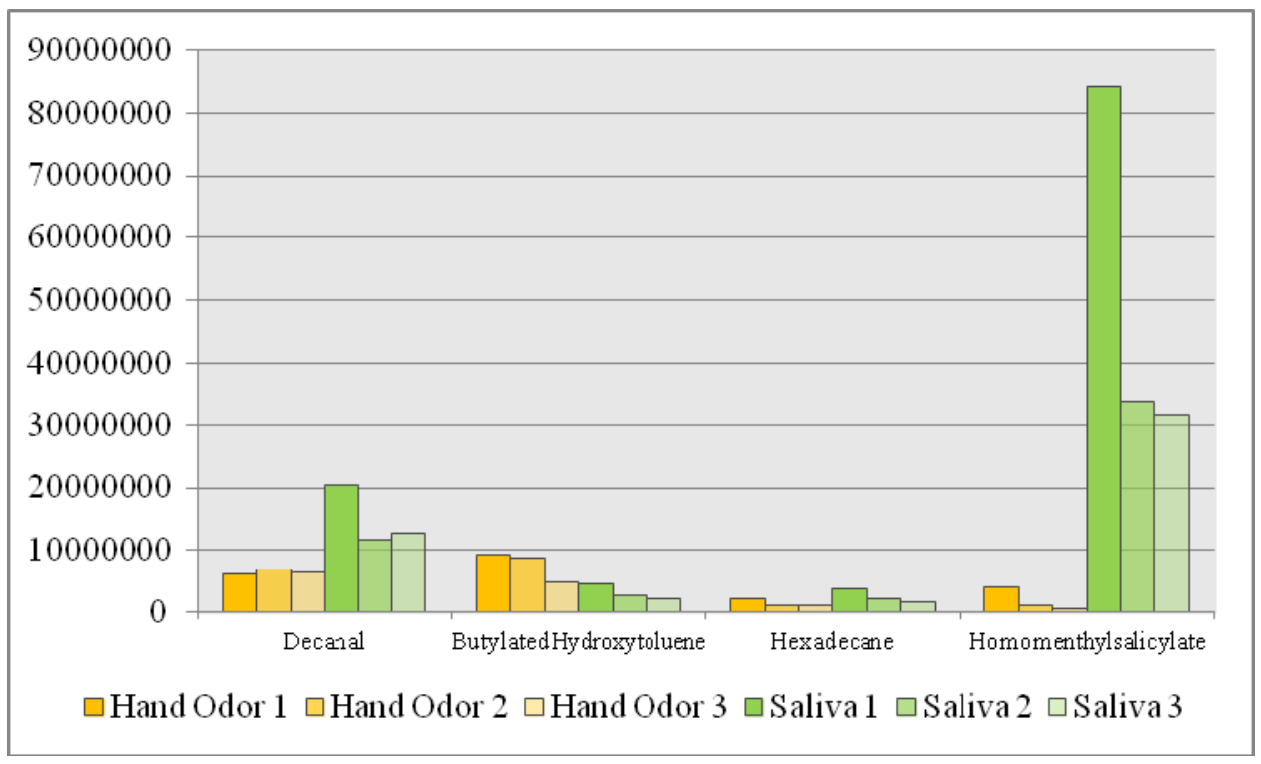

Figure 77-Abundance of common compounds in hand odor and saliva samples from Subject 23F

\subsubsection{Canine response to blank samples}

In addition to test samples, blank samples were also incorporated into canine field testing. Blank samples are simply the collection material, i.e., a cotton gauze pad, which does not contain human scent. When presenting a blank sample to a canine, theoretically the canine would not detect human scent and would remain still, or not begin to trail. During field testing of biological specimens, $13 \%$ of the canines did not begin to trail, when presented with a blank sample, and $88 \%$ of the canines did begin trailing. Of the canines that began trailing when presented with a blank sample, not one canine followed the path of a target meaning that the blanks were not likely to have been contaminated with 
human scent and the canines were not responding correctly. These trials had fewer canines properly respond to blank samples when compared to the previous three biological specimen trials. Again, these results emphasize the importance of incorporating blanks into training programs, so canines can become easily decipher between human scent samples and blanks samples, which only contain odors from the local environment. 


\section{CONCLUSION}

The VOCs of four biological specimens (hand odor, hair, fingernails and saliva) were evaluated instrumentally and by trained canines with the main objective of determining whether the extracted VOCs can be used to differentiate individuals. The present work provided the first account for the evaluation of VOCs from hair and fingernails, for their use in identifying individuals. Instrumental analysis was performed using headspace solid phase microextraction gas chromatography-mass spectrometry. This work began with the optimization of the HS-SPME extraction time, sample mass of hair samples and fingernail sample type. Subsequently, biological specimens were collected from 60 individuals (30 males, 30 females), which varied in age and race, and the VOCs emanating from these samples were analyzed.

An initial assessment, consisting of an intra-subject specimen evaluation, was performed. Through the analysis of four subjects' samples, many of the extracted VOCs were shared across the four specimen types; however, overall each biological specimen produced a different profile of volatile organic compounds. Hair and fingernail samples, which are both made of the keratin protein, had the greatest similarities. These samples grouped closely together after performing statistical evaluations including principal component analysis and cluster analysis. Saliva was the most dissimilar from the other specimens and contained many VOCs that were never detected in the other three biological specimens. The differences in the total profile of VOCs for each specimen made it difficult to cross-match specimen types that were collected from the same individual (they would appear to be dissimilar); therefore, it was determined that the proceeding evaluations would occur within a specimen type and not between. 
Triplicate samples of the four specimens were collected from 60 individuals providing a total of 714 samples (180 hand odor, 176 hair, 178 fingernail and 180 saliva) for analysis. Over 1,000 chromatographic peaks were identified from among the samples; however, a selection of 47 VOCs, which have been previously identified, in literature, as compounds emanating from humans, were used during data analysis and included acids, alcohols, aldehydes, aliphatic hydrocarbons, an aromatic hydrocarbon, esters, heterocyclics and ketones. Differences in the frequency of occurrence of VOCs were evaluated between the genders. The occurrence of VOCs in male and female subjects were often similar; however, there were two VOCs that did appear more frequently in one gender, across the different specimen types, which include dodecanoic acid for males and tetradecane for females. Though it could not be confirmed by this study, these two VOCs suggest a potential use as biomarkers for gender.

Spearman rank correlations were performed to determine the distinctiveness of biological specimens between individuals. The correlations of 60 individuals' samples produced a total of 1770 pair-wise comparisons for each specimen type. The distinguishability of the samples was determined by the number of samples that correlated at 0.89 or less. From these values, the percentage of distinguishable samples was calculated and determined to be $98.8 \%$ for hand odor, $99.8 \%$ for hair, $99.4 \%$ for fingernails and $99.5 \%$ for saliva samples. The application of Spearman rank correlations revealed that the VOCs emanating from each specimen are highly distinctive and can be used to distinguish individuals.

In addition to distinctiveness, the persistence of VOCs from biological specimens was assessed over a six month period. Biological specimens were collected from six 
individuals once a month for a total of six months. This procedure identified common human scent VOCs, which were the most persistent compounds, based upon the fact that they were detected in five or more of the sampling months. On average, the six subjects possessed nine common VOCs in hand odor, five in hair, four in fingernails and nine in saliva. This indicates that the chemical composition of hand odor and saliva are the most consistent over time. Another way persistence of VOCs was assessed was through the cluster analysis of the six month samples, which provided a value for similarity of the samples. Hand odor and hair samples were the most similar, over time, at $83.9 \%$, and $83.6 \%$, respectively, and continued with saliva at $74.6 \%$ and fingernails at $63.9 \%$.

To supplement the laboratory studies, canine field trials were conducted to evaluate whether different biological specimens can be used as a scent source for trained canines. Additional field trials were performed to evaluate how two different scent collection devices can impact canine performance. The evaluation of different biological specimens showed that canines can respond similarly to hair, fingernails and saliva, as they do with hand odor. Regarding the scent collection device, canines performed better with the scent collection device that has a higher airflow rate (STU-100). It can be surmised that the device with the higher airflow rate, draws in a larger volume of air and, therefore, will allow for the collection of more odor.

There is still plenty of work to be done that pertains to human scent. Primarily, new techniques of collection, extraction and analysis need to be explored to improve sensitivity and reduce sampling time of human scent samples. Each procedure suffers from their own inherent drawbacks and with the creation of new, efficient and sensitive methods researchers will be able to uncover novel features of human scent that have 
never been seen before. Furthermore, to bolster the use of human scent in criminal investigations it will be essential to develop techniques that allow scent from an object to be matched back to the person it originated from, with the use of analytical instruments. Up until now, all human scent work has been performed under controlled laboratory conditions; however, it would be beneficial to devise ways to analyze human scent under real-life scenarios. Lastly, future work should, also, continue to explore chemical biomarkers for gender, age, race and medical condition across different biological specimens so that, forensically, people of interest can be identified or excluded. Though it was not confirmed, this work tentatively identified potential chemical biomarkers that signify gender, demonstrating another way human scent can be applied in forensic science.

The analysis of the profiles of the VOCs produced from the different biological specimens showed that each specimen possesses a distinct array of chemicals, which can be differentiated by a variety of statistical methods. Intuitively, it might be assumed that when applying this knowledge to criminal investigations, trained canines would not be able to cross-match specimens back to the original person; however, this is not the case. These field trials reveal that there are commonalities in the scents that can be recognized by canines. The results demonstrate that while the chemical analysis supports the ability of canines to differentiate the scent of individuals, there are other chemicals being used by canines not detected with the current method. Therefore, researchers should be cautious in generalizing laboratory results to operational conditions. 


\section{REFERENCES}

1. A.M. Curran, S.I. Rabin, P.A. Prada, K.G. Furton, Comparison of the volatile organic compounds present in human odor using SPME-GC/MS. Journal of Chemical Ecology 31 (2005) 1607-1619.

2. Hodge v. State, 98 Ala. 10. (Ala. 1893).

3. People v. Salcido, Cal. App. $2^{\text {nd }}$ (Cal. Ct. App. 2005).

4. People v. Wade. Akd. 5927 (Akd. 2008).

5. Cranford v. State. 130 Ark. 101 (Ark. 1917).

6. A. Curran, R. Stockham, B. Warren, B. Eckenrode. Human scent evidence: Scientific support of canine operations and teaching an old dog new tricks. Research Partnership Program of 34th Annual Symposium on Crime Laboratory Development. 2006.

7. A. Schoon, R. Haak K9 suspect discrimination, Detselig Enterprises Ltd., Calgary, Alberta, Canada, 2002.

8. D. Penn, W. Potts, The evolution of mating preferences and major histocompatibility complex genes. The American Naturalist, 153 (1999) 145-164.

9. C. Wedekind, T. Seebeck, F. Bettens, A. Paepke, The intensity of human body odors and the MHC: Should we expect a link? Evolutionary Psychology, 4 (2006) 85-94.

10. C. Wedekind, T. Seebeck, F. Bettens, A. Paepke, MHC dependent mate preferences in humans. Proceedings of the Royal Society B, 260 (1995) 245-249.

11. C. Wedekind, D. Penn, MHC genes, body odours, and odour preferences. Nephrology Dialysis Transplantation, 15 (2000) 1269-1271.

12. J. Kwak, A. Willse, G. Preti, K. Yamazaki, G. Beauchamp, In search of a chemical basis for MHC odourtypes. Proceedings of the Royal Society B, 277 (2010) 2417-2425.

13. A. Aksenov, A. Gojova, W. Zhao, J. Morgan, S. Sankaran, C. Sandrock, C. Davie. Characterization of volatile organic compounds in human leukocyte antigen heterologous expression systems: a cell's chemical odor fingerprint. Chemistry and Biochemistry. 2012. 
14. A. Martin, M. Saathoff, F. Kuhn, H. Max, L. Terstegen, A. Natsch, A functional ABCC11 allele is essential in the biochemical formation of human axillary odor. Journal of Investigative Dermatology, 130 (2010) 529-540.

15. M. McKinley, V. O'Loughlin Cartilage and Bone Connective Tissue. Human Anatomy, McGraw-Hill, New York, 2008, pp. 145-170.

16. K. Saga, Structure and function of human sweat glands studied with histochemistry and cytochemistry. Progress in Histochemistry and Cytochemistry, 37 (2002) 323.

17. Structure and function of skin. 2009. http://www.lhsc.on.ca/Health_Professionals/Wound_Care/intro/structur.htm, London Health Sciences Center. Accessed on 5-31-2012.

18. A. Faller, M. Schunke, G. Schunke The skin and its appendages. The human body: An introduction to structure and function, Stuttgart, Thieme, 2004, pp. 663672.

19. R. Smallegange, N. Verhulst, W. Takken, Sweaty skin: an invitation to bite? Trends in Parasitology, 27 (2011) 143-148.

20. A. James, J. Casey, D. Hyliands, G. Mycock, Fatty acid metabolism by cutaneous bacteria and its role in axillary malodour. World Journal of Microbiology and Biotechnology, 20 (2004) 787-793.

21. B. Burger, Mammalian Semiochemicals. Topics in Current Chemistry, 240 (2005) 231-278.

22. N. Goetz, H. Burgaud, C. Berrebi, P. Bore, Analysis of the lipid content of single hair bulbs. Comaprison with the content of the sebaceous gland with surface lipids. Journal of the Society of Cosmetic Chemists, 35 (1984) 411-422.

23. N. Jablonski Skin: a natural history, University of California Press, Berkeley, 2006.

24. N. Verhulst, H. Beijleveld, B. Knols, W. Takken, G. Schraa, H. Bouwmeester, R. Smallegange, Cultured skin microbiota attracts malaria mosquitoes. Malaria Journal, 8 (2009) 3.

25. F. Kuhn, A. Natsch, Body odour of monzygotic human twins: a common pattern odorant carboxylic acids released by a bacterial aminoacylase from axilla secretions contibuting to an inherited body odour type. Journal of the Royal Socitey Interface, 6 (2009) 377-392. 
26. A. Natsch, H. Gfeller, P. Gygax, J. Schmid, G. Acuna, A specific bacterial aminoacylase cleaves odorant precursors secreted in the human axilla. The Journal of Biological Chemistry, 278 (2003) 5718-5727.

27. J. Kanitakis, Anatomy, histology and immunohistochemistry of normal human skin. European Journal of Dermatology, 12 (2002) 390-401.

28. C. Acevedo, E. Sanchez, J. Reyes, M. Young, Volatile profiles of human skin cell cultures in different degrees of senescence. Journal of Chromatography B, 878 (2010) 449-455.

29. W. Syrotuck Scent and the scenting dog, Barkleigh Productions, Mechanicsburg, 2000.

30. G. Settles, W. McGann, Potential for portal detection of human chemical and biological contamination. SPIE Aerosense, 4378 (2001) 1-9.

31. A. Ostrovskaya, P.A. Landa, M. Sokolinsky, A.D. Rosalia, D. Maes, Study and identification of volatile compounds from human skin. Journal of Cosmetic Science, 53 (2002) 147-148.

32. A.M. Curran, P.A. Prada, K.G. Furton, The Differentiation of the Volatile Organic Signatures of Individuals Through SPME-GC/MS of Characteristic Human Scent Compounds. Journal of Forensic Sciences, 55 (2010) 50-57.

33. G. Horvath, J. Chilo, T. Lindblad, Different volatile signals emitted by human ovarian carcinoma and healthy tissue. Future Oncology, 6 (2010) 1043-1049.

34. D. Penn, E. Oberzaucher, K. Grammer, G. Fischer, H. Sioni, D. Wiesler, M. Novotny, S. Dixon, Y. Xu, R. rereton, Individual and gender fingerprints in human body odor. Journal of the Royal Socitey Interface, 4 (2007) 331-340.

35. Y. Xu, S. Dixon, R. Brereton, H. Soini, M. Novotny, K. Trebesius, I. Bergmaier, E. Oberzaucher, K. Grammer, D. Penn, Comparison of human axillary odour profiles obtained by gas chromatography/mass spectrometry and skin microbial profiles obtained by denaturing gradient gel electrophoresis using multivariate pattern recognition. Metabolomics, 3 (2007) 427-437.

36. X.-N. Zeng, J. Leyden, A. Spielman, G. Preti, Analysis of characteristic human female axillary odors: Qualitative comparison to males. Journal of Chemical Ecology, 22 (1996) 237-257.

37. M. Gallagher, C.J. Wysocki, J.J. Leyden, A.I. Spielman, X. Sun, G. Preti, Analyses of volatile organic compounds from human skin. British Journal of Dermatology, 159 (2008) 780-791. 
38. Z.-M. Zhang, J.-J. Cai, G.-H. Ruan, G.-K. Li, The study of fingerprint characteristics of the emanations from human arm skin using the original sampling system by SPME-GC/MS. Journal of Chromatography B, 822 (2005) 244-252.

39. S. Riazanskaia, G. Blackburn, M. Harker, C. Thomas, The analytical utility of thermally desorbed polydimethylsilicone membranes for in-vivo sampling of volatile organic compounds in and on human skin. The Analyst, 133 (2008) 1027.

40. H. Soini, K. Bruce, I. Klouckova, R. Brereton, D. Penn, M. Novotny, In situ surface sampling of biological objects and preconcentration of their volatiles for chromatographic analysis. Analytical Chemistry, 78 (2006) 7161-7168.

41. J. Logan, M. Birkett, S. Clark, S. Powers, N. Seal, L. Wadhams, A. Mordue (Luntz), J. Pickett, Identification of human-derived volatile chemicals that interfere with attraction of Aedes aegypti mosquitoes. Journal of Chemical Ecology, 34 (2008) 308-322.

42. U.R. Bernier, D.L. Kine, D.R. Barnard, C.E. Schreck, R.A. Yost, Analysis of human skin emanations by gas chromatography/mass spectrometry. 2. Indentification of volatile compounds that are candidate attractants for the yellow fever mosquito (Aedes aegypti). Analytical Chemistry, 72 (2000) 747-756.

43. P. Martinez-Lozano, Mass spectrometric study of cutaneous volatiles by secondary electrospray ionization. International Journal of Mass Spectrometry, 282 (2009) 128-132.

44. J. Pawliszyn, B. Pawliszyn, M. Pawliszyn, Solid phase microextraction (SPME). The Chemical Educator, 2 (1997) 1-7.

45. D. Skoog, F. Holler, T. Nieman Gas chromatography. Principles of instrumental analysis, Thomson Learning Inc., South Melbourne, 1998, pp. 701-724.

46. S. Dawling, S. Jickells, A. Negrusz Gas chromatography. in: S. Jickells and A. Negrusz (Eds.) Clarke's Analytical Forensic Toxicology, Pharmaceutical Press, London, 2008, pp. 469-512.

47. Capillary GC Columns, by phase polarity. 2011. http://www.sigmaaldrich.com/analytical-chromatography/analyticalproducts.html?TablePage=103218999, Sigma-Aldrich. Accessed on 5-29-2012.

48. D. Watson, S. Jickells, A. Negrusz Mass spectrometry. in: S. Jickells and A. Negrusz (Eds.) Clarke's Analytical Forensic Toxicology, London, Pharmaceutical Press, 2008, pp. 557-586. 
49. D. Skoog, F. Holler, T. Nieman Molecular mass spectrometry. Principles of Instrumental Analysis, Thomson Learning Inc., South Melbourne, 1998, pp. 498534.

50. A.M. Curran, C.F. Ramirez, A.A. Schoon, K.G. Furton, The frequency of occurrence and discriminatory power of compounds found in human scent across a population determined by SPME-GEMS. Journal of Chromatography BAnalytical Technologies in the Biomedical and Life Sciences, 846 (2007) 86-97.

51. Y. Xu, F. Gong, S. Dixon, R. Brereton, Application of dissimilarity indices, principal coordinates analysis and rank tests to peak tables in metabolomics of the gas chromatography/mass spectrometry of human sweat. Analytical Chemistry, 79 (2007) 5633-5641.

52. H.C. Lee, C. Ladd, Preservation and collection of biological evidence. Croatian Medical Journal, 42 (2001) 225-228.

53. Without a trace? Advances in detecting trace evidence. National Institute of Justice Journal, 249 (2003) 2-9.

54. B. Craven, E. Paterson, G. Settles, The fluid dynamics of canine olfaction:unique nasal airflow patterns as an explanation of macrosmia. Journal of the Royal Socitey Interface, 7 (2010) 933-943.

55. L. Harvey, S. Harvey, M. Hom, A. Perna, J. Salib, The use of bloodhounds in determining the impact of genetics and the environment on the expression of human odortype. Journal of Forensic Science, 51 (2006) 1109-1114.

56. G. Schoon, J. De Bruin, The ability of dogs to recognize and cross-match human odours. Forensic Science International, 69 (1994) 111-118.

57. R. Stockham, D. Slavin, W. Kift, Specialized use of human scent in criminal investigations. Forensic Science Communications, 6 (2004).

58. R. Saferstein Criminalistics: An introduction to forensic science, Prentice Hall, Upper Saddle River, 2007.

59. B.A. Benner, J.V. Goodpaster, J.A. DeGrasse, L.A. Tully, B.C. Levin, Characterization of surface organic components of human hair by on-line supercritical fluid extraction-gas chromatography/mass spectrometry: A feasibility study and comparison with human identification using mitochondrial DNA sequences. Journal of Forensic Sciences, 48 (2003) 554-563. 
60. K.L. Opel, E.L. Fleishaker, J.A. Nicklas, E. Buel, B.R. Mccord, Evaluation and quantification of nuclear DNA from human telogen hairs. Journal of Forensic Sciences, 53 (2008) 853-857.

61. M. Barroso, M. Dias, D.N. Vieira, M. Lopez-Rivadulla, J.A. Queiroz, Simultaneous quantitation of morphine, 6-acetylmorphine, codeine, 6acetylcodeine and tramadol in hair using mixed-mode solid-phase extraction and gas chromatography-mass spectrometry. Analytical and Bioanalytical Chemistry, 396 (2010) 3059-3069.

62. H. Sachs, P. Kintz, Testing for drugs in hair - Critical review of chromatographic procedures since 1992. Journal of Chromatography B-Analytical Technologies in the Biomedical and Life Sciences, 713 (1998) 147-161.

63. M. Harkey, Anatomy and physiology of hair. Forensic Science International, 63 (1993) 9-18.

64. N. Goetz, G. Kaba, D. Good, G. Hussler, P. Bore, Detection and identification of volatile compounds evolved from human-hair and scalp using headspace gas chromatography. Journal of the Society of Cosmetic Chemists, 39 (1988) 1-13.

65. J.V. Goodpaster, B.C. Drumheller, B.A. Benner, Evaluation of extraction techniques for the forensic analysis of human scalp hair using gas chromatography/mass spectrometry (GC/MS). Journal of Forensic Sciences, 48 (2003) 299-306.

66. Scientific Working Group for Materials Analysis. 2012. http://www.swgmat.org/. Accessed on 7-19-2012.

67. R.A. Wickenheiser, Trace DNA: A review, discussion of theory, and application of the transfer of trace quantities of DNA through skin contact. Journal of Forensic Sciences, 47 (2002) 442-450.

68. A. Piccinini, F. Betti, M. Capra, A. Comino, A 5-year study on DNA recovered from fingernail clippings in homicide cases in Milan. International Congress Series, 1239 (2003) 929-932.

69. P. Wiegand, T. Bajanowski, B. Brinkmann, Dna Typing of Debris from Fingernails. International Journal of Legal Medicine 106 (1993) 81-83.

70. O. Cook, L. Dixon, The prevalence of mixed DNA profiles in fingernail samples taken from individuals in the general population. Forensic Science InternationalGenetics, 1 (2007) 62-68. 
71. T. Lederer, P. Betz, S. Seidl, DNA analysis of fingernail debris using different multiplex systems: a case report. International Journal of Legal Medicine, 114 (2001) 263-266.

72. Nail health. 1999. http://www.aad.org/pamphlet/nailhealth.html, American Academy of Dermatology.

73. E.I. Brima, P.I. Haris, R.O. Jenkins, D.A. Polya, A.G. Gault, C.F. Harrington, Understanding arsenic metabolism through a comparative study of arsenic levels in the urine, hair and fingernails of healthy volunteers from three unexposed ethnic groups in the United Kingdom. Toxicology and Applied Pharmacology, 216 (2006) 122-130.

74. D. de Berker, B. Forslind The structure and properties of nails and periungual tissues. in: B. Forslind and M. Lindberg (Eds.) Skin, hair and nails:Structure and function, Marcel Dekker, Inc., New York, 2004, pp. 409-464.

75. D. de Berker, J. Andre, R. Baran, Nail biology and nail science. International Journal of Cosmetic Science, 29 (2007) 275.

76. M.N. Hochmeister, B. Budowle, J. Jung, U.V. Borer, C.T. Comey, R. Dirnhofer, Pcr-Based Typing of Dna Extracted from Cigarette Butts. International Journal of Legal Medicine, 104 (1991) 229-233.

77. F. Fridez, R. Coquoz, PCR DNA typing of stamps: Evaluation of the DNA extraction. Forensic Science International, 78 (1996) 103-110.

78. M. Yonamine, N. Tawil, R.L.D. Moreau, O.A. Silva, Solid-phase microextraction-gas chromatography-mass spectrometry and headspace-gas chromatography of tetrahydrocannabinol, amphetamine, methamphetamine, cocaine and ethanol in saliva samples. Journal of Chromatography B-Analytical Technologies in the Biomedical and Life Sciences, 789 (2003) 73-78.

79. J.G. Kostelc, G. Preti, P.R. Zelson, N.H. Stoller, J. Tonzetich, Salivary Volatiles As Indicators of Periodontitis. Journal of Periodontal Research, 15 (1980) 185192.

80. M. Kusano, E. Mendez, K.G. Furton, Development of headspace SPME method for analysis of volatile organic compounds present in human biological specimens. Analytical and Bioanalytical Chemistry, 400 (2011) 1817-1826.

81. Salivary glands (diagram). 2012. http://www.patient.co.uk/diagram/SalivaryGlands.htm, Patient.co.uk. Accessed on 5-31-2012.

82. J. Crouch Functional Human Anatomy, Lea and Febiger, Philadelphia, 1985. 
83. S. Chiappin, G. Antonelli, R. Gatti, E.F. De Palo, Saliva specimen: A new laboratory tool for diagnostic and basic investigation. Clinica Chimica Acta, 383 (2007) 30-40.

84. P. De Almeida, A. Gregio, M. Machado, L. Azevedo, Saliva composition and functions: A comprehensive review. Journal of Contemporary Dental Practice, 3 (2008) 72-80.

85. Frye v. United States, 293 F. 1013. (D.C. Cir. 1923).

86. Daubert v. Merrell Dow Pharmaceuticals, Inc., 509 US 579. (1993).

87. R. Saferstein Forensic Science Handbook, Prentice Hall, Upper Saddle River, 2002.

88. J. Miller, J. Miller Statistics and Chemometrics for Analytical Chemistry, Pearson Edition Limited, Harlow, 2005.

89. S. Haze, Y. Gozu, S. Nakamura, Y. Kohno, K. Sawano, H. Ohta, K. Yamazaki, 2Nonenal newly found in human body odor tends to increase with aging. Journal of Investigative Dermatology, 116 (2001) 520-524.

90. D.T. Hudson, A.M. Curran, K.G. Furton, The Stability of Collected Human Scent Under Various Environmental Conditions. Journal of Forensic Sciences, 54 (2009) 1270-1277.

91. M. Phillips, Method for the collection and assay of volatile organic compounds in breath. Analytical Biochemistry, 247 (1997) 272-278.

92. P. Prada, A. Curran, K. Furton, The evaluation of human hand odor volatiles on various textiles: A comparison between contact and non-contact sampling methods. Journal of Forensic Science, 56 (2011) 866-881.

93. A.A. Vass, R.R. Smith, C.V. Thompson, M.N. Burnett, D.A. Wolf, J.A. Synstelien, N. Dulgerian, B.A. Eckenrode, Decompositional odor analysis database. Journal of Forensic Sciences, 49 (2004) 760-769. 


\section{APPENDICES}

Appendix A

Color charts of the profiles of the VOCs produced from the biological specimens of six subjects collected over a six month period.

Figure 78- Chemical profiles of biological specimens from Subject $2 \mathrm{~F}$ over a six month period

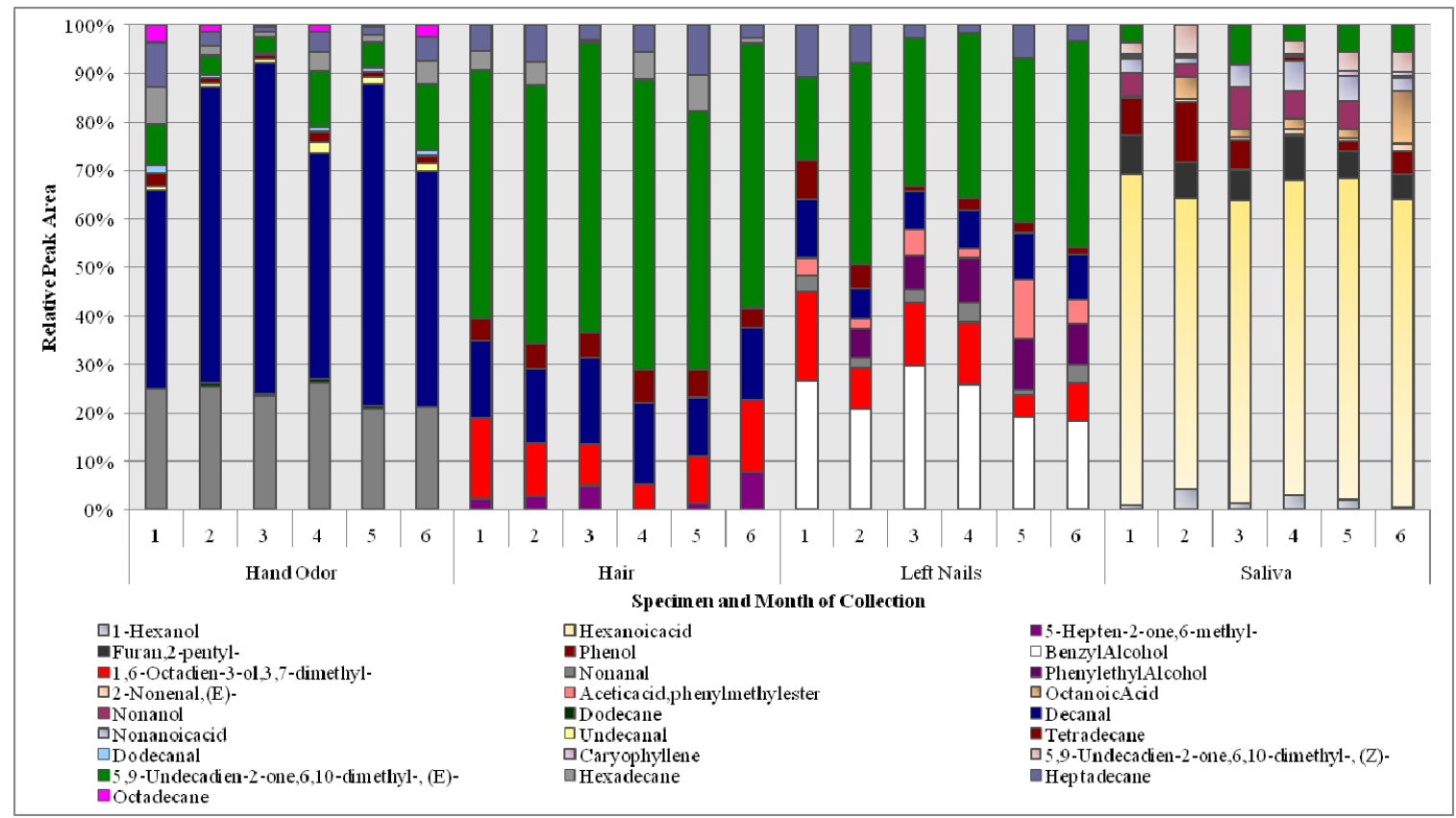


Figure 79- Chemical profiles of biological specimens from Subject 8F over a six month period

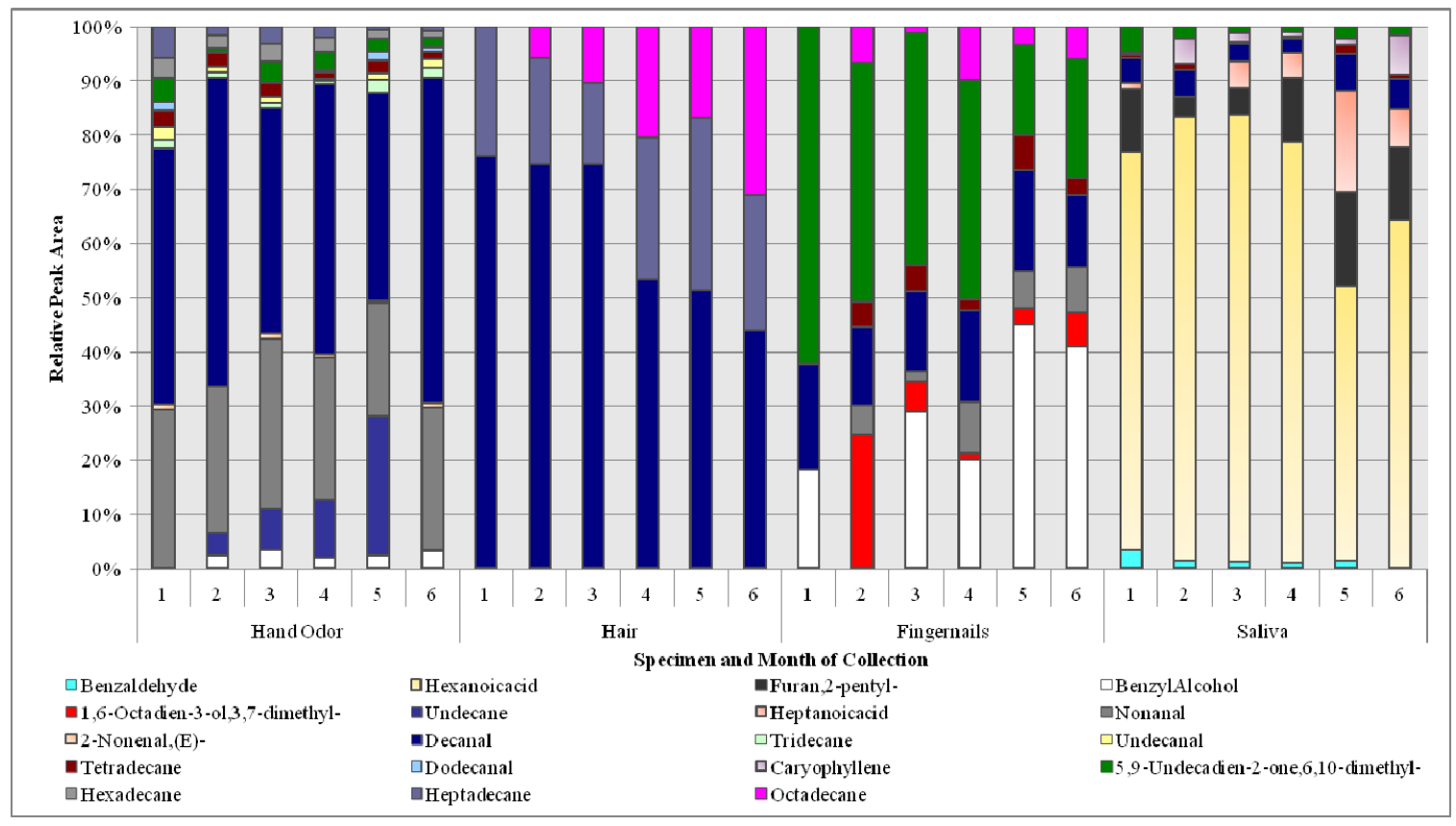

Figure 80- Chemical profiles of biological specimens from Subject 4M over a six month period

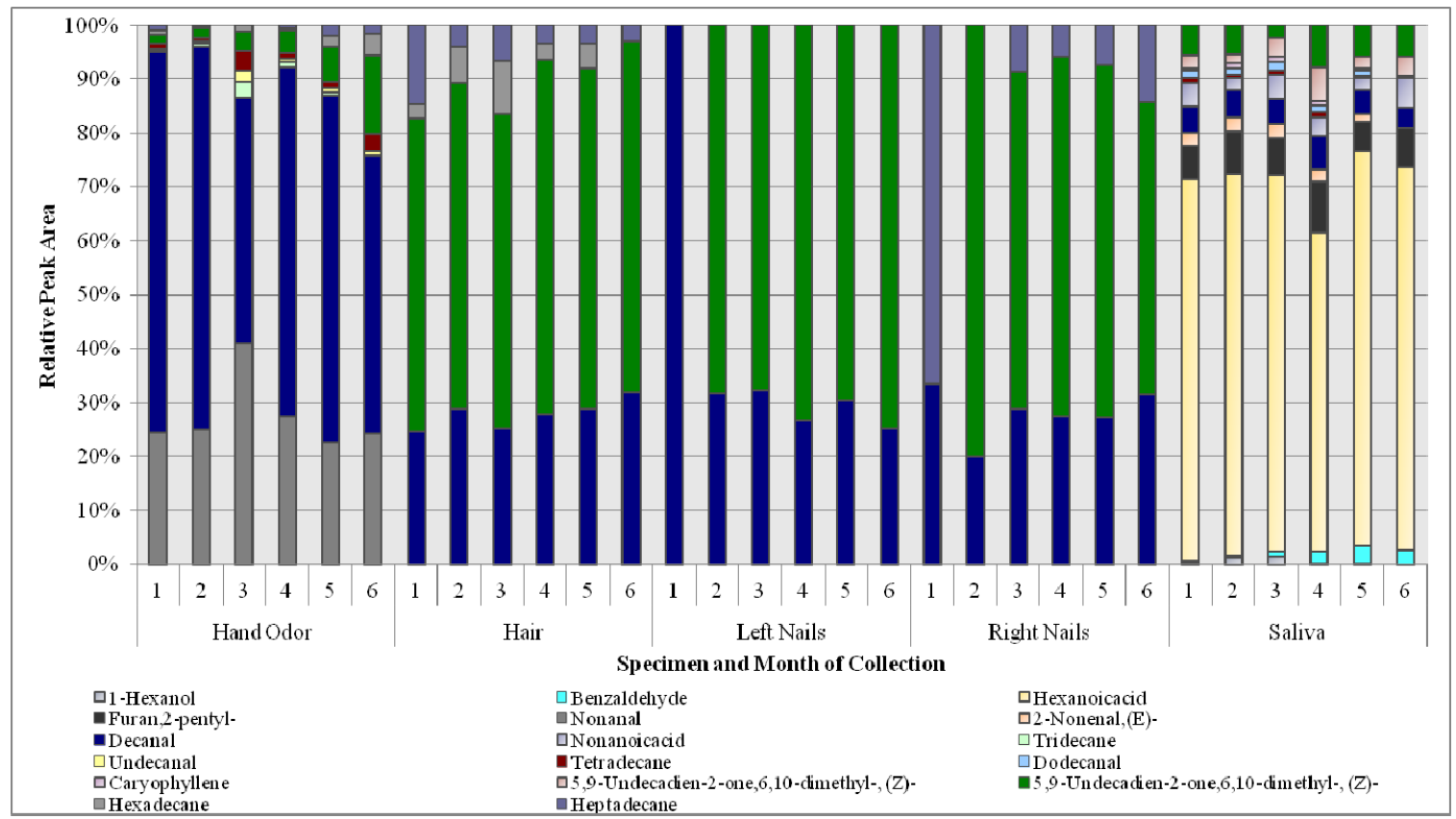


Figure 81- Chemical profiles of biological specimens from Subject 16M over a six month period

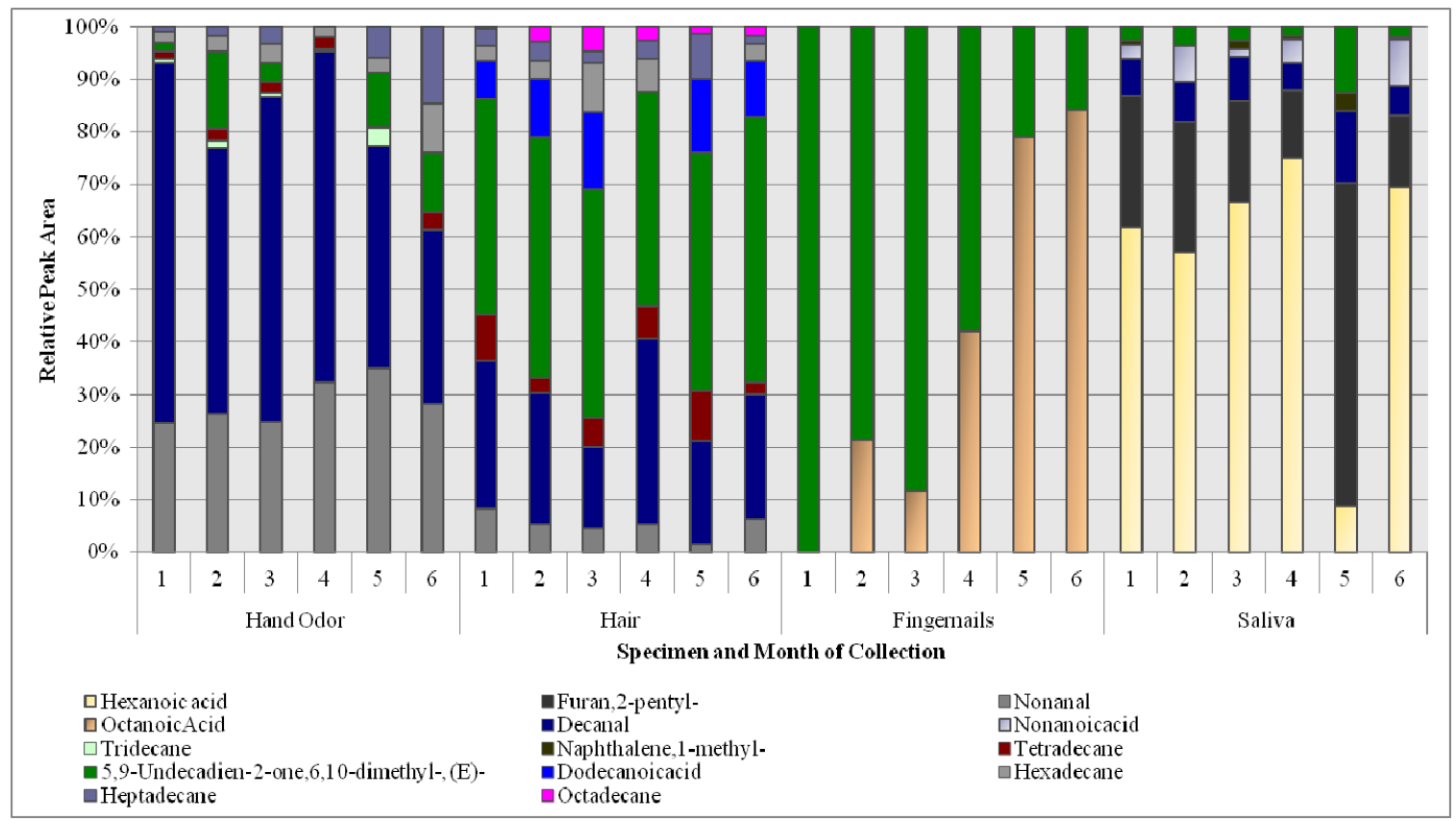

Figure 82- Chemical profiles of biological specimens from Subject 28M over a six month period

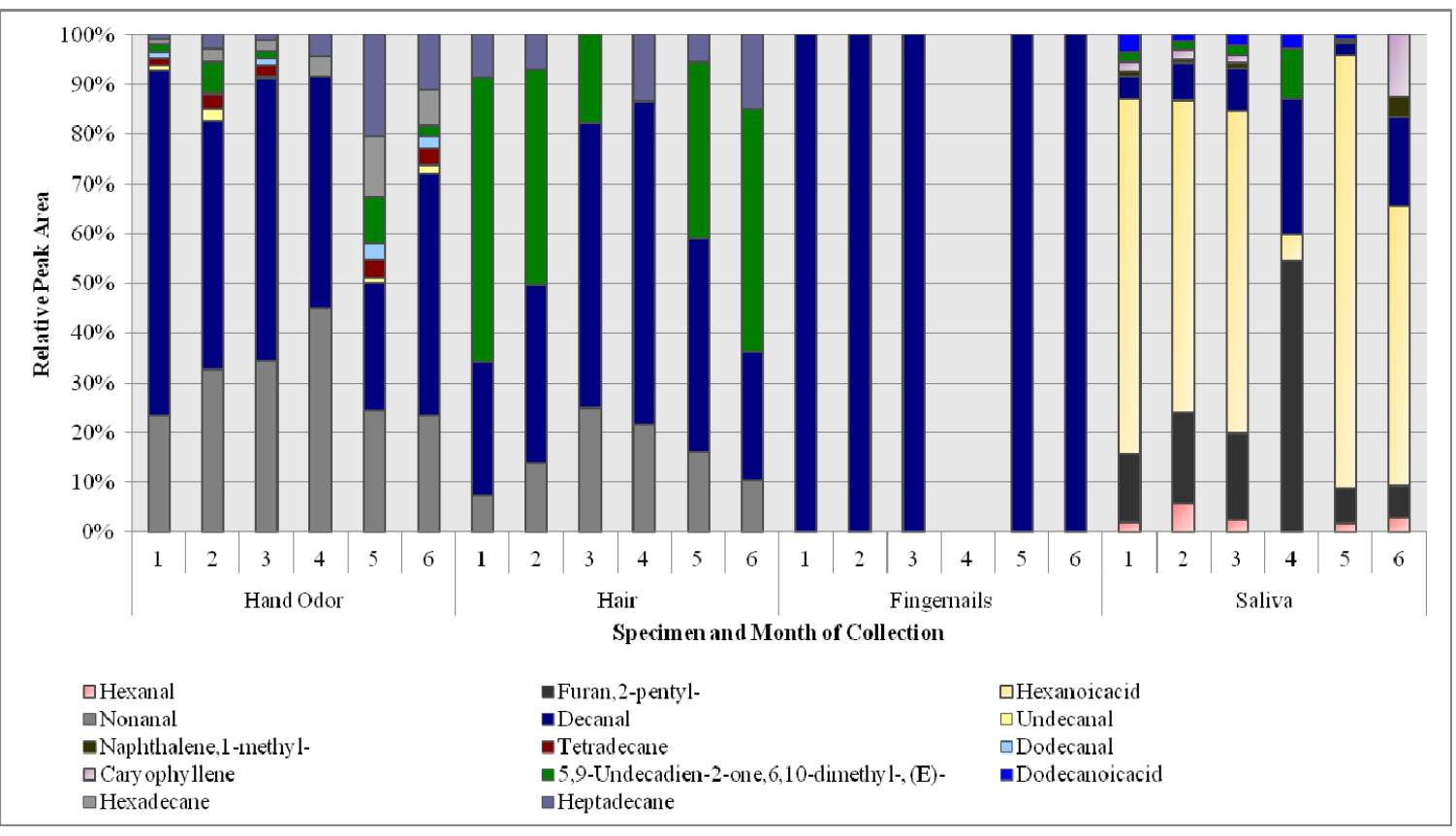


Appendix B

Dendograms of biological specimens from six subjects collected over a six month period

Figure 83-Dendogram of biological specimens from Subject 2F collected over a six month period

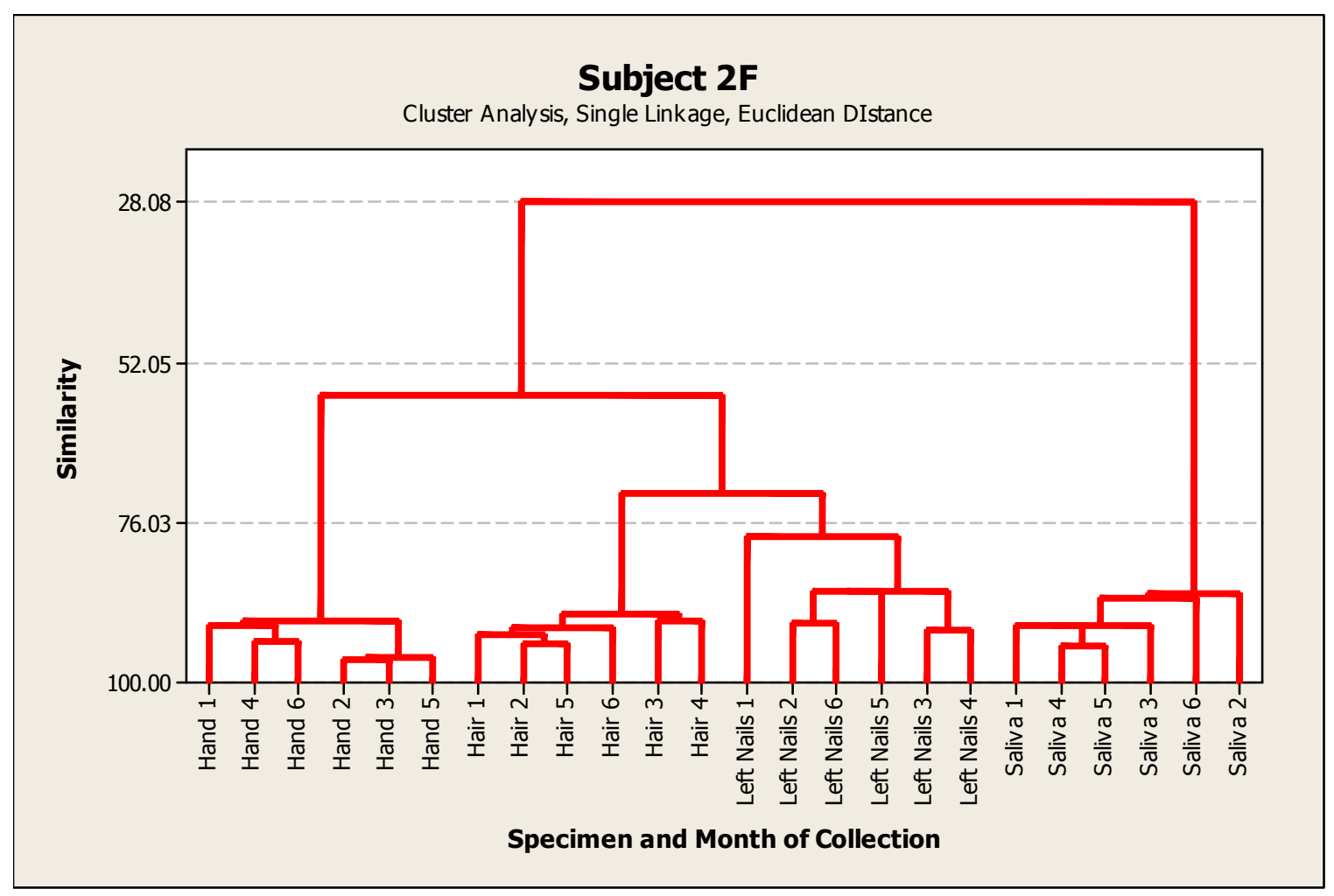


Figure 84-Dendogram of biological specimens from Subject 8F collected over a six month period

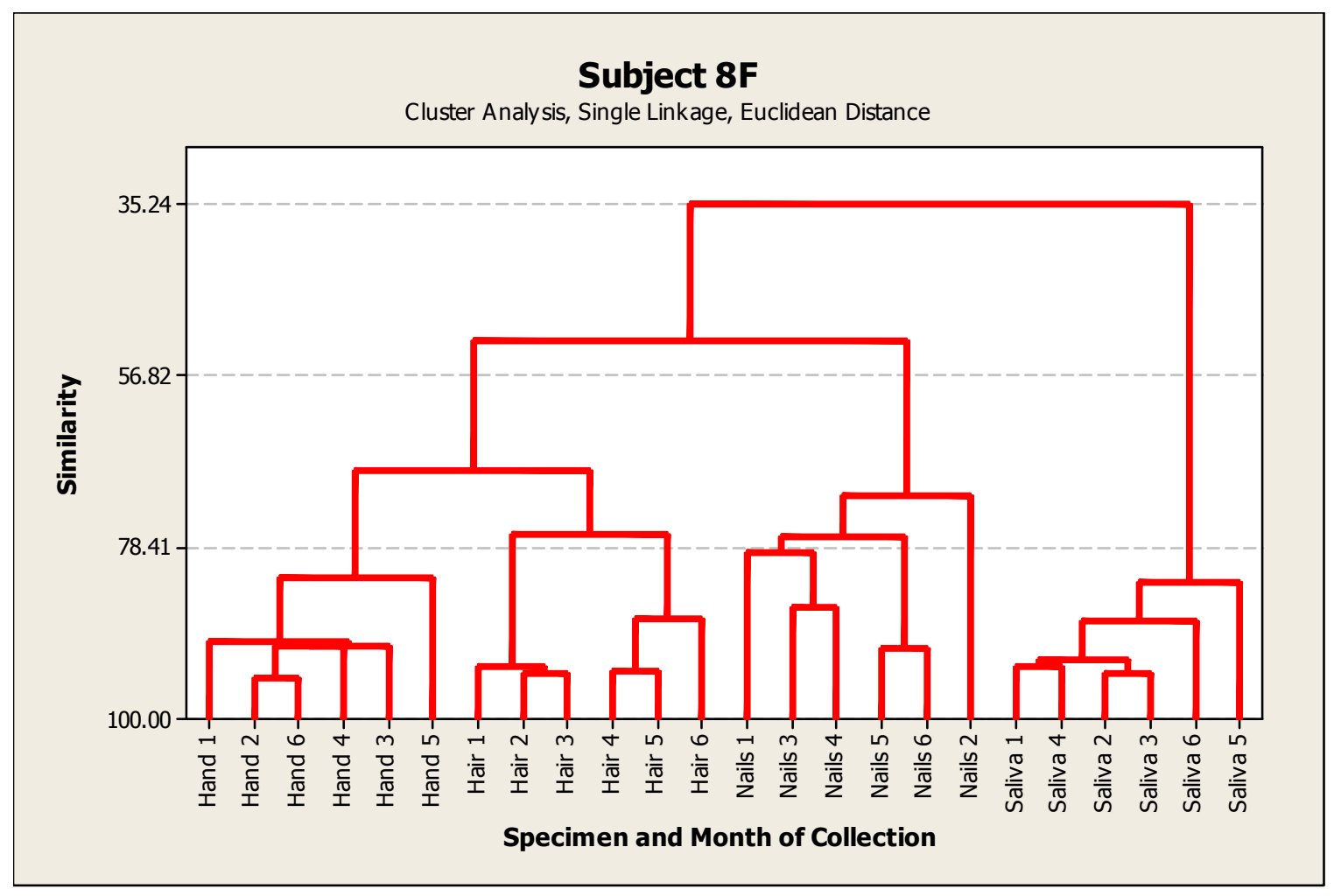


Figure 85-Dendogram of biological specimens from Subject $4 \mathrm{M}$ collected over a six month period

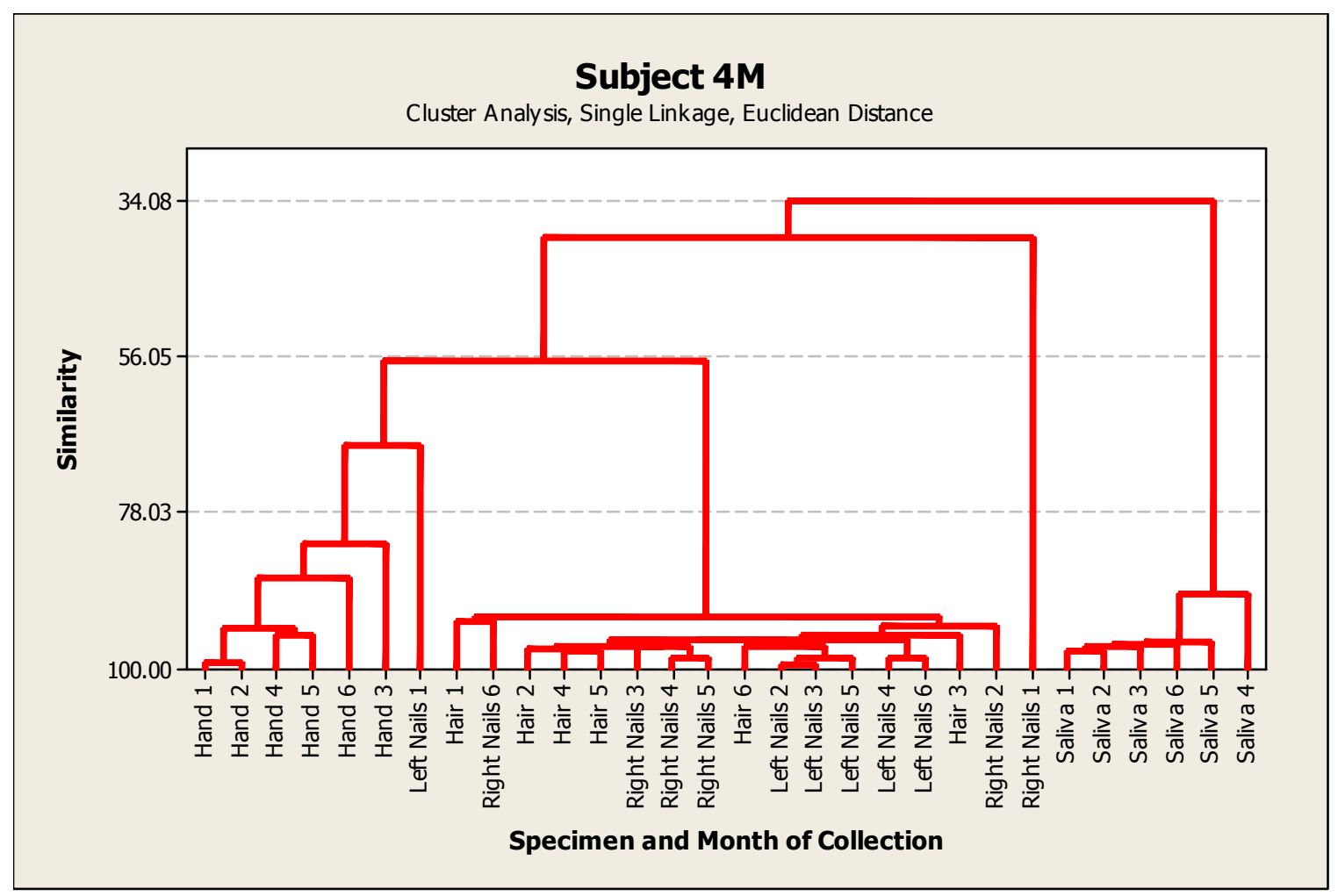


Figure 86-Dendogram of biological specimens from Subject 16M collected over a six month period

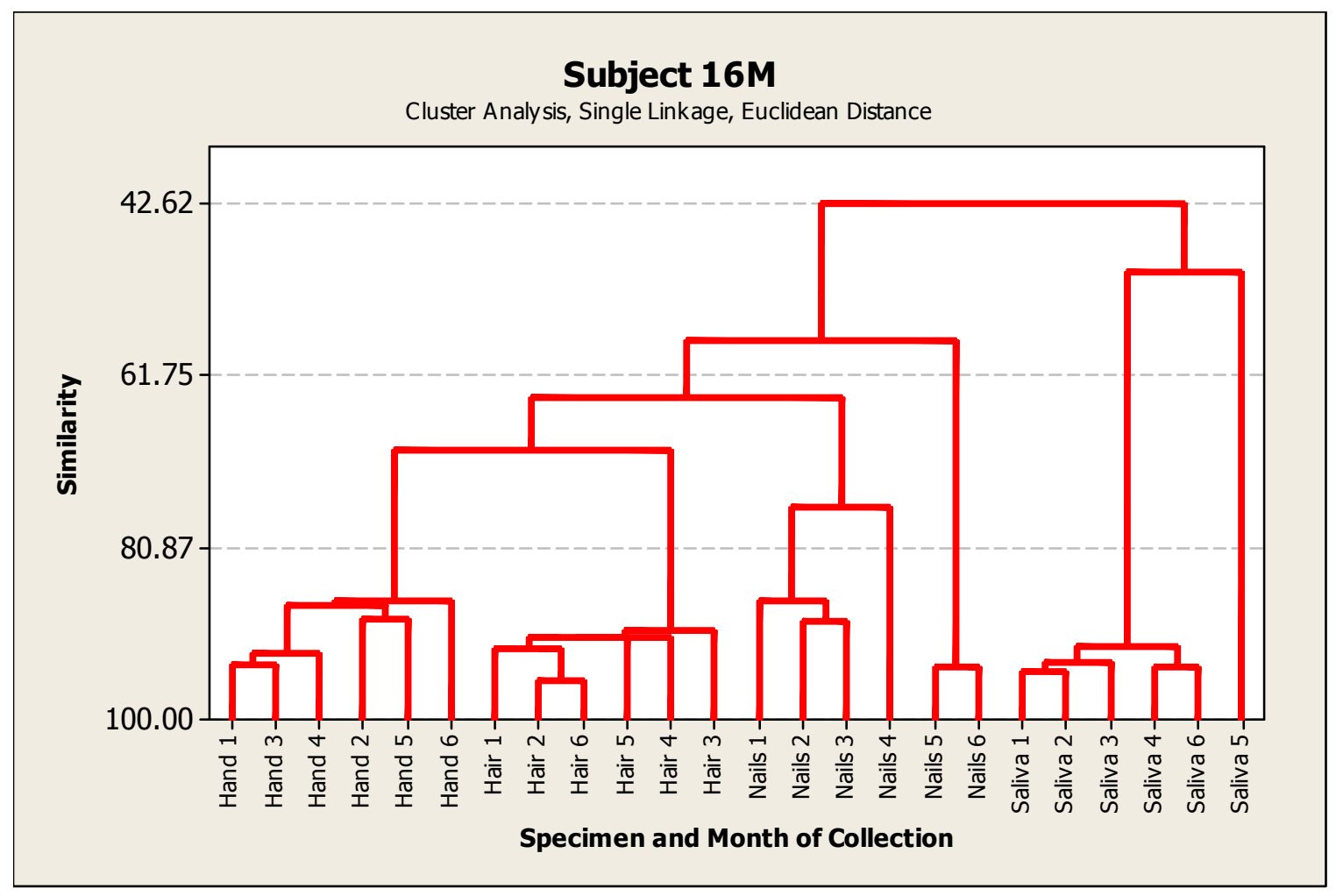


Figure 87-Dendogram of biological specimens from Subject 28M collected over a six month period

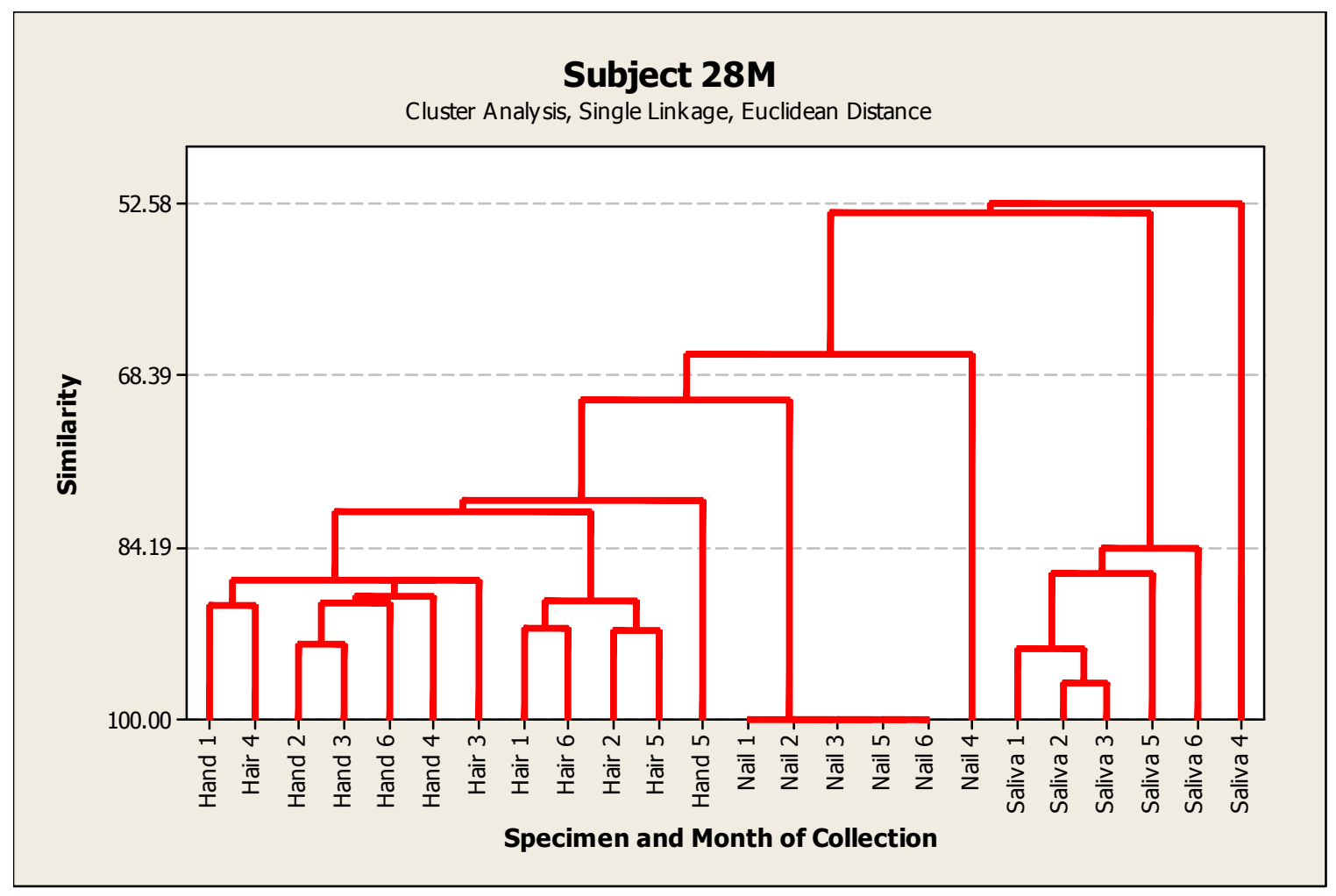




\section{JESSICA SARA BROWN}

June 16, 1984

2002-2007

2006-2007

2007

2007-2008

2008-2012
Born, Miami, Florida

B.S., Chemistry

Florida International University

Miami, Florida

Undergraduate Assistant

Florida International University

Miami, Florida

Preservation Research and Testing Division Intern

Library of Congress

Washington, District of Columbia

Teaching Assistant

Florida International University

Miami, Florida

Research Assistant

Florida International University

Miami, Florida

\section{PUBLICATIONS AND PRESENTATIONS}

Brown JS, Prada PA, Curran AM, Furton KG. Applicability of emanating volatile organic compounds from various forensic specimens for individual differentiation. Forensic Science International, Submitted.

Brown JS and Furton KG. Exploring human scent with instruments and canines. Presented at th $88^{\text {th }}$ Annual Meeting, Florida Annual Meeting and Exposition, Innisbrook, FL, May 2012.

Brown JS and Furton KG. The use of canine field testing to optimize the operating parameters of a non-contact collection device for human scent. Presented at the $64^{\text {th }}$ Annual Scientific Meeting, American Academy of Forensic Science, Atlanta, GA, February 2012.

Brown JS and Furton KG. Analysis of hand odor utilizing various extraction techniques to provide a comprehensive assessment of volatile components. Presented at the Pittsburg 
Conference on Analytical Chemistry and Applied Spectroscopy, Atlanta, GA, March 2011.

Brown JS and Furton KG.Comparison of the instrumental and canine evaluations of the chemical composition of biological specimens for human scent discrimination. Presented at the $63^{\text {rd }}$ Annual Scientific Meeting, American Academy of Forensic Science, Chicago, IL, February 2011.

Wirks-Brown JS and Furton KG. Assessment of human scent volatiles for the discrimination of individuals. Presented at the $86^{\text {th }}$ Annual Meeting, Florida Annual Meeting and Exposition, Innisbrook, FL, May 2010.

Wirks-Brown JS and Furton KG. The evaluation of volatile organic compounds from novel biological specimens by non-destructive analytical techniques for the potential use in forensic identifications. Presented at the Pittsburg Conference on Analytical Chemistry and Applied Spectroscopy, Orlando, FL, March 2010.

Wirks-Brown JS and Furton KG. An evaluation of volatile organic compounds from biological specimens over time. Presented at the $62^{\text {nd }}$ Annual Scientific Meeting, American Academy of Forensic Science. Seattle, WA, February 2010.

Wirks JS, Prada PA, Curran AM, Furton KG. The potential utilization of human hair for scent discrimination. Presented at the $6^{\text {th }}$ International Working Dog Conference, Ieper, Belgium, March 2009.

Wirks JS, Prada PA, Curran AM, Furton KG. The optimization and evaluation of the headspace analysis of head hair samples for the application as a human scent source. Presented at the $61^{\text {st }}$ Annual Scientific Meeting, American Academy of Forensic Science, Denver, CO, February 2009.

Wirks JS, Prada PA, Furton KG. Evaluation of fiber composition of human scent collection materials and their effect on collected human hand odor. Presented at the Young Forensic Scientist Forum, $60^{\text {th }}$ Annual Scientific Meeting, American Academy of Forensic Science, Washington, DC, February 2008. 